\title{
ANL Site Response for the DOE FY1994 \\ Information Resources Management Long-Range Plan
}
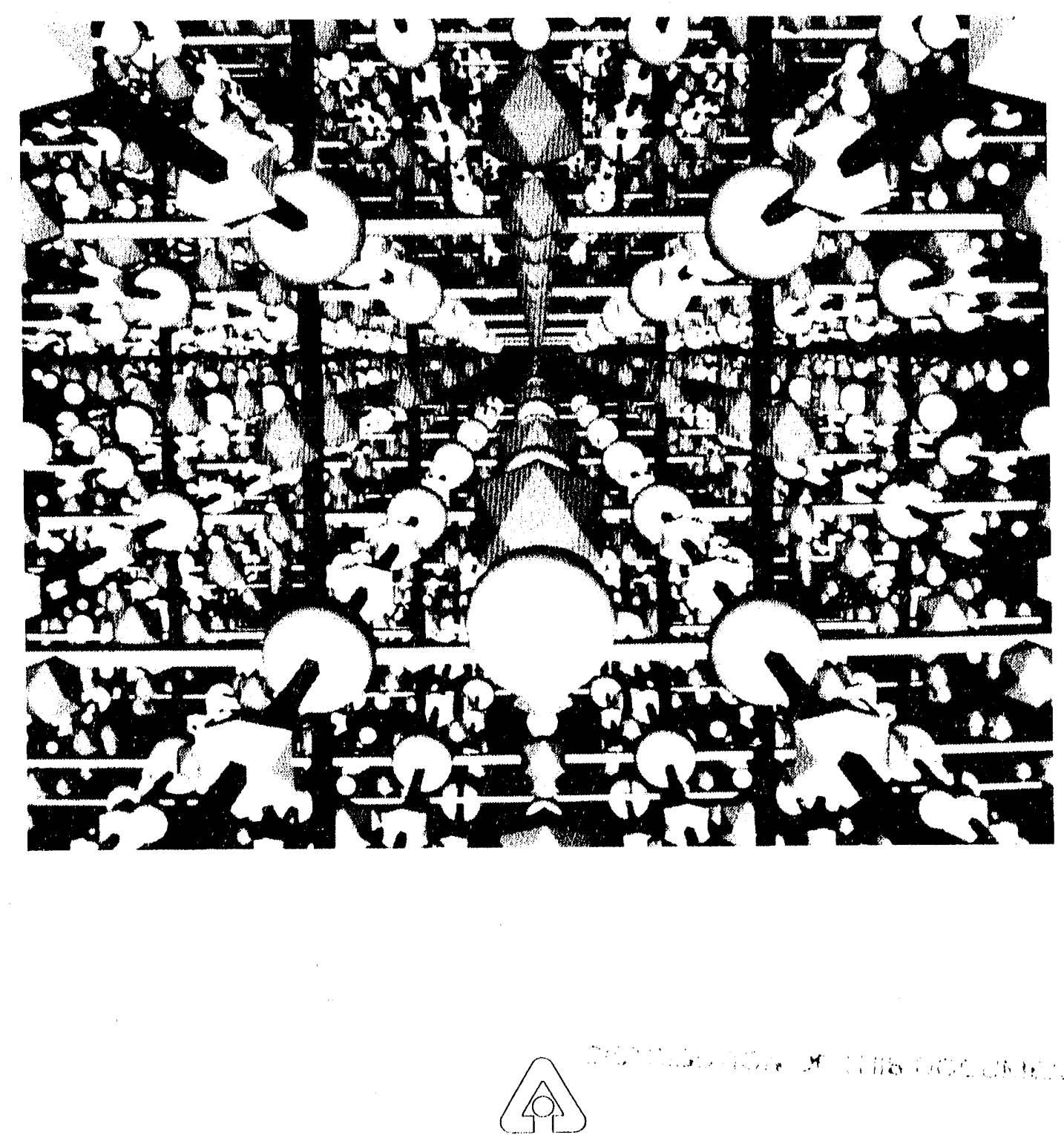
Argonne National Laboratory, with facilities in the states of Illinois and Idaho, is owned by the United States government, and operated by The University of Chicago under the provisions of a contract with the Department of Energy.

\section{DISCLAIMER}

This report was prepared as an account of work sponsored by an agency of the United States Government. Neither the United States Government nor any agency thereof, nor any of their employees, makes any warranty, express or implied, or assumes any legal liability or responsibility for the accuracy, completeness, or usefulness of any information, apparatus, product, or process disclosed, or represents that its use would not infringe privately owned rights. Reference herein to any specific commercial product, process, or service by trade name, trademark, manufacturer, or otherwise, does not necessarily constitute or imply its endorsement, recommendation, or favoring by the United States Government or any agency thereof. The views and opinions of authors expressed herein do not necessarily state or reflect those of the United States Government or any agency thereof'.

Reproduced from the best available copy.

Available to DOE and DOE contractors from the

Office of Scientific and Technical Information

P.O. B० 62

Oak Ridge, TN 37831

Prices available from (615) 576-3401, FTS 626-840)1

Available to the public from the

National Technical Information Service

U.S. Department of Commerce

528.5 Port Royal Road

Springficld, VA 22161 


\section{ANL Site Response for the DOE FY1994 Information Resources Management Long-Range Plan}

By

L. Michael Boxberger

March 1992 
ANL Site Response for the DOE FY1994 Information Resources Management Long Range Plan March 25, 1992

\section{Acknowledgments}

Many participants throughout the Laboratory have contributed time and materials necessary to complete the ANL Site Response for the DOE FY1994 Information Resources Management Long-Range Plan. The Computing Policy Committee, representatives of the Associate Laboratory Directors, the Strategic Planning Office and many members of Computing and Telecommunications provided extensive reviews and valuable comments.

Representatives of all divisions and programs, the Associate Laboratory Directors, the Chief Financial Officer, and the Chief Operations Officer provided the majority of the program narrative and statistics.

The Computing Policy Committee provided overall comments and direction relative to the stratezy for computing and telecommunications at Argonne National Laboratory. The Strategic Planning Office reviewed the Site Response for consistency with the ANL Institutional Plan. 


\section{CONTENTS}

Acknowledgments

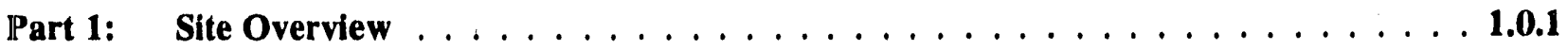

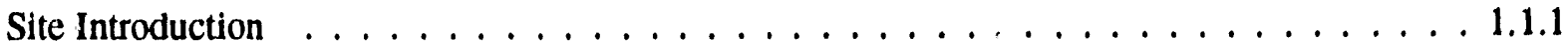

Site Profile and Missions Supported . . . . . . . . . . . . . . . . . . 1.2.1

Site Information Resources Management Strategic Overview . . . . . . . . . . . . . . 1.3.1

Site Information Resources Management Planning Process _ . . . . . . . . . . . . 1.4 .1

Discussion of General Comments/Major Issues $\ldots \ldots \ldots \ldots \ldots \ldots \ldots \ldots$

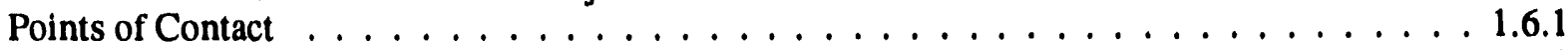

Special Areas of Interest $\ldots \ldots \ldots \ldots \ldots \ldots \ldots$

GOSIP Transition Plan $\ldots \ldots \ldots \ldots \ldots \ldots \ldots \ldots . \ldots \ldots \ldots$

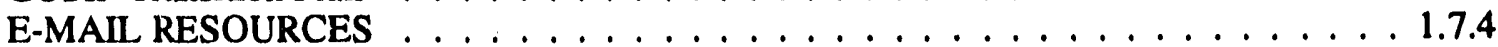

Part 2: Software Plans (Parts 2A, 2B, and 2C) $\ldots \ldots \ldots \ldots \ldots \ldots \ldots \ldots \ldots$

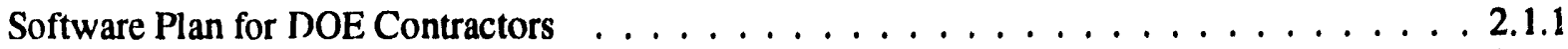

Software Management Plans and Strategles . . . . . . . . . . . . . 2.1 .2

Software Initiatives and Resource Requirements . . . . . . . . . . . . . . . . . . . 2.1 .4

Software Reporting Requirements . . . . . . . . . . . . . . . . . . . . . . . . . . . . . . . . .

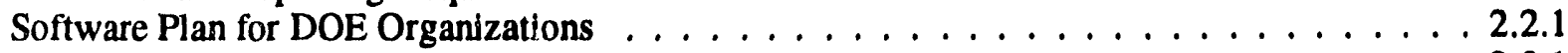

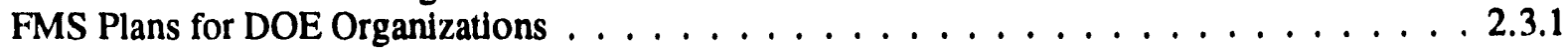

Part 3: Computing Resources Plan $\ldots \ldots \ldots \ldots \ldots \ldots \ldots \ldots \ldots$

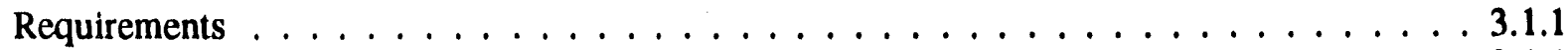

ADP Requirements Schedule . . . . . . . . . . . . . . . . 3.1.1

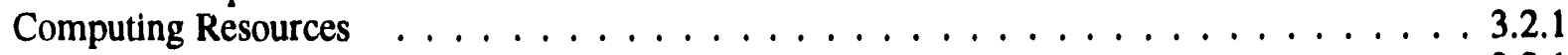

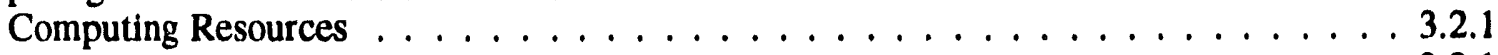

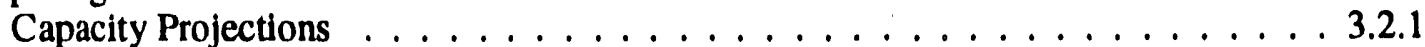

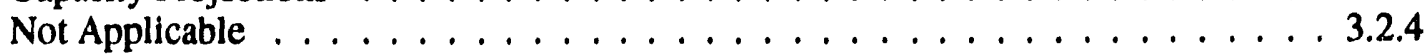

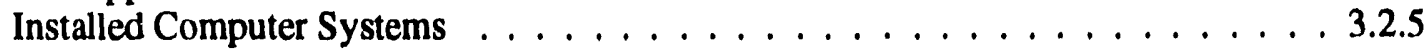

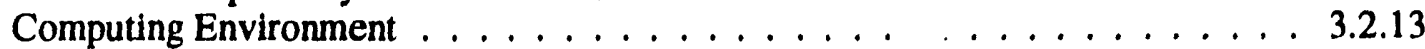

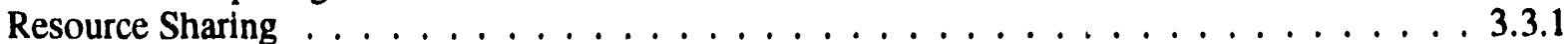

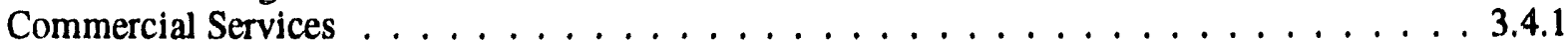

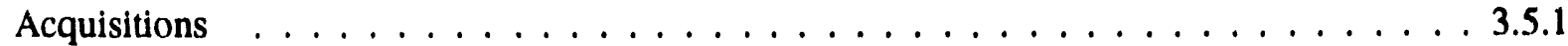

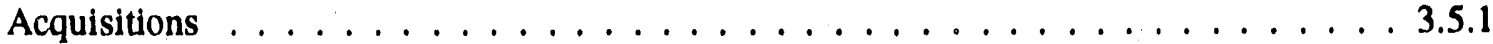

Major Planned Acquisitions/Lease Continuations . . . . . . . . . . . 3.5.1

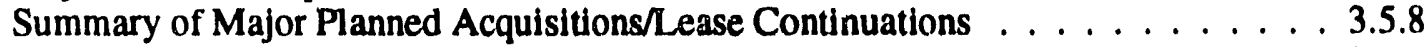

Financial Alternative Analyses . . . . . . . . . . . . . . . . . . . . . 3.5 .9

Reutilization Opportunities/Obsolete System Retirement . . . . . . . . . . . . . . 3.6.1

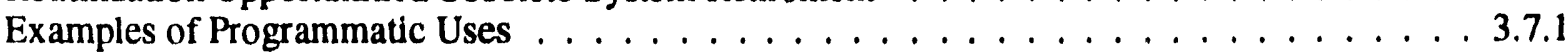

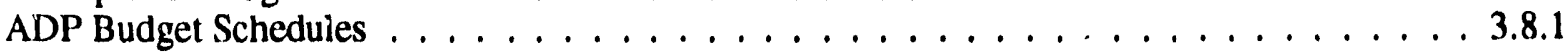


ANL. Site Response for the DOE FY1994 Information Resources Management Long Range P: In March 25, 1992

Contents

Not Applicable

Reconciliation

\section{Part 4: Telecommunications Plan}

Telecommunications

Strategies and Major Accomplishments . . . . . . . . . . . . . . . . 4.1.1

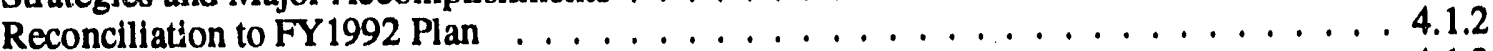

Currently Utlized Services/Planned Minor Enhancements . . . . . . . . . . . . . . . . . . . . . . . . . . . . . . . . .

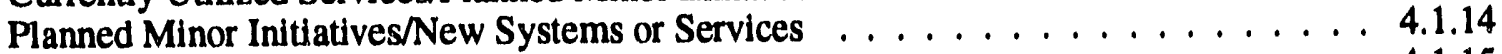

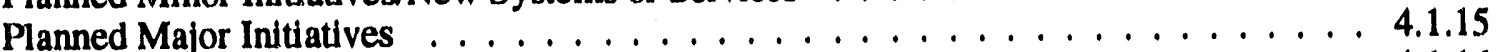

Schedule 4-1A, Telecommunications Resource Estimates . . . . . . . . . . . . 4.1 .16

Schedule 4-2, Major Telecommunications Initiatives . . . . . . . . . . . . . . 4.1 .18

Schedule 4-5, Computer Networking Resources . . . . . . . . . . . . . . . . . . . . . . . . . . . . . . . . . . .

Schedule 4-6, Long Distance Transport Cost Estimates . . . . . . . . . . . . . . . . 4.1.31

Schedule 4-7, SACNET Resource Estimates . . . . . . . . . . . . . . . . . . 4.1 .32

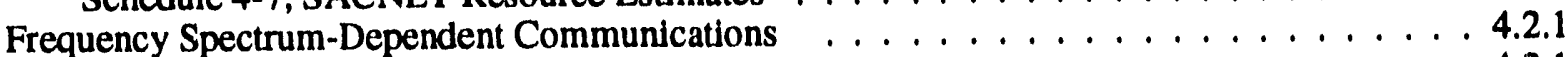

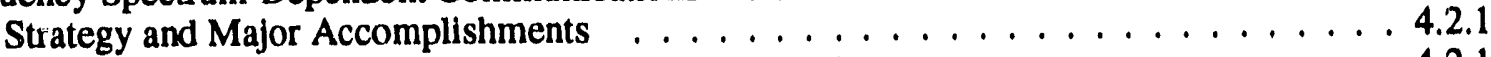

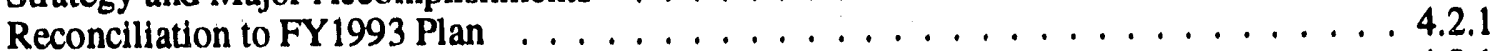

Currently Utilized Services/Planned Minor Enhancements . . . . . . . . . . . . . . . . . . . . . . . . . . . . . .

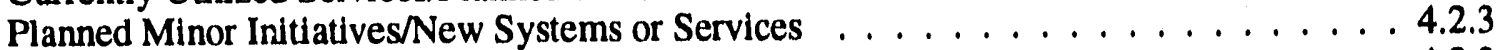

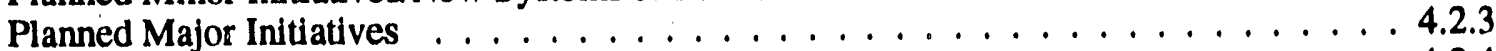

Schedule 4-1B, Telecommunications Resource Estimates $\ldots \ldots \ldots$. . . . . . . 4.2.4

Schedule 4-2, Major Telecommunications Initiatives . . . . . . . . . . . . . . . . . . . . . . . . . . . . . . . .

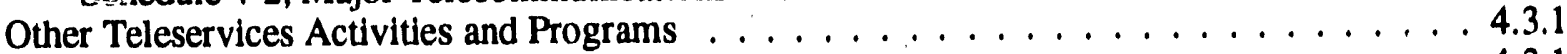

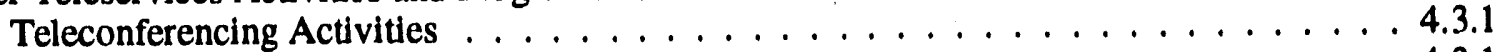

Strategies and Major Accomplishments . . . . . . . . . . . . . . 4.3.1

Reconciliation to FY1993 Plan . . . . . . . . . . . . . . . . . . . . . . . . . . . . . . . . . . . . . .

Currently Utilized Services/Planned Minor Enhancements . . . . . . . . . . . . . 4.3.1

Planned Minor Initiatives/New Systems or Services . . . . . . . . . . . . . . . 4.3.2

Planned Major Initiatives . . . . . . . . . . . . . . . . . . . 4.3 .2

Schedule 4-1C1, Telecommunications Resource Estimates . . . . . . . . . . . . 4.3.3

Schedule 4-2, Major Telecom nunications Initiatives . . . . . . . . . . . . . 4.3 .5

Communications Security (COMSEC) Programs . . . . . . . . . . . . . . . . 4.3 .5

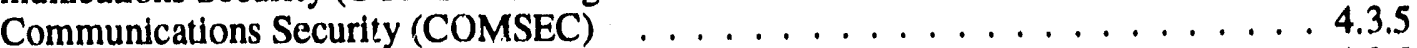

Strategies and Major Accomplishments . . . . . . . . . . . . . 4.3.5

Reconciliation to FY1992 Plan . . . . . . . . . . . . . . . . . . 4.3.5

Currently Utilized Services . . . . . . . . . . . . . . . . . . . . . . . . . . . . . . . . . . . . .

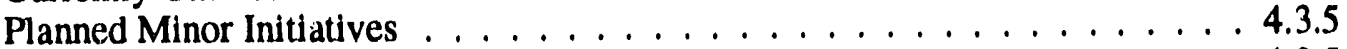

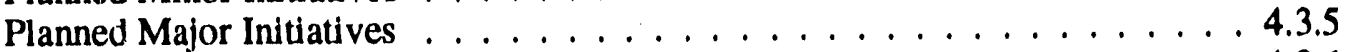

Schedule 4-1C2.1, Telecommunications Resource Estimates . . . . . . . . . 4.3.6

Schedule 4-2, Major Telecommunications Acquisitions . . . . . . . . . . . 4.3.8

Emission Security (TEMPEST) Testing Program . . . . . . . . . . . . . . . . . . . . . . . . . . . . . .

Protected Distribution System (PDS) Program . . . . . . . . . . . . . . . . . . 4.3 .8

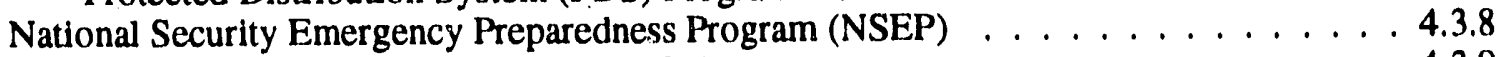

DOE Teleprocessing Services Program (TSP) . . . . . . . . . . . . . . . . . 4.3 .9 
ANL Site Response for the DOE FY1994 Information Resources Management Long Range Plan Contents

Port 5: Printing and Publishing Plan $\ldots \ldots \ldots \ldots \ldots \ldots \ldots \ldots \ldots \ldots \ldots$

Three-Year Printing and Publishing Activities Plan $\ldots \ldots \ldots \ldots \ldots \ldots . \ldots \ldots . . \ldots \ldots$

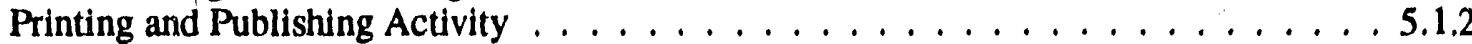

Printing Activities Report $\ldots \ldots \ldots \ldots \ldots \ldots \ldots \ldots \ldots \ldots \ldots \ldots \ldots \ldots$

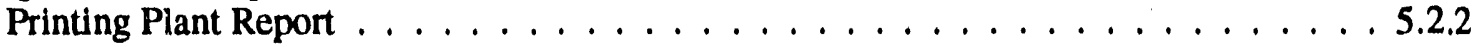

Appendix A: Computer Protection Policy $\ldots \ldots \ldots \ldots \ldots \ldots \ldots \ldots$ A.1

\section{I.IST OF SCHEDULES}

1.1 Schedule 3 A-1 ADP Requirements $\ldots \ldots \ldots \ldots \ldots \ldots \ldots . \ldots \ldots . \ldots \ldots$

2.1 Schedule 3B-1 Capacity Projections $\ldots \ldots \ldots \ldots \ldots \ldots \ldots \ldots \ldots . \ldots \ldots \ldots .2 .2$

2.2 Schedule 3B-3.1, Personal/Microcomputer/Word Processor Data $\ldots \ldots \ldots \ldots \ldots$. . . . . . .

2.3 Schedule 3B-3.2, Installed Personal, Microcomputer, Word Processors . . . . . . . 3.2.12

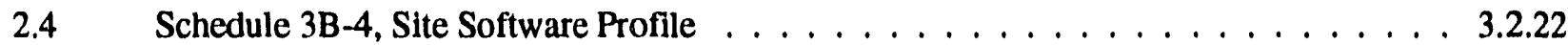

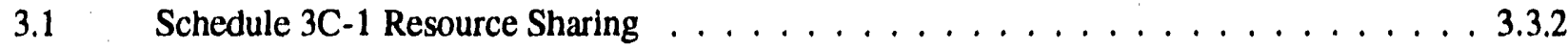

4.1 Schedule 3D-1 ADP Commercial Services (RCUs And Costs) $\ldots \ldots \ldots . \ldots . . \ldots 3.2$

5.1 Schedule 3E-1 ANL-84-1 Continuation of the Advanced Computing Research

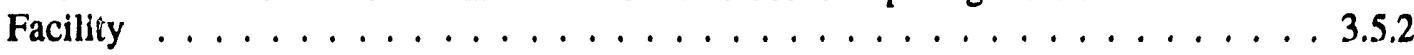

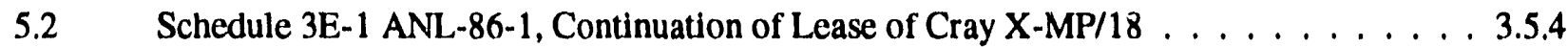

5.4 Schedule 3E-1 ANL-94-1 Data Acquisition and Reduction Facility for Advanced Photon Source . . . . . . . . . . . . . . . . . . . 3.5.6

5.5 Schedule 3E-2 Summary of Major Plañed Acquisitions/Lease Continuations $\ldots \ldots$. 3.5 .8

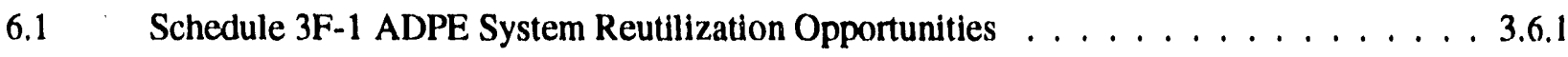

8.1 Schedule 3H-1 Major Computer Acquisitions and Other ADP Capital Requirements

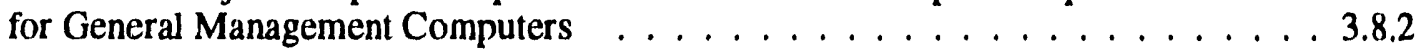

8.2 Schedule 3H-2 ADP Operating Costs Associated with General Management Computers $\ldots \ldots \ldots \ldots \ldots \ldots \ldots \ldots \ldots \ldots . \ldots \ldots \ldots$

1.1 Schedule 4-1A, Telecommunications Resource Estimates $\ldots \ldots \ldots$. . . . . . 4.1.16

1.2 Schedule 4-5, Computer Networking Resources . . . . . . . . . . . . . . 4 4.1.19 
ANL Site Response for the DOE FY 1994 Information Resources Management Long Range Plan March 25, 1992

Contents

$1.2 \quad$ Schedule 4-5, Computer Networking Resources . . . . . . . . . . . . . . 4.1 .20

1.2 Schedule 4-5, Computer Networking Resources $\ldots \ldots \ldots$. . . . . . . . . . 4.1.21

1.2 Schedule 4-5, Computer Networking Resources $\ldots \ldots \ldots$. . . . . . . . . . . . 4.1 .22

1.2 Schedule 4-5, Computer Networking Resources $\ldots \ldots \ldots$. . . . . . . . . 4.1.23

1.2 Schedule 4-5, Computer Networking Resources _ . . . . . . . . . . . . . . . . . 4.1.24

1.2 Schedule 4-5, Computer Networking Resources . . . . . . . . . . . . . 4.1.25

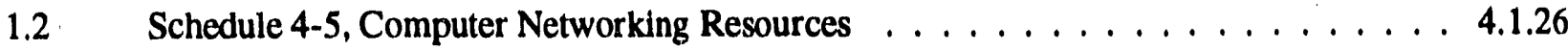

1.2 Schedule 4-5, Computer Networking Resources . . . . . . . . . . . . . . . 4.1.27

1.2 Schedule 4-5, Computer Networking Resources _ . . . . . . . . . . . . . . 4.1.28

1.2 Schedule 4-5, Computer Networking Resources . . . . . . . . . . . . . . . . . . 4.1 .29

1.2 Schedule 4-5, Computer Networking Resources $\ldots \ldots \ldots$. . . . . . . . . . . . 4.1.30

1.2 Schedule 4-6, Long Distance Transport Cost Estimates $\ldots \ldots \ldots$. . . . . . . 4.1.31

2.1 Schedule 4-1B General Frequency Spectrum-Dependent Communications Resource Estimates . . . . . . . . . . . . . . . . . . . . 4.2 .4

3.1 Schedule 4-1C1 Teleconferencing Resource Estimates . . . . . . . . . . . . . 4.3.3

3.2 Schedule 4-1C2.1 Communications Security (COMSEC) Resource Estimates _ . . . . 4.3.6

$3.5 \quad$ Schedule 4-4, DOE Teleprocessing Services Program (TSP) $\ldots \ldots \ldots$

3.6 Schedule 4-4, DOE Teleprocessing Services Progran (TSP) $\ldots \ldots \ldots$. . . . . . . 4.3 .10

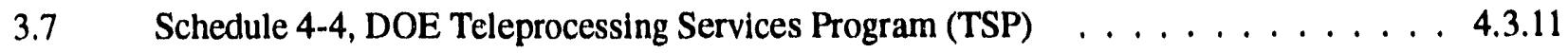

$3.8 \quad$ Schedule 4-4, DOE Teleprocessing Services Program (TSP) $\ldots \ldots \ldots .4 .12$

3.9 Schedule 4-4, DOE Teleprocessing Services Program (TSP) $\ldots \ldots \ldots$. . . . . . . 4.3 .13

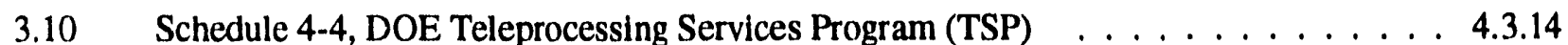

3.11 Schedule 4-4, DOE Teleprocessing Services Program (TSP) $\ldots \ldots$. . . . . . . 4.3 .15

3.12 Schedule 4-4, DOE Teleprocessing Services Program (TSP) $\ldots \ldots \ldots \ldots$

3.13 Schedule 4-4, DOE Teleprocessing Services Program (TSP) $\ldots \ldots \ldots$. . . . . . . 4.3 .17

1.1 Schedule 5-1, Equipment Acquired During Fiscal Year $1991 \ldots \ldots . \ldots$ 
ANL Site Response for the DOE FY 1994 Information Resour ces Management Long Range Plan

1.2 Schedule 5-2, Nar ative Report - JCP Approved Equipment only . . . . . . . . . 5.1.4

$1.3 \quad$ Schedule 5-3, Budget Projections $\ldots \ldots \ldots \ldots \ldots \ldots \ldots$

1.4 Schedule $5-4$, Production Projections $\ldots \ldots \ldots \ldots \ldots \ldots$

1.5 Schedule 5-5, New Equipment Justification $\ldots \ldots \ldots \ldots \ldots . \ldots \ldots$

1.6 Schedule 5-6, New Equipment Justification $\ldots \ldots \ldots \ldots . \ldots \ldots$

1.7 Schedule 5-7, Projected Publishing Activities $\ldots \ldots \ldots \ldots . \ldots \ldots$

$1.8 \quad$ Schedule $5-8$, Journal Publishing Activities $\ldots \ldots \ldots \ldots \ldots . \ldots \ldots \ldots$

$2.1 \quad$ Schedule $5-9$, Printing Plant Report $\ldots \ldots \ldots \ldots \ldots \ldots . \ldots \ldots \ldots$

$2.2 \quad$ Schedule $5-9$, Printing Plant Report $\ldots \ldots \ldots \ldots \ldots . \ldots \ldots$

$2.2 \quad$ Schedule 5-10, Printing Plant Report $\ldots \ldots \ldots \ldots \ldots . \ldots \ldots$

$2.3 \quad$ Schedule 5-11, Printing Plant Report $\ldots \ldots \ldots \ldots . \ldots \ldots$

2.4 Schedule 5-12, Duplicating Facility Report $\ldots \ldots \ldots \ldots \ldots \ldots$

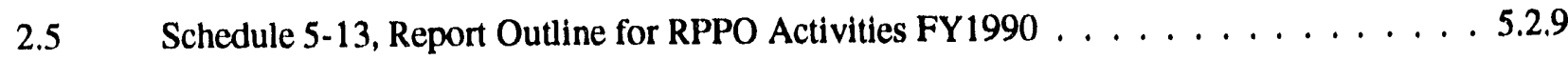

$2.6 \quad$ Schedule 5-14, Report Outline for RPPO Activities FY1990 _ . . . . . . . . . . . 5.2.10

$2.7 \quad$ Schedule 5-15, Report Outline for Copying Activities FY1990 _ . . . . . . . . 5 5.2 .11

$2.8 \quad$ Schedule 5-16, Survey of GPO Performance for Fiscal Year $1991 \ldots \ldots .2 \ldots$

\section{LIST OF EXHIBITS}

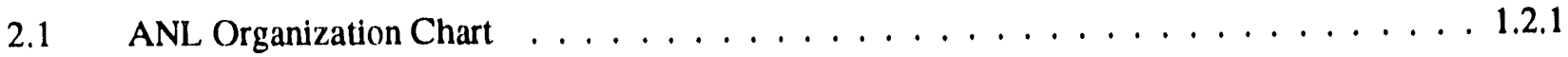

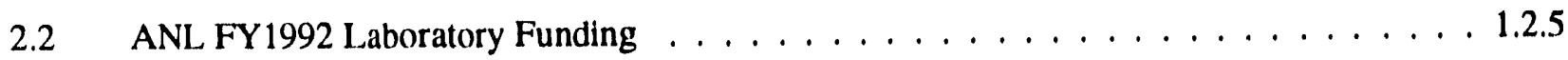

3.1 Information Resource Management Organization $\ldots \ldots \ldots \ldots . \ldots \ldots$

1.1 Category $\mathrm{P}$ Requirements $\ldots \ldots \ldots \ldots \ldots \ldots \ldots \ldots$

1.2 Category $\mathrm{Q}$ Requirements $\ldots \ldots \ldots \ldots \ldots \ldots \ldots \ldots$

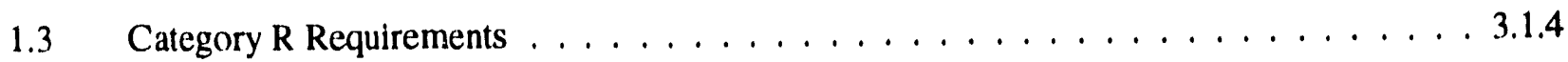

2.1 Configuration Diagram for Central IBM computer system . . . . . . . . . . . . 3.2 .8 
ANL Site Response for the DOE FY1994 Information Resources Management Long Range Plan March 25, 1992

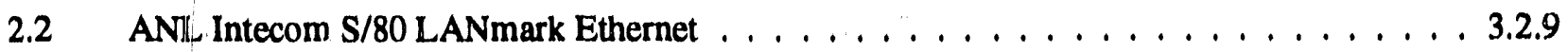

2.5 Computing and Telecommunications Activities $\ldots \ldots \ldots \ldots \ldots \ldots \ldots$

8.1 ADP Operating Costs General Management Computers $\ldots \ldots \ldots$. . . . . . . . 3.8.1

1.1 ANL Voice Network $\ldots \ldots \ldots \ldots \ldots \ldots \ldots$

1.2 ANL External Networks $\ldots \ldots \ldots \ldots \ldots$

1.3 ANL DECnet Network $\ldots \ldots \ldots \ldots \ldots \ldots \ldots \ldots \ldots$

1.4 ANL TCP/RP Network $\ldots \ldots \ldots \ldots \ldots \ldots \ldots \ldots \ldots$ 
ANL Site Response for the DOE FY 1994 Information Resources Management Long Range Plan Part 1:

\section{Part 1}

Site Overview

ANL-1.0.1 
ANL Site Response for the DOE FY1994 Information Resources Management Long Range Plan A. Site Introduction

March 25, 1992

\section{Section A}

\section{Site Introduction}

Argonne National Laboratory's ANL Site Response for the DOE FY1994 Information Resources Management (IRM) Long-Range Plan (ANL/TM 500) is one of many contributions to the DOE information resources management long-range planning process and, as such, is an integral part of the DOE policy and program planning system. The Laboratory has constructed this response according to instructions in a Call issued in September 1991 by the DOE Office of IRM Policy, Plans and Oversight.

As one of a continuing series, this Site Response is an update and extension of the Laboratory's previous submissions. The response contains both narrative and tabular material. It covers an elght-year perlod consisting of the base year (FY1991), the current year (FY1992), the budget year (FY1993), the plan year (FY1994), and the out years (FY1995-FY1998). This Site Response was complled by Argonne National Laboratory's Computing and Telecommunications Division (CTD), which has the responsibility to provide leadership in optimizing computing and information services and disseminating computer-related technologies throughout the Laboratory.

The Site Response consists of four parts. Part 1, "Site Overview," describes the ANL mission, overall organization structure, the strategic approach to meet information resource needs, the planning process, major issues, and points of contact. Part 2A, "Software Plan for DOE Contractors," defines the current and planned automated information systems associated with the management of ANL, the stewardship of its resources, and the provision of day-to-day general operations and services. (Part 2B, "Software Plan for DOE Organizations," and Part 2C, "FMS Plan for DOE Organizations," do not apply to Argonne Nati Jnal Laboratory.) Part 3, "Computing Resources," defines the requirements, resources, acquisitions, and budget for computing at ANL for FY1991 through FY1998. Part 4, "Telecommunications," documents the existing and planned telecommunications resources required at ANL from FY1991 through FY 1998. Part 5, "Printing and Publishing," updates the ANL Printing and Publishing Activities Plan (FY1993-FY1995) and contains the FY1991 Printing Activities Reports.

The ANL-W facility is located at the Idaho National Engineering Laboratory (INEL), which is administered by DOE-ID. As the landlord of the INEL, DOE-ID through its prime contractor EG\&G provides local voice telephone and radio communications faclities at the INEL, and these items are reported in the INEL Information Resources Management Long-Range Plan. The computing resources used by ANL-W are included in this Site Response as well as all inter-Laboratory data communication between ANL-E and ANL-W.

The Computing and Telecommunications Division prepared this report with the assistance and cooperation of the many Laboratcry organizations that are involved with planning, acquiring, and providing information resources. The Computing Policy Cormmittee, Associate Laboratory Directors, Division Directors, and Program Managers supplied data for the computing requirements sections. Additional information required in the total plan preparation came from a variety of sources, including computer use and billing records, the Laboratory-wide equipment inventory list, acquisition plans, and information from knowledgeable people in Computing and Telecommunications Division and other Laboratory organizations. The report provides data related to all aspects of information resources mi ragement at the Laboratory. 
ANL Site Response for the DOE FY1994 Information Resources Management Long Range Plan B. Site Profile and Missions Supported

\section{Section B}

\section{Site Profile and Missions Supported}

\section{SITE PROFILE}

Argonne National Laboratory is a large multiprogram laboratory conducting basic and technologydirected research at two sites owned by the U.S. Department of Energy. Argonne-East is located on a 1700-acre site in DuPage County, Illinois, about 25 miles southwest of Chicago. Argonne-West is located on an 800-acre tract within the Idaho National Engineering Laboratory, about 35 miles west of Idaho Falls, Idaho. Exhibit 2.1 depicts the organization of the Laboratory.

Exhibit 2.1: ANL Organization Chart

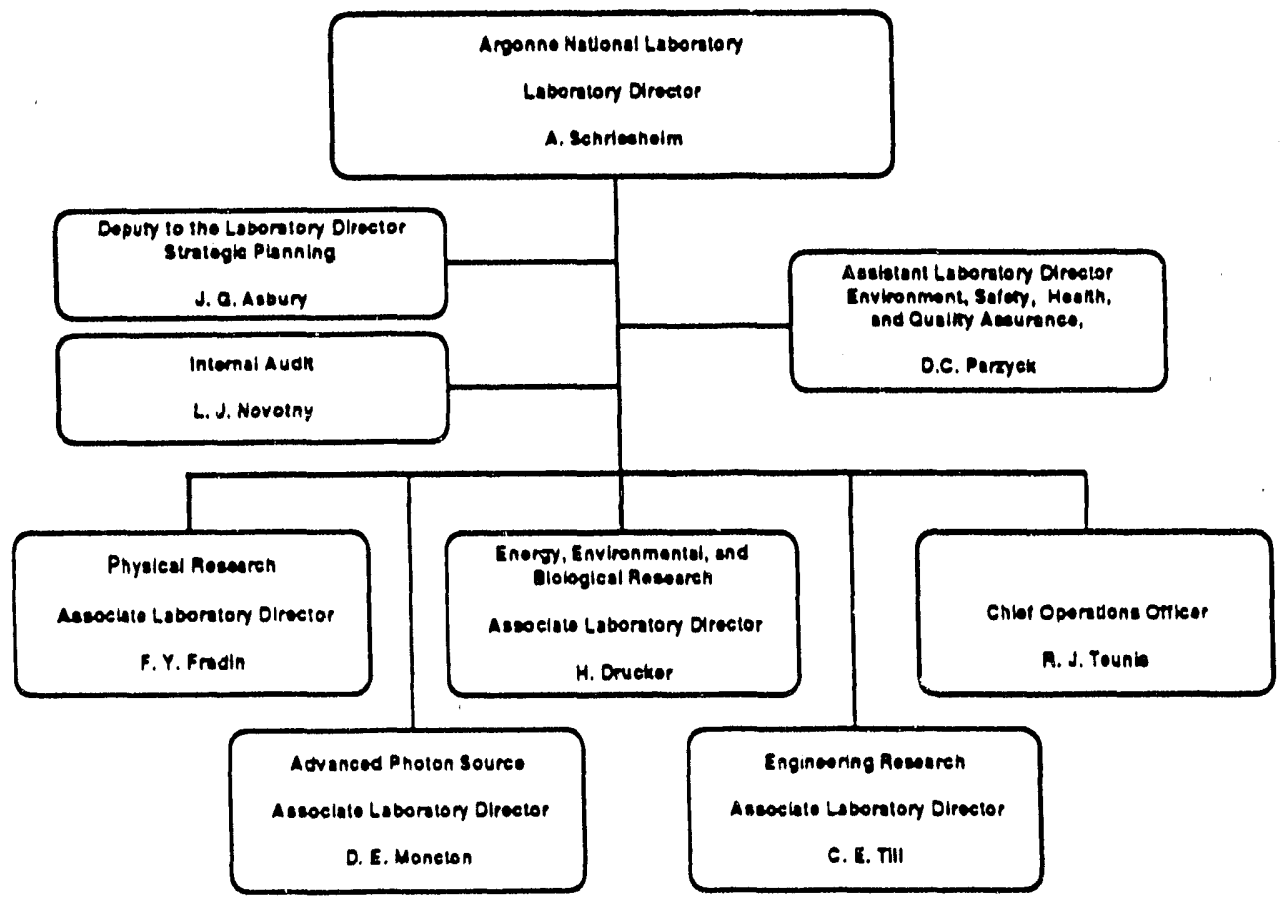

\section{Argonne-East}

Activities at Argonne-East support the full range of missions for Argonne National Laboratory. Major facilities at the site include the Intense Pulsed Neutron Source, the Argonne Superconducting Tandem Linear Accelerator System (ATLAS), and the High-Voltage Electron Microscope. All these facilities are heavily used by researchers outside Argonne. Construction of th: Advanced Photon Source began on June 4, 1990. 
ANL Site Response for the DOE FY1994 Information Resources Management Long Range Plan March 25, 1992

Argonive-East also houses a full spectrum of administrative and technical support organizations as well as the DOE Chicago Operations Office and the New Brunswick Laboratory, both of which use facilities operated and maintained by Argonne.

Altogether, Argonne-East houses roughly 5,300 persons, of whom about 3,800 are regular Argonne employees. The Argonne-East site includes 131 buildings with 3.7 million total square feet of floor space. Almost all buildings and site infrastructure were built between 1948 and 1986, with most construction during the 1950s and early 1960s. In addition, the Laboratory is leasing 94,000 square feet of office space in a commercial park near the Argonne-East site to alleviate a temporary space shortage during construction of the Advanced Photon Source. The replacement value of existing facilities at Argonne-East is estimated at \$1.1 billion.

\section{Argonne-West}

Argonne-West accommodates major national experimental facilities designed for studying a broad range of issues important for developing advanced fission reactors, usually designs incorporating cooling by liquid metal. Major facilities at the site are the Experimental Breeder Reactor II (EBR-II), a small, sodium-cooled, pool-type fast reactor with a power plant rated at $20 \mathrm{MWe}$; the Fuel Manufacturing Facility, used to fabricate nonplutonium-bearing metal fuel assemblies for EBR-II; the Transient Reactor Test Facility, a reactor designed for high-power-transient safety tests on both thermal-reactor and fast-reactor fuels; the Zero Power Physics Reactor, a zero-power, split-core assembly that provides full-size physics mockups of fast-reactor cores up to 1,000 MWe in size; the Hot Fuel Examination Facility, a hot-cell facility with an argon atmosphere cell designed for handling and examining large experiments containing sodium and plutonium; and, the Fue' Cycle Facility (FCF), originally used for on-site reprocessing and refabrication of metallic fuel for EISR-II. Current plans call for modifying the FCF in order to demonstrate the pyrometallurgical fuel cycle oi the Integral Fast Reactor (IFR) concept in a cost-effective manner. A full array of shops, warehouses, laboratories, offices, and utility systems supports these major facilities.

Argonne-West houses approximately 765 full-time employees plus 50 consultants and students. The site has 33 buildings with 600,000 square feet of floor space. The buildings and other infrastructure were built between 1958 and 1986 with most construction during the mid to late 1960s. Replacement value of the existing facilities at Argonne-West is estimated at $\$ 285$ million.

\section{SITE MISSIONS}

The Laboratory's mission is basic and applied research that supports the development of energy-related technologies.

\section{National Research Facilities}

- Development and operation of national facilities for use by university, industry, and national laboratory groups in research on basic and technology-related problems; development of advanced instruments and methods for facilities-centered research. Argonne operates several major national user facilities; notably the Intense Pulsed Neutron Source, the Argonne Tandem Linear Accelerator System, and the Advanced Computing Research Facility. The Laboratory is constructing the Advanced Photon Source, the world's most brilliant source of X-rays for use in forefront research in science and technology. 
ANL Site Response for the DOE FY 1994 Information Resources Management Long Range Plan B. Site Profile and Missions Supported

\section{Basic Research}

- Experimental and theoretical research on fundamental problems in the physical, life, and environmental sciences to advance scientific understanding in general and to support development of energy technologies. Major research thrusts include advanced techniques using synchrotron radiation for research in the physical and life sciences, algorithms and tools for massively parallel computers, studies of the human genome, synthesis of advanced materials, and detector systems for the Superconducting Super Collider.

\section{Technology-Directed Research}

- Conceptualization, design, and testing of advanced fission-reactors, especially liquid metal reactors, and other technologies for power applications in the civilian and defense sectors; supporting research to overcome materials, chemical, and electrochemical barriers to the development of these technologies. The Laboratory's core competencies in these areas are focused on the Integral Fast Reactor, advanced batterles and fuel cells, thermal sciences, biotechnology, materials and components that are superconducting at relatively high temperatures, and advanced coal technology.

\section{Technical Evaluation}

- Characterization and evaluation of nationally important projects and technology options in terms of their environmental, cost, or other implications. Laboratory activities in this area include sitespecific environmental impact and remediation studies, evaluation of advanced energy technologies, and assessments of en'rironmental regulatory policy.

\section{Technology Transfer}

- Transfer of Laboratory technologies to the private sector for commercialization through cooperative research and development agreements, sponsored research, staff exchanges, the licensing of intellectual property, and the formation of new firms. The ARCH Development Corporation licenses technology and, where appropriate, organizes new firms.

In carrying out its missions, Argonne conducts work for each of DOE's program secretarial offices. A large proportion of its work is, however, concentrated in two areas: basic energy sciences, where the Advanced Photon Source and associated facilities are prominent, and advanced reactor technology, where development of the Integral Fast Reactor is the focus. Basic energy sciences and advanced reactor technology currently constitute half of all Argonne research.

Argonne's policy in conducting its missions is that environment, safety, and health receive the highest priority in the Laboratory's operations. All research and operational programs are conducted so that first consideration is given to worker and public safety and protection of the environment.

Argonne works closely with colleges and universities. Participation by faculty and students in Laboratory programs brings their talents to bear on important research problems and contributes to the education of future scientists and engineers. The Laboratory also conducts many programs for precollege students and faculty to enhance mathematics and science education. A particular purpose of these programs is to encourage members of underrepresented societal groups to enter careers in science and engineering. 


\section{GOALS AND OBJECTIVES}

The Laboratory's goals for addressing five national research and development policy objectives are as follows:

\section{Energy Technology}

To develop, test and carry to proof-of-concept technologies that can substantially improve the safety and reduce the costs of fission energy systems. To conduct base-technology research to understand and remove barriers to the development of other advanced energy technologies.

\section{Science And Technology}

To maintain the excellence of existing programs, while developing initiatives at scientific frontiers that will lead to development of advanced energy technologies. To develop and operate user facilities that support the advancement of science and technology across a wide range of disciplines. To develop innovative experimental concepts and instrumentation.

\section{Environmental Quality}

To continue to strengthen existing programs and broad capabilities in environmental sciences and technology, while undertaking research that contributes significantly to the solution of major national problems.

\section{Industrial Competitiveness}

By strengthening associations with industry, to establish and accomplish research objectives that will improve the competitiveness of U.S. industries that depend on energy-related technologies and manufacturing processes.

\section{National Security}

To apply the Laboratory's unique technical resources to define and solve problems encountered in the development of advanced defense technologies.

The specific research initiatives to support the Laboratory goals identified above are more fully described and documented in the ANL Institutional Plan, FY1992-FY1997, December 1991.

Research in both the physical and life sciences will increase. A substantial part of the expanded work in Energy Research involves activities needed to construct and operate the APS and associated research centers and facilities.

Work in Nuclear Energy will expand over the next five years, as the Laboratory proceeds with testing and evaluation of the complete IFR fuel cycle and undertakes a major program to develop an actinide recycling technology for spent fuel from light-water reactors. Overall effort in the areas of Fossil Energy and energy conservation is expected to remain roughly stable.

Support for New Production Reactors will trend downward as work on the environmental impact statement is completed and engineering development issues are resolved. 
Activity for Environmental Restoration and Waste Management will expand greatly because of cleanups at the Argonne sites and research and development and technical support for cleanups at other major DOE sites. (FY1990 activity is represented as zero because it was funded through other secretarial offices under obsolete Budgeting and Reporting codes.)

The Department of Energy will continue to fund well over 80 percent of Argonne research. Industrial participation will increase across all major program areas, but private funding will remain less than 5 percent of the Laboratory total. Support of defense-related work by sponsors other than DOE will not exceed 10 percent.

\section{FUNDING SOURCES}

Argonne is anticipating an operating budget of approximately $\$ 392$ million (\$BA) for FY1992. The Laboratory employs approximately 4,500 persons, including approximately 2,400 scientists and engineers. More detailed information on the Laboratory's budget for FY1992 appears in Exhibit 2.2 in the various DOE Assistant Secretary categories as well as Work for Others.

Exhibit 2.2: ANL FY1992 Laboratory Funding

(By Secretarial Office .. Estimated Operating Funds .. \$Millien-BA)

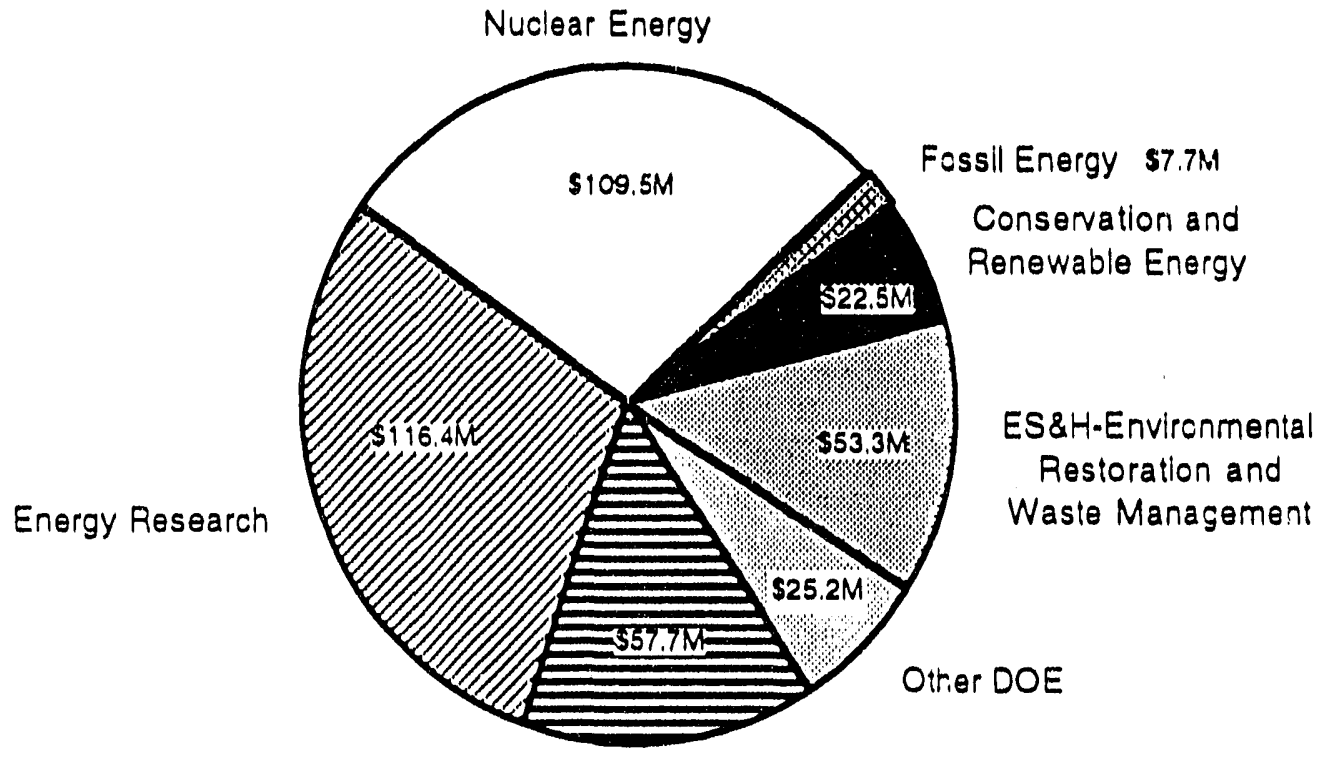

Work For Others

Argonne National Laboratory Institutional Plan FY1992.FY1997, November 1991 
ANL Site Response for the DOE FY 1994 Information Resources Management Long Range Plan C. Site Information Resources Management Strategic Overview

March 25, 1992

\section{Section C \\ Site Information Resources Management Strategic Overview}

\section{The Role of Information Resource Management Organizations}

The success of virtually all major Argonne and DOE programs depends heavily on easy access to computing and telecommunication resources. The role of the information resource management organizations of the Laboratory is to plan for and guide the acquisition of resources required by the programs of the Laboratory. The organizational structure of the Laboratory's information resources management appears in Exhibit 3.1

The Laboratory Management Council consists of the Laboratory Director, the programmatic Associate Laboratory Directors, the Chief Operations Officer, the Assistant Laboratory Director for Environment, Safety and Health/Quality Assurance Oversight, the Chief Financial Officer, and the Deputy to the Laboratory Director. It is the Laboratory body which formally approves all Laboratory policies and procedures. The Management Council reviews and approves long-term computing resource development strategy.

The Chief Operations Officer has responsibility for coordinating the overall planning and implementation of information resources management, for executing Laboratory-wide computing policies and procedures, and for recommending approval of new policies and procedures to the Laboratory Management Council.

The Computing Policy Committee is responsible for formulating ANL's overall computing policy and plans for scientific and administrative computing for departments and for Argonne as a whole. It also recommends to Laboratory management equitable policies for allocation of the Laboratory's shared computational resources and addresses such issues as internal standardization of computing hardware and software.

The Administrative Data Processing Oversight Committee (ADPO) is charged with overseeing implementation of the Laboratory's long-range administrative data processing strategy. ADPO reviews, evaluates, and ranks candidate projects for new development and enhancements of administrative management information systems and recommends levels of funding and scheduling to the Laboratory's Chief Operations Officer. The Computing and Telecommunications Division drafts plans and prepares recommendations for ADPO and works with ANL divisions, departments, user groups, and Laboratory management to identify specific needs and opportunities.

The Computing and Telecommunications Division has primary responsibility for planning the computing and telecommunications environment necessary to achieve the goals of Argonne's scientific and technical programs and administrative organizations. The Computing and Telecommunications Division and the Electronics, Procurement, and Materials and Services Departments of the Laboratory provide planning, acquisition, inventory assistance and services to the programs of the Laboratory.

The Computer Users Group and its subcommittees are forums where interested users of the Computing and Telecommunications Division (representing programs throughout the Laboratory) meet on a regular basis to discuss problems, suggestions for improvement, and other important issues concerning Laboratory information resources management. 
ANL Site Response for the DOE FY 1994 Information Resources Management Long Range Plan March 25, 1992

Exhibit 3.1: Information Resource Management Organization

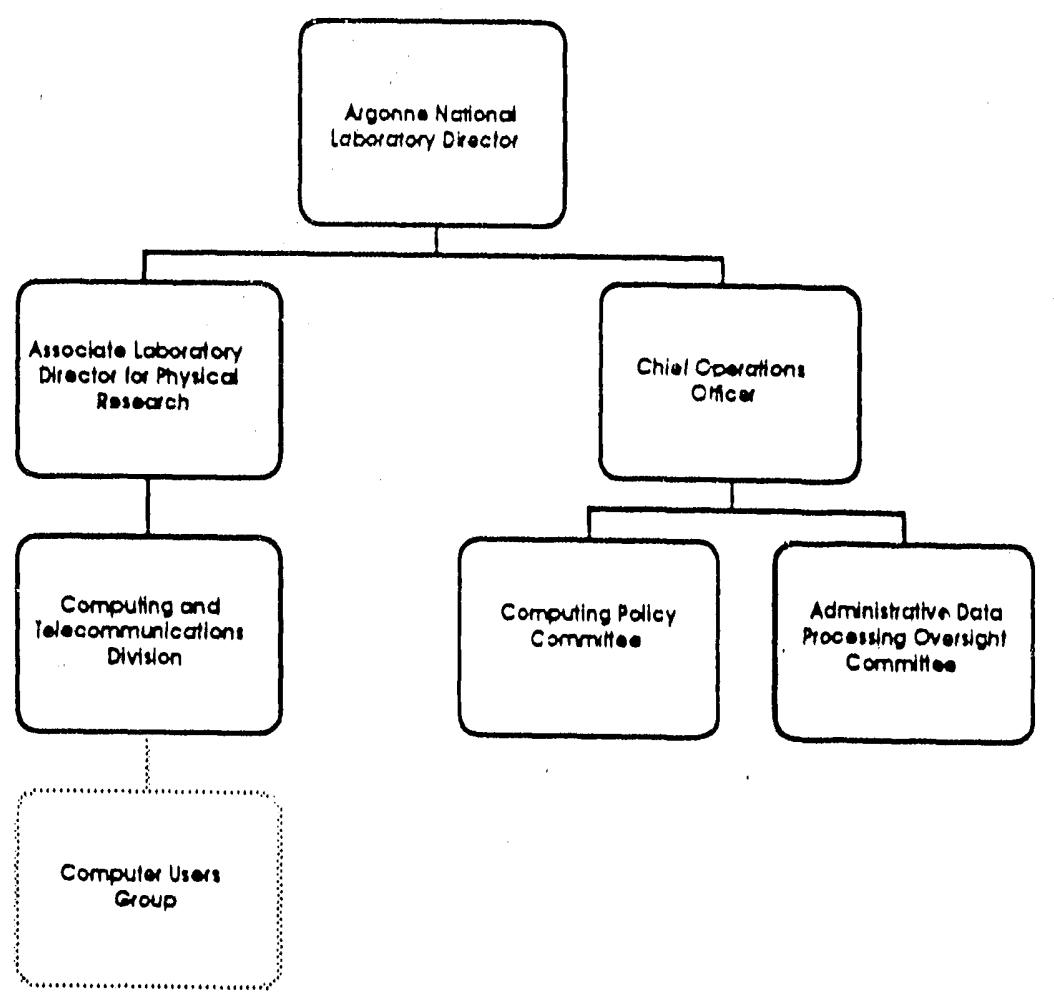

\section{Strategic Overview}

The scientific, engineering, and administrative activities of the Laboratory are heavily dependent upon the availability of computing and telecommunications resources. Furthermore, this dependence and the importance of computing and telecommunications to the Laboratory's programs will grow substantially in the future. Because of the crucial importance of computing and telecommunications resources, the Laboratory continues to pursue a long-term information resnurce management strategy that encompasses a complete integrated hierarchy of computing capabilities: supercomputers, centralized general purpose computers, multipurpose minicomputers, scientific and engineering workstations, and computing workstations and office automation support systems--all coupled together through an effective communications network. The most critical element of this strategy is the availability of advanced high-speed computers, which will provide new programmatic computational opportunities for Argonne researchers. With such a hierarchy available through an effective network, individual researchers will have transparent and easy access to the specific level of computing resources they require to pursue their activities.

\section{Supercomputing}

One of the more critical strategic needs of ANL's research programs is access to substantial supercomputer resources. The latent demand for access to supercomputing by ANL researchers has been demonstrat- 
ANL Site Response for the DOE FY 1994 Information Resources Mwitagement Long Range Plan C. Site Information Resources Management Strategic Overview

ed by the programs funded by Energy Research (ER). Annually, ANL Energy Research and Fusion Power researchers develop proposals requesting a significant portion of the avallable resources of the computIng center at the National Energy Research Supercomputer Center (NERSC). The actual allocation of time in past years has only partially satisfied this demand. Other major segments of the Laboratory's programmatic activities (e.g., the Reactor Program) also require access to the highest speed computers avaliable, but they do not have similar opportunities for access to substantial allocations of external supercomputing resources.

To meet the expanding needs of computational scientists, the Laboratory's strategy is to provide substantial onsite supercomputing capability based upon state-of-the-art vector supercomputers, to provide access to offsite supercomputing centers available to ANL scientists, and to develop advanced computational resources based on parallel processing. Closely coupled in this strategy are tive development and implementation of high-speed networking capabilities and scientific visualization resources to meet the computational demands of real-time, interactive scientific computing. Our strategy is to allow users to access the local and remote supercomputing resources from their normal computing environment. This has been accomplist. $2 d$ by providing users access from the central IBM computers as well as distributed DECnet and TCP/AP based local area networks.

An important step in the modernization and upgrading of the Laboratory's central computers was taken with installation of a Cray X-MP/14 supercomputer in FY1988. This computer provides five times the processing capability of the Laboratory's IBM 3084QX computer for scientific and engineering computations. This high performance computer has sufficient capacity and capability to satisfy a substantial portion of the demand for high-speed onsite computing resources. The memory size of the Cray was increased to eight megawords in FY 1991.

The Laboratory may consider replacement opportunities for the Cray X-MP/18. Advances in microprocessors developed since Argonne's acquisition of the Cray X-MP may permit a more cost effective high performance computing platform to be obtained for the Laboratory. A replacement could offer larger memory and so permit the solution of problems with greater geometric detail, finer physical resolution, or increased numbers of phenomenological variables. Additionally, a replacement could offer multiple processors and so the capability for parallel processing and greater throughput.

In the area of offsite supercomputing access, Argonne National Laboratory has joined several leading U.S. research institutions to form the Concurrent Supercomputing Consortium (CSC). Through the CSC, Argonne researchers have access to the Touchstone DELTA System. The DELTA, currently the world's fastest computer with a peak speed of 32 gigaflops, will enable researchers to start tackling the Grand Challenges in science and ergineering. Argonne is also actively pursuing the establishment of a HighPerformance Computing Research Center. The center will be the focus for Argonne's high-performance computing activities and will provide the environment for development and evaluation of software, tools, and methods for parallel computing. The center will have two types of hardware full-sized systems, supported by extensive networking, visualization, and data systems infrastructure; and modest-scale experimental or research prototypes. ANL is also continuing development of its capability to utilize effectively the ER supercomputing resources allocated to ANL. ANL has worked closely with NERSC and ER to establish a major ESnet network node at ANL, to serve not only ANL but also Midwest universities, which are heavy users of the NERSC facilities.

In the long term, ANL will continue to pursue initiatives to meet the Laboratory's growing computing resource requiremicnts by using parallel supercomputer architectures and networks of distributed workstations working concurrently. Current research activities in this area are being conducted by several scientific divisions, as well as the Mathematics and Computer Science Division, the Computing and Telecommunications Division, and the Environmental Assessment and Information Sciences Division.

ANL-1.3.3 
A. Nit Site Response for the DOE FY 1994 Information Resources Management Long Range Plan March 25, 1992

C. Site Information Resources Management Strategic Overview

\section{Centralized General Purpose Computing}

The Laboratory's general-purpose computing requirements are met primarily by centrally maintained and operated IBM and VAX processors. These rescources include an IBM 3084QX and a DEC VAX Cluster (VAX 8700) and VAX 6410). The IBM 3084QX is used for both scientific and administrative computing. IBM-compatible computing capability continues to be an essential Laboratory-wide resource relative to 1) cost-effective sharing of expensive input/output devices; 2) maintaining Laboratory-wide databases; 3) providing front-end processing for the Cray X-MP/18; 4) performing scientific work that cannot be cost effectively performed on the Cray X-MP/18;5) serving administrative systems; and 6) providing some scientific time sharing functions, particularly for text editors and graphics.

IBM-compatible cycles must be provided for administrative computing, as the Laboratory has made substantial investments in developing and acquiring approximately one million lines of code. The Laboratory is pursuing a strategy that encourages the purchase of software rather than in-house development, thus leveraging our maintenance dollars with other purchases of software. The greatest selection of powerful administrative application software is currently on IBM compatible hardware. The Laboratory has purchased three major IBM-based applications: payroll, personnel, and financial systems. During the next few years, the Laboratory will study major materials applicadons. It is likely that the Laboratory's major materials applications will be replaced with applications that will run on the centralized computer mainframes or on local area network servers with Labnratory-wide access provided through the central computer mainframes.

The Digital Equipment Corporation VAX 8700 and VAX 641() computer systems with the VMS operating system provide shared, general-purpose, interactive computing services. The VAX cluster is a flexible, full-featured computing system that enables the Computing and Telecommunications Division to provide a broad range of computer-based services. A vector processor, additional memory, and additional disk storage are planned for FY 1992.

The clustered VAX service provides front-end processing capability for the Cray X-MP/18. Front-end capacity is necessary for job preparation and review of output as well as for the communications services necessary to transport data to and from the Cray-X-MP/18. In addition, the VAX Cluster is available to extend and improve the cost effectiveness and utility of the Laboratory's distributed VAX minicomputers. It improves and extends the IBM-based computing services and it provides new computing tools and services for the Argonne community. The cluster configuration serves as a focal point for the implementation of improved Laboratory-wide data communications services, giving Argonne users improved access to both internal and external computing network resources.

The Laboratory has purchased and installed the BASIS/TECHLIB system software for use on the VAX 8700 . This software is used by the ANL Technical Information Service (TIS) to provide online access and bibliographic search capabilities for the Laboratory's researchers and library staff.

\section{Multipurpose Minicomputers}

The primary need for such computers has been for division or facility real-time data acquisition and analysis capabilities. However, workstations are supplanting multipurpose minicomputers, a trend that will result in a continued decrease in the minicomputer population. The Computing Policy Committee critically reviews all proposed procurements of minicomputers to ensure their effectiveness in this important complementary role. For those cases where a sizable use of a proposed minicomputer involves interactive or batch computing, the Computing Policy Committee conducts a detalled assessment to ensure that such use and acquisition represent a cost-effective approach to providing such capabilities as compared to use of the Laboratory's centralized computers. 


\section{Scientific and Engineering Workstations}

Currently, several types of high performance scientific and engineering workstations are in use at Argonne. Predominantly, researchers are using Sun workstations, DEC RISCstations, IBM RISCstations, Silicon Graphics workstations, and workstations with Unix operating systems and TCP/IP communications for mathematical software programming and scientific and engineering applications. ANL has experienced increasing interest in this class of computing workstation for specific scientiflc and engineering applications. The computational power, graphics, and windowing capabilities of scientific workstations will provide scientists a popular platform for preparing work for and reviewing results from supercomputers and parallel processors.

The workstation environmeit at ANL is becoming increasingly more important to scientific computing. Workstations now are commonly used to conduct interactive sessions on remote computers with graphics and windowing capabilities. With emerging distributed file systems such as NFS and AlisaTalk, workstations are positioned to replace certain functions previously carried out by multi-user interactive systems. These functions include interactive file editing, review of output, communicating via electronic mail, and file management.

We expect that the acquisition of low-cost scientific workstations will continue at a brisk pace. To a lesser degree, scientists will acquire high-performance workstations for conducting computation-intensive calculations. Some production computing will move to high performance workstations and consume background CPU cycles or otherwise unused evening and weekend cycles. Many production codes, however, cannot easily be accommodated by this type of computing.

We expect the biggest benefit of workstations will occur as a result of increased distributed processing. Movement to standards like TCP/IP, Unix, NFS and X Windows enables increased workstation capabilities for interactive graphics display, graphics postprocessing, visualization, concurrent sessions on multiple hosts, and interactive debugging of supercomputer and mainframe applications.

CTD's strategy is to promote central capabilities and services that integrate well with workstations to create an effective distributed computing environment. Representative activities include providing $\mathbf{X}$ Window drivers for the DISSPLA graphics library, promoting the UNICOS cdbx interactive debugger with $\mathrm{X}$ Window capability, providing communications libraries for programming distributed applications, and providing IEEE data conversion routines for the Cray.

These and other activities will move workstations, supercomputers and related services closer to the notion of seamless computing (1.e., where the cooperative processing between workstation and supercomputer maximizes use of computer resources without significant user effort or awareness).

\section{Computing Workstations and Office Automation Support Systems}

Personal computers are being used for a wide range of activities including digital instrumentation, business applications, and scientific programming. The long history of digital instrumentation and the large number of experimenters provided a climate for the rapid introduction of personal computers into the Laboratory. The availability of electronic spreadsheets and database software is responsible for converting budget planning and other administrative activities to personal computers. As personal computers continue to increase in capability, capacity, and speed, they are given more consideration for scientific programming applications. 
ANL Site Response for the DOE FY 1994 Information Resources Management Long Range Plan March 25, 1992

C. Site Information Resources Management Strategic Overview

One of the growing uses of personal computer, at Argonne is for computer-aided design stations for twodimensional drafting. With the addition of the appropriate commerclal softwase, personal computerbased workstations can provide some of the capability of larger minicomputer based and mainframe based computer-aided design (CAD) systems. In addition to IBM-based systems, a number of staff are using Macintosh computers as drafting and design stations. This use of personal computers as design stations is expected to increase in the future.

The Laboratory acquires workstations, personal computers, and offlce automation support systems in a cost-effective manner in accordance with the DOE-CH approved ANL Statement of Site Strategy for Computing Workstations (ANL/TM 458, Revision 3). The Laboratory has established basic goals for acquiring and installing computing workstations that integrate with and communicate with the other levels of the Argonne computing hierarchy.

\section{PBX-based Digital Telecommunications System}

Extensive telecommunications capabilities are essential to ANL's computing strategy. A key element in ANL's long-range planning is the PBX-based digital telecommunications system. This system, which is discussed in detail in Part 4, has been installed and was operational at the end of FY1987. The system benefits Argonne and DOE operations at the Illinols site through superior volce cornmunication, improved flexibility to adapt to changes in operations, and improved scientific and administrative data communications. Argonne has a flexible system that is easily adaptable to changes within the Laboratory, and the Laboratory is in a much better position to take advantage of advances in communications for computing and in the entire sphere of automated information handling.

The PBX system at Argonne provides new capabilities for site-wide communication among terminals and computers. With a maximum bandwidth of 56 Kbaud at each telephone station, terminals and computing workstations scattered throughout the site are able to communicate at their full bandwidth $(9,600)$ or 19,200 bits per second). In addition, the PBX has the capability of emulating a high-speed local area network. This capability provides a Laboratory-wide Ethernet and allows computers and workstations to communicate across the site.

Argonne has added a voice processing system to the PBX. The system is fully integrated with the PBX and has a present capacity for 1600 voice mailboxes and already has 130() subscribers.

\section{Fiber Distributed Data Interface (FDDI)}

There exists a current and growing demand at Argonne for better interoperability between computers. This demand is dictated by the need to transfer large quantities of information between systems. Scientific visualization, Network File System (NFS) support, diskiess workstation support, and the need for cooperative computing between computing systems are all examples of applications requiring high performance networking. These needs translate into a demand for networks that are faster and more reliable and span greater distances, making it imperative that the implementation of FDDI technology at Argonne proceed at an accelerated pace.

FDDI, the Fiber Distributed Data Interface, is an international networking standard. As such, it will become as important to the area of networking as the Ethernet standard is today. FDDI uses dual, counter rotating, token passing, fiber optic rings as its communication medium. This conflguration provides an extremely reliable network which will continue to operate if part of the ring is physically broken. The data rate on the ring is $1(0) \mathrm{M}$ bits per second (10) times Ethernet) and is capable of 80 percent efficiency (Ethernet performance begins to decrease at 35 percent capacity). Because of the dual ring configuration, It is possible to transmit data on both rings, thus doubling the $1(X) \mathrm{M}$ bits per second data rate. 
Argonne has investlgated FDDI, installed and tested a prototype FDDI network, and implemented a limited production FDDI network that serves several divisions. In the near future, Argonne plans to expand this prototype network to a production backbone network which runs throughout the Laboratory. General Physical Plant funds have been requested to install the fiber optic cable plant necessary for this expansion. Once the physical plant is in place, Ethernet LANs can connect to the FDDI backbone through Ethernet/ FDDI routers. Hosts such as the Cray X-MP and Sun workstations are connected directly to the FDDI cable plant in order to use the full available bandwidth of FDDI. These types of connectlons will accommodate the applications mentloned above such as scientific visualization, NFS, diskless workstation support, and cooperative computing.

\section{National and International Network Connections}

The Laboratory maintains national and international network connections to provide file transfer, interactive access, and electronic mail capabilities to a large number of professional peers and potential collaborators. There are connections between the Internet and Laboratory computers that link major universities and laboratories together. The Laboratory's central IBM computers and DEC VAX computers also participate in BITnet, an international university file transfer network interconnecting over three thousand computers. The Laboratory is connected to ESnet, a T1 natlonal network funded by DOE's Energy research program; ESnet provides a communications backbone for both HEPnet and the Internet. ESnet runs the DECnet and TCP/IP protocols. The Laboratory participates in the dedicated computer network for High Energy Physics Research (HEPnet) through the ESnet, interoperated with major High Energy Physics laboratories and university collaborators. The Laboratory's DECnet and TCP/IP based networks are linked to CICnet, a T1 reglonal network. A T3 National Sclence Foundation network (NSFnet) node was installed at Argonne in 1991. NSFnet runs the TCP/IP protocol. The Laboratory is represented on the CICnet Board of Directors, the HEPnet Technical Coordinating $C^{\circ}$.nittee, and the ESnet Technical Steering Committee.

\section{Scientific Visualization}

Scientific visualization is essential to effective use of supercomputing and computational science. It is widely recognized that visual methods are required to improve the timeliness and effectiveness of data analysis. Visual techniques must be developed to analyze the increasing volume of data generated by supercomputers and data acquisition systems. ANL scientists have begun to increase their reliance on images in addition to ordinary computer print output. The use of color and motion takes advantage of the human visual system for interpretation. Color establishes or emphasizes differences in data; animation reveals subtle change.

CTD visualization staff continue to collaborate with scientific researchers to visualize the results of scientific computations. CTD is considering alternatives for high-speed networking at rates of gigabits per second for transmitting video images for interactive visualization. CTD is establishing a scientific visualization facility which provides visualization services to the scientific community and conducts research in specialized visualization applications.

CTD is also working to establish a distributed computing environment where visual analysis tools are common. The effective combination of staff, networks, graphics standards, and workstations will speed the use and acceptance of scientific visualization. The capabilities that researchers need include a) easy to use generic tools to visualize data, b) capabilities to display images from computation-intensive applications in real time and to interact with the computation, c) the capability to review results of computations in animated sequences, and d) the capability to record animation sequences for archive or presentation. CTD expects that much of the capability of this computing environment will be accessible to researchers 
ANL Site Response for the DOE FY 1994 Information Resources Management Long Range Plan Murch 25, 1992

at the workstations in their offices. Examples below describe hardware and software tools for visualizathon that CTD is pursuing.

ANL researchers have a large investment in Fortran codes that use the Disspla graphics library. To preserve that investment and yet give users new capabilities, CTD has developed an X Windows graphlcs driver for Disspla. The $X$ driver permits users to generate images on the Cray $X-M P / 18$ computer and display those images on workstations that use $X$ Windows. The result is interactive animation of computational-intensive calculations.

CTD promotes the NCSA Image tool program for Macintosh and SUN workstations for data analysis. CTD provides classes to instruct users on how to modify Fortran programs to create multiple files of 2-D Images that can be transferred for viewing to Macintosh or SUN workstations.

With the increase in population of SUN and Microvax workstations, CTD is evaluating capabilities of visualization packages for those systems. Precision Visuals PV-wave, AVS, and SUNVISION are products that enable the creation, display, and manipulation of 3-dimensional graphics.

In FY1990, CTD acquired specialized video recording equipment for stop-frame animation. A scan converter and an Abekas A60 digital disk recorder enable the recording of animations from workstations such as the Apple Macintosh, SUN, SGI and Stardent Titan. In FY1991, CTD established a Laboratory-wide service to provide video recording for users on a routine basis. 
ANL Site Response for the DOE FY 1994 Information Resources Management Long Range Plan D. Site Information Resources Management Planning Process

March 25, 1992

\section{Section D}

\section{Site Information Resources Management Planning Process}

Planning for information resources nranagement at Argonne is a continuous process throughout the year, with helghtened activity from October through January to prepare the formal annual Plan for the Department of Energy. This Laboratory-wide planning activity involves individual divisions and programs as well as the top Laboratory management. Principal responsibility for coordinating the Laboratory's effort and preparing the annual plan is vested in the Computing and Telecommunications Division.

Throughout the year, several standing Laboratory committees (Computing Policy Committee, Administrative Data Processing Oversight Committee, Computer Users Group, etc.) as well as special ad hoc committees meet to discuss, plan, and review computing and telecommunications strategles for the Laboratory.

The membership of these committees includes principal users of the resources as well as management personnel of the Laboratory. The Computing Pollcy Committee consists of 16 members and is currently chaired by the Deputy to the Laboratory Director. The committee includes the Chlef Financial Officer, the Director of the Computing and Telecommunications Division, and staff members and management from the major scientific and engineering divisions. The Administrative Data Processing Oversight Cornmittee, chaired by the Chief Financial Officer, consists of representatives of the major operations support organizations, the Director of the Computing and Telecommunications Division, and staff members and management from the programmatic divisions.

The Administrative Data Processing Oversight Committee (ADPO) issues a call each year to the appropriate Laboratory organizations for proposals to develop or enhance administrative computing and management information systems for the coming fiscal year. Prior to each fiscal year, ADPO reviews proposals and develops a ranked list of recommendations to the Laboratory's Chief Operations Officer. The Computing and Telecommunications Division prepares the management information systems plan and submits it to the Administrative Data Processing Oversight committee for review and approval. After approval by the Administrative Data Processing Oversight Committee, the management information systems plan and a letter of approval from the Administrative Data Processing Oversight Committee go to the Chief Operations Officer for review and concurrence.

ANL continues to develop a planning process based on the planning activities of the divisions and programs of the Laboratory. The Computing Policy Committee provides general guidance relating to broad Laboratory computing and telecommunications goals and objectives and reviews the formal submission of the ANL Site Response to the DOE FY1994 Information Resources Management Long-Range Plan to the Department of Energy. Each Associate Laboratory Director has appointed staff representatives to work closely with the Computing and Telecommunications Division in preparing the annual computing resources plan. Additionally, divisional and programmatic representatives are enlisted to develop the computing requirement projections for each individual program activity, as well as to provide the needed justifications and program narratives. The Computing Policy Committee critically reviews and approves drafts of the computing resources plan. Following this review, the Computing and Telecommunications Division submits the computing resources plan to the Chief Operations Officer for review and approval.

The Computing and Telecommunications Division prepares the Telecommunications Part of the Site Response after detailed analysis of the Laboratory's telecommunications needs. This analysis is based upon historical trends as well as detailed assessment of individual organizational needs. The Computing 
ANL Site Response for the DOE FY 1994 Information Resources Management Long Range Plan March 25, 1992

D. Site Information Resources Management Planning Process

and Telecommunications Division then submits the telecommunications part of the Site Response to the Chief Operations Officer for review and approval.

The Media Services and Technical Information Services Departments of the Information and Publishing Division prepare and submit Part 5, Printing and Publishing, of the Site Response to the DOE Argonne Area Office on behalf of the Chief Operations Officer.

The Chief Operations Officer receives all parts of the Site Response after review and approval by the appropriate Laboratory standing committees. After review and approval by the Chief Operations Officer, the Site Response is submitted to the DOE Argonne Area Office. 
ANL Site Response for the DOE FY 1994 Information Resources Management Long Range Plan E. Discussion of General Comments/Major Issues

March 25, 1992

\section{Section E}

Discussion of General Comments/Major Issues 
ANL Site Response for the DOE FY1994 Information Resources Management Long Range Plan F. Points of Contact

\section{Section $\mathbf{F}$}

Points of Contact

Information Resources Management Plan

*L. M. Boxberger

Associate Director

Computing and Telecommunications Division

Argonne National Laboratory

Argonne, Illinois 60439

Phone: FTS 972-5638

EMAIL: BOXBERGER@ANL.GOV

Management Information Systems

Diane E. O'Brien

Associate Director

Computing and Telecommunications Division

Argonne National Laboratory

Argonne, Illinois 60439

Phone: FTS 972-7156

EMAIL: B26424@ANLVM.CTD.ANL.GOV

Unclassified Computer Security

L. Jean Troyer

Computer Protection Program Manager

Computing and Telecommunications Division

Argonne National Laboratory

Argonne, Illinols 60439

Phone FTS $972-7440$

EMAIL: B18216@ANLVM.CTD.ANL.GOV
Computational Science and Engineering

Dr. Charles J. Mueller

Associate Director

Computing and Telecommunications Division

Argonne National Laboratory

Argonne, Illinois 60439

Phone: FTS 972-7153

EMAIL: CJMUELLER@ANL.GOV

Telecommunications

Larry Amiot

Associate Director

Computing and Telecommunications Division

Argonne National Laboratory

Argonne, Illinois 60439

Phone: FTS $972-5432$

EMAIL: AMIOT.ANL.GOV

Printing and Publishing

Kathryn Macal

Director

Information and Publishing Division

Argonne National Laboratory

Argonne, Illinois 60439

Phone: FTS 972-3742

Records Management

Mary L. Wilson

Records Coordinator

Materials and Service Department

Argonne National Laboratory

Argonne, Illinois 60439

Phone: FTS 972-7618

*Primary individual with respect to questions concerning the contents of the FY1994 Information Resources Management Long Range Plan. 


\section{Section G}

\section{Special Areas of Interest}

\section{A. GOSIP Transition Plan}

Argonne National Laboratory is committed to a transition to using Open System Interconnect (OSI) products as they become available in the market place. Argonne acquisitions will be compliant with the Government OSI Profile (GOSIP) as specified in the Federal Information Processing Standard Publication (FIPS PUB 146). It is the goal of the Laboratory to achieve interoperability between the Argonne site and other DOE sites by October 1, 1995, using GOSIP protocols.

The strategy that Argonne will use to effect the GOSIP transition is based on a number of activities:

- Participation on DOE GOSIP committees,

- Early prototyping and experimentation with GOSIP products,

- Participation in the transport of OSI packets on national networks, and

- Construction of gaieways between GOSIP and other network protocols.

ANL Network Environment--The network environment at Argonne is described in detail in Parts 3 and 4 of the Site Response. Generally, the environment is heterogeneous in that the Laboratory has acquired computers and computing equipment from most of the major vendors (Cray, IBM, DEC, SUN, etc. to name a few). External network connections are also numerous and heterogeneous in nature--ESnet, HEPnet, BITnet, NSFnet, and CICNet. Network protocols in use include TCP/IP, DECnet, SNA, XNS, AppleTalk, etc. Any transition to new network protocols must thus protect the existing investment in computing and networking hardware and software. New systems and major upgrades to existing systems can clearly justify early use of GOSIP products; other systems will require gateways between the existing networks and the new GOSIP compliant networks.

GOSIP Accomplishments--Argonne has been an early supporter of GOSIP activities. It has members on both the DOE GOSIP Council and the DOE GOSIP Migration Working Group and thus has been active in helping DOE plan a smooth transition to the use of GOSIP in DOE and at contractor sites. Argonne is also involved with a number of other GOSIP activities, including:

ISODE--Argonne has OSI applications running on top of IP using ISODE on SUN Sparc workstations.

SUNLINK OSI--Argonne has OSI applications running on CLNS using SUNLINK OSI on a SUN workstation.

ESnet--An ESnet/OSI Working Group has been formed of which Argonne is a member. The Working Group has as its goal the transport of OSI CTLS packets. 
ANL Site Response for the DOE FY 1994 Information Resources Management Long Range Plan March 25, 1992

G. Spectal Areas of Interest

EDWG--We are participating in the Energy Sclences DECnet working group responsible for planning and implementing DECnet/OSI.

CICnet Technical Committee--Argonne is chairing the CICNet Technical Committee that has as its goal the transport of OSI CLNS packets on the CICNet regional network on which Argonne has a node.

GOSIP Migration Plans--The GOSIP transition activities at Argonne follow the GOSIP transition strategy outlined above. Argonne personnel will continue to be represented on the DOE GOSIP Council and the DOE GOSIP Migration Working Group. Argonne will also continue to interact with the CICNet Technical Committee, the ESnet OSI Working Group, and the IETF OSI Operations Working Group. The following represent the activities and milestones that comprise the plan:

X.400/ISODE--This application is currently running on a SUN workstation. It is not fully GOSIP compliant because it uses IP at the lower levels. Argonne expects to continue testing $\mathrm{X} .400$ by using this product as a part of the IETF OSI Operations Working Group activities in FY1992.

X.400/OSI--Argonne plans to test fully compliant products by using both IBM developed software for IBM RISC platforms and SUNLINK OSI for SUN platforms. Argonne will be testing interoperability between the ANL X.40() implementation and X.400) implementations at other sites by using the OSI routing capabilities of CICNet, ESnet, and NSFnet. These are all activities that were initiated in FY1991 and are expected to be completed in FY1992.

X.500/ISODE--Argonne ci rrently has X.50) configured for a SUN workstation. A test database for the system was built and made operational in the summer of 1991.

X.500/OSI--As yet Argonne is unaware of any commercial X.5(0) implementations that are fully GOSIP compliant. Argonne expects such implementations to be available well before August 1993 when Version III of GOSIP will require X.5(X) to be functional.

VT/ISODE--Argonne currently has the virtual terminal application configured on a SUN platform by using IP at the lower levels. Argonne does not plan extensive testing of this application until late FY 1992.

VT/OSI--Fully GOSIP compliant virtual terminal products will not be required until GOSIP Version Il is approved in March 1992. Argonne does not expect to have virtual terminal software available for testing before the spring of 1992.

FTAM/ISODE--Argonne currently has the file transfer protocol (FTAM) configured on a SUN platform by using IP at the lower levels. We plan to test this product along with the testing of the X.4(X)/ISODE application in FY1991.

FTAM/OSI--Argonne plans to test fully compliant FTAM by using both the IBM developed software for the RISC platforms and the SUNLINK OSI software for SUN platforms. This activity was initiated in early FY1991 and will be completed in early FY 1992. 
FTAM/FTP--Argonne plans to test the IBM and SUNLINK OSI software described above and choose one to build a FTAM to FTP application gateway. We expect this gateway to be operational by August of 1992.

X.400/SMTP--Argonne plans to bulld a X.400 to SMTP mail gateway. We expect this gateway to be operational in FY1992.

FTS2000 X.25/OSI--Argonne plans to bulld a FTS2000 X.25 to OSI gateway that will allow mail and file transfer between the FTS2000 X.25 packet switch network and the Internet.

DECnet/OSI--It is expected that the Digital Equipment Corporation developed DECnet/OSI software will be fully GOSIP compliant and initially provide X.400 and FTAM OSI services. The DEC X.500 directory services product will be used in the DECnet/OSI implementation. The software avallability has been delayed by DEC recently on several occasions. Our best estimate is that it will be avallable in the fall of 1992. Argonne plans to acquire and utilize DECnet/OSI shortly after it becomes avallable. Argonne will run a DEC station 5000 UItrix name server for DECnet/OSI and plan to begin testing the name server in the third quarter of FY1992.

FDDI--Argonne has installed the first phase of a Laboratory-wide FDDI network connecting Bulldings 221, 308, 362 and 900. We have plans in FY1992 to complete the Laboratorywide FDDI backbone.

Network Management/CMIP.-Argonne currently makes extensive use of SNMP based network management products. We plan to test the CMIP products as they become available.

GOSIP Procurement Strategies--Argonne procurement personnel have developed strategies for ensuring that procurements are compliant with GOSIP. User presentations have been prepared to inform users about GOSIP. A questionnaire has been prepared that users must fill out when obtaining communications equipment, software, or services. FIPS PUB 146 has been made available to interested users as have selected documents prepared by the DOE GOSIP Migration Working Group. A short document containing a description of the GOSIP requirement and answers to frequently asked questions has been prepared and distributed.

GOSIP Authorities---The following Argonne National Laboratory GOSIP Authorities are:

$\begin{array}{lll}\text { Acquisition Authority } & \text { Bernell Bohlmann } & 708-252-7137 \\ \text { Addressing Authority } & \text { Linda Winkler } & 708-252-7236 \\ \text { Registration Authority } & \text { Linda Winkler } & 708-252-7236 \\ \text { Protection Authority } & \text { Jean Troyer } & 708-252-7440\end{array}$


ANL Site Response for the DOE FY1994 Information Resources Management Long Range Plan March 25, 1992

G. Special Areas of Interest

\section{B. E-MAIL RESOURCES}

Argonne National Laboratory

1. Site Name: ARGONNE NATIONAL LABORATORY

2. E-Mail System Used: CMS NOTE $X, 4 \mathrm{CO}$

3. System Location: LOCAL $\square$ OTHER

\section{System Service Area:}

5. Number of Subscribers: 1000

6. System To System Interconnection:

7. Future Plans for E-Mail Upgrade or Acquisition:

8. System Administrator: RAYMOND CARLSON

9. FTS Number: $252-5805$

10. Commercial Number: $\quad 708-252-7805$

11. Address: 
ANL Site Response for the DOE FY 1994 Information Resources Management Long Range Plan G. Special Areas of Interest

Argonne National Laboratory

1. Site Name: ARGONNE NATIONAL LABORATORY

2. E-Mail System Used: VMS MAIL

$x, 400$

3. System Location: LOCAL

OTHER

4. System Service Area:

LOCAL $X$

NATIONWIDE $X$

INTERNATIONA.L $\bar{X}$

5. Number of Subscribers: 600

6. System To System Interconnection: MULTINET TCP/IP CONNECTS VMS MAIL TO INTERNET

7. Future Plans for E-Mail Ungrade or Acquisition:

8. System Administrator: RICHARD RAFFENETTI

9. FTS Number: $252-8497$

10. Commercial Number: $\quad 708-252-8497$

11. Address: 
ANL Site Response for the DOE FY 1994 Information Resources Management Long Range Plan March 25, 1992

G. Special Areas of Interest

Argonne National Laboratory

E-Mall Resources

Schedule $1 \cdot 1$

1. Site Name: ARGONNE NATIONAL LABORATORY

2. E-Mail System Used: CC:MAIL

$X, \angle C C !$

3. System Location:

LOCAL $\square$ OTHER

4. System Service Area:

LOCAL $X$

NATIONWIOE $X$

INTERNATIONF:- $\bar{X}$

5. Number of Subscribers: $\quad 30$

6. System To System Interconnection: SMTP GATEWAY CONNECTS CC:MAIL TO INTERNE:

7. Future Plans for E-Mail Upgrade or Acquisition:

8. System Administrator: JAMES REGULA

9. FTS Number: $252-7622$

10. Commercial Number: $\quad 708-252-7622$

11. Address:

ANL-1.7.6 
ANL Site Response for the DOE FY 1994 Information R.esources Management Long Range Plan G. Special Areas of Interest.

Argonne National Laboration

1. Site Name: ARGONNE NATIONAL LABORATORY

2. E-Mail Sysfem Used: QUUICKMAlL

$x .400$

3. System Location:

LOCAL $\square$ OTHER

4. System Service Area:

LOCAL $X$

NATIONWIDE $X$

INTERNATIONA! $x$

5. Number of Subscribers: 400

6. System To System Interconnection: APPLETALK; SMTP GATEWAY CONNECTS QUICKMAilL TO INTERNET

7. Future Plans for E-Mail Upgrade or Acquisition:

8. System Administrator: DAVID LIFKA

9. FTS Number: $252-3251$

10. Commerclal Number: $\quad 708-252 \cdot 3251$

11. Address: 
ANL Site Response for the DOE FY 1994 Information Resources Management Long Range Plan March 25, 1992

Argonne National Laboratory

1. Sile Name: ARGONNE NATIONAL LABORATORY

2. E-Mall System Used: UNIX MAIL

$x, 400$

3. System Location:<smiles></smiles>

OTHER

4. System Service Area:

5. Number of Subscribers: 300

6. System To System Interconnection:

7. Future Plans for E-Mall Upgrade or Acquisition:

8. System Administrator: RICHARD CARLSON

9. FTS Number: $\quad 252-7289$

10. Commerclal Number: $\quad 708-252-7289$

11. Address: 
ANL Site Response for the DOE FY 1994 Information Resources Management Long Range Plan G. Special Areas of Interest

Argonne Natlonal Laboratory

1. SIte Name: ARGONNE NATIONAL LABORATORY

2. E-Mall System Used: PROFS

3. System Location: LOCAL $\square$ OTHER

4. System Service Area:

5. Number of Subscribers:

143

6. System To System Interconnection:

PROFS EXTENDED MAIL GATEWAY TO INTERNET

7. Fufure Plans for E-Mall Upgrade or Acquisition:

8. System Administrator: FRAN CARNAGHI

9. FTS Number: 252.5425

10. Commercial Number: $\quad 708-252.5425$

11. Address: 
ANL Site Response for the DOE FY1994 Information Resources Management Long Range Plan Part 2:

March 25, 1992

\section{Part 2}

Software Plans (Parts 2A, 2B, and 2C)

ANL-2.().1 
ANL Site Response for the DOE FY 1994 Information Resources Management Long Range Plan A. Software Plan for DOE Contractors

\section{Section A}

\section{Software Plan for DOE Contractors}

Administrative computing at the Laboratory has been primarily concerned with building computer systems to automate operational tasks within the non-programmatic business units. Today's challenge is to get information into the hands of the decision-makers of the Laboratory when they need it and in a form they can easily use.

The Administrative Data Processing Oversight Committee was formed by the Chief Operations Officer in October 1982 for the purposes of:

- Advising Laboratory management and the Computing Policy Committee regarding administrative computing issues.

- Formulating policy for administrative computing.

- Acting as an advocate for the establishment of administrative computing policy.

- Recommending funding and schedules for new equipment, new software development, and enhancements for all administrative computing systems.

The Committee's recommendations for the allocation of Laboratory resources for administrative computing projects are based on an analysis of benefits and costs as well as on the extent to which such projects can enable the Laboratory to achleve the following goals:

- Manage information as a Laboratory resource.

- $\quad$ Provide integrated business systems.

- Develop an integrated infrastructure for administrative systems.

- Promote standard business practices.

- Promote user self-sufficiency.

- Serve as advisors to bullders of unofficial systems.

- Develop more effective systems.

- $\quad$ Provide expertise in developing and managing systems.

The systems identified in Section C of Part 2A are the major planned, developmental, and operational management Information Systems (IS) of Argonne National Laborator; that meet the criteria for being reported in the ANL Site Response to the DOE FY1994 Information Resources Management Long Range Plan. Additional detall on these systems appears in A Plan For Administrative Computing At ANL FY1992 Through FY1994 (ANL/TM 489), November 1991. 
ANL Site Response for the DOE FY1994 Information Resources Management Long Range Plan March 25, 1992

A. Software Plan for DOE Contractors

\section{A. Software Management Plans and Strategies}

\section{Software Management}

In anticipation of the formal implementation of DOE Order 1330.1C, Argonne has incorporated formal Software Management practices and activities in the charter of the Administrative Data Processing Oversight (ADPO) Committee.

The Administrative Data Processing Oversight Committee includes in its purview the planning, funding, and development of all official Laboratory business systems. Unofficial administrative systems that serve only an internal purpose for an organization are subject to review by the Committee if they meet any of the following criteria:

1. Require more than $\$ 25,000$ in purchased hardware and/or software.

2. Require more than four months of technical effort.

3. Interface with an existing official administrative system by transferring data between the systems.

4. Manage information that is used by Laboratory personnel in another organization.

Developing information systems is an expensive process which consumes Laboratory resources. The Laboratory must have the assurance that development of business systems occurs in the most effective manner, that planned business systems do not duplicate existing systems, and that planned systems contain the proper interfaces to official systems. Management Information Systems (MIS) of the Computing and Telecommunications Division (CTD) acts as a resource for the Administrative Data Processing Oversight Committee for knowledge of computing resources and expertise in ANL's operating system. The area staff collects, distributes, and recommends priorities for proposals which affect administrative data processing and the Argonne computing environment.

The Administrative Data Processing Oversight Committee reviews proposed administrative computing projects at either regularly scheduled or special meetings. The proposal submissions cover the following points:

- Statement of the Problem and Proposed Solution

- Information Resource Issues and Technical Review

- Participants and Schedule of Deliverables

- Success Factors and Risks

- Costs and Benefits

The full format for proposals to the Administrative Data Processing Oversight Committee appears in Appendix D of Plan for Administrative Computing at ANL, FY1992-FY1994 with forms for cost and benefit analysis and examples of quantifiable and non-quantifiable aspects of the proposal.

The cost benefit section of the proposal was modified to provide greater detail in accordance with Aralysis of Benefits and Costs (ABC). 
ANL Site Response for the DOE FY 1994 Information Resources Management Long Range Plan

One of the responsibilities of the Administrative Data Processing Oversight Committee is to review proposals for administrative system projects and to recommend funding through the Laboratory General Expense Budget for those that provide a tangible cost benefit to the Laboratory, that are necessary to the continuing operation of the Laboratory, or that enhance the way the Laboratory performs its business functions. In addition, because of the limited resources available for administrative computing projects, the Committee sets priorities on projects that best fulfill the goals of administrative computing. The Committee may assign a priority to a project based on the goals for administrative computing and other management considerations, or the Committee may not recommend funding for the proposed project.

Projects reviewed by the Administrative Data Processing Oversight Committee vary in size and complexity. As necessary, the Committee requests assistance in the technical assessment of proposed projects from Computing and Telecommunications associate directors, section heads, and group managers. Generally, Computing Policy Committee approval is necessary for hardware acquisition. The Administrative Data Processing Oversight Committee submits a funding recommendation to the Chief Operations Officer for the approved projects. This funding recommendation is for the next fiscal year but proposals address mortgages for future fiscal years.

During the lifetime of an approved administrative computing project, the Administrative Data Processing Oversight Committee reviews the status of the project on a regularly scheduled basis, recommends redirection when necessary, reviews and approves major changes in project direction, and reports the findings to the Chief Operations Officer. Projects under review will utilize the following format for presentations:

- Statement of project charter and scope as approved

- Chart of major milestones as originally approved

- Narrative review of status of each milestone

- Anticipated and actual deviations from plan

- Potential problems and opportunities

As appropriate, the Committee will forward recommendations or the results of the review of a project to the Chief Operations Officer or the Computing Policy Committee.

In most cases, users initiate the request for the development of new applications and the enhancement or maintenance of existing applications written by the Laboratory. The initiating request for service may result from:

- an individual user organization, which perceives a specific need and communicates with a CTD analyst.

- $\quad$ MIS, which perceives a Laboratory-wide need, perhaps across functional areas, and communicates to Laboratory management through the Administrative Data Processing Oversight Committee. 
ANL Site Response for the DOE FY 1994 Information Resources Management Long Range Plan March 25, 1992

A. Software Plan for DOE Contractors

Once a proposed project has become a reality and for as long as it is funded, MIS monitors the application throughout its existence from inception to replacement. The application undergoes development in phases, occupies a sensitivity rank, and is evaluated in the light of risk assessment, disaster recovery, and quality assurance. After the Chief Operations Officer has approved funding for a service request, the CTD staff has historically used a phased approach to proceed with the application. One of the established methods has been the use of SDM/70, a standard approach used for new application development and major enhancements to existing applications. It involves a series of chronological, well-structured, and well-documented phases. The eight SDM/70 phases fall into three major categories: analysis, design, and construction.

At the end of each phase, the requesting division or committee makes a decision on whether it is feasible to continue the development process. With the completion of each phase, the user's ability to estimate the benefits and costs of the application has improved, because the specifications for the application have become progressively more explicit. In the traditional structure of design phases, documentation of specifications accumulates until the final preparation and circulation of a formal document subject to review and approval by all involver parties. However, this structured phased appproach has proved to be a costly and time-consuming activity, so as part of its software management policies and procedures, CTD-MIS is documenting other approved techniques more recently available. For major applications, such as the Automated Materials/Payables System or the Integrated Financial System, representatives from the affected areas form steering committees to review and approve phases of the project. For all administrative data systems, the Administrative Data Processing Oversight Committee has a major role in defining administrative policies. A rewrite of software management policies and procedures will be completed and published during FY1992.

\section{B. Software Initiatives and Resource Requirements}

MIS performs business analysis, gathers the systems requirements, defines and examines the alternative solutions, and then designs and implements new official administrative computing systems for the Laboratory. MIS is responsible for the publication of A Plan For Administrative Computing at ANL FY1992 Through FY1994. In addition, the staff of Management Information Systems manage, enhance, and maintain approximately fifty-four administrative software applications. Expertise is provided in the areas of business analysis, feasibility studies, commercial software evaluation, systems design, database design, programming, and project management in both the IBM and Hewlett-Packard computing environments. Although the administrative divisions of the Laboratory are the principal customers of the Section, programmatic divisions also purchase services from MIS.

Contract analysts and programmers supplement the permanent staff when a large project requires a temporary expansion in effort. No subcontractors are currently scheduled to be used by Management Information Systems.

The personnel resources associated with administrative/business software are described in detail in A Plan For Administrative Computing At ANL FY1992 Through FY1994. The Computing and Telecommunications Division within Physical Research is organized into separate areas of responsibility in accord with the mission of the division. Management Information Systems constitutes a significant segment of the division's mission and is the responsibility of an Associate Division Director. 
ANL Site Response for the DOE FY1994 Information Resources Management Long Range Plan

Within Management Information Systems, the staff, consisting of 23 full-time analysts and 4 operators, forms four groups: Financial Systems, Human Resource Systems, Information and Production Services, and Materials and Plant Systems. The Financial Systems Implements and maintains the accounting and business systems of the Laboratory. The Human Resource Systems maintains the Laboratory's people-related systems, including personnel and payroll. Information and Production Services schedules most of the administrative batch computing on the IBM and HewlettPackard computers, submits jobs, verifies the results, and manages the output. This section also provides training and information for administrative computing users. Materials and Plant Systems develops and maintains those computer systems which order, track, and report the status of materials Laboratory-wide and those systems that record and report the various aspects of the Laboratory's physical plant.

The following administrative/business systems are worthy of special note:

- $\quad$ Argonne Material Order System (AMOS)

AMOS is an integrated system for requisitioning, receiving and invoicing of commonly used materials held in selected vendor's warehouses rather than held in stock warehouses at the Laboratory.

- $\quad$ Automated Materials Payable System (AMPS)

AMPS is an integrated Purchasing and Accounts Payable system that manages purchase orders from requisition to payment.

- Integrated Financial System (IFS)

The Integrated Financial System (IFS) is a multi-year project that is replacing all financial software with commercial systems, where feasible. General Ledger, Financial Controller and Information Expert were put into production in mid-FY1989. Other aspects of the project include Implementation of BrightVlew, Budgeting, Accounts Payable for CheckWriting, Purchasing for Internal Purchasing, and Budgetary Control.

- Integrated Payroll and Personnel System

The Personnel and Payroll System is part of the Laboratory's Human Resource Management System with which it shares common data. The personnel components assist in the Laboratory's personnel record keeping and reporting activities. Terminals at the ANL East and West sites provide for update and review of employee records. The payroll components provide real time updating of data, produce payroll checks, and process retirement, absence, bond, overtime and benefits data.

- $\quad$ Automated Requisition Tracking

The planned Argonne Requisition and Tracking System (ARTS) represents a first phase of improving the Laboratory's procurement and material system. ARTS will provide a CICSbased online requisitioning and inquiry capability for purchase requisitions. It will allow user organizations to use a system that is accessible Laboratory-wide to enter their purchase requisitions, route their requisitions for approval, and track their purchases both before and after the requisition is passed to the AMPS system. 
ANL Site Response for the DOE FY 1994 Information Resources Management Long Range Plan March 25, 1992

A. Software Plan for DOE Contractors

- $\quad$ Stock Tracker System (STS)

STS keeps track of material supplied through storerooms at ANL East and ANL-West. STS generates requisitions for stock replenishment and keeps track of inventory.

With respect to operating system software, the Computing and Telecommunications Operations component of CTD has primary responsibility for installing, maintaining, and protecting the integrity of central Cray, IBM, and VAX operating systems. The 12 to 16 systems programmers responsible for operating systems (including network operating systems) also work with and assist administrators of Sun and VAX distributed systems throughout the site.

Scientific/Engineering software is acquired, developed, and maintained by individual researchers and scientists in the programmatic divisions. Some of the more notable activities and developments in the area of scientific/engineering software are described in Section G of Part I and Section G of Part III of the ANL Site Response to the DOE FY1994 Information Resources Management Long-Range Plan. Additionally, scientific/engineering software of potential use and impact to other DOE organizations and sites are formally transmitted to and maintained for distribution by the National Energy Software Center, (NESC) as required by DOE Order.

The most significant ANL use or planned use of manufacturing oriented or computer-assistedmanufacturing applications (CAM) is within the Central Shops Department of the Support Services Division. Central Shops intends to acquire and use several manufacturing oriented software packages. Personnel resources to evaluate, support, and install such systems are provided by Manage-

ment Information Systems. Additional detail on the manufacturing-oriented systems and plans of Central Shops is contained in A Plan for Administrative Computing at ANL FY1992 through FY1994.

\section{Software Reporting Requirements}

No software development projects have a direct external impact or cost more than one million dollars to develop and implement. 
ANL Site Response for the DOE FY1994 Information Resources Management Long Range Plan

B. Software Plan for DOE Organizations

March 25, 1992

\section{Section B}

\section{Software Plan for DOE Organizations}

None of the sections of Part 2B, SOFTWARE PLAN FOR DOE ORGANIZATIONS apply to Argonne National Laboratory.

Section A. Software Management Plans and Strategies

Section B. Software Initiatives

Section C. Personnel Resources Required

Section D. Software Reporting Requirement

Section E. Prior Year Software Accomplishments

Section F. Unmet Data Requirements and Software Changes 
ANL Site Response for the DOE FY1994 Information Resources Management Long Range Plan C. FMS Plans for DOE Organizations

March 25, 1992

\section{Section C}

FMS Plans for DOE Organizations

None of the sections of Part 2C, FMS PLANS FOR DOE ORGANIZATIONS apply to Argonne National Laboratory. 
ANL Site Response for the DOE FY 1994 Information Resources Management Long Range Plan Part 3:

March 25, 1992

\section{Part 3}

Computing Resources Plan

ANL-3,().1 


\section{Section A}

\section{Requirements}

\section{A. ADP Requirements Schedule}

Part 1, the Site Overview, of the Argonne National Laboratory Site Response to the DOE FY1994 Information Resources Management Long-Range. Plan describes the programmatic activitles of the Laboratory with particular emphasis on the development of new major program areas. The Laboratory's continuing research programs and the new initiatives (either directly or through anclllary supporting programs) will necessitate additional increases in future computing resources at the Laboratory. These resources must cover the entire hlerarchy of computer systems including supercomputers, centralized general purpose computers, multipurpose minicomputers, scientific and engineering workstations, personal computing workstations, and office automation support systems.

Part 3, the Computing Resources Plan, identifies the requirements for computing at ANL, the existing general purpose computers, and ANL plans to meet computing resource needs. The combination of these factors has prompted efforts at ANL for the modernization of ANL's computing resources. The focus of ANL activities addressing the future large-scale scientific and engineering computing at the Laboratory is the ANL Site Response to the DOE FY1994 Information Resonurces Management Long-Range Plan. This plan documents ANL initiatives 1) to expand the Laboratory's supercomputing capability to meet programmatic needs and opportunities, 2) to modernize the Laboratory's current central computers, 3) to gain increased access to offsite supercomputing resources to complement existing ANL computer resources, and 4) to develop production computing capability using state-of-the-art parallel processor computers and workstations.

Argonne has, during the past several years, undergone a number of substantial changes in its programmatic activities, with particular emphasis on development of major new programs which are of national scope and importance. The Laboratory operates two major national user facilities in the area of materials research-- the Intense Pulsed-Neutron Source (IPNS) and the High Voltage Electron Microscope (HVEM) Facility. In nuclear physics, the Argonne Tandem-Linac Accelerator System (ATLAS) began operation in FY1985 as a national users' facility for heavy-ion physics research. The Integral Fast Reactor (IFR) design study has led to a major new thrust in the U. S. breeder reactor program. In addition to these relatively new activities, Argonne is planning other initiatives in accelerator design and construction, fossil energy research, fusion, and physical and biological research.

Schedule 3A-1 identifies the program requirements for computing resources for the planning period as identified by the respective programs. The justification and documentation of the requirements defined for programs of the Laboratory are contained in the narrative of this section. RCUs (Relative Capacity Units) are used by the Department of Energy to express computing requirements and installed compuiting capacity. They allow headquarters staff to aggregate the requirements and capacity of whole programs, program areas, or even the entire Department, independently of the specific computing systems involved. The RCU is used to identify the following categories of computers:

- Category $\mathrm{P}$ (consisting of minicomputers and superminis)

- Category Q (consisting of mainframe computers) 
ANI. Site Response for the DOF FY 1994 Information Resourees Management Long Range Plan March 25, 1992

A. Requirements

- Category R (consisting of supercomputers)

The primary assumptions which underlie these forecasts of recuirements are:

- There are a number of important problems which researchers throughout the Laboratory have deferred due to the lack of access to very last computing (capability) or lack of adequate machine cycles (capacity) or both.

- Argonne programs continue to request allocatton of additional resources from the ER-funded computers at the National Energy Research Supercomputer Center (NERSC) and the Supercomputing Research Institute (SCRI) at Florida State University.

- The introduction and use of high performance workstations will increase substantially, as well as the need for considerably expanded data communications capabilities.

- The modernization of the central computing resources at the Laboratory will result in ident1fication of additional requirements (latent demand) which have not heen prevtously identifled.

- The operation of the Advanced Photon Source as a national research facility will necessitate a significant increase in computing resource requirements.

Argonne has been designated as the site for the new Advanced Photon Light Source. Construction was initiated in FY 1990. This is a major facility which will support 15 beam lines initially and be expandable to at least 70 beam lines. Intensities will be six orders of magnitude higher than existing synchrotron radiation sources. A data analysis computer facility which can meet the needs of most users is proposed as part of this project. The proposed facility includes a cluster of multiple computers with an aggregate theoretical capacity in excess of 20.0 P RCUs, at least 4 gigabytes of disk storage, and 50 workstations. The computer facility will expand as the number of beam lines and users of the facility increase. The Advanced Photon Source (APS) computer facility will be linked to the Argonne central computers and provide access to the centrallzed Cray X-MP/18, IBM 3084QX, the VAX Cluster, specialized graphics devices, and high capacity disk storage devices. Construction of this facility is also expected to stimulate theoretical work in support of the measurements made at the facility. Much of this theoretical work will be carried out on the Cray $\mathrm{X}-\mathrm{MP} / 18$ or at ER supercomputer facilities which can be accessed through the Energy Sclences network (ESnet).

Exhibits 1.1 through 1.3 depict the forecast of requirements of ANL programs in Schedule 3 A.1 expressed in RCUs. The differences between the forecast requirements of the program areas and the capacity projections are more fully described in individual program narratives in this section. The differences are in large measure attributable to the need for high performance computing resources. These needs as described in this plan and the shortfall in capacity will be met through the planning period with the Laboratory's Cray X-MP/18 computer and by expanding use of and access to offsite supercomputers like those avallable at National Energy Research Supercomputer Center (NERSC) and Florida State University (see Schedule C1).

The major changes in the requirements sectlon of the ANL Site Response for FY 1994 are the result of increased scientific computational demands associated with initiatives of the laboratory and the APS. 
ANL Slte Response for the DOE FY 1994 Information Resources Management Long Range Plan

\section{Requirements for Category $P$ \\ Relative Capacity Units (RCUs)}

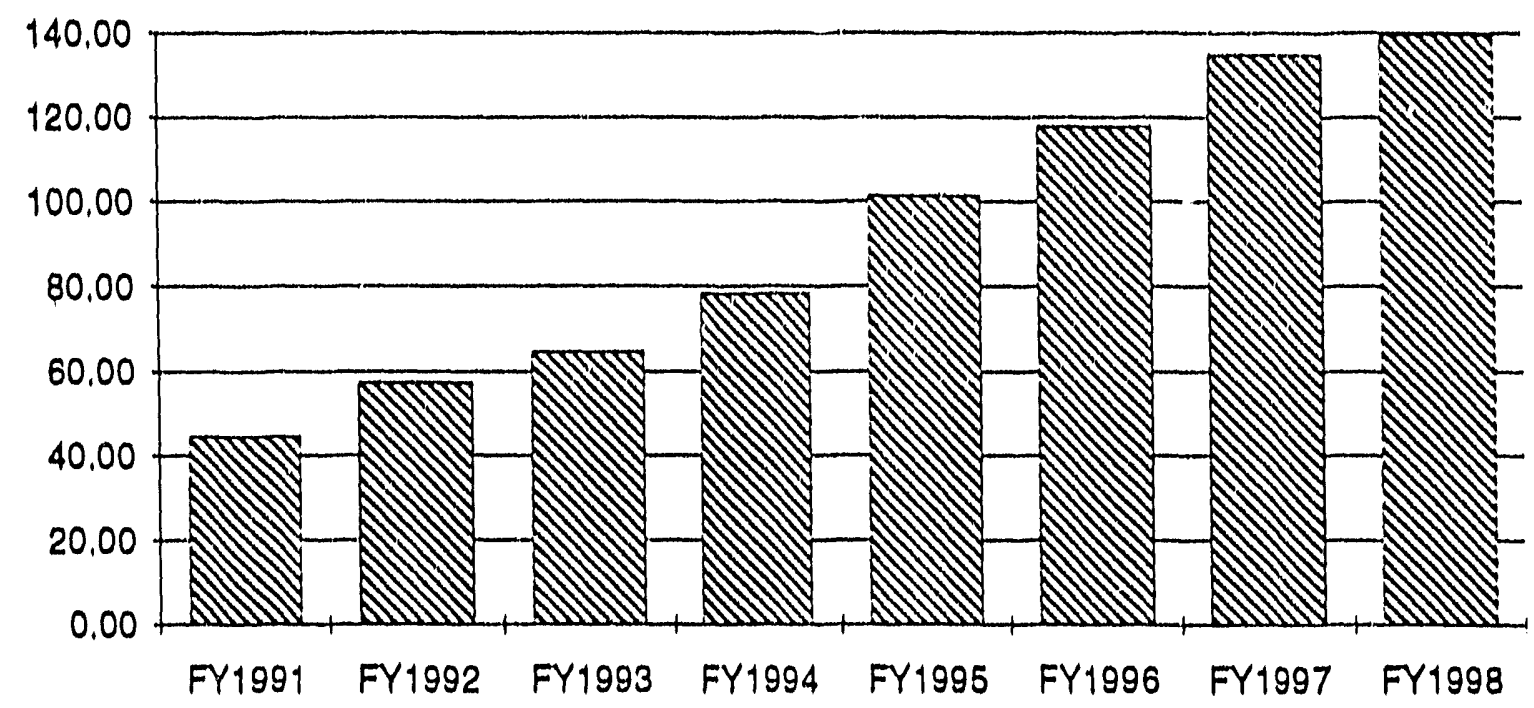

Requirements for Category $Q$

Relative Capacity Units (RCUs)

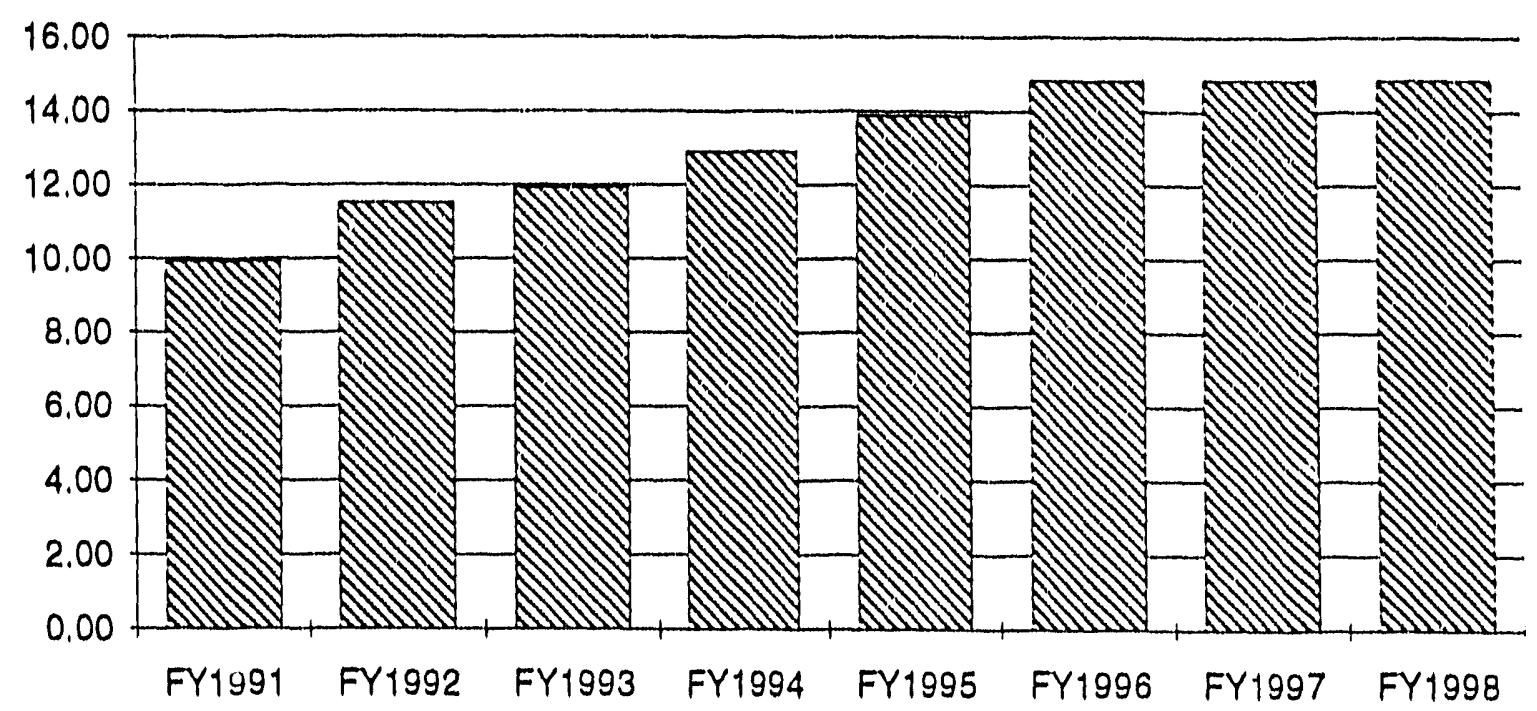


ANL Slte Response for the DOE FY 1994 Informatton Resources Management Long Range Plan

Exhibit 1.3: Category R Requirements

Requirements for Category $R$

Relative Capacity Units (RCUs)

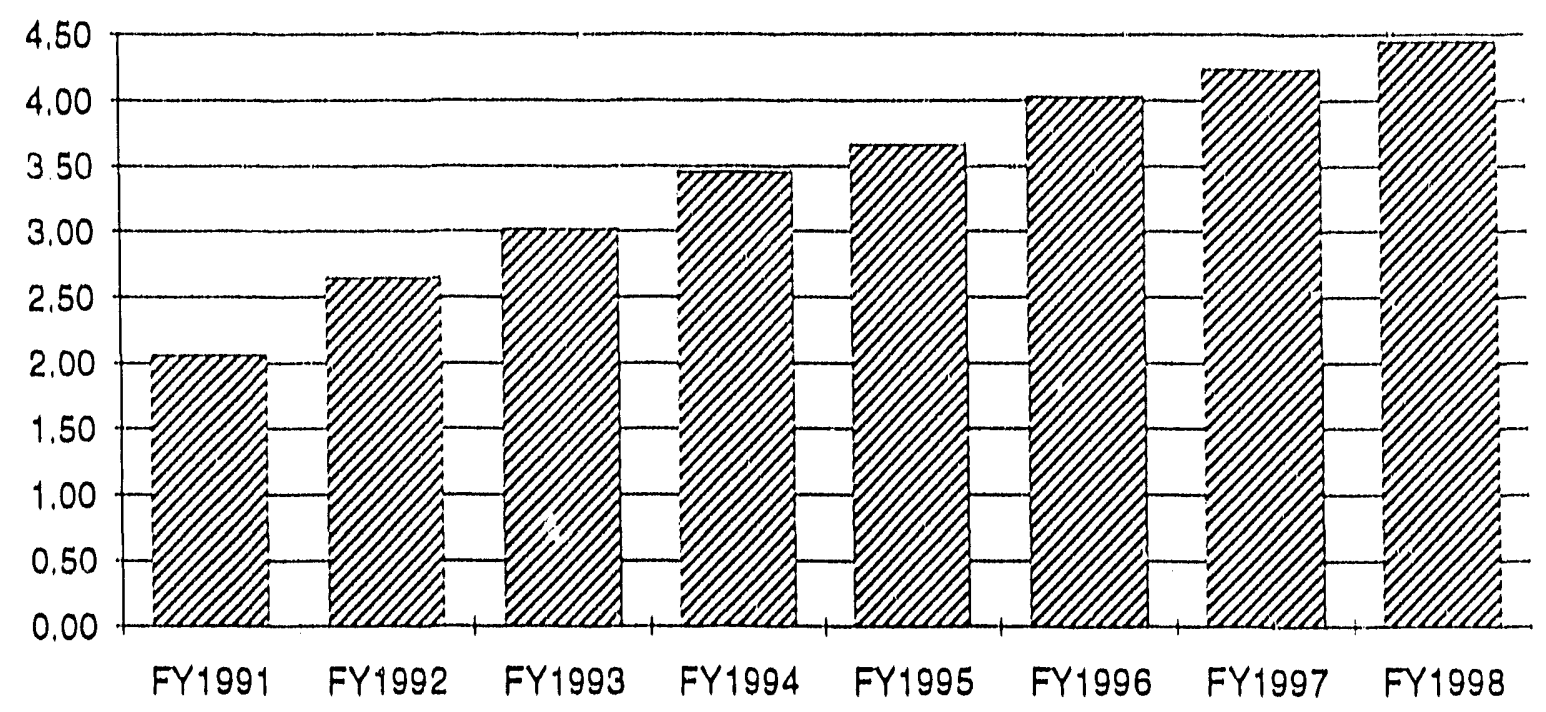


ANL Situ Response for the DOE FY1994 Information Resources Management Long Range Plan A. Requlrements

Schedule 1.1: Schedule 3A-1 ADP Requirements

Slie: Ardonne Nallonal Laboralory. ANL

\begin{tabular}{|c|c|c|c|c|c|c|c|c|c|c|}
\hline \multirow{2}{*}{$\begin{array}{c}B \text { and } \bar{A} \\
\text { Codo }\end{array}$} & \multirow[b]{2}{*}{ Program } & & \multirow{2}{*}{$\begin{array}{c}\text { Payl } \\
\text { FY1001 } \\
\end{array}$} & \multirow{2}{*}{$\begin{array}{l}\text { Current } \\
\text { FY1992 } \\
\end{array}$} & \multirow{2}{*}{$\begin{array}{l}\text { Budgal } \\
\text { FY1893 }\end{array}$} & \multirow{2}{*}{$\begin{array}{l}\text { Flan } \\
\text { FY1904 }\end{array}$} & \multicolumn{4}{|c|}{ Outygars } \\
\hline & & & & & & & FY1995 & FY1000 & FY1997 & FY1098 \\
\hline$\overline{A A}$ & Coal & $\begin{array}{l}\text { Calegory } \\
\text { Calogory Q } \\
\text { Calogory } \\
\end{array}$ & $\begin{array}{l}0.69 P \\
0.120 \\
0.0019 \\
\end{array}$ & $\begin{array}{l}0.75 \mathrm{P} \\
0.110 \\
0.00 \mathrm{~A} \\
\end{array}$ & $\begin{array}{l}0.82 P \\
0.09 Q \\
0.00 \mathrm{~A} \\
\end{array}$ & $\begin{array}{l}0.82 \mathrm{P} \\
0.00 \mathrm{Q} \\
0,00 \mathrm{P} \\
\end{array}$ & $\begin{array}{l}0.82 P \\
0.000 \\
0.009 \\
\end{array}$ & $\begin{array}{l}0.82 \mathrm{P} \\
0.090 \\
0.00 \mathrm{~A} \\
\end{array}$ & $\begin{array}{l}0.82 P \\
0.100 \\
0.00 \mathrm{R}\end{array}$ & $\begin{array}{l}0.82 \mathrm{P} \\
0.10 \mathrm{Q} \\
0.00 \mathrm{R} \\
\end{array}$ \\
\hline AF & $\begin{array}{l}\text { Clvillan Reactor } \\
\text { Dovelopment }\end{array}$ & $\begin{array}{l}\text { Calegory } \\
\text { Calogory Q } \\
\text { Calogory } R \\
\end{array}$ & $\begin{array}{l}.49 P \\
1,89 Q \\
0.20 \mathrm{P} \\
\end{array}$ & $\begin{array}{l}3.84 P \\
1.890 \\
0.20 \mathrm{~A} \\
\end{array}$ & $\begin{array}{l}.84 \mathrm{P} \\
1.89 \mathrm{Q} \\
0.20 \mathrm{~A} \\
\end{array}$ & $\begin{array}{l}.84 \mathrm{P} \\
1.89 \mathrm{Q} \\
0.20 \mathrm{R} \\
\end{array}$ & $\begin{array}{l}4.27 \mathrm{P} \\
1.090 \\
0.20 \mathrm{~A} \\
\end{array}$ & $\begin{array}{l}4.27 \mathrm{P} \\
1.990 \\
0.20 \mathrm{~A} \\
\end{array}$ & $\begin{array}{l}.27 \mathrm{P} \\
1.20 \mathrm{Q} \\
0.20 \mathrm{~A} \\
\end{array}$ & $\begin{array}{l}.28 \mathrm{P} \\
1.99 \mathrm{Q} \\
0.20 \mathrm{P} \\
\end{array}$ \\
\hline AT & Magnello Fusion & $\begin{array}{l}\text { Calogory P } \\
\text { Calogory a } \\
\text { Calogory }\end{array}$ & $\begin{array}{l}1.74 P \\
0.030 \\
0.04 \mathrm{~B} \\
\end{array}$ & $\begin{array}{l}2.009 \\
0.030 \\
0.049 \\
\end{array}$ & $\begin{array}{l}2.00 \mathrm{P} \\
0.030 \\
0.04 \mathrm{~A} \\
\end{array}$ & $\begin{array}{l}2.00 \mathrm{P} \\
0.03 \mathrm{Q} \\
0.04 \mathrm{~A} \\
\end{array}$ & $\begin{array}{l}2.69 P^{\circ} \\
0.030 \\
0.04 R \\
\end{array}$ & $\begin{array}{l}2.69 P \\
0.030 \\
0.04 \mathrm{~A} \\
\end{array}$ & $\begin{array}{l}2.69 P \\
0.03 Q \\
0.019 \\
\end{array}$ & $\begin{array}{l}2.69 \mathrm{P} \\
0.03 \mathrm{Q} \\
0.04 \mathrm{~A} \\
\end{array}$ \\
\hline KP & $\begin{array}{l}\text { Blological and } \\
\text { Environmental } \\
\text { Research }\end{array}$ & $\begin{array}{l}\text { Calogory P } \\
\text { Calogory O } \\
\text { Calogory A } \\
\end{array}$ & $\begin{array}{l}0.28 P \\
0.160 \\
0.01 \mathrm{R} \\
\end{array}$ & $\begin{array}{l}0.28 P \\
0.14 Q \\
0.01 \mathrm{~A} \\
\end{array}$ & $\begin{array}{l}0.28 \mathrm{P} \\
0.14 \mathrm{Q} \\
0.04 \mathrm{~A}^{\circ} \\
\end{array}$ & $\begin{array}{l}0.28 \mathrm{P} \\
0.140 \\
0.04 \mathrm{~A} \\
\end{array}$ & $\begin{array}{l}0.28 P \\
0.140 \\
0.04 \mathrm{~A} \\
\end{array}$ & $\begin{array}{l}0.28 \mathrm{P} \\
0.14 \mathrm{Q} \\
0.04 \mathrm{R} \\
\end{array}$ & $\begin{array}{l}0.289 \\
0.140 \\
0.04 \mathrm{~A} \\
\end{array}$ & $\begin{array}{l}0.28 \mathrm{P} \\
0.14 Q \\
0.04 \mathrm{~A} \\
\end{array}$ \\
\hline $\mathrm{KA}$ & $\begin{array}{l}\text { High Energy } \\
\text { Physicas }\end{array}$ & $\begin{array}{l}\text { Calegory } \\
\text { Calogory Q } \\
\text { Calegory } \\
\end{array}$ & $\begin{array}{l}0.30 \mathrm{P} \\
0.120 \\
0.08 \mathrm{~A} \\
\end{array}$ & $\begin{array}{l}0.30 \mathrm{P} \\
0.12 \mathrm{Q} \\
0.11 \mathrm{~A} \\
\end{array}$ & $\begin{array}{l}0.35 \mathrm{P} \\
0.110 \\
0.14 \mathrm{~A} \\
\end{array}$ & $\begin{array}{l}0.35 \mathrm{P} \\
0.10 \mathrm{Q} \\
0.15 \mathrm{~A} \\
\end{array}$ & $\begin{array}{l}0.40 P \\
0.00 \mathrm{Q} \\
0.15 \mathrm{~A} \\
\end{array}$ & $\begin{array}{l}0.40 \mathrm{P} \\
0.06 \mathrm{Q} \\
0.20 \mathrm{R}^{\circ} \\
\end{array}$ & $\begin{array}{l}0.40 \mathrm{P} \\
0.069 \\
0.30 \mathrm{~A}^{\circ} \\
\end{array}$ & $\begin{array}{l}0.40 \mathrm{P} \\
0.06 \mathrm{Q} \\
0.50 \mathrm{~F}^{\circ} \\
\end{array}$ \\
\hline $\mathrm{KB}$ & Nuclear Physlas & $\begin{array}{l}\text { Calogory } \\
\text { Calogory Q } \\
\text { Calogory } A \\
\end{array}$ & $\begin{array}{l}4.36 P \\
0.11 Q \\
0.30 R \\
\end{array}$ & $\begin{array}{l}4.88 \mathrm{P}^{\circ} \\
0.19 \mathrm{Q}^{\circ} \\
0.50 \mathrm{R}^{\circ} \\
\end{array}$ & $\begin{array}{l}4.86 P \\
0.170 \\
0.55 \text { A } \\
\end{array}$ & $\begin{array}{l}.86 P \\
0.170 \\
0.85 \mathrm{~A} \\
\end{array}$ & $\begin{array}{l}4.86 P \\
0.17 Q \\
0.70 \mathrm{P} \\
\end{array}$ & $\begin{array}{l}4.86 P \\
0.170 \\
0.80 R \\
\end{array}$ & $\begin{array}{l}4.86 P \\
0.17 Q \\
0.90 R \\
\end{array}$ & $\begin{array}{l}4.86 \mathrm{P} \\
0.17 \mathrm{Q} \\
0.90 \mathrm{P} \\
\end{array}$ \\
\hline $\mathrm{KC}$ & $\begin{array}{l}\text { Basio Energy } \\
\text { Sclences }\end{array}$ & $\begin{array}{l}\text { Calegory } \\
\text { Calegory } \\
\text { Calegory } \\
\end{array}$ & $\begin{array}{r}27.26 \mathrm{P} \\
6.45 \mathrm{O} \\
1.26 \mathrm{~A} \\
\end{array}$ & $\begin{array}{r}38.59 \mathrm{P} \\
7.86 \mathrm{Q} \\
1.63 \mathrm{~A} \\
\end{array}$ & $\begin{array}{r}45.89 \mathrm{P} \\
8.47 \mathrm{Q} \\
1.95 \mathrm{R} \\
\end{array}$ & $\begin{array}{r}59,69 \mathrm{P}^{\circ} \\
0,470 \\
2,29 \mathrm{~A} \\
\end{array}$ & $\begin{array}{r}80.03 \mathrm{P}^{\circ} \\
10.47 \mathrm{Q} \\
2.45 \mathrm{R} \\
\end{array}$ & $\begin{array}{r}86.53 \mathrm{P} \\
11.47 \mathrm{O} \\
2.66 \mathrm{~A} \\
\end{array}$ & $\begin{array}{r}113.54 \mathrm{P} \\
11.47 \mathrm{Q} \\
2.67 \mathrm{~A} \\
\end{array}$ & $\begin{array}{r}118.54 \mathrm{P} \\
11.47 \mathrm{Q} \\
2.68 \mathrm{~A} \\
\end{array}$ \\
\hline & & $\begin{array}{l}\text { Calegory } \\
\text { Calegory } \\
\text { Calegory } \\
\end{array}$ & $\begin{array}{l}0.00 \mathrm{P} \\
0.00 \mathrm{Q} \\
0.00 \mathrm{~A}\end{array}$ & $\begin{array}{l}0.008 \\
0.000 \\
0.00 R \\
\end{array}$ & $\begin{array}{l}0.00 \mathrm{P} \\
0.00 \mathrm{Q} \\
0.00 \mathrm{~A}\end{array}$ & $\begin{array}{l}0.00 P \\
0.000 \\
0.00 R \\
\end{array}$ & $\begin{array}{l}0.00 \mathrm{P} \\
0.000 \\
0.00 \mathrm{R} \\
\end{array}$ & $\begin{array}{l}0.00 \mathrm{P} \\
0.000 \\
0.00 \mathrm{~A}\end{array}$ & $\begin{array}{l}0.00 \mathrm{P} \\
0.000 \\
0.00 \mathrm{~A} \\
\end{array}$ & $\begin{array}{l}0.00 \mathrm{P} \\
0.00 \mathrm{Q} \\
0.00 \mathrm{R} \\
\end{array}$ \\
\hline & & $\begin{array}{l}\text { Calegory } \\
\text { Calegory O } \\
\text { Category }\end{array}$ & $\begin{array}{l}0.00 \mathrm{P} \\
0.000 \\
0.00 \mathrm{R} \\
\end{array}$ & $\begin{array}{l}0.00 P \\
0.00 Q \\
0.00 \mathrm{~A} \\
\end{array}$ & $\begin{array}{l}0.00 \mathrm{P} \\
0.00 \mathrm{Q} \\
0.00 \mathrm{R} \\
\end{array}$ & $\begin{array}{l}0.00 \mathrm{P} \\
0.00 \mathrm{Q} \\
0.00 \mathrm{R}\end{array}$ & $\begin{array}{l}0.00 P \\
0.000 \\
0.001 \\
\end{array}$ & $\begin{array}{l}0.00 \mathrm{P} \\
0.000 \\
0.00 \mathrm{R}\end{array}$ & $\begin{array}{l}0.00 \mathrm{P} \\
0.00 \mathrm{Q} \\
0.00 \mathrm{R} \\
\end{array}$ & $\begin{array}{l}0.00 \mathrm{P} \\
0.00 \mathrm{Q} \\
0.00 \mathrm{~A}\end{array}$ \\
\hline $\begin{array}{l}\text { Other Pro } \\
\text { DB,EB, } \\
\text { GC,GE. }\end{array}$ & $\begin{array}{l}\text { grams }\left(A H, A K, A L, A A_{1}\right. \\
C,, E D, E E, E G, Q B \text {, } \\
\mid A O 1, K E, N A, P E, V P)\end{array}$ & $\begin{array}{l}\text { Calogory } \\
\text { Calogory } 0 \\
\text { Calegory } R \\
\end{array}$ & $\begin{array}{l}5.57 P \\
0.82 Q \\
0.10 A \\
\end{array}$ & $\begin{array}{l}0.04 P \\
0.82 Q \\
0.15 R \\
\end{array}$ & $\begin{array}{l}5.84 P \\
0.79 Q \\
0.09 R \\
\end{array}$ & $\begin{array}{l}5.74 \mathrm{P} \\
0.77 \mathrm{Q} \\
0.08 R\end{array}$ & $\begin{array}{l}6.99 P \\
0.75 Q \\
0.08 \mathrm{Q} \\
\end{array}$ & $\begin{array}{l}6.89 P \\
0.74 Q \\
0.08 R\end{array}$ & $\begin{array}{l}6.89 P \\
0.740 \\
0.08 \mathrm{~A}\end{array}$ & $\begin{array}{l}6.89 P \\
0.74 \mathrm{Q} \\
0.08 \mathrm{H}\end{array}$ \\
\hline
\end{tabular}

- Fequlrements for this program Inorease or decrease by $30 \%$ or more in a calegory and by al least 1.OP RCU or more over the prevlous year's progrein requirements or lor the same year ol last year's Plan (Briet explanallons of the reasons lor such Increase/decrease lollow Schedule 3A.1). 
ANL Site Response for the DOE FY 1994 Information Resources Management Long Range Plan March 25, 1992

A. Requirements

Site: Argonne Nallonal Laboratory - ANL

ADP Fequirements (RCU's)

Schedule 3A.1

\begin{tabular}{|c|c|c|c|c|c|c|c|c|c|}
\hline \multirow{2}{*}{$\begin{array}{c}B \text { and } A \\
\text { Code }\end{array}$} & & \multirow{2}{*}{$\begin{array}{l}\text { Pasl } \\
\text { FY1091 } \\
\end{array}$} & \multirow{2}{*}{$\begin{array}{l}\text { Curtenl } \\
\text { FY1992 }\end{array}$} & \multirow{2}{*}{$\begin{array}{l}\text { Budgol } \\
\text { FY1993 } \\
\end{array}$} & \multirow{2}{*}{$\begin{array}{l}\text { Plan } \\
\text { FY1994 }\end{array}$} & \multicolumn{4}{|c|}{ Outyears } \\
\hline & & & & & & FY1096 & FY1000 & FY1997 & FY1598 \\
\hline \multirow{3}{*}{$\begin{array}{l}\text { Relmbursables } \\
\text { DOE - Farmilab, Molo, Others }\end{array}$} & Calegory $P$ & $0.04 \mathrm{P}$ & $0.04 \mathrm{P}$ & $0.04 \mathrm{P}$ & $0.04 \mathrm{P}$ & $0.04 P$ & $0.04 P$ & $0.04 \mathrm{P}$ & $0.04 P$ \\
\hline & Calegory Q & 0.060 & 0.060 & 0.060 & 0,060 & 0.060 & 0.060 & 0.060 & 0.060 \\
\hline & Calegory $R$ & $0.00 \mathrm{~A}$ & $0.00 \mathrm{~A}$ & 0.00 月 & $0.00 \mathrm{~A}$ & $0,00 \mathrm{~A}$ & $0.00 \mathrm{~A}$ & $0,00 R$ & $0.00 \mathrm{R}$ \\
\hline \multirow{3}{*}{$\begin{array}{l}\text { Pelmbursables } \\
\text { NHO Imlemal }\end{array}$} & CalegoryP & $0.02 \mathrm{P}$ & $0.02 P$ & $0.02 \bar{P}$ & $0.02 P$ & $0.02 \mathrm{P}$ & $0.02 \mathrm{P}$ & $0.02 \mathrm{P}$ & $0.02 \mathrm{P}$ \\
\hline & & $0.02 Q$ & $0.02 Q$ & 0,020 & 0.020 & $0.02 \mathrm{Q}$ & 0,020 & 0.020 & 0.020 \\
\hline & Calegory $\mathrm{A}$ & $0.00 \mathrm{~A}$ & $0.00 \mathrm{~A}$ & $0.00 \mathrm{R}$ & $0.00 \mathrm{~A}$ & $0,00 \mathrm{~A}$ & $0.00 R$ & $0.00 \mathrm{R}$ & $0.00 \mathrm{R}$ \\
\hline \multirow{3}{*}{$\begin{array}{l}\text { Relmbursables } \\
\text { DOD External }\end{array}$} & Calegory P & $0,52 \mathrm{P}$ & $0.42 P$ & $0.42 \mathrm{P}$ & $0.32 P$ & $0.22 \mathrm{P}$ & $0.2 \bar{P}$ & $0.22 \mathrm{P}$ & $0.22 \mathrm{P}$ \\
\hline & Oalegory Q & 0.030 & $0.03 Q$ & 0.030 & 0.030 & 0.030 & 0.030 & 0.030 & $0.03 Q$ \\
\hline & Calegory $A$ & $0.00 \mathrm{R}$ & $0.00 \mathrm{~A}$ & $0,00 \mathrm{R}$ & $0.00 \mathrm{~A}$ & $0,00 \mathrm{~A}$ & $0.00 \mathrm{R}$ & $0 . \infty R$ & $0.00 \mathrm{~A}$ \\
\hline \multirow{3}{*}{$\begin{array}{l}\text { Relmbursables } \\
\text { DOD Inlemal }\end{array}$} & Calegory $\mathrm{P}$ & $0.03 \mathrm{P}$ & $0.03 \mathrm{P}$ & $0.03 P$ & $0.03 P$ & $0.03 \mathrm{P}$ & $0.03 \mathrm{P}$ & $0.03 \mathrm{P}$ & $0.03 P$ \\
\hline & Calegory Q & $0.04 Q$ & 0.040 & 0.040 & $0.04 Q$ & 0.040 & 0,040 & 0.040 & 0.040 \\
\hline & Calegory A & $0.00 \mathrm{~A}$ & 0,00 A & $0.00 \mathrm{~A}$ & $0.00 \mathrm{~A}$ & $0.00 \mathrm{R}$ & $0,00 \mathrm{R}$ & $0,00 \mathrm{R}$ & $0.00 \mathrm{~A}$ \\
\hline \multirow{3}{*}{$\begin{array}{l}\text { Reimbursables } \\
\text { Other Execulive Intemal } \\
\text { (DOO,DOT,EPA,NASA,DHHR) }\end{array}$} & Calogory $P$ & $0.00 P$ & $0.00 \mathrm{P}$ & $0.00 \mathrm{P}$ & $0.00 P$ & $0,00 P$ & $0.00 \bar{P}$ & $0 . \bar{P} \bar{P}$ & $0.00 \mathrm{P}$ \\
\hline & Calegory Q & $0.00 Q$ & 0.000 & 0.000 & 0.000 & 0.000 & 0,000 & $0.00 Q$ & 0.000 \\
\hline & Calegory R & $0.00 \mathrm{~A}$ & $0.00 \mathrm{~A}$ & $0.00 R$ & $0.00 \mathrm{~A}$ & $0.00 \mathrm{R}$ & $0.00 \mathrm{R}$ & 0,008 & $0.00 \mathrm{R}$ \\
\hline \multirow{6}{*}{$\begin{array}{l}\text { Relmbursables } \\
\text { Other Internal }\end{array}$} & Calegory P & $0.53 P$ & $0,61 P$ & $0.67 P$ & $0.61 \mathrm{P}$ & $0.82 \mathrm{P}^{\circ}$ & $0.82 \mathrm{P}$ & $0.82 P$ & $0.82 \mathrm{P}$ \\
\hline & Calegory a & 0.010 & 0.010 & 0.010 & 0.010 & 0.010 & 0.010 & $0.01 Q$ & $0.01 Q$ \\
\hline & Calogory $\mathrm{R}$ & $0.00 \mathrm{R}$ & $0.00 \mathrm{~A}$ & $0,00 R$ & $0.00 \mathrm{R}$ & $0.00 \mathrm{R}$ & $0.00 \mathrm{R}$ & 0.008 & $0.00 \mathrm{~A}$ \\
\hline & Calogory $\mathrm{P}$ & $0.00 P$ & $0.00 \mathrm{P}$ & $0.00 P$ & $0.00 P$ & $0.00 \mathrm{P}$ & $0.00 \mathrm{P}$ & $0.00 P$ & $0.00 \mathrm{P}$ \\
\hline & Calogory Q & 0.000 & $0.00 \mathrm{Q}$ & $0.00 Q$ & $0.00 Q$ & 0,000 & 0.000 & 0.000 & $0.00 Q$ \\
\hline & Calogory $R$ & $0.00 \mathrm{~A}$ & $0.00 \mathrm{R}$ & $0.00 \mathrm{R}$ & $0.00 \mathrm{R}$ & $0.00 \mathrm{~A}$ & $0.00 \mathrm{R}$ & $0.00 \mathrm{R}$ & $0.00 \mathrm{~A}$ \\
\hline \multirow{3}{*}{$\begin{array}{c}\text { DOE Program Requirements } \\
\text { (Subtolals) }\end{array}$} & Calegory $P$ & $43.64 \mathrm{P}$ & $56.45 \mathrm{P}$ & $63.67 \mathrm{P}$ & $77.37 \mathrm{P}$ & $100.33 \mathrm{P}$ & $116.73 P$ & $133.74 \mathrm{P}$ & $138.75 \mathrm{P}$ \\
\hline & Cullegory Q & 9.790 & 11.360 & 11.790 & $12.76 \mathrm{Q}$ & $13.73 Q$ & 14,690 & 14.700 & $14.70 \mathrm{Q}$ \\
\hline & Calogory $R$ & 2.06 月 & $2.65 \mathrm{~A}$ & $3,02 \mathrm{~A}$ & $3.46 \mathrm{R}$ & $3.67 \mathrm{R}$ & $4.03 \mathrm{~A}$ & $4.24 \mathrm{~A}$ & $4.45 \mathrm{~A}$ \\
\hline \multirow{3}{*}{$\begin{array}{l}\text { Peimbursables } \\
\text { (Subtolals) }\end{array}$} & Calogory $P$ & $1.13 \mathrm{P}$ & $1.11 \mathrm{P}$ & $1.17 \mathrm{P}$ & $1.01 P$ & $1.12 P$ & $1.12 P$ & $1.12 \mathrm{P}$ & $1.12 \mathrm{P}$ \\
\hline & Calegory Q & 0.160 & $0.16 Q$ & 0.160 & $0.16 Q$ & $0.16 \mathrm{Q}$ & 0.100 & 0.160 & 0.160 \\
\hline & Calogory $\mathrm{A}$ & $0.01 \mathrm{~A}$ & $0.01 \mathrm{~A}$ & $0.01 R$ & $0.01 \mathrm{~A}$ & 0.018 & $0.01 \mathrm{R}$ & 0.01 A & 0.01 A \\
\hline \multirow[t]{2}{*}{ Totals } & Calogory $P$ & $44.77 \mathrm{P}$ & $57.56 \mathrm{P}$ & $64.84 P$ & $78,38 \mathrm{P}$ & $101.45 \mathrm{P}$ & $117.85 P$ & $134.86 P$ & $139.87 \mathrm{P}$ \\
\hline & $\begin{array}{l}\text { Calegory Q } \\
\text { Calegory } A\end{array}$ & $\begin{array}{l}9.95 \mathrm{Q} \\
2.06 \mathrm{~A}\end{array}$ & $\begin{array}{r}11.520 \\
2.65 \mathrm{R}\end{array}$ & $\begin{array}{r}11.95 \mathrm{Q} \\
3.02 \mathrm{~A}\end{array}$ & $\begin{array}{r}12.920 \\
3.46 \mathrm{~A}\end{array}$ & $\begin{array}{r}13,89 Q \\
3,67 \mathrm{Q}\end{array}$ & $\begin{array}{r}14.850 \\
4.038\end{array}$ & $\begin{array}{r}14.860 \\
4.249\end{array}$ & $\begin{array}{r}14.800 \\
4.45 \mathrm{O}\end{array}$ \\
\hline
\end{tabular}

- Requirements for this program Increase or decrease by $30 \%$ or more in a calegory and by al leasl 1.OP RCU or more over the prevlous year's program requirements or for the same year of last year's Plan (Brief explanalions of the reasons lor such increase/decrease follow Schedule $3 \mathrm{~A} \cdot 1$ ). $2 / 26 / 92$ 
ANL Site Response for the DOE FY1994 Information Resources Management Long Range Plan B. Computing Resources

\section{Section B}

\section{Computing Resources}

\section{A. Computing Resources}

\section{Capacity Projections}

All general management computers with a theoretical capacity in excess of $1.0 \mathrm{P}$ RCUs appear on Schedule 3B-1. The listed capacities are determined as follows:

- Theoretical capacity: The theoretical capacities are identical to the nominal capacities multiplied by the percentage of the year that each system is installed for use.

- Practical Capacity: The available capacity after reductions have been made to reflect learning and usage patterns.

RCUs are used hy the Department of Energy to express computing requirements and installed computing capacity. They allow headquarters staff to aggregate the requirements and capacity of whole programs, program areas, or even the entire Department, independently of the specific computing systems involved. The RCU is used to identify the following categories of computers:

- Category $\mathbf{P}$ (consisting of minicomputers and superminis)

- Category $\mathrm{Q}$ (consisting of mainframe computers)

- Category $\mathbf{R}$ (consisting of supercomputers) 
ANL Site Response for the DOE FY 1994 Information Resources Management Long Range Plan March 25, 1992

Schedule 2.1: Schedule 3B-1 Capacity Projections

Site: Argonne Nattonal Laboratory - ANL

ADPE Capacity (RCU's)

Schedula 38-1 Page 1012

\begin{tabular}{|c|c|c|c|c|c|c|c|c|c|}
\hline \multirow{2}{*}{$\begin{array}{l}\text { UnivSystem } \\
\text { or MIE No. }\end{array}$} & \multirow[b]{2}{*}{ ADPE System } & \multirow{2}{*}{$\begin{array}{c}\text { Past } \\
\text { FY1991 } \\
\end{array}$} & \multirow{2}{*}{$\begin{array}{l}\text { Current } \\
\text { FY1992 } \\
\end{array}$} & \multirow{2}{*}{$\begin{array}{l}\text { Budgol } \\
\text { FY1993 } \\
\end{array}$} & \multirow{2}{*}{$\begin{array}{l}\text { Plan } \\
\text { FY1994 }\end{array}$} & \multicolumn{4}{|c|}{ Outvears } \\
\hline & & & & & & FY1995 & FY1996 & FY1997 & FY1998 \\
\hline \multicolumn{10}{|c|}{ Computhng and Tolocommunicatlons Division } \\
\hline \multirow{3}{*}{$601 / 49$} & Cray X-MP/18 (0.50R) & & & & & & & & \\
\hline & - Theoretical & $0.50 \mathrm{R}$ & $0.50 \mathrm{R}$ & $0.50 \mathrm{R}$ & $0.50 \mathrm{R}$ & $0.50 \mathrm{R}$ & $0.50 \mathrm{R}$ & $0.50 \mathrm{~A}$ & $0.50 \mathrm{~A}$ \\
\hline & - Practical & $0.40 \mathrm{R}$ & $0.40 \mathrm{R}$ & $0.40 R$ & $0.40 \mathrm{R}$ & $0.40 \mathrm{R}$ & $0.40 \mathrm{R}$ & $0.40 \mathrm{R}$ & $0.40 \mathrm{R}$ \\
\hline \multirow[t]{3}{*}{$601 / 49$} & VAX Cluster(14.20P) & & & & & & & & \\
\hline & - Theoretical & $7.20 P$ & $14.20 \mathrm{P}$ & $14.20 P$ & $14.20 P$ & $14.20 P$ & $14.20 P$ & $14.20 \mathrm{P}$ & $14.20 \mathrm{P}$ \\
\hline & - Practical & $6.00 P$ & $10.00 \mathrm{P}$ & $11.00 P$ & $11.00 \mathrm{P}$ & $11.00 \mathrm{P}$ & $11.00 \mathrm{P}$ & $11.00 \mathrm{P}$ & $11.00 \mathrm{P}$ \\
\hline \multirow[t]{6}{*}{$601 / 49$} & IBM 3084QX.96 & & & & & & & & \\
\hline & - Theoretical & 5.400 & 5.400 & 5.400 & 5.400 & $5.40 \mathrm{Q}$ & 5.400 & $5.40 Q$ & $5.40 \mathrm{O}$ \\
\hline & - Practical & 3.000 & 4.000 & 4.000 & $4.00 \mathrm{O}$ & 4.500 & 4.500 & 4.500 & $4.50 \mathrm{Q}$ \\
\hline & Other Newwork Capacity (Two & $000 / 44)(1.0 F$ & & & & & & & \\
\hline & - Theoretical & $1.00 P$ & $1.00 \mathrm{P}$ & $1.00 P$ & $1.00 \mathrm{P}$ & & & & \\
\hline & - Practical & $0.75 P$ & $0.75 P$ & $0.75 P$ & $0.75 P$ & & & & \\
\hline
\end{tabular}

\begin{tabular}{|c|c|c|c|c|c|c|c|c|c|}
\hline \\
\hline \multicolumn{10}{|c|}{$\begin{array}{l}\text { High Energy Physies } \\
601 / R 4 \text { VAX Clustar (7.0P) }\end{array}$} \\
\hline & $\begin{array}{l}\text { - Theoretical } \\
\text { - Practical }\end{array}$ & $\begin{array}{l}7.00 P \\
5.60 P\end{array}$ & $\begin{array}{r}10.00 P \\
8.00 P\end{array}$ & $\begin{array}{l}13.00 \mathrm{P} \\
11.20 \mathrm{P}\end{array}$ & $\begin{array}{l}15.00 P \\
12.00 P\end{array}$ & $\begin{array}{l}17.00 P \\
13.60 P\end{array}$ & $\begin{array}{l}17.00 P \\
13.60 P\end{array}$ & $\begin{array}{l}17.00 P \\
13.60 P\end{array}$ & $\begin{array}{l}17.00 P \\
13.60 P\end{array}$ \\
\hline
\end{tabular}

Advanced Photon Source

601/XXX 2.VAXCluster (14.4P)

- Theorebical

$\begin{array}{llll}20.00 P & 20.00 P & 20.00 P & 20.00 P\end{array}$

- Practical

$\begin{array}{llll}7.20 P & 10.00 P & 1500 P & 16.00 P\end{array}$

\begin{tabular}{|c|c|c|c|c|c|c|c|c|c|}
\hline \multicolumn{10}{|c|}{ Chemical Technology } \\
\hline \multirow[t]{5}{*}{$601 \times x \times$} & $\operatorname{VAX} 6220(6.6 P)$ & $7.80 \mathrm{P}$ & $9.00 P$ & $9 . \infty P$ & $9.00 P$ & $9.00 \mathrm{P}$ & $13.00 P$ & $13.00 P$ & $13.00 P$ \\
\hline & & $7.00 \mathrm{P}$ & $8.00 P$ & $8.00 P$ & $8.00 P$ & $8.00 P$ & $12.00 \mathrm{P}$ & $12.00 P$ & $12.00 \mathrm{P}$ \\
\hline & Other Nelwork Capacity $(4.0$ & & & & & & & & \\
\hline & - Theoretical & $12.70 P$ & $14.20 P$ & $14.20 \mathrm{P}$ & $14.20 P$ & $14.20 \mathrm{P}$ & $18.00 P$ & $18.00 P$ & $18.00 \mathrm{P}$ \\
\hline & - Practical & $10.20 P$ & $11.40 \mathrm{P}$ & $11.40 \mathrm{P}$ & $11.40 P$ & $11.40 \mathrm{P}$ & $16.00 P$ & $16.00 P$ & $16.00 \mathrm{P}$ \\
\hline
\end{tabular}

\begin{tabular}{|c|c|c|c|c|c|c|c|c|c|}
\hline \multirow{3}{*}{$\begin{array}{l}\text { Intense Py } \\
601 / X X X\end{array}$} & \multicolumn{9}{|l|}{ MicroVAX 3500 Cluster (3.6P) } \\
\hline & - Theoretical & $6.00 P$ & $6.00 P$ & $24.00 \mathrm{P}$ & $24.00 P$ & $24.00 P$ & $48.00 \mathrm{P}$ & $48.00 P$ & $48.00 \mathrm{P}$ \\
\hline & - Practical & $5.00 \mathrm{P}$ & $5.00 P$ & $20.00 \mathrm{P}$ & $20.00 P$ & $20.00 P$ & $40.00 P$ & $40.00 P$ & $40.00 \mathrm{P}$ \\
\hline \multicolumn{10}{|c|}{ Other Network Capacity (VAXServer/Microvaxes) • } \\
\hline & $\begin{array}{l}\text { - Theoretical } \\
\text { - Practical }\end{array}$ & $\begin{array}{l}4.10 P \\
2.00 P\end{array}$ & $\begin{array}{r}14.10 P \\
9.40 P\end{array}$ & $\begin{array}{l}14.10 P \\
11.70 P\end{array}$ & $\begin{array}{l}24.10 P \\
17.70 P\end{array}$ & $\begin{array}{l}24.10 P \\
20.00 P\end{array}$ & $\begin{array}{l}44.10 P \\
32.00 P\end{array}$ & $\begin{array}{l}44.10 P \\
32.00 P\end{array}$ & $\begin{array}{l}44.10 P \\
36.60 P\end{array}$ \\
\hline
\end{tabular}

- Other Network Capability described in detail in Sections 81 and 83. 
ANL Site Response for the DOE FY1994 Information Resources Management Long Range Plan B. Computing Resources

Site: Argonne National Laboratory - ANL

ADPE Capacity (RCU's)

Schedule 3B-1

Page 2 of 2

\begin{tabular}{|c|c|c|c|c|c|c|c|c|c|}
\hline \multirow{2}{*}{$\begin{array}{l}\text { UniUSystem } \\
\text { or MIE No. }\end{array}$} & \multirow[b]{2}{*}{ ADPE Svsiem } & \multirow{2}{*}{$\begin{array}{c}\text { Past } \\
\text { FY1991 }\end{array}$} & \multirow{2}{*}{$\begin{array}{l}\text { Current } \\
\text { Fy1992 }\end{array}$} & \multirow{2}{*}{$\begin{array}{l}\text { Budget } \\
\text { FY1993 }\end{array}$} & \multirow{2}{*}{$\begin{array}{c}\text { Plan } \\
\text { FY1994 }\end{array}$} & \multicolumn{4}{|c|}{ Outyears } \\
\hline & & & & & & FY1995 & FY1996 & FY1697 & Fr1998 \\
\hline \multicolumn{10}{|l|}{ Physics } \\
\hline \multirow[t]{6}{*}{$601 / 53$} & VAX Cluster (7.OP) & & & & & & & & \\
\hline & - Theoretical & $7.20 \mathrm{P}$ & $7.20 P$ & $7.20 P$ & $7.20 P$ & $7.20 P$ & $7.20 P$ & $7.20 \mathrm{P}$ & $7.20 \mathrm{P}$ \\
\hline & - Practical & $5.60 P$ & $5.60 P$ & $5.60 \mathrm{P}$ & $5.60 P$ & $5.60 \mathrm{P}$ & $5.60 \mathrm{P}$ & $5.60 \mathrm{P}$ & $5.60 \mathrm{P}$ \\
\hline & Other Network Capacity (4.8P) & & & & & & & & \\
\hline & - Theoretical & $34.00 \mathrm{P}$ & $37.00 \mathrm{P}$ & $41.00 P$ & $45.00 \mathrm{P}$ & $50.00 P$ & $55.00 \mathrm{P}$ & $60.00 P$ & $66.00 \mathrm{P}$ \\
\hline & - Practical & $27.00 P$ & $30.00 \mathrm{P}$ & $33.00 \mathrm{P}$ & $36.00 P$ & $40.00 P$ & $44.00 P$ & $48.00 P$ & $53.00 \mathrm{P}$ \\
\hline \multicolumn{10}{|l|}{ Chemistry } \\
\hline \multirow[t]{9}{*}{$601 / S 5$} & VAX Cluster (2.8P) & & & & & & & & \\
\hline & - Theoretical & $2.80 P$ & $7.00 \mathrm{P}$ & $7.00 P$ & $7.00 P$ & $7.00 \mathrm{P}$ & $7.00 \mathrm{~F}$ & $7.00 \mathrm{P}$ & $7.00 \mathrm{P}$ \\
\hline & - Practical & $2.40 \mathrm{P}$ & $2.50 \mathrm{P}$ & $3.00 P$ & $3.20 P$ & $3.80 P$ & $4.60 \mathrm{~F}$ & $5.60 \mathrm{P}$ & $6.00 P$ \\
\hline & Alllant12 Processors (12.00) & & & & & & & & \\
\hline & - Theoretcal & 3.000 & $12.00 \mathrm{C}$ & 12.000 & $12.00 \mathrm{C}$ & 12.000 & $12.00 \mathrm{c}$ & 12.000 & 12.000 \\
\hline & - Practical & $2.50 Q$ & $6.00 \mathrm{C}$ & $\cdot 7.500$ & 8.000 & 9.000 & $10.00 c$ & $11.00 \mathrm{Q}$ & 11.000 \\
\hline & Other Network Capacity (3.1P) & & & & & & & & \\
\hline & - Theoretical & $6.30 \mathrm{P}$ & $5.40 \mathrm{~F}$ & $6.00 P$ & $6.00 \mathrm{P}$ & $7.30 \mathrm{P}$ & $9.50 \mathrm{~F}$ & $11.70 \mathrm{P}$ & $13.90 P$ \\
\hline & - Practical & $5.00 P$ & $5.20 \mathrm{~F}$ & $5.40 P$ & $5.60 \mathrm{P}$ & $6.80 \mathrm{P}$ & $8 . \infty \mathrm{F}$ & $9.00 \mathrm{P}$ & $9.90 \mathrm{P}$ \\
\hline
\end{tabular}

\begin{tabular}{|c|c|c|c|c|c|c|c|c|c|}
\hline \multicolumn{10}{|l|}{ Total Capacity } \\
\hline Catogory $P$ & $\begin{array}{l}\text { - Theoretical } \\
\text { - Practical }\end{array}$ & $\begin{array}{l}96.10 P \\
76.55 P\end{array}$ & $\begin{array}{r}125.10 \mathrm{P} \\
95.85 \mathrm{P}\end{array}$ & $\begin{array}{l}150.70 P \\
121.05 P\end{array}$ & $\begin{array}{l}166.70 P \\
131.25 P\end{array}$ & $\begin{array}{l}194.00 P \\
147.40 P\end{array}$ & $\begin{array}{l}253.00 P \\
196.80 P\end{array}$ & $\begin{array}{l}26020 P \\
207.80 P\end{array}$ & $\begin{array}{l}268.40 \mathrm{P} \\
219.70 \mathrm{P}\end{array}$ \\
\hline Category 0 & $\begin{array}{l}\text { - Theoretical } \\
\text { - Practical }\end{array}$ & $\begin{array}{l}8.400 \\
5.500\end{array}$ & $\begin{array}{l}17.400 \\
10.000\end{array}$ & $\begin{array}{l}17.40 \mathrm{Q} \\
11.50 \mathrm{Q}\end{array}$ & $\begin{array}{l}17.400 \\
12.000\end{array}$ & $\begin{array}{l}17.40 \mathrm{O} \\
13.50 \mathrm{Q}\end{array}$ & $\begin{array}{l}17.400 \\
14.500\end{array}$ & $\begin{array}{l}17.400 \\
15.500\end{array}$ & $\begin{array}{l}17.400 \\
15.500\end{array}$ \\
\hline Calegory $A$ & $\begin{array}{l}\text { - Theoretical } \\
\text { - Practical }\end{array}$ & $\begin{array}{l}0.50 R \\
0.40 R\end{array}$ & $\begin{array}{l}0.50 R \\
0.40 R\end{array}$ & $\begin{array}{l}0.50 R \\
0.40 R\end{array}$ & $\begin{array}{l}0.50 R \\
0.40 R\end{array}$ & $\begin{array}{l}0.50 \mathrm{R} \\
0.40 \mathrm{~A}\end{array}$ & $\begin{array}{l}0.50 \mathrm{R} \\
0.40 \mathrm{R}\end{array}$ & $\begin{array}{l}0.50 R \\
0.40 \mathrm{~A}\end{array}$ & $\begin{array}{l}0.50 \mathrm{~A} \\
0.40 \mathrm{~A}\end{array}$ \\
\hline
\end{tabular}

- Other Network Capability described in detail in Sections B1 and B3.

$2 / 26 / 92$ 
ANL Site Response for the DOE FY1994 Information Resources Management Long Range Plan March 25, 1992

B. Computing Resources

The following paragraphs describe capacity projections for computing systems identified in Schedule 3B-1.

Computing and Telecommunications (CTD)

The 3.0 Q RCUs associated with the IBM 3033s and reported in previous ANL submissions were replaced in August 1990 with an IBM 3084 QX, thereby increasing theoretical capacity to 5.4 Q RCUs. The increasing practical capacity of 3.0 and 4.0 Q RCUs for FY1991 and FY1992 reflect the learning curve for this new system, migration to the IBM VM/XA and MVS/XA operating systems, and performance timing.

The theoretical capacity of the central VAX Cluster was increased to 14.2 P RCUs during FY1991 to reflect the midyear acquisition of a DEC VAX 6410 processor that provides roughly the same capacity as the existing VAX 8700 . The increase in practical capacity for 8.0 P RCUs in FY1991 to 11.0 P RCUs in FY1993 is the result of the learning curve for new system as well as performance timing of the VAX Cluster as a whole.

\section{High Energy Physics (HEP)}

The VAX 780 and 750s were decommissioned in FY1990. Local computing is now accomplished with a distributed systems of workstations and other microcomputers. Both VMS and UNIX operating systems are used. Additional microcomputers as well as disks and other peripherals are to be acquired as needed.

\section{Chemical Technology Division (CMT)}

The VAX 6220's theoretical capacity is estimated at 6.6P RSUs. Because the system runs 24 hours a day, 365 days a year, the practical capacity is estimated to be close to the theoretical capacity (6.0P). This system has been upgraded to a VAX 6320 (9.0P theoretical capacity/8.0P practical capacity). A VAXstation $3100 / 38$ (4.2P/3.4P) is used to support general PC networking activities. Other systems utilized by CMT in the Basic Energy Sciences program (KC) include a VAXStation 3200 (3.0P/2.4P), VAXstation 3100/76 (6.04P/4.8P), and a MicroVAX-II (1.0P/0.8P).

\section{Advanced Photon Source (APS)}

The increased theoretical capacity of type P RCUs in FY1994 is the result of acquisition and installation of two clustered RISC processors to support the data acquisition and reduction requirements of the Advanced Photon Source. These computers complement and enhance the existing MicroVAXes, VAX workstations, and RISC workstations in use.

\section{Not Applicable}


ANL Site Response for the DOE FY 1994 Information Resources Management Long Range Plan B. Computing Resources

March 25, 1992

\section{Installed Computer Systems}

\section{General Management Computer Systems}

The configuration and networking diagrams relating to these general management computer systems appear in Exhibit 2.1 and Exhibit 2.2

0601-49 Computing and Telecommunications Division (CTD)

The central computing needs of Argonne National Laboratory are served primarily by:

- A Cray X-MP/18 with the UNICOS operating system.

- An IBM 3084QX-96 with MVS/JES3 and VM operating systems.

- A VAX 8700 and VAX 6410 with VAX/VMS.

- Connections to an array of onsite computer networks and connections to offsite networks (e.g., ESnet, NSFnet, Internet, etc.)

CTD also operates two Hewlett Packard computers that are used for administrative systems. Section B.4, Computing Environment, describes the ANL central computing resources in greater detail.

0601-XX Mathematics and Computer Science Division (MCS)

MCS operates a distributed network environment based on scientific workstations linked to each other, to machines in the ACRF, to the central computing resources of Argonne, and to other facilities via the national networks.

\section{1-R4 High Energy Physics Division (HEP)}

The High Energy Physics Division has replaced its VAX 780 and 750 cluster with a new MicroVAX cluster and new disk and tape subsystems. Three MicroVAX 3400 systems and three workstations have been installed and share a total of 9.6 gigabytes of disk storage capacity. Large capacity helical scan tape drives are installed on each MicroVAX system which provide approximately 2.0 gigabytes of capacity per cartridge. Additionally, a number of Unix workstations have been acquired. Expansions of computing are expected to emphasize distributed Unix- based computing systems/servers.

\section{1-R6 Chemical Technology Division (CMT)}

The Chemical Technology Division VAX-6220 System has 64 megabytes of memory, a floating-point accelerator, 6.0 gigabytes of disk storage, one 6250 bpi tape drive, 20 printers and plotters, 16 terminal lines and four 32-line terminal servers. A FAXCOMM communications processor and formatter permits direct transmittal of word presessing documents 
from the 6220 to Group-III compatible facsimile machines. Additional capacity includes a general purpose VAXstation $3100 / 30$ with 32 megabytes of memory, 2.0 gigabytes of disk storage, a 600 megabyte CDROM, and two $4 \mathrm{~mm}$ DAT tape drives; a clustered microVAX-Il with 7 megabytes of memory, 1.0 gigabytes of magnetic disk storage, a dual 625 megabyte erasable optical disk subsystem, and a TK50 tape drive; a clustered VAXstation 3200 with 16 megabytes of memory, 380 megabytes of disk storage, and a VHS-format ( 2.5 gigabyte capacity) tape drive; and a clustered BES VAXstation $3100 / 38$ with 16 megabytes of memory, 1.2 gigabytes of disk storage, and a 600 megabyte CDROM.

The VAX 6220 is used primarily as a general purpose time-sharing facility during prime shifts. Applications include word processing, graphics, scientific and engineering calculations, data reduction and other office automation applications, e.g., calendar and facility management, and business database systems. The 6220 also provides network disk, file and print services to IBM PCs running DEC's PCSA software and to Macintosh PCs using Alisatalk softwarc. The system operates in a protected, air-conditioned environment. During offpeak periods, the system primarily provides computing cycles for batch scientific codes as well. The VAXstation 3100,3200, and MicroVAX-II are used almost exclusively in batch mode for large scientific code production runs.

\section{1-S5 Chemistry Division (CHM)}

The Chemistry Division VAX Cluster consists of a VAX 11/780, five MicroVAX IIs and a VAXstation 2000, with a total of 42 megabytes of memory, ten disk drives (FUJ 2331s, RA81s, RP07), two mag tape drives (TU77, TU78), one printer/plotter (LXY-11, 300 1pm), one printer (LP26, $600 \mathrm{1pm}$ ), and 140 terminal lines. The other VAXes on the Division's network are two MicroVAX IIs. A building-wide Ethernet interconnects the VAXes and supports four remotely located LSI 11/73 data acquisition computers and two MicroVAXes used for data analysis and code development. Nine terminal servers on the local Ethernet provide another 96 terminal connections. Two terminal servers (16 lines) are connected to PBX 16 ADI-101 data lines, a connection which provides dial-in service from any ANL ADI-100 equipped telephone at speeds up to 19.6 Kbaud. A PDP-11/34 computer serves as a bridge between the low-speed DECnet communication ( 9600 baud) and our Ethernet, for 13 remotely located LSI $11 / 23$ computers that control experiments and acquire experimental data. A 12-processor Alliant computer has replaced the 4-processor Alliant computer for the performance of theoretical computations.

\section{1-S3 Physics Division (PHY)}

The Physics Division has two VAX 3300)s, three VAX-11/750), two microVAX IIs, three VAXstation 3200s, and five VAXstation 3100s. The two VAX 3300s are the hub of the division network with connections to the site-wide Ethernet and through ANL routers to national and international networks. An Equinox DSS-5 terminal switch provides for terminal access to all of the VAXes as well as central computing resources. The terminal switch is connected to an Ethernet terminal server, providing access to all VAX computers in the Division, site-wide connections to VAX with LAT support, and to Internet via TELNET. The VAX-11/780 was decommissioned in FY1991. Unix machines include an IBM RS6000/320 and two SUN IPCs. 
ANL Site Response for the DOE FY 1994 Information Resources Management Long Range Plan B. Computing Resources

0601-XX Advanced Photon Source (APS)

The Advanced Photon Source (APS) is being designed as a national user facility for research involving synchrotron radiation. The APS will consist of a chain of three injection accelerators and a $7 \mathrm{GeV}$ positron storage ring. The control of these accelerators and storage ring will require an elaborate system of computers and workstations. A VAX 360), a VAXstation 3200 workstation, and two VAXstation 2000 s are the first members of this system. The predominant use of this initial set of computers is to test control system concepts and to develop control software. An additional use during the design phase of the APS will be to support general design activities. The system in its final form and mission will be totally dedicated to the control and monitoring of the APS accelerator and storage ring systems. During FY1989 a microVAX 3600 and project management software were added.

A data analysis computer facility which would meet the needs of most users is proposed as part of this project. The proposed data analysis facility will include a cluster of multiple computers with an aggregate theoretical capacity in exess of 20.0 P RCUs, at least 4 gigabytes of disk storage, and 50 workstations. The APS computer facility would be linked to the Argonne central computers to provide access to the centralized computing and telecommunications resources at ANL.

0601-XX Environmental Assessment and Information Sciences Division (EID)

In FY1991, EID relocated its entire division (over $4(X)$ people) to a new of fsite facility approximately 3 cable miles from its high-performance computing facility on the main campus. This was a major undertaking which involved planning and installation of fiber optic communications between facilities over railroad, gas and highway right-of-ways; designing and implementing interoffice fiber optic and twisted pair networks and subnetworks; deinstallation, relocation, and re-installation of approximately $8(X)$ electronic devices, including workstations, file servers, microcomputers, printers, routers, and various communications components; establishing various special purpose electronically-based rooms including central computing, prototyping, workstation, high-performance graphics, and multi-media presentation rooms.

In FY1992, EID will relocate its large-scale, parallel processing, mini- supercomputer facility from the main campus to its new offsite facility. In addition, file servers will be upgraded to include a parallel processor; older workstations will be upgraded to current RISC architectures; and new file servers, peripherals, and other electronic devices will be added to provide additional resources to meet the continuing increase in need for expanded, high performance, distributed computing systems. Additionally, EID will install dedicated $56 \mathrm{kbps}$ communications lines to ANL offices in Washington, DC, and Denver, as well as to the United States Central Command (USCENTCOM) Headquarters at MacDill Air Force Base. 
ANL Site Response for the DOE FY 1994 Information Resources Management Long Range Plan March 25, 1992

B. Computing Resources

Exhibit 2.1: Configuration Diagram for Central IBM computer system

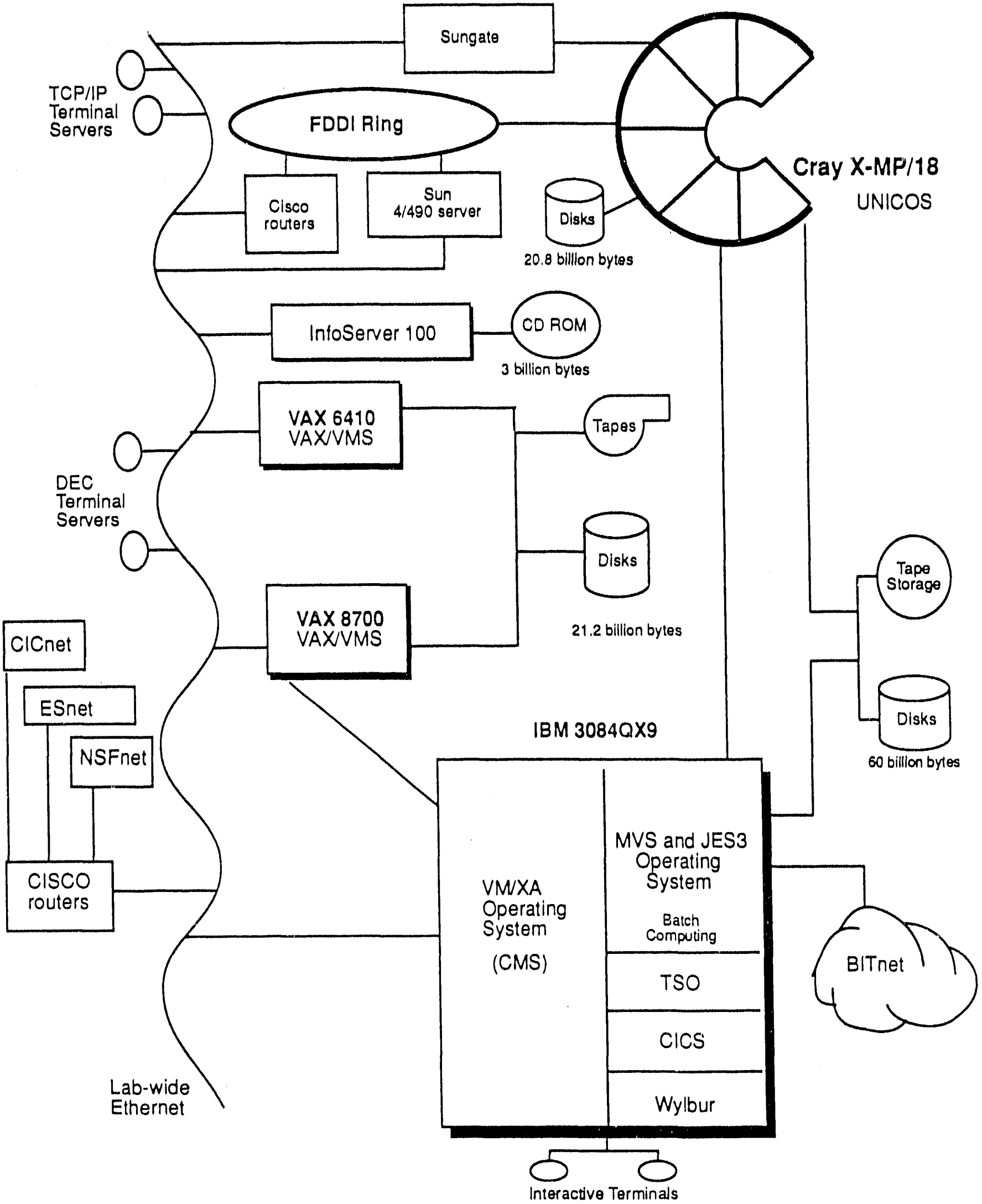


ANL Site Response for the DOE FY 1994 Information Resources Management Long Range Plan

Exhibit 2.2; ANL Intecom S/80 LANmark Ethernet

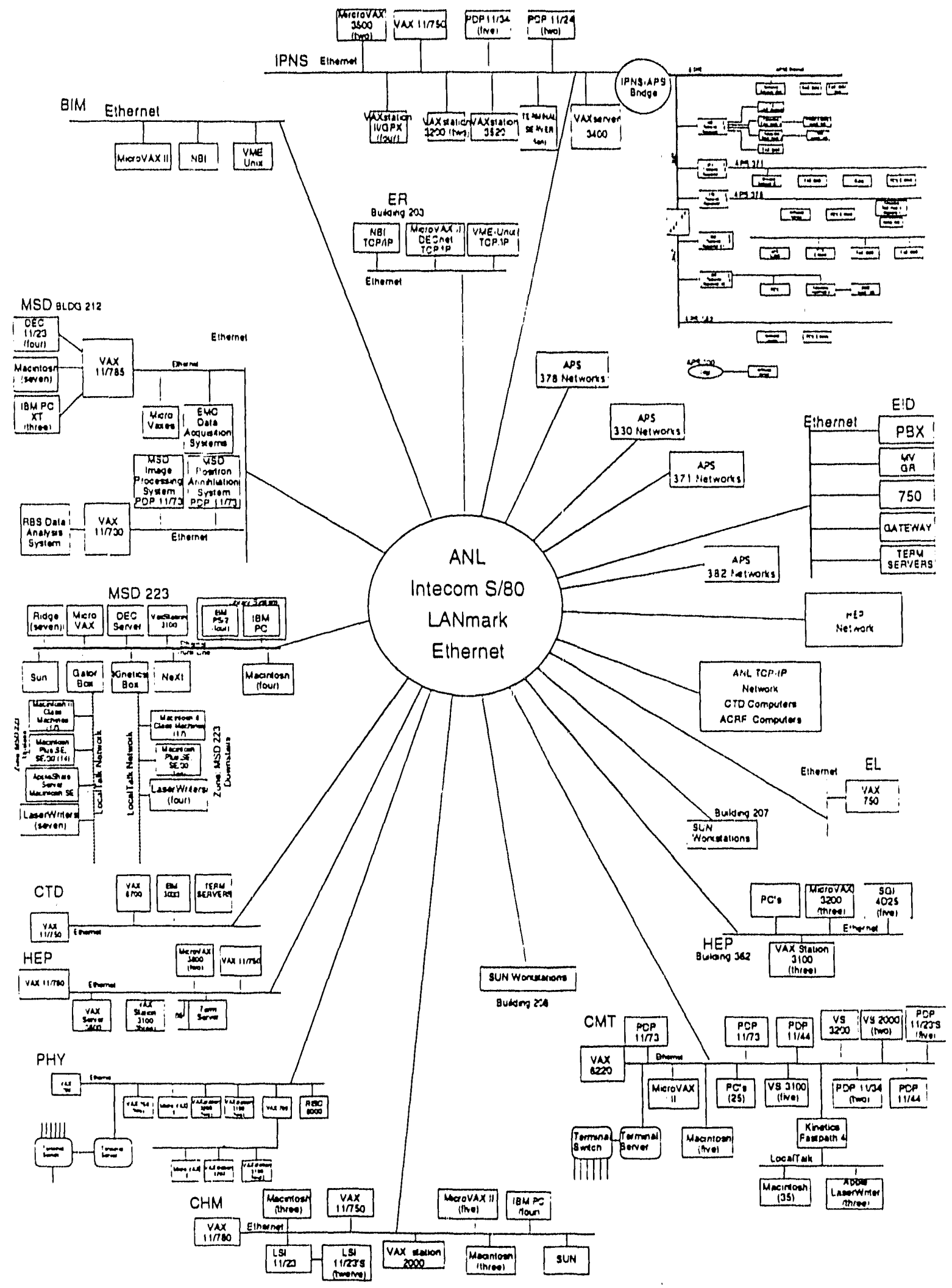

ANL-3.2.9 


\section{Spectal Management Computer Systems}

0601.08

The TYCHO II system is a computer system operated by the BIM Protein Mapping Group to handle the analysis of large sets of two-dimensional electrophoretic protein separations. The hardware system is a cluster consisting of a VAX $11 / 780$ and two VAXstations. The VAX-11/780 has attached two FPS 120B array processors, a Gould Imaging IP8500 image analysis and display system, an Optronics P1000 film scanner, and an Elkonix 785 2048-element scanner. An Elkonix 1412 4096-element CCD scanner is connected to one of the workstations. The VAX-11/780 is being phased out with software being converted to run on workstations alone.

\section{1-S4}

The Intense Pulsed Neutron Source (IPNS) is a national user facility for neutron scattering research. Acquisition and analysis of the data from this facility requires considerable computational resources. Data acquisition is handled by dedicated microcomputer systems coupled with PDP-11 and VAX station computers. The data acquisition computer systems are connected through Ethemet to two VAX computers for data analysis. The primary computer for data analysis is a DEC VAX $11 / 780$ with a floating point accelerator, 16 megabytes of main memory, and 1200 megabytes of disk storage. The other computers for data analysis are a DEC VAX $11 / 750$ with a floating point accelerator, six megabytes of main memory, and 750 megabytes of disk storage, and a VAX station 3200. Each VAX has two tape drives, with one capable of reading and writing at $6250 \mathrm{bpi}$. The VAX 11/750 is also used for word processing with MASS11 software with various printers for output. The number of experiments in IPNS has increased significantly in the past five years. IPNS has installed an enriched uranium target that gives three times as many neutrons, resulting in a large increase in data production rate. The VAX 11/780 was purchased in 1980 and requires a great deal of space, power, and hardware maintenance. It should be replaced with a more efficient processor within the next year.

IPNS is in the process of converting from the use of PDP-11 computers to VAXstations for data acquisition and display. These systems will also be able to do more data reduction than the PDP-11 systems and the effort required to support the systems and develop new code will be reduced. Replacement of all the PDP-11 computers should be completed over a three-year period.

\section{Personal Computers, Microcomputers, And Word Processors}

Personal computers are being used for a wide range of activities including digital instrumentation, business applications, and scientific programming. The long history of digital instrumentation and the large number of experimenters has provided a climate for the rapid introduction of personal computers into the Laboratory. The availability of electronic spreadsheets and database software is responsible for converting budget planning and other administrative activities to personal computers. As personal computers continue to increase in capability, capacity, and speed, they are given more consideration for scientific programming applications. Word processors continue to be a dominant tool in the preparation of correspondence and reports. 
ANL Site Response for the DOE FY 1994 Informalion Resources Management Long Range Plan B. Computing Resources

Personal computers at Argonne are Increasingly useful as computer-alded design (CAD) statons for two dimensional drafting. With the addition of the appropriate commercial software, personal computer-based workstations can provide some of the capabillty of larger mini-computer based and main-frame based (CAD) systems. The main limiting factor in acquiring more stations to increase both design and drafting efficlency is the cost involved and the operating time needed to train staft on the systems. In addition to IBM-based systerns, a number of staff are using Macintosh computers as drafting and design stations, This use of personal computers as design stations is expected to increase in the future.

The widespread practice at Argonne is to purchase rather than develop software. However, in the areas of digital instrumentation and scientific programming, software may be tailored for a specific scientific application. 
ANL Slte Response for the DOE FY1994 Information Resources Management Long Range Plan March 25, 1992

B. Computing Resources

PersonalMlorocomputerWord Processor Data

Slte: Argonne Nallonal Laboratory

Sohedule 38.3.1

\begin{tabular}{|c|c|c|c|}
\hline \multicolumn{4}{|c|}{ PO Cost Summary } \\
\hline & $\begin{array}{c}\text { Cost as of } \\
9 / 30 / 91\end{array}$ & $\begin{array}{l}\text { Estlmate } \\
\text { FY1892. }\end{array}$ & $\begin{array}{l}\text { Estlmate } \\
\text { FY1993 }\end{array}$ \\
\hline Hardwaro & $\$ 17,015,742$ & $\$ 2,000,000$ & $\$ 2,000,000$ \\
\hline Soliware & $\$ 5,104,723$ & $\$ 600,000$ & $\$ 600,000$ \\
\hline
\end{tabular}

Installed Personal, Mlorocomputer, and Word Processers

as of Septembar 30, 1991

Slte: Argonne Nallonal Laboratory

Schedule 38-3,2

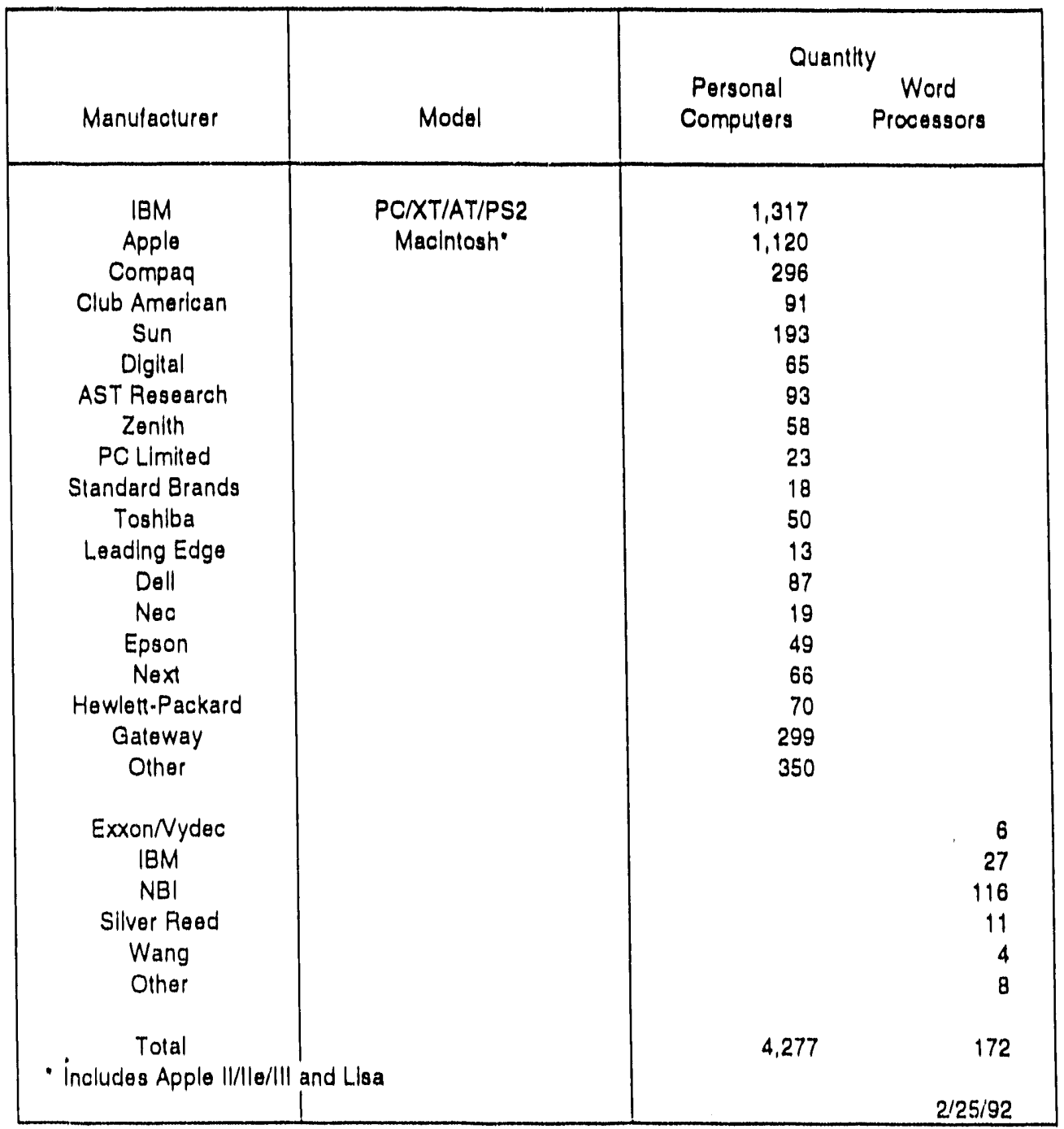

ANL-3.2.12 


\section{Computing Environment}

Argonne's scientffic, engineering, and administrative actlvitles depend increasingly heavily on the Laboratory's computing resources. The overall ANL computing and tolecommunicathons strategy is to dovelop a complete, integrated hlorarchy of computing capabilitles that includes supercomputers, centralized general purpose computers, multipurpose minicomputers, scientific and engineering workstations, and computing workstations and office automation support systems - all coupled together through an effectivo communications network (see Exhibit 2.5). The most crittcal element of this strategy is the avalability of advanced, high-speed network access to high performance computing systems.

For computatlo.sal-intensive applications, Argonne researchers hatve on-site access to vector processing computers, multiprocessor purallel architectures, medium-scale central computers, and associated scientific visualization tonls. High-speed networking and fiber-optic technology allow transmission of scientific data over a variety of local, reglonal, national, and international networks that let users transfer flles, exploit Interactive access, send electronic mall, and run application programs on possibly distant computing systems. In general, this hierarchy and networking of facilities increasingly give Argonne researchers conven. lent access to the type of computing they need.

The computing resources provided at Argonne Natlonal Laboratory are generally avallable to all members of the Laboratory, DOE and other U.S. Government agencles are served by arrangement. In addition, other organizations may apply for permission to use these services. Some computing services are avallable in limited quantities or only to certain users, either for technical or contractual reasons.

Only those with active computer accounts may use the central Argonne computers, and these users are charged through these accounts for the computing resources they use. Computing rates reflect shift differentials and include service premlums and discounts. Argonne National Laboratory adds an overhead surcharge for general and administrative services used by non-ANL organizations; DOE adds administrative and depreciation surcharges for services used by non-DOE organizations. Rate changes appear in the Argonne Computing Newsletter, and a list of current rates is avallable at the CTD) Document Distribution Counter (BuildIng 221, Room A-134) or through the mall (by calling (7()8) 252-54(15) and requesting a copy). Extensive documentation is avallable for purchase at the Document Distribittion Center to assist computer users with avallable computing resources. 
ANL Site Response for the DOE FY 1994 Information Resources Management Long Range Plan March 25, 1992

B. Computing Resources

\section{Exhibit 2.5: Computing and Telecommunications Activities}

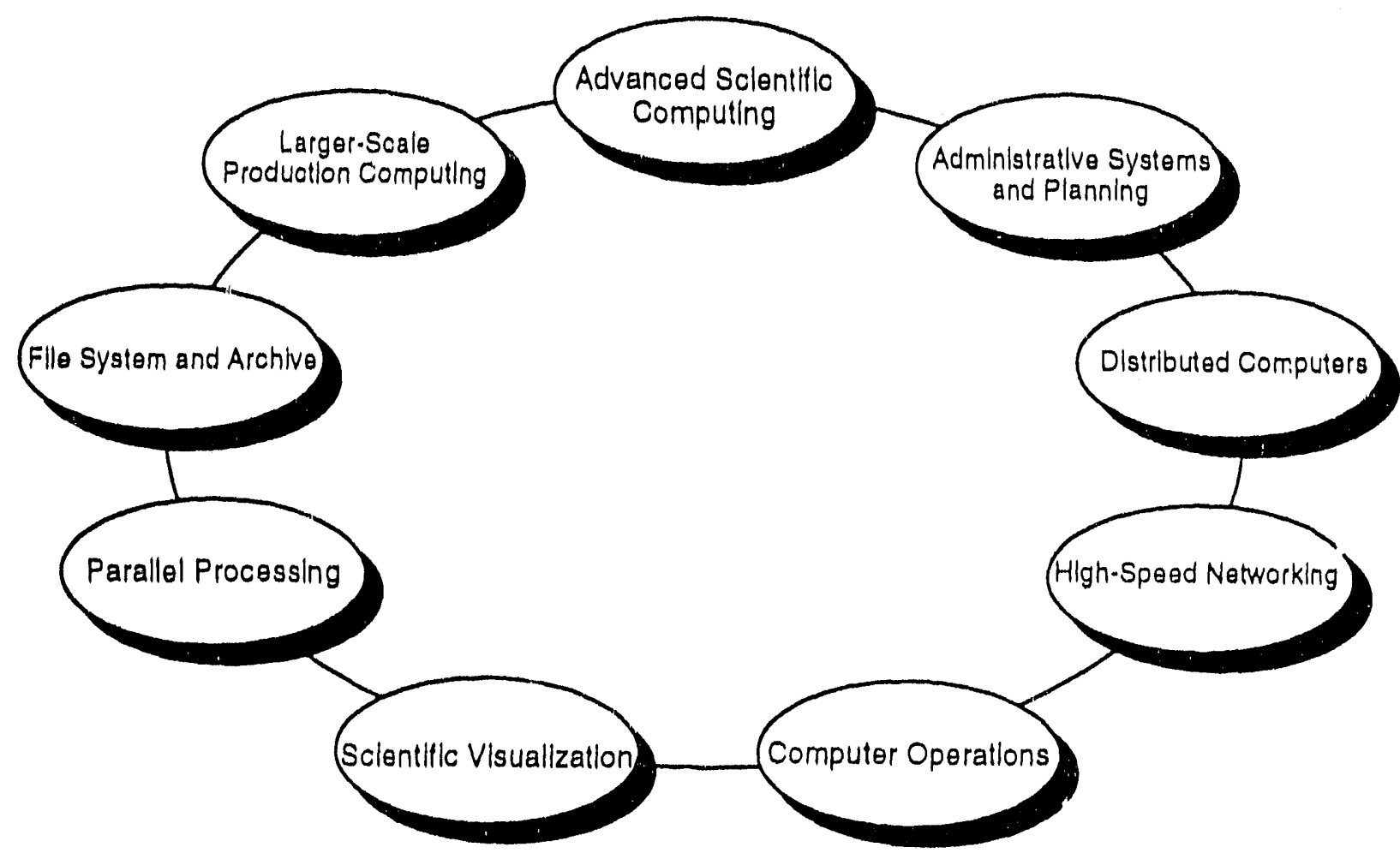


Cray X-MP/18--Argonne National Laboratory operates a Cray X-MP/18 computer with eight megawords of memory, an 8.5 nanosecond cycle time, the complete X-MP vector instruction set including the compressed-index scatter-gather vector instructions, and two vector logical units. The theoretical peak performance of the Cray X-MP floating point unit is 235 million floating point operations per second for overlapped multiply and add instructions.

Online disk storage for the Cray X-MP computer consists of a DS-40 disk subsystem with 20 gigabytes of storage capacity, capable of transferring data into and out of the Cray X-MP memory at nearly 40 megabytes per second. Additionally, the Cray X-MP has access to four IBM 3420-8 tape drives that permit data transfer at 1.25 megabytes per second with $1600 / 6250$ bpi tapes and access to eight STK 4480 cartridge drives that permit data transfer up to 4.5 megabytes per second.

Access to the Cray X-MP/18 batch system for IBM MVS and VM/CMS users is possible through NJE via a Cray-supplied MVS front-end station installed on the IBM 3084 computer. Job submission to the Cray and the indirect processors is provided by this MVS frontend station. DEC VAX and Unix users can use TCP/IP to access the Cray X-MP. The Cray $\mathrm{X}-\mathrm{MP} / 18$ is also physically connected over a Cray-provided SUN FEI-3 connection to a central SUN 3/280 TCP/IP gateway computer and to NSC FDDI interface. The SUN gateway and FDDI interface provide the links between the Cray UNICOS operating system and the ANL TCP/IP network.

The Cray X-MP computer system runs the UNICOS Release 6.0.1 operating system with the NQS batch job scheduler. UNICOS derives from the AT\&T System V Unix operating system and also includes many of the Berkeley Unix extensions. This system provides users with a complement of programming languages necessary for high performance computing. Both the CFT and CFT77 Fortran 77 compilers are available for scientific and engineering programming; a $C$ language compiler and the CAL assembler are also available. These programming languages enable users to access all the features of the Cray architecture. ANL has also made the Network File System (NFS) available to Cray X-MP users. NFS allows users with Unix workstations to access data stored on the Cray disks as if the data were locally attached to the user's workstation.

A large selection of subroutine libraries provided by Cray Research, Inc., is available with UNICOS. These libraries contain basic intrinsic mathematical routines and the EISPACK and LINPACK packages of Fortran subroutines. Cray-supplied UNICOS software libraries include:

- A library of routines for Fortran-specific features (libf)

- A library of mathematical functions (libm)

- A library of $\mathrm{V} / \mathrm{O}$ routines (libio)

- A library of scientific application routines (libsci)

- A utilities library (libu)

- X-Windows Release 11.4 for graphics 
Additionally, Argonne has installed several other software libraries:

- Disspla (a graphics library from Computer Associates International, Inc.)

- IMSL (a mathematical and statistical library from IMSL, Inc.)

- NAG (a mathematical library from the Numerical Algorithm Group)

- $\quad$ SLATEC (a mathematical library distributed by the National Energy Software Center)

Cray X-MP computing resources are accessible to offsite users via the NSFnet, ESnet, BITnet, HEPnet, CICnet, and Milnet computer networks. Users of the Cray must have valid accounts on a batch or interactive service with CTD.

Batch users can submit UNICOS jobs from the Cray MVS front-end station or any BITnet node including most of the DEC VAXes. The front-end station submits UNICOS jobs to the Cray X-MP system and returns the printed output to the origin of the job, unless users supply network commands to redirect output to another site. Batch Cray usage is preferable to interactive Cray usage to ensure that resources are available for long running production jobs, although Argonne encourages interactive use of the Cray for debugging and interactive graphics.

The Cray is connected to the Laboral ory-wide TCP/IP network by an interface to a Sun gateway computer and a NSC FDDI interface. These TCP/IP interfaces provide interactive access and file transfer capabilities (including NFS) to the Cray from Unix-based computers and other computers which support the TCP/IP network protocol, including most of the DEC VAXes, PCs and Macintoshes. National TCP/IP-based networks such as NSFnet are able to transfer files to any ANL TCP/IP host, including the UNICOS system and its front-end stations.

Advanced Computing Research Facility--The Mathematics and Computer Science Division operates the Advanced Computing Research Facility (ACRF) as part of a continuing emphasis on advanced computing. The facility currently contains nine computers with diverse advanced (parallel and vector-parallel) architectures. The following computers are research tools for Argonne scientists and for qualified researchers from other institutions:

- An Active Memory Technology DAP-510-8 with 1024 single-bit processors, each with eight kilobytes of memory.

- An Alliant FX/8 system with eight high-speed vector processors sharing 128 megabytes of memory.

- A Stardent Titan graphics supercomputer, with four processors and a peak performance of 64 megaflops.

- $\quad$ A BBN TC2000, with 45 nodes, each having four megabytes of memory.

- A BBN GP1000, with 96 nodes, each having four megabytes of memory. 
- A Connection Machine Model 2, with 16,384 nodes, each having eight kilobytes of memory.

- An Encore Multimax, with 20 processors sharing 64 megabytes of memory.

- A Sequent Symmetry, with 26 processors sharing 32 megabytes of memory.

- An Intel iPSC/860 Gamma, with eight nodes, each having 16 megabytes of memory.

- A Solbourne, with 25 gigabytes of memory.

The ACRF also serves as the liaison through which researchers at ANL have access to the Touctstone DELTA System, located at the California Institute of Technology. The DELTA, currently the world's fastest computer with a peak speed of 32 gigaflops, will enable researchers to start tackling the so-called Grand Challenges in science and engineering. The machine was acquired by the Concurrent Supercomputing Consortium (CSC), of which Argonne is a leading participant.

Advanced Database and Analytical Model Research Center (ADAM)--The Advanced Computer Applications Center (ACAC) of the Environmental Assessment and Information Sciences Division (EID) operates the Advanced Database and Analytical Model (ADAM) Research Center to provide a national concentration of advanced architecture computing resources for developers of software for the Force, Structure, Resource, and Assessment Directorate (J-8) of the Joint Staff in the Pentagon, various Commander-in-Chief (CINC) Headquarter organizations around the world, and the Department of Energy.

ADAM also acts as a testbed for hardware, software, and communications systems to be integrated into heterogeneous, distributed computing netwo.ks at sponsor locations around the world. As such, the center undergoes continuing change. In FY 1991, ADAM relocated two of its mini-supercomputers to facilities in the Pentagon and at MacDill Air Force Base. Currently installed at its main campus computer facility are:

- A A Sequent Symmetry S81, symmetric, parallel processing mini-supercomputer with 24 processors, 120 megabytes of main memory, and 10.8 gigabytes of disk storage. This system delivers 96 MIPS of processing power.

- Various communications equipment which provide accessibility by way of direct dialup telephone, lab-wide Ethernet, and fiber optic communications networks. Telephone baud rates available include $12(x), 24(X)$ and 9600 bps.

ADAM also includes in its extension an offsite, distributed, heterogeneous, computing environment with over 100 components, including file servers, high-performance workstations, microcomputers, peripherals, and communications devices interconnected via various local and remote fiber optic and twisted pair networks and subnetworks which provide the computing and communications needs for over 65 people in ACAC alone. Additionally, ADAM maintains a dedicated 56kbps communications line to USCENTCOM Headquarters at MacDill Air Force Base. 
ANL Site Response for the DOE FY1994 Information Resources Management Long Range Plan

Centralized General Purpose Computers-- The central computing needs of Argonne National Laboratory are served primarily by:

- An IBM 3084QX computer with the MVS/XA-JES3 and VM/XA operating systems.

- $\quad$ Clustered VAX 8700 and VAX 6410 computers with VAX/VMS.

- Connections to onsite computer networks (e.g., TCP/IP) and offsite networks (e.g., the National Energy Research Supercomputing Center Network).

These computers and their associated peripheral equipment provide over 92 billion bytes of online disk storage, 18 magnetic tape drives, many remote job-entry stations, and extensive libraries of mathematical, statistical, and graphical programs and subroutines. Users access these computers from remote job-entry terminals and from interactive terminals via dedicated and dial-up ports and network connections.

\section{Centralized Network Resources}

The Computing and Telecommunications Division (CTD) provides centralized volce and data communications services and a Laboratory-wide Ethernet that interconnects the TCP/IP network, the DECnet, the AppleTalk network, and the XNS network. CTD also maintains a Laboratory-wide NJE network that enables distributed computers to access the central complex and its many resources and services (e.g., graphics, specialized software, microfilm, databases, and fast printers).

Centralized networking activities of CTD also include maintenance of national and international network connections to provide file transfer, interactive access, and electronic mail capabilities to a large number of professional peers and potential collaborators. There are connections between the Internet and Laboratory computers that link major universities and laboratories together. The Laboral ry's central IBM computers and DEC VAX computers also participate in BITnet, an international university file transfer network interconnecting over three thousand computers. The Laboratory is connected to ESnet, a T1 national network funded by DOE's Energy research program; ESnet provides a communications backbone for both HEPnet and the Internet. ESnet runs the DECnet and TCP/IP protocols. The Laboratory participates in the dedicated computer network for High Energy Physics Research (HEPnet) through the ESnet, interoperated with major High Energy Physics laboratories and university collaborators. The Laboratory's Decnet and TCP/IP based networks are linked to CICnet, a T1 regional network. A T3 National Science Foundation network (NSFnet) node was installed at Argonne in 1991. NSFnet runs the TCP/IP protocol. The Laboratory is represented on the CICnet Board of Directors, the HEPnet Technical Coordinating Committee and the ESnet Technical Steering Committee.

\section{Multi-Purpose Minicomputers}

DEC VAX distributed multi-purpose minicomputer centers are located in several of the major divisions at ANL and provide a significant number of general interactive computing services for individual scientific organizations. The computing capacity of the distributed centers continues to expand with the addition of numerous MicroVAXes to the existing VAX clusters. Multinet allows these distributed VAX/VMS systems to participate in TCP/IP networking. 
ANL Site Response for the DOE FY 1994 Information Resources Management Long Range Plan B. Computing Resources March 25, 1992

There are several hundred identifiable minicomputers deployed in laboratories to record and control experiments, with numerous additional minicomputers and microcomputers imbedded in experimental equipment. Digital Equipment Corporation is the dominant supplier of digital instrumentation computers, but there is a diverse population of other equipment.

ANL also has two Hewlett-Packard 3000 minicomputers in Building 201 for the Automated Materials/Payables System (AMPS), the Stock Tracker System, and the Maintenance Control and Reporting System (MCRS). Access to these computers is limited (by dedicated connections) to Information Systems analysts and to the users of these applications.

\section{Scientific and Engineering Workstations}

Scientific and Engineering workstations comprise a significant computing capability at ANL. While vendors vary (e.g. SUN, Silicon Graphics, IBM, Digital), there are uniform capabilities that define the standard scientific workstation environment. These capabilities include:

- Unix operating system

- TCP/IP Ethernet Networking

- Network File System Data Access

- $\quad \mathrm{X}$ Windows graphics

Increasing speeds of RISC processors enable workstations to function in much the same manner as minicomputers did several years ago, i.e., serving multiple simultaneous users. The maturity and robustness of scientific workstations makes them effective for a wide range of applications. Increasing processing speeds enable running applications previously suited for mainframes. The sizable population will enjoy continued growth. The standard graphics capabilities of most workstations obviate the need for special graphics terminals. Even lower-end Macintosh and PC-based workstations are widely used for emulating graphics terminals to access applications on mainframes and supercomputers.

\section{Performance Measurement}

The KOMAND package from Pace Applied Technology, Inc, builds a database of resource utilization statistics for all the IBM systems. IBM's System Management Facility (SMF), with extensions from Pace, provides the information on batch, JES3, and Wylbur. An extension to the KOMAND package, called VMCI, generates data from VM/CMS for this database. Extensions to the KOMAND package written at Argonne also generate data from the VAX 8700, VAX 6410, and Cray X-MP/18 computers for the database. The SAS package from SAS Institute, Inc. generates hourly, daily, and monthly reports on service times for batch jobs from this database. The Resource Measurement Facility (RMF) (from IBM) and Look (from Advanced Data Research) perform detailed analyses of problems on MVS. VMPRF (from IBM) provides regular information on the performance of VM/CMS and the response time VM/CMS users receive. It generates a daily report of VM/CMS performance. The RTM/SF package (also distributed by IBM) does detailed studies of particular problems and provides realtime warnings of bottlenecks. The VAX Performance Advisor allows real time analysis of VAX system performance and bottlenecks. 
ANL Site Response for the DOE FY1994 Information Resources Management Long Range Plan March 25, 1992

Cray X-MP performance is monitored through the regular collection of hardware performance monitor data. These data allow the identification of applications that do not effectively use the Cray's vector architecture. CTD staff aid users in subsequently adapting their codes to vector architecture. This capabllity was developed at Argonne and is now incorporated into the UNICOS product. It was also the basis of a paper presented by CTD staff at the Fall 1991 Cray Users Group meeting.

In addition to identifying performance bottlenecks and measuring the results of tuning efforts, the data collected permits identification of changes in the workload, supplies much of the information for charging back system usage, and helps identify capacity problems. The response time a user experiences on an interactive system or the turnaround time for a batch job can become unacceptably long when performance problems exist, when reliability is poor, or when the workload simply exceeds the capacity of the equipment.

\section{Computer Protection}

Laboratory policy (see Appendix A) requires that managers of all computer applications determine the sensitivity of their applications. Computer Protection Program Representatives have been appointed for all divisions, programs, or departments of the Laboratory. They inventory all computer applications along with their sensitivity and forward the information to the Computer Protection Program Manager, who keeps the information on flle in a database. Managers of sensitive applications prepare protection plans for their applications with the help of their Computer Protection Program Representatives, who approve each plan and keep it on file. A summary sensitive computer application checklist is prepared by the Representative and sent to the Computer Protection Program Manager, who approves it and schedules dates for updating the plan and conducting the next risk analysis.

Similarly, Assistant Computer Protection Program Managers are appointed for each sensitive computer in the Laboratory. These Assistants prepare and keep on file protection plans for the sensitive computer for which they are responsible. A summary sensitive computer system checklist is prepared and sent by the Assistant to the Computer Protection Program Manager, who approves it and schedules dates for updating the plan and conducting the next risk analysis.

Periodic training sessions are held for the Computer Protection Program Representatives and for the Assistant Computer Protection Program Managers. The Computer Protection Program Representatives hold computer security education sessions for computer users, programmers, operators, and managers in the ANL organizations they represent.

The physical security of the central computer room is assured by seals and alarms on all doors except the main access door. These seals and the alarm are routinely tested several times per day. Personnel reach the main access door only by passing through a key card or operator controlled door that is opened by the operators after the persons seeking entry have been identified as authorized to enter the main computer room. The lock on the main entrance door to the computer room is also controlled and requires a valid key card or an operator inside the computer room to open it. The door is further protected by emergency bolts that can be operated from within the computer room; activation of these bolts sends signals to the Laboratory's Security Division. 
ANL Site Response for the DOE FY 1994 Information Resources Management Long Range Plan

In addition to the central computers, the Laboratory has an auxiliary computing facility housing the standalone Hewlett-Packard minicomputers on which the Automated Materials Payable System and some other sensitive applications run. I ocking all the doors to the computer room and sealing all except the main access door protect this facility. A cipher lock controls the main access door during working hours. At other times Security monitors the area to protect against intrusion by unauthorized personnel. All terminals connected to the Hewlett-Packards use direct connections or leased lines. There is no uncontrolled dial-up access to these systems. Passwords protect the operating system, MPE V, and each user can perform only those transactions that his or her job function requires. An operator can allow remote diagnosis of system problems by activating the modem and making the connection. The operator also can observe all commands issued and override any unauthorized actions.

Regular backup procedures minimize the inadvertent loss or alteration of computer-based data. Users who need to control access to their data can use the IBM Resource Access Control Facility (RACF) Program Product to do so. RACF controls access to data on disk and tapes. In addition, for tapes, we use the CA-1 Tape Management System, which also provides some limited protection under user control.

The operating systems require user veriffcation passwords in addition to user identification. The MVS and VM/CMS operating system resources are protected by RACF, while the VMS and UNICOS operating systems provide their own security.

The ANL Disaster Recovery Plan for Administrative Systems' (ANL/TM 456), Revision 1, has been developed and is tested annually to provide for continuity of processing of critical applications in the case of a disaster. This plan calls for using the data processing facilities at the University of Chicago. Data to be used in such processing are kept in a tape vault in a building separate from that housing the computers normally used to process the data. Weekly backups of on-line disk data are also kept in that separate tape vault. Also, computer users can request that coples of tapes containing user data of a critical nature be stored in the same tape vault. 
ANL Site Response for the DOE FY1994 Information Resources Management Long Range Plan March 25, 1992

B. Computing Resources

\section{Slte Software Proflle \\ (as of September 30, 1991)}

Site: Argonne National Laboratory

Schedule 38.4

\begin{tabular}{|l|c|c|c|}
\hline & $\begin{array}{c}\text { Administrative, } \\
\text { Business, } \\
\text { Manufacturing }\end{array}$ & $\begin{array}{c}\text { Scientifle, } \\
\text { Engineering }\end{array}$ & Both \\
\hline
\end{tabular}

\begin{tabular}{|l|c|c|c|}
\hline Operating Systems & DEC Ultrix & IBM VMSP 2.1 \\
& HP MPEN Ver. 5 & IBM AIX 3.0 & IBM MVS 1.3.5 \\
& HP MPEN Ver. 1P & Apple AUX & DEC VMS 5.3 \\
& IBM CICS & Sun OS 4.1.1 & Next 2.1 \\
& & RSX 11M DOS & MS Windows \\
\hline
\end{tabular}

\begin{tabular}{|c|c|c|c|}
\hline $\begin{array}{l}\text { Data Base Management } \\
\text { Systems }\end{array}$ & $\begin{array}{c}\text { BASIS } \\
\text { Inquire, Image } \\
\text { S2000 } \\
\text { DEC VAX RDB } \\
\text { MS SQL Server } \\
\text { FoxPro, FoxBase } \\
\text { Dbase III, Dbase IV }\end{array}$ & MASS 11 Manager & $\begin{array}{c}\text { Oracle } \\
\text { Sybase } \\
\text { DEC VAX Datatrieve } \\
\text { Ingress }\end{array}$ \\
\hline
\end{tabular}

\begin{tabular}{|l|c|c|c|}
\hline Data Dictionaries, Directories, & & & DEC VAX CDD PIUS \\
Encyclopedia & Quiz \\
& Query & & \\
\hline
\end{tabular}

\begin{tabular}{|c|c|c|c|}
\hline $\begin{array}{l}\text { Programiner Productivity, } \\
\text { Computer-Assisted Soltware } \\
\text { Engineering (CASE) Tools }\end{array}$ & $\begin{array}{c}\text { Quiz } \\
\text { Query } \\
\text { Information Expert } \\
\text { Excelerator } \\
\text { Inquire } \\
\text { ER win/SQL } \\
\text { Object View } \\
\text { CICS DBUG.AID } \\
\text { FILE.AID }\end{array}$ & Historian & $\begin{array}{c}\text { Librarian } \\
\text { SAS } \\
\text { VAX CMS } \\
\text { VAX MMS } \\
\text { Oracle Case }\end{array}$ \\
\hline
\end{tabular}

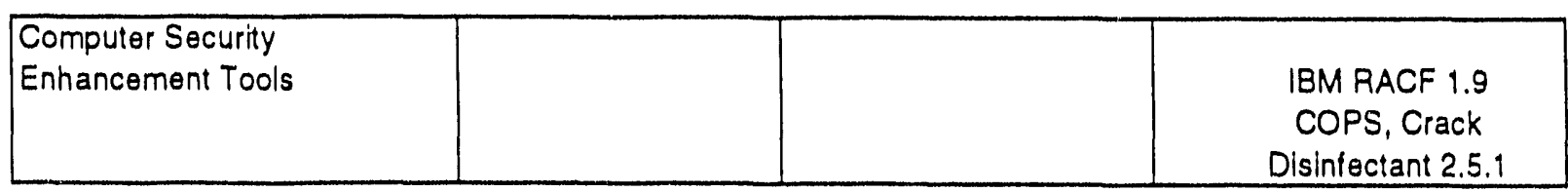


ANL Site Response for the DOE FY 1994 Information Resources Management Long Range Plan C. Resource Sharing

March 25, 1992

\section{Section C}

\section{Resource Sharing}

Schedule C1, Resource Sharing, summarizes resource sharing opportunities reported by the program areas. The National Energy Research Supercomputer Center (NERSC) and Florida State University resources provide the majority of the FY1992 and FY1993 resource sharing requirements for programs AT-15, $\mathrm{KA}, \mathrm{KB}$, and $\mathrm{KC}$. 
ANL Site Response for the DOE FY 1994 Information Resources Management Long Range Plan March 25, 1992

C. Resource Sharing

ADPE System Resource Sharing (RCU's and Cosis)

Sohedule 3C.1

(Dollars in Thousands)

Site: Argonne National Laboratory - ANL

Point ol Contaot: L. M. Boxbergor FTS 972.5638

Commerolal 312.252 .5638

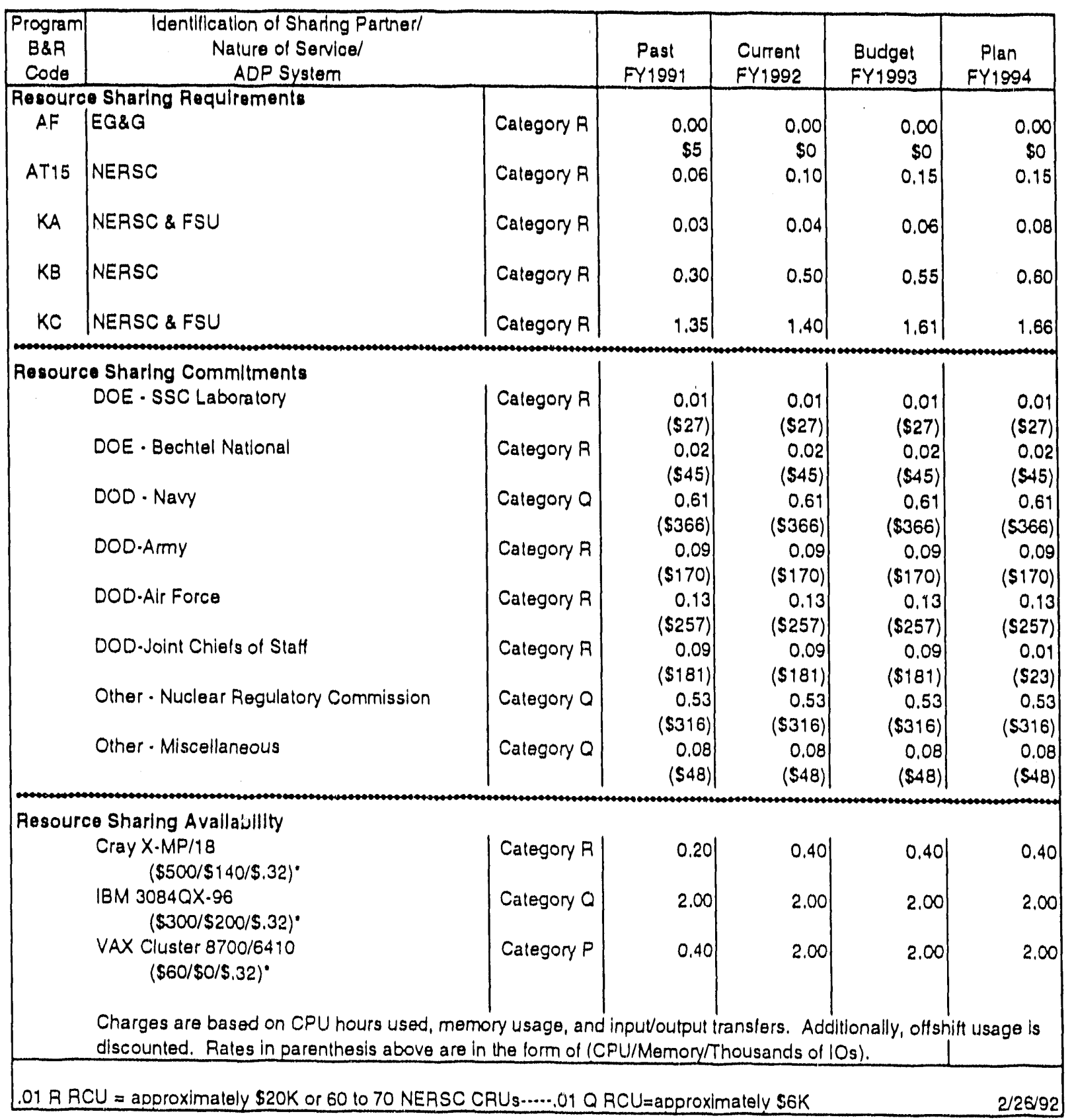

ANL-3.3.2 
ANL. Site Response for the DOE FY 1994 Information Resources Management Long Range Plan D. Commerclal Survices

\section{Section D \\ Commercial Services}

Schedule 3D-1, ADP Commercial Services Requirements, depicts reported or anticlpated use of commerclal services by programs at Argonne National Laboratory, Q RCUs are estimated on the basis of approximately $\$ 25,(0) 0$ per .01 Q RCU. 
ANL Site Response for the DOE FY 1994 Information Resources Management Long Range Plan March 25, 1992

D. Commerclal Services

Schedule 4.1: Schedule 3D.1 ADP Commercial Services (RCUs And Costs)

STTE, Argonne NatLonal Laboratory - ANL

(Do11ars fin Thousands)

PROGRAM

IDENTIFICATION OF VENDOR/

PAS'T'

CURREN'I'

BUDGES PLAN

B\&R CODE

NATURE OF' SERVICE/ADP SYSTEM

FY1991

FY1992

FY1993 FY1994

IIME (RCUs and Cogta)

$A F$

FEDLINK
Blbl lographic Retrieval

. 1.1Q

$(\$ 6,6)$

.130

$\$ 81$

.130

$\$ 81$

.130

$A A$

\author{
Data Resources \\ Economic Model \& \\ Forecast service \\ S'IN International \\ Ilinet/OCLC Servicea
}

.120

(\$75)

120

(\$75)

.120

(\$75)

.120

.040

(\$25)

. $04 Q$

(\$27)

.040

(\$27)

.039

$\$ 18$

.030

.030

.030

$\$ 20$

$\$ 20$

$\$ 20$ 
ANL Site Response for the DOE FY 1994 Informalion Resources Management Long Range Plan E. Accuulsitions

\section{Section E \\ Acquisitions}

\section{A. Acquisitions}

\section{Major Planned Acquisitions/Lease Continuations}

The major planned acquisitions or lease continuations for Argonne National Laboratory durIng the planning perlod are defined in the following Schedule $3 \mathrm{E}-1 \mathrm{~s}$ and accompanying justifications:

- ANL-84-1 Continuation of the Advanced Computing Research Facility

- ANL-86-1 Continuation of Lease of Cray X-MP/18

- ANL-94-1 Data Acquisition and Reduction Facility for Advanced Photon Source 
ANL Site Response for the DOE FY 1994 Information Resources Maragement Long Range Plan Murch 25, 1992

E. Acquisitions

Major Planned Aoqulaltlone/Lease Contlmuatlons

Schodule 3E.1

Sllo: Argonne Natlonal Laboratory. ANL MIE No, ANL.84.1 Last MIE No.

MIE Name: Contlnuatlon of the Actuanoed Computlng Researah Faallity and Slart of High Partormanoe Computing and Communioations Program

Programe \& R Oode: KCO7 Program Name: Advanood Oomputer Systems Conoepts

MIE Desoriptlon:

\begin{tabular}{|c|c|c|c|c|c|c|c|}
\hline \multirow[b]{3}{*}{ ACQUISITION } & \multirow{3}{*}{$\begin{array}{c}\text { CURRENT } \\
\text { FY } 1932\end{array}$} & \multirow{3}{*}{$\begin{array}{l}\text { BUDQET } \\
\text { FY1993 }\end{array}$} & \multicolumn{5}{|c|}{ Fundling Prollle $(\$ 000)$} \\
\hline & & & PLAN & & OUT & ARS & \\
\hline & & & FY 1994 & FY1995 & FY1996 & FY1097 & FY1988 \\
\hline Capttal & $\$ 300$ & $\$ 8,800$ & $\$ 9,650$ & $\$ 11,750$ & $\$ 11,750$ & $\$ 11,750$ & $\$ 11,750$ \\
\hline Operating & $\$ 400$ & $\$ 2,810$ & $\$ 5,540$ & $\$ 7.125$ & $\$ 7.125$ & $\$ 7,125$ & $\$ 7,125$ \\
\hline Construction & & & & & & & \\
\hline
\end{tabular}

NON.ACQUISITION (FOR ITEMS ACOUIRED IN FY94 AND BEYOND)

Maintenanco

Involves Faollity Changes with Budgatary Impact

Installatlon Date (Mo/Yr) From: Oct.93

Management Classitication

Initlal Purchase Equivalent Cost (all leased Hems)

ACQUISITION STAATEQY

\section{$\$ 260$}

$\$ 1,160$

$\$ 2.325$

$\$ 2,325$

$\$ 2,325$

\section{No}

To: Sep.99

$\square$ GENEAAL

$\square$ SPECIAL

X]RESEARCH

\section{PROCUREMENT STRATEGY (For ltems Nol Yel Acquired)}

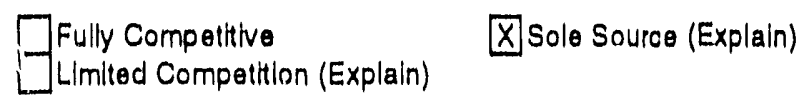

Explanatlon:

\section{MILESTONES (For ltems to be Acquired in FY92 thru FY94)}

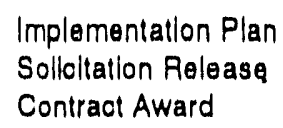

Solloitation Release

Contract Award
Doperatlons OHice $\square$ HQ 
Justification for ANL-84-1, Continuation of the Advanced Computing Research Facility and Start of High-Performance Computing and Communications (HPCC) Program

The Advanced Computing Research Facility mission is to operate computers with innovative architectures that promise to be effective for DOE work. In FY 1992 and subsequent years we expect to acquire and install one or more prototypes of massively parallel computer systems, to be used in conjunction with the HPCC program. In FY1992, we are working closely with Alliant on the feasibility of using a cluster model to make up a massively parallel system. Because we constantly monitor available or planned machines, our ideas on suitable machines change frequently. The selection of a particular machine will depend on what is available within the constraints of the budget.

A beta-test Intel SIGMA will be installed in the first half of 1992. We also plan to upgrade the memory and disc systems on several of the shared-memory multiprocessors. Finally, we intend to acquire modest-scale versions of emerging new architectures that are likely to scale to large configurations. Candidates are the Kendall Square Research UCS-1 and the MOSAIC.

Our goal for the HPCC program is to increase the total available computing power by znother factor of five over the next 18 months. To accomplish this goal, we plan to acquire a system with a capacity of about 40 gigaflops. Our visualization resources will similarly be augmented to provide a completely digital postproduction environrzent. 
ANL Site Response for the DOE FY 1994 Information Resources Management Long Range Plan March 25, 1992

E. Acquisitions

Major Planned Acqulsitlons/Lease Continuations

Schedule 3E-1

Site: Argonne National Laboratory. ANL

MIE No. ANL-86.1 Last MIE No.

MIE Name: $\quad$ Cray X.MP Memory Upgrade Lease Continuation

Program B \& R Cods: KC· Program Name: Basic Energy Sciences

MIE Description:

CrayX-MP/14 lease completed 11/91.

Lease costs of 4 megaword memory upgrade to existing Cray X-MP.

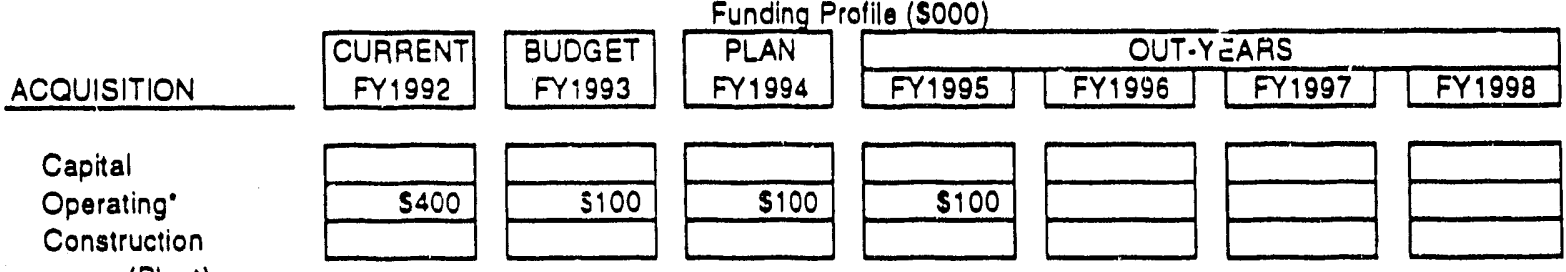

(Plant)

NON-ACQUISITION (FOR ITEMS ACQUIRED IN FY94 AND BEYOND)

Maintenance

Involves Facility Changes with Budgetary Impact

Installation Date (Mo/Yr) From: Nov.87

Management Classitication

Initial Purchase Equivalent Cost (all leased items)

X GENERAL

$\$ 5.400 \mathrm{~K}$

\section{ACQUISITION STRATEGY}

Purchase $\square$ LEASE FOR ___ YEARS

Lease with Option to Purchase; Exercise Purcha! Option (Mo/Yr)

X Lease to Ownership: Payments to be Completed

Other (Explain)

\section{PROCUREMENT STRATEGY (For ltems Not Yel Acouired)}

X Fully Competitive $\square$ Sole Source (Explain)

Limited Competition (Explain)

Explanation:

MILESTONES (For Hems io be Accuired in FY92 thru FY94)

Implementation Plan

Solicitation Release

Coniract Award

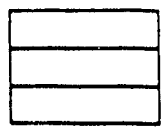

$\square$ Operations OHice $\square$ HQ

- Oparating costs are distributed among users on an actual usa hasis 
ANL Site Response for the DOE FY 1994 Information Resources Management Long Range Plan E. Acquisitions

Justification for ANL-86-1 Continuation of Lease of Cray X-MP/18

Acquisition of the Cray X-MP/14 in FY1988 was an initial step in modernizing and upgrading central computing resources to meet the increasing needs for onsite resources in the most cost-effective manner possible.

During the FY1991, additional memory was added, converting the Cray X-MP/14 to a Cray $\mathrm{X}-\mathrm{MP} / 18$. This upgrade has allowed for better system utilization and has opened up new opportunities for interactive graphics and debugging. During off shift hours, larger problems can also be run.

The lease of the Cray X-MP/14 was completed on November 30, 1991. The lease of the additional four megawords of memory will continue through FY1994. The total annual operating costs are distributed via central computing charge-back to users on an actual use basis. 
ANL Site Response for the DOE FY1994 Information Resources Management Long Range Plan March 25, 1992

Site: Argonne National Laboratory - ANL

MIE No. ANL-95.1 Last MIE No. ANL-94.1

MIE Name:

Data Acquisition and Reduction Facility for the Advanced Photon Source

Program B \& R Code: MIE Description:

$$
\text { KC Program Name: } \quad \text { Easic Energy Sciences }
$$

See accompanying justification and descripition

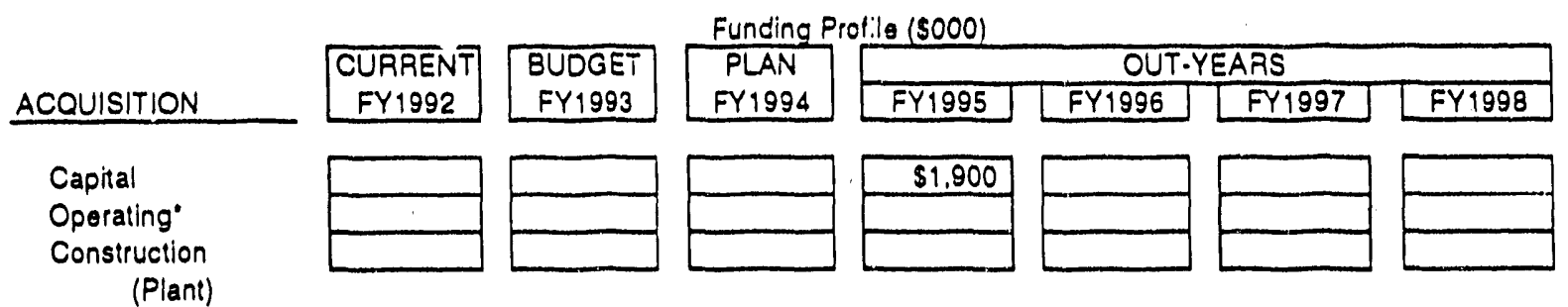

NON-ACQUISITION (FOR ITEMS ACQUIRED IN FY94 AND BEYOND)

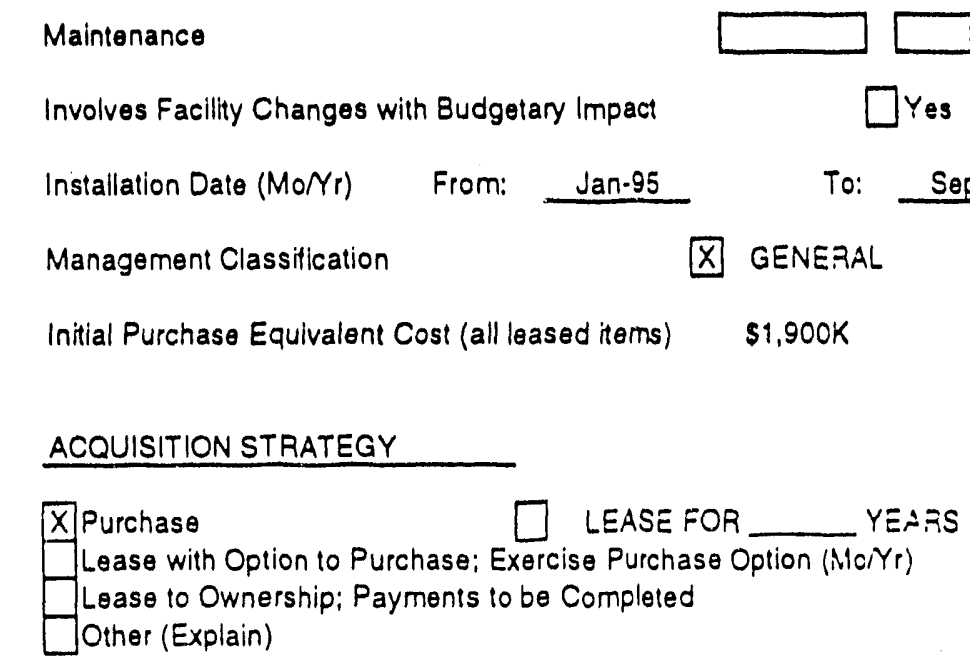

Involves Facillty Changes with Budgetary Impact<smiles>C1CCCCC1</smiles>

(1)

\section{PROCUREMENT STRATEGY (For ltems Not Yel Acquired)}

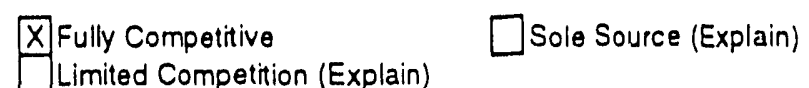

Explanation:

\section{MILESTONES (For ltems to be Acouired in FY92 thru FY94)}

\begin{tabular}{l|l|}
$\begin{array}{l}\text { Implementation Plan } \\
\text { Solicitation Release } \\
\text { Contract Award }\end{array}$ & Mar.94 \\
\hline Sep.94 & Dec.94 \\
\hline
\end{tabular}


ANL Site Response for the DOE FY1994 Information Resources Management Long Range Plan E. Acquisitions

\section{Justification for ANI_94-1, Data Acquisition Facility for Advanced Photon Source}

Argonne has been designated as the site for a new Advanced Photon Source (APS) which began construction in FY 1990. This is a major facility which will support 16 beam lines initially and be expandable to at least 70 beani lines. Intensities will be six orders of magnitude higher than that of IPNS. A data analysis and experimental support facility which would meet the needs of the initial users of the facility is proposed as part of this project. The proposed facility would include a cluster of two type P RCU computers employing the Unix operating system with at least eight gigabytes of disk storage and several workstations. An extensive data communication facility based on FDDI and extending to the user experimental areas will be included. We expect the computer facility to expand as the number and needs of the APS users increase. The APS facility will be linked to the Argonne central computers to provide access to special graphics and higher performance computers. Building of the facility is also expected to stimulate theoretical work in support of the measurements made at the facility. Much of this theoretical work would be carried out by using the ANL centralized computers or at the ER supercomputer facility via ESnet.

The APS equipment will be purchased so that delivery would occur before the start of the experimental program. The procurement activity will be initiated in FY1994. The total cost of the hardw'are is expected to be $\$ 1.9$ million with another $\$ 400,000$ for software. 
ANL Site Response for the DOE FY 1994 Information Resources Management Long Range Plan March 25, 1992

E. Acquisitions

\section{Summary of Major Planned Acquisitions/Lease Continuations}

\section{Sunirnary of Malor Planned Acquisitlons/Lease Continuations \\ (Dollars in Thousands) \\ Site: Argonne National Laboratory-ANL}

Schedule 3E-2

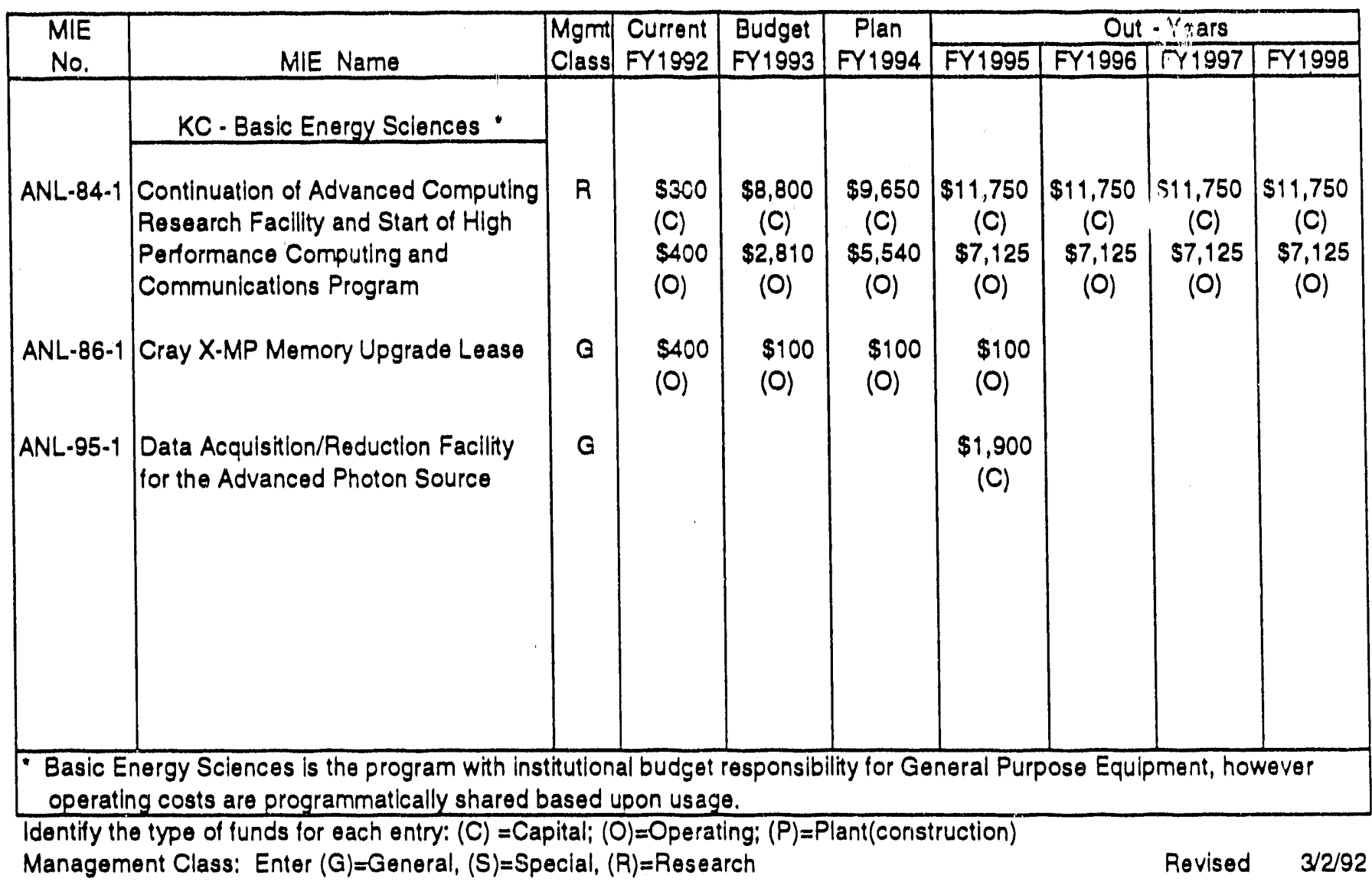


ANL Site Response for the DOE FY 1994 Information Resources Management Long Range Plan E. Acquisitions

Marrh 25, 1992

3. Financial Alternative Analyses

None 
ANL Site Response for the DOE FY 1994 Information Resources Management Long Range Plan

F. Reutilization Opportunities/Obsolete System Retirement

Marclı 25, 1992

\section{Section F}

Reutilization Opportunities/Obsolete System Retirement

Schedule 6.1: Schedule 3F-1 ADPE System Reutilization Opportunities

None. 
ANL Site Response for the DOE FY 1994 Information Resources Management Long Range Plan G. Examples of Programmatic Uses

\section{Section G}

\section{Examples of Programmatic Uses}

During FY1991 and FY1992, the Computing and Telecommunications Division published and distributed several documents that provide excellent examples of advanced computational science and engineering applications by Argonne National Laboratory researchers and collaborators. Three such documents are:

- $\quad$ Computational Science and Engineering at Argonne National Laboratory (an Argonne brochure)

- Illinois: Gateway to Advanced Computing and Communications (an Illinois Coalition brochure)

- Argonne National Laboratory Study of the Transfer of Federal Computational Technology to Manufacturing Industry in the State of Michigan

(ANL/TM 498)

Coples of these documents can be obtained at the Document Distribution Counter (Building 221, Room A-134), or through the mail (by calling extension 2-5405 and requesting a copy). 


\section{Section $\mathrm{H}$}

\section{ADP Budget Schedules}

Exhibit 8.1 Identifies budgeted costs of major computer requirements and other ADP requirements for general management computers and ADP operating costs associated with general management computers. Representatives from each of the program areas of the Laboratory, the Chlef Financial Offlcer, and the Chlef Operations Officer provided the computing requirements, acquisitions, budget costs, and narrative information for all of the programs and organizations of the Laboratory. The information necessary to complete this Site Response was obtained at the individual program level or lower in some cases (four digit bu at and reporting code), and then submitted to CTD for aggregation at the level of detail required by DOE.

Exhibit 8.1: ADP Operating Costs General Management Computers

\section{General Management Computing Operating Costs}

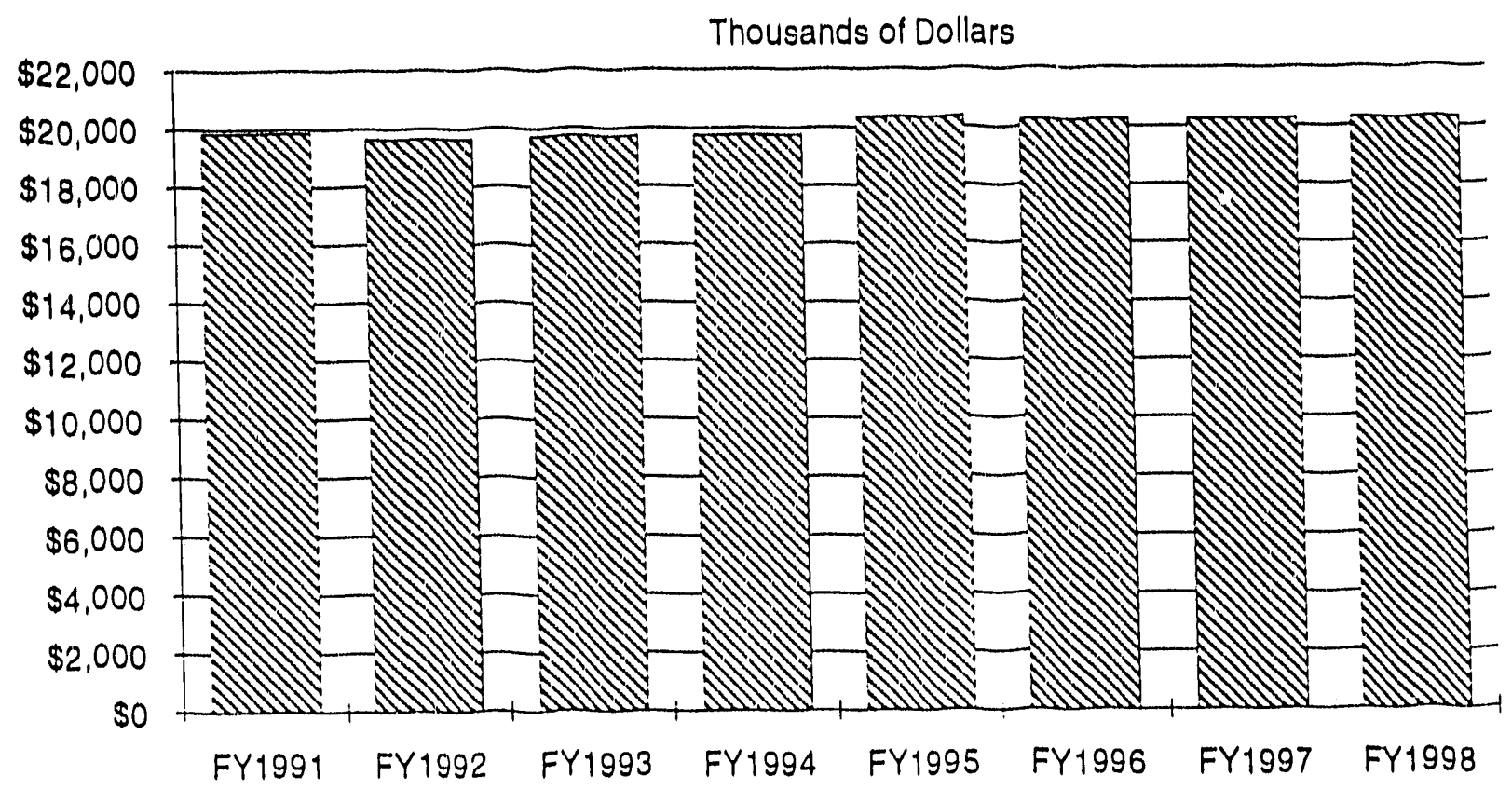


ANL Site Response for the DOE FY 1994 Information Resources Management Long Range Plan March 25, 1992

H. ADP Budget Schedules

Summary Major Computing Resource Acqulsitlons and Other Capltal Requirements Site: Argonne Natlonal Laboratory. ANL for General Management Computers

Schedule $3 H \cdot 1$

(Dollars in Thousands)

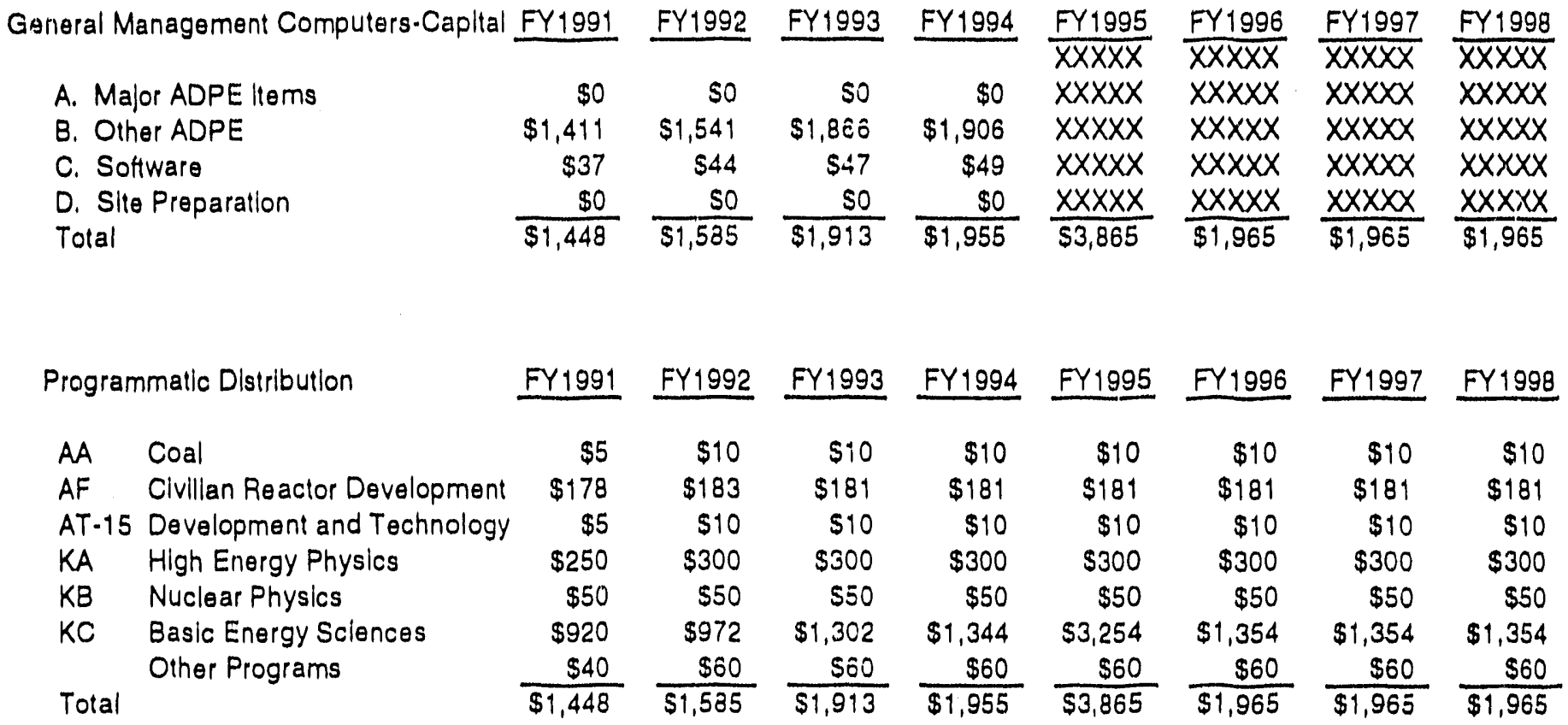


ANL Slte Response for the DOE FY 1994 Information Resources Management Long Range Plan H. ADP Budget Schedules March 25, 1992

Operalling Costs Assoclated with General Management Computers

(Dollars in Thousands)

Schedule $3 \mathrm{H}-2$

Page 1 of 2

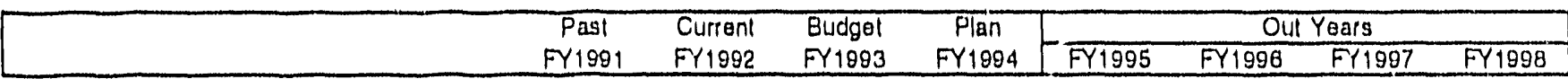

1. Operatirkg Cosls

\begin{tabular}{|c|c|c|c|c|c|}
\hline A. In-House Porsonnel & & & & & 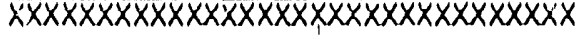 \\
\hline 1. Sottware & $\$ 5,189$ & $\$ \theta, 115$ & $\$ 6,430$ & $\$ 6,435$ & 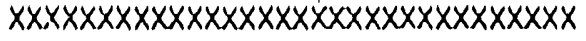 \\
\hline 2. ADPE Operations & $\$ 2,032$ & $\$ 2,338$ & $\$ 2,388$ & $\$ 2,392$ & 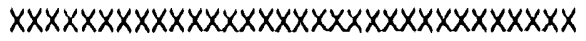 \\
\hline 3. ADPE Mainlenanoe & \$o77 & $\$ 707$ & $\$ 728$ & $\$ 730$ & 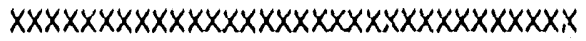 \\
\hline 4. ADPE Studles and Other & $\$ 1,155$ & $\$ 1,318$ & $\$ 1,339$ & $\$ 1,339$ & 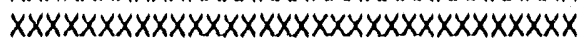 \\
\hline 5. Soltware Studles and Other & S993 & $\$ 1,163$ & $\$ 1,180$ & $\$ 1,181$ & 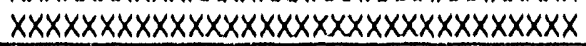 \\
\hline ublotal In House Personnel & $\$ 10,046$ & $\$ 11,641$ & $\$ 12.065$ & $\$ 12,077$ & 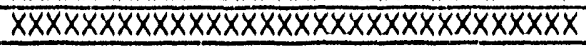 \\
\hline
\end{tabular}

\begin{tabular}{|c|c|c|c|c|c|}
\hline Other In. House & & & & & 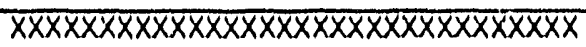 \\
\hline 1. ADPE Purchasos & $\$ 1,184$ & $\$ 914$ & $\$ 931$ & $\$ 951$ & $x \times x \times x \times x \times x \times x \times x \times x \times x \times x \times x x x \times x \times x \times x \times x \times x \times x \times x \times x \times x$ \\
\hline 2. Major ADPE Leases & $\$ 1,734$ & $\$ 300$ & \$o & \$o & $x \times x \times x \times x \times x \times x \times x \times x \times x \times x \times x \times x \times x \times x \times x \times x \times x \times x$ \\
\hline 3. Othor ADPE Leases & $\$ 16$ & $\$ 195$ & $\$ 127$ & $\$ 127$ & 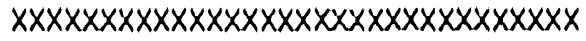 \\
\hline 4. Space & $\$ 1,084$ & $\$ 1,107$ & $\$ 1,132$ & $\$ 1,134$ & 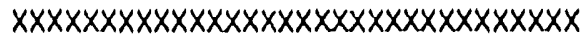 \\
\hline 5. Supplies and Other & $\$ 2.520$ & $\$ 2,212$ & $\$ 2,224$ & $\$ 2,225$ & 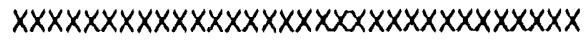 \\
\hline 5. Soltware Purchases & $\$ 052$ & $\$ 629$ & $\$ 631$ & $\$ 636$ & $x \times x \times x \times x \times x \times x \times x \times x \times x \times x \times x \times x \times x \times x x \times x \times x \times x \times x \times x x$ \\
\hline 6. Soltware Studles and Other & 5422 & $\$ 480$ & $\$ 480$ & $\$ 480$ & $x \times x \times x \times x \times x \times x \times x \times x \times x \times x \times x x \times x \times x \times x \times x \times x \times x \times x \times x x$ \\
\hline Subtolal Other In.House & $\$ 7.612$ & $\$ 5,837$ & $\$ 5,525$ & $\$ 5,553$ & 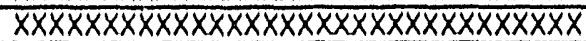 \\
\hline
\end{tabular}

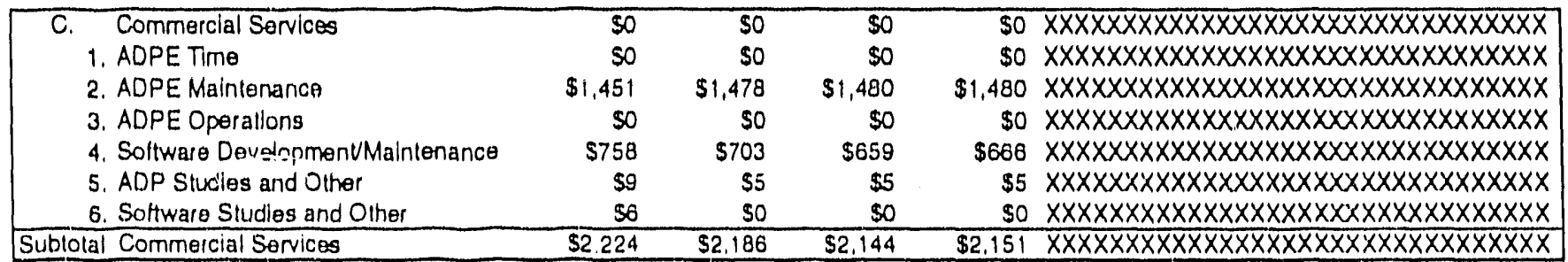

\begin{tabular}{|c|c|c|c|c|}
\hline D. Nonkommercial Senvices & \$o & \$o & \$o & 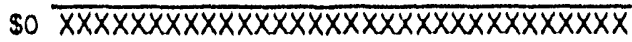 \\
\hline 1. Other DOE Siles & so & so & $\$ 0$ & 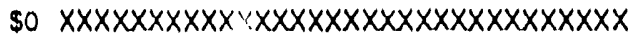 \\
\hline 2. Other Executive Branch Agencies & so & so & \$o & 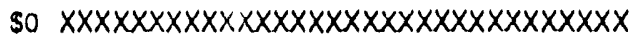 \\
\hline 3. Other & so & \$o & $\$ 0$ & 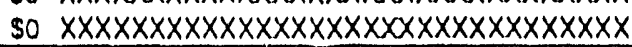 \\
\hline Subtolal Noncommercial Services & so & so & $\$ 0$ & 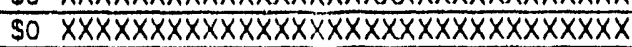 \\
\hline
\end{tabular}

\begin{tabular}{|c|c|c|c|c|c|c|c|}
\hline Tolal of $A, B, C$, and $D$ & $\$ 19,882$ & $\$ 19,664$ & $\$ 19,734$ & $\$ 19,781$ & $\$ 20,367$ & $\$ 20,266$ & $\$ 20.275$ \\
\hline
\end{tabular}


ANL Site Response for the DOE FY1994 Information Resources Management Long Range Plan March 25, 1992

H. ADP Budget Schedules

Slle: Argonne Natlonal Laboralory. ANL

Oparating Custs Assoolated with Genural Management Computors

(Dollars In Thousands)

Schodulo 3H.2

Pago 2 of 2

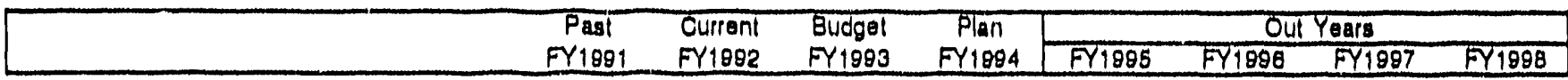

II. Work Years (Not Required of Thls Sile)

$x \times x \times x \times x \times x \times x \times x \times x \times x \times x \times x \times x \times x \times x \times x \times x \times x x$

$x \times x \times x \times x \times 1 \times x \times x \times x \times x \times x \times x \times x \times x \times x \times x \times x \times x \times x \times x$

$x \times x \times x \times x \times x \times x \times x \times x \times x \times x \times x \times x \times x \times x \times x \times x \times x$

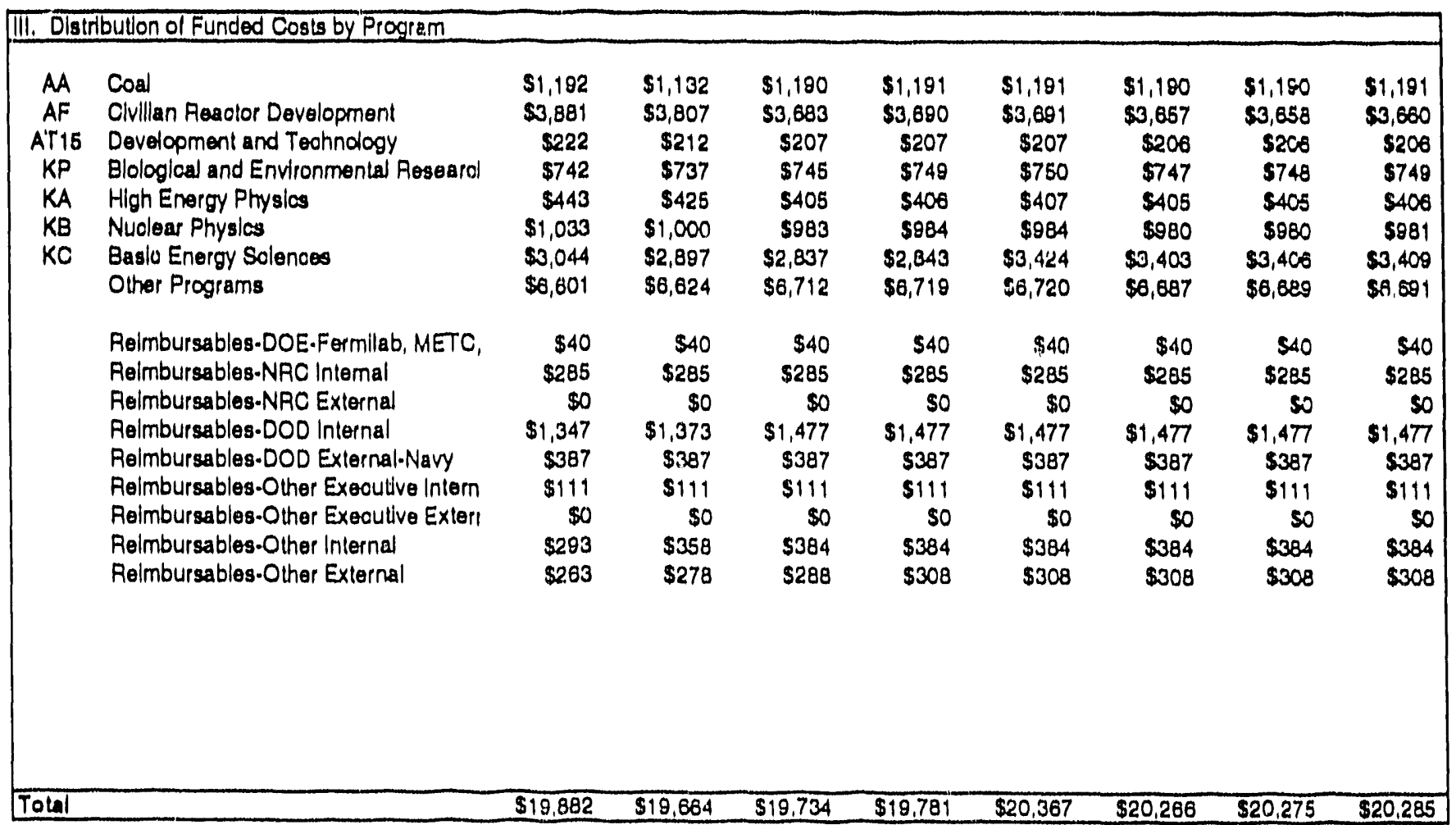


ANL Site Response for the DOE FY 1994 Information Resources Management Long Range Plan I. Not Appllcable

\section{Section I}

Not Applicable

Section I is not applicable to Argonne National Laboratory.

ANL-3,9.1 


\section{Section J}

\section{Reconcillation}

The most significant aspect of this Site Response and prior submissions are the changes in the working environment of the individual scientist/engineer/researcher. More and more organizations are adopting or implementing distributed local area networks of scientific workstations. More often than not they are attached to site-wide networks and generally add significant new computing capability for the site as a whole. The work performed on these distributed systems is predominantly work that was previously performed on distributed minicomputers or central mainframe computers. Additionally, new types of work are performed on these systems which in the past was done by hand or was not done at all.

The current basis for quantifying requirements and capacity, the relative capacity unit (RCU), is no longer a comprehensive measurement. The changing and new computing and network technologies including powerful distributed scientific workstations, parallel processing, and mini-supercomputers have added significant new capabilities and capacities that can no longer be accurately depicted by the relative capacity unit. Therefore, it is likely that the requirements and capacity of ANL and all sites are understated. Each year the introduction and implementation of new technologies further erode the value of the relative capacity unit and the ability to measure the total capacity and requirements of any particular site.

ANL-3.10.1 
ANL Site Response for the DOE FY1994 Information Resources Management Long Range Plan Part 4:

\section{Part 4}

Telecommunications Plan 
ANL Site Response for the DOE FY1994 Information Resources Management Long Range Plan

\section{Section A}

Telecommunications

\section{A. Strategies and Major Accomplishments}

\section{Strategy}

The digital integrated voice/data telephone system at Argonne National Laboratory forms an exceptional communications environment to facilitate Laboratory programs as well as administrative and support operations. Ancillary systems are in place to serve emergency operations.

The Laboratory strategy for improving services and controlling costs includes taking advantage of PBX hardware and software updates, adjusting trunking levels, reconfiguring FX services, taking advantage of long distance carrier discount packages, expanding voice processing applications, and improving disaster recovery posture through alternate routing and continuing disaster recovery planning.

PBX services for increasing site population and new construction projects will be accommodated through modular PBX expansion.

The Laboratory plans to expand the existing prototype Fiber Distributed Data Interface (FDDI) fiber optic network to all major buildings on the site. FDDI has become a standard for high speed (100 megabits per second) fiber optic networks. The fiber optic network will also include fibers for video application and future gigabit per second data networking.

Argonne is pursuing becoming a member of the 622 megabits per second BLANCA testbed facility which runs through the Chicago area. The BLANCA testbed will support research in distributed applications over a wide-area, high-speed network. It is proposed that linking Argonne to the BLANCA gigabit testbed will allow the demonstration of specific nuclear power applications on distributed high performance computers accessible to Argonne and researchers at the National Center for Supercomputing Applications (NCSA). The demonstration studies envisioned involve code packages from the nuclear industry with potential teraflop requirements that may eventually require the combined resources of computers distributed across the country. Specific examples of these code packages include Monte Carlo-based fuel depletion analysis codes targeted for massively parallel machines and real time accident monitoring codes which now run on the current generation of vector supercomputers.

\section{Major Accomplishments}

Laboratory PBX telephone service was expanded to a nearby offsite leased building. This required installation of $21 / 2$ miles of fiber and copper cables to a remote PBX node to serve $4(x)$ telephones and provide data communications.

An Octel Maxum voice processing system was installed in 1991 and serves over 1200 voice mailbox subscribers. Special applications have already improved efficiency and productivity of service organizations. 
ANL Site Response for the DOE FY 1994 Information Resources Management Long Range Plan March 25, 1992

A. Telecommunications

The National Science Foundation installed a major National Science Foundation network (NSFnet) switching node at Argonne. The switching node is connected to the NSFnet backbone at 45 megabits per second transmission speed. The node serves as a major hub for Chicago area and Midwest region universities.

\section{B. Feconciliation to FY1992 Plan}

None.

\section{Currently Utilized Services/Planned Minor Enhancements}

An InteCom IBX S-80 digital DBX serves the Illinols site of Argonne National Laboratory. The PBX cutover was on Septemt 19, 1987. The lease-to-purchase contract extends to September, 1997. The PBX supports standard analog telephones, InteCom manufactured digital stations for voice, data, or simultaneous volce and data service, and LANmark local area networking. Nearly 27 percent of all PBX ports are used for digital data communications or a combination of digital data and voice.

The Telephone System consists of a main PBX node and seven distributed nodes connected to the main node by fiber optic cables. Each node serves a building or group of buildings via a copper wire and cable plant. In addition to switched PBX services, the PBX wire and cable plant provides point to point copper circuits for onsite data communications, alarm systems, control systems and audio systems. The wire and cable plant also provides for extending external private lines and miscellaneous services from the Illinois Bell interface to onsite user locations. A buried conduit system facilitates installations of new cables to all major buildings.

Approximately 6800 telephones serve the three major organizations on the Argonne site: Argonne National Laboratory, DOE Chicago Operations Office, and the New Brunswick Laboratory. Four Argonne employed operators staff the three attendant consoles in the ANL Comcenter, 17 hours per day, five days per week.

An Octel Maxum voice processing system serves over 1200 mailbox subscribers. Laboratory organizations are using special voice processing applications to improve efficiency and productivity.

A No. 1 ESS switch in the Illinois Bell central office located one mile west of the site provides Direct In Dial and Direct Out Dial commercial service with 90 DID and 53 DOD trunks. Local metropolitan area calling is provided through $18 \mathrm{FX}$ lines into Chicago, four FX lines to Summit, seven FX lines to Joliet, five FX lines to Bensenville, and nine FX lines to Warrenville. There are also six tie lines connecting Argonne to Fermilab on a microwave link primarily used for data communications. Connection to FTS 2000 consists of 36 trunks in two land-based T1s. ANL has four interstate 800 Service lines to be used in lieu of collect and credit card calls relative to matters of employment, employee benefits, and official travel. One interstate and four intrastate 800 service lines are used to provide information on hazardous materials to state and local emergency organizations. MCI provides direct access long distance service via $\mathrm{Tl}$ microwave from the Laboratory to the MCI office in Downers Grove, Illinois. MCI overflow calls are provided by AT\&T via equal access. The MCI microwave link has a capacity of three DS3s and provides both voice and data service. Exinibit 1.1 depicts the current voice network serving the Laboratory. 
ANL Site Response for the DOE FY 1994 Information Resources Management Long Range Plan

Exhibit 1.1: ANL Voice Network

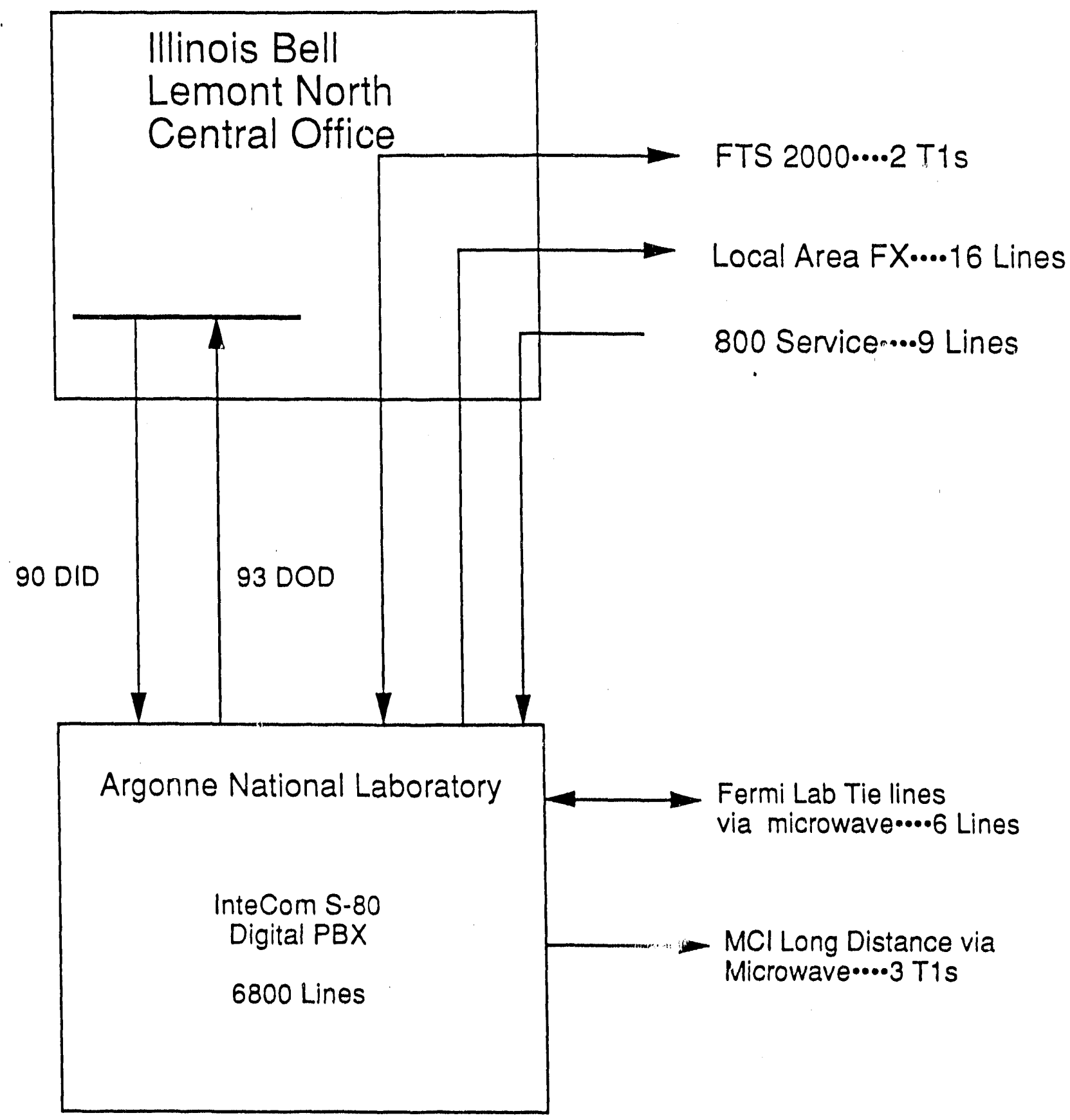


ANL Site Response for the DOE FY1994 Information Resources Management Long Range Plan March 25, 1992

Bell Atlanticom, the vendor who installed the PBX, and Argonne personnel perform all of the physical moves, changes, and installations. The maintenance contract with Bell Atlanticom is renewed on an annual basis.

Laboratory Telephone Service personnel perform administrative moves and changes via data terminals linked to the PBX.

Five mobile cellular telephones and forty transportable cellular telephone units are in operation and use commercial radio frequencies and services. In addition to normal use, all units are available for providing enhanced communications capabilities for emergency operations.

Thirteen non-P $\mathrm{BX}$ business lines served from an offsite telephone exchange provide backup in the event of PBX switch failure. Other emergency cornmunications include a separate forty-station Laboratory-owned dial intercom and conferencing system and a sitewide public address system.

Argonne computer users have access to an extensive variety of communication capabilities, including both onsite and remote access to local, Laboratory-wide, national, and international networks. These c/pabilities involve a wide range of telecommunications technologles, from simple point-topoint data communications Hnks to sophisticated networks with complex software and hardware configurations (e.g., network bridges, gateways, routers, and servers).

Argonne networks include the Transmission Control Protocol/Internet Protocol (TCP/IP), the Digital Equipment Corporation DECnet protocol, Appletalk, and the Xerox Network Systems protocols. Network software and hardware allow users to transfer flles, gain interactive access, send electronic mail, and run application programs on computing systems connected to networks.

Argonne's network topology consists of a hierarchy of networks, including local area networks based on Ethernet encompassing buildings or programs, a Laboratory-wide network based on an Ethernet-compatible capability (LANmark) and on the Fiber Distributed Data Interface (FDDI) token ring network, and gateways to major national and international networks (ESnet, NSFnet, CICnet and BITnet).

Argonne has identified FDDI, a widely accepted standard for high-speed (100 megabits per second) fiber optic networks, as an important networking technology. Argonne has used Support Development Funds for investigating FDDI and has created a plan for installing it at the Laboratory. In February 1990, Argonne installed a prototype FDDI network across the Laboratory. This installation was the culmination of an extensive effort to investigate FDDI and its applicability to the Argonne computing environment. Argonne believes that increased use of FDDI is needed to better accommodate applications such as high-speed host-to-host file transfer, distributed network file systems, scientific visualization, and distributed processing that require faster network transmission speeds than is commonly avallable today.

General Purpose Equipment funds have been used to connect the Cray X-MP/18 to the FDDI network and to connect tile Laboratory-wide Ethernet network to the FDDI network. The equipment installed consisted of an FDDI/Cray Low-Speed Channel router and an FDDI/Ethernet Multiprotocol router. In addition, a SUN 4/490 server and a Silicon Graphics Inc. workstation have been connected to the FDDI network. The VAX 6410 cluster in CTD is expected to be connected in early 1992. CTD has submitted a General Physical Plan Proposal (GPP) to expand this fiber optic cable network throughout most of the Argonne East site. 
ANL Site Response for the DOE FY1994 Information Resources Management Long Range Plan A. Telecommunications

In July 1991, the National Science Foundation completed installation of a major National Science Foundation network (NSFnet) switching node at Argonne. This switching node is connected to the NSFnet backbone at 45 megabits per second transmission speed. The NSFnet node has now been connected to the Laboratory FDDI prototype network. The NSFnet node at Argonne also serves as a major hub for Chicago area universities and universities in the Midwest region.

In October 1991, CTD reorganized its support of Laboratory computer networks: connections to external networks, Laboratory-wide LANmark and Fiber Distributed Data Interface Networks, and the Central Computing facility networks. CTD formed a Network Operations Center (NOC) to ensure the reliability of ANL Laboratory-wide and local area networks and to provide early notification and timely responses for network failures. The NOC is using automated network monitoring tools for TCP/IP, DECnet and SNMP agents to keep the current status of network components. A manual trouble ticket system was implemented to be replaced with an automated system in the future for tracking network problem resolution.

Argonne provides users of data processing equipment with a variety of data communications facilities to supply the means for remote access to data processing resources. These data communications capabilities accommodate user access to onsite and offsite computing networks: local area networks located on the ANL site, e.g., Argonne Integrated Heterogeneous Flle Transfer Network, ANL DECnet Networks, PC Networks, etc. and wide area networks located throughout the world, e.g., Bitnet, ESnet, HEPnet, NSFnet etc. (see Exhibit 1.2 ).

Data--The Laboratory installed a new PBX-Based Digital Telecommunications System (DTS), which was cut over on September 19, 1987. The system provides simultaneous voice/data capabilities. Users can select station equipment that provides them with switched asynchronous data service to $19.2 \mathrm{kbps}$ and switched synchronous data service to $56 \mathrm{kbps}$ from any standard telephone jack at the Laboratory. A major data strategy is thus to provide Laboratory-wide terminal computer connectivity at high speeds.

The DTS also provides a Laboratory-wide Local Area Network capability (LANmark). Users can select station equipment that provides gateways between industry standard Ethernet devices and the DTS's internal packet switched network. A major local network strategy is to provide a Laboratory-wide Ethernet which allows simultaneous connectivity to hosts running a variety of network protocols: DECnet, TCP/IP, XNS, LAT, NI Fiuster, NSP-IP, etc. Local Ethernet coaxial cables interconnect computers within a division, program, or building and are, in turn, interconnected into a Laboratory-wide network through gateways to LANmark. Fifty-eight LANmark devices are currently in use on the Laboratory-wide Ethernet.

In January 1989, CTD installed a new digital microwave system between Argonne National Laboratory and Fermi National Accelerator Laboratory (FNAL). CTD installed International Microwave Corporation modern digital equipment that uses the existing parabolic antennae and passive reflectors and operates on the same frequencies allocated to the old Motorola microwave. The new microwave system has the capacity to allow four T1 (1.544 megabits per second) channels and is used to support a variety of data services. 


\section{Eribit 1.2: ANL External Networks}

\section{ARGONNE NATIONAL LABORATORY EXTERNAL NETWORKS}

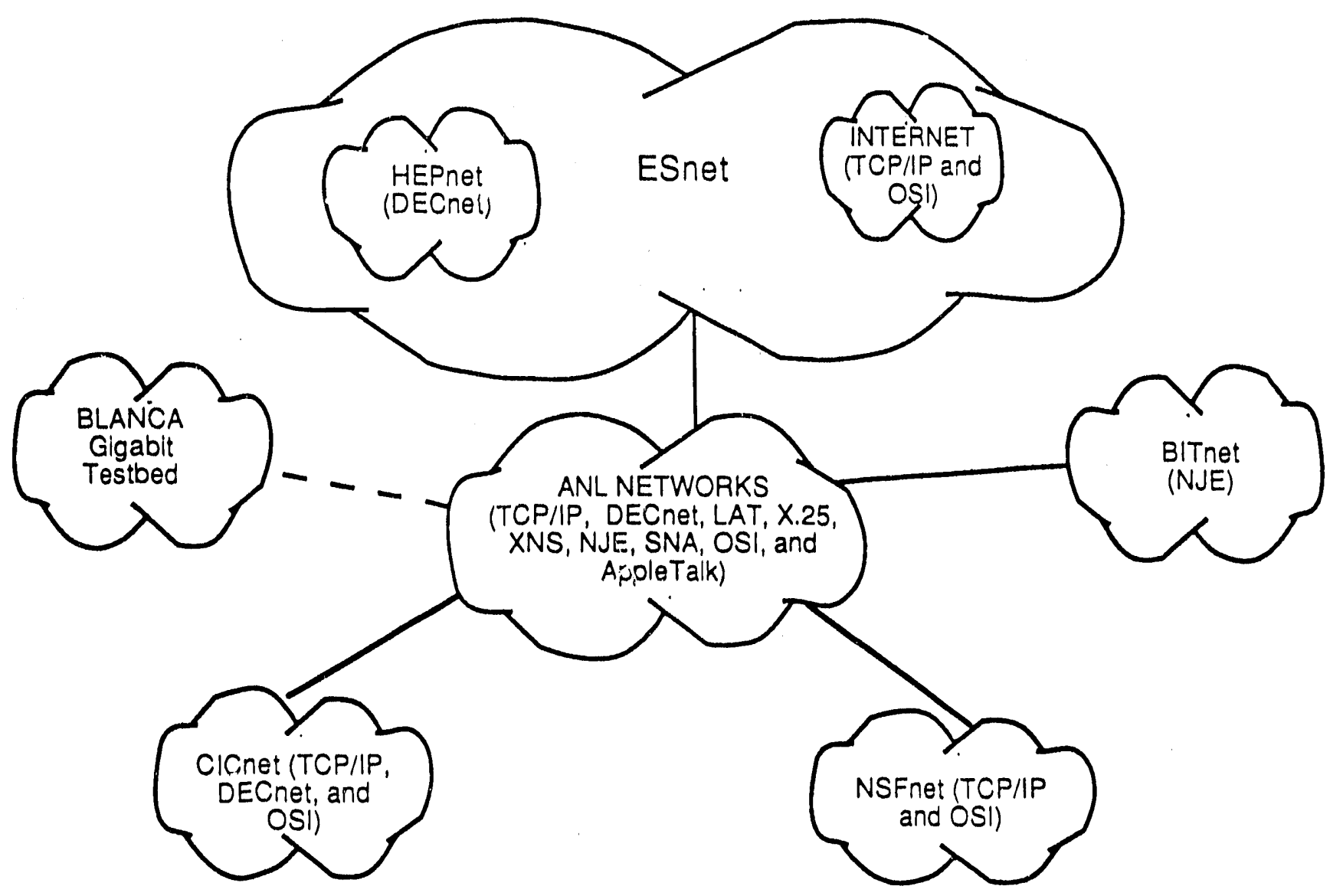


Argonne File Transfer Network--The IBM host computers operated by the Computing and Telecommunications Division are loosely coupled by telecommunication links, channel-to-channel adaptors, and virtual channel-to-channel adaptors, all of which use a standard IBM protocol, Network Job Entry (NJE). This protocol allows the transfer of files, jobs, and messages among connected systems. The network connects to offsite locations at the Fermi National Accelerator Laboratory, the University of Chicago, the University of Illinois at Chicago (UIC), Northern Illinois University, and the Morgantown Energy Research and Development Center. Several years ago Argonne developed software to run in a VMS operating system on a VAX computer. The VAX computers connect to the central IBM host computers by 9600 to $, 56,000$ bits per second telecommunication links in a star configuration.

BITnet--The IBM and VAX computers that compose the Argonne File Transfer Network are connected to a nationwide university computer network called BITnet. As of December 1990, over 3273 academic and research systems are currently on BITnet. BITnet uses the same store-andforward protocol as the networking for the Argonne File Transfer Network. This connection allows enhanced collaborative efforts between Argonne scientists and scientists at universities on Bitnet. BITnet allows users to share programs and data with other BITnet users and to communicate with them through electronic mail. Argonne connects to BITnet through a 9600 baud binary synchronous communication link to the University of Illinois at Chicago. The University of Chicago and Northern Illinois University gain access to BITnet through the Argonne node.

IRM Systems Network Architecture--Systems Network Architecture (SNA) is a networking architecture developed by IBM. Most of the new communications products that IBM and other vendors are announcing are compatible with SNA, and many may run only in an SNA environment. SNA has been put into the production system for the MVS and VM systems. An IBM 3745 communication controller allows remote cluster controllers to connect to the central IBM systems at 56 kilo bits per second. Some of the advantages of SNA to Argonne are:

- Direct system select for IBM 3270 users.

- Improved system availability.

- Provision for a multitude of communication devices.

- Sharing of communication lines by devices of different types.

Idaho Telecommunication Links--There are currently two $14.4 \mathrm{~K}$ bps communication links between ANL-W (Idaho) and ANL-E. These links use multiplexors to provide for a variety of functions as follows:

- Nineteen Hewlett-Packard terminals and two printers in Idaho are connected to the two Hewlett-Packard computer systems in the Administration Building (Building 201).

- Two IBM 3278 terminals are connected through a 3274 cluster controller to the IBM ho . in Building 221.

- Two HASP workstations in Idaho are connected to the IBM 3705 in Building 221.

- One virtual HASP workstation at ANL-E connects to a CDC CYBER computer at EG\&G in Idaho Falls. 
ANL Site Response for the DOE FY 1994 Information Resources Management Long Range Plan March 25, 1992

A. Telecommunications

- One hundred sixty-five terminals in Idaho are connected to a Micom voice/data system that in turn connects to a 272 port Tellabs digital switch. Fifty four of the Tellabs ports are connected to computers and one hundred sixty-five are connected to terminals. The Tellabs switch connects to two $14.4 \mathrm{~K}$ bps modems over volce grade lines to ANL-E. At the ANL-E end, a similar Tellabs switch allows the ANL-W user to select among:

- Dynapac X.25 connected to the IBM hosts

- Tellabs X.25 connected to the IBM hosts

- Two NBI OASys 64 word processor systems

- DEC MicroVAX-II in Building 208

ESnet--The DOE Office of Euergy Research (OER) under the management of the OER Scientific Computing staff has initiated a new effort in data communications networking designated the Energy Sciences network (ESnet). The ESnet concept is intended to bring together the various data communication efforts of the different research programs funded by OER into a single network that would use protocols being developed by the International Standards Organization for Open Systems Interconnect. A phased implementation of ESnet is now underway. ESnet supports dual protocols using Cisco routers: TCP/IP with gateways planned to connect to the Internet and DECnet for the HEPnet backbone. A T1 backbone is installed connecting major nodes. ANL is currently connected to ESnet with a T1 connection to Fermi National Accelerator Laboratory, Princeton Plasma Physics Laboratory, Iowa State University, and Oak Ridge National Laboratory.

Asynchronous Support--Dial-up and dedicated lines connected to the central IBM computing facility through IBM 3705 communication controllers are the means of access for asynchronous telecommunications to the interactive systems: CMS, Wylbur, and TSO. Dial-up lines are available at speeds of 300 to 19,200 bps. We provide dial-up lines for both onsite and offsite users in pools through the Private Branch Exchange (PBX). Onsite users with electronic telephone stations have access to the IBM computing facilities at speeds from 300 to 19,200 bps through Asynchronous Data Interfaces (ADI) on the PBX.

X.25 Concentrators--In addition to the asynchronous lines mentioned above, both offsite and onsite users may access the interactive systems from ASCII compatible terminals connected to X.25 concentrators. These concentrators allow terminals to be connected at speeds up to 19,200 bps. The traffic from these terminals is then multiplexed by the concentrators onto 9,600 or 56,000 baud lines (with the X.25 protocol), which are connected to the central computing complex.

3270 Terminal Accommodation--The interactive systems running under CICS, as well as the interactive systems CMS, Wylbur, and TSO, are accessible from IBM 3270-compatible full screen displays. While some of the displays in Computing and Telecommunications are directly connectis via coaxial cable to channel-connected controllers, the majority are connected via coaxial cables to remote IBM 3274 cluster controllers. These remote cluster controllers are connected via dedicated $56 \mathrm{~K}$ bps communication lines to the central computing complex. A high performance 3745 communication controller has been purchased and is installed to support 3274 cluster controller links at 56K bps. This controller will supply the premier data path to the central IBM facilities. The cluster controllers thus act as concentrators and allow (depending on the model) up to 32 displays to be connected. The controllers provide error checking and retransmission, flow control, and some local processing, all of which reduce the overall traffic between the controller and the host computers. 
A 3174 Subsystem control unit is connected to the byte multiplexor channel on the central IBM 3084 VM machine. The 3174 supports up to 32 simultaneous IBM 3270 full screen terminals or IBM 3186 printers. The 3174 is connected to IBM's systems network architecture (SNA) Telecommunications program allowing access to the interactive systems running on the central IBM complex, including CICS, Wylbur, CMS and TSO. The 3174 ports are dedicated to a data interface unit (DIU-7) that connects to the PBX. The ports on the 3174 are accessed through the PBX on a contention basis, allowing these resources to be shared. Users of 3278 full screen terminals can connect directly to the PBX through an LDI700. The LDI700s connect the IBM 3278 terminals to the PBX, thus providing them with full screen support through the IBM 3174.

Hydra II Protocol Converter--The Hydra II protocol convarter supports up to 62 asynchronous terminal connections into the IBM 3084 VM machine doing 3270 full screen emulation. A Hydra II protocol converter is connected to the byte multiplexor channel on the central IBM 3084 VM machine. The Hydra II is connected to IBM's Systems Network Architecture (SNA) Telecommunications program allowing access to the interactive systems running on the central IBM complex including CICS, Wylbur, CMS and TSO.

The Hydra II asynchronous ports are dedicated to asynchronous data interface devices (ADIs) that connect to the PBX. The Hydra II asynchronous ports are accessed through the PBX on a contention basis, allowing these resources to be shared. The Hydra II asynchronous ports are capable of auto bauding through the PBX, allowing terminal access to 19,200 bits per second. Argonne plans to purchase an additional Hydra II to provide additional ports and backup.

Central Onsite Distributed Print Queues--The Central VAX Cluster Computers and the Central IBM Computer provide onsite distributed print queues for remote printers--high speed line printers, laser writers, etc.

Remote Access Data System (RADS) - The RADS system is an onsite, remote batch system designed at ANL. The system emulates the standard IBM HASP Workstation protocol operating on binary synchronous telecommunication lines. The system provides users with workstations that support line printers, perforated paper tape punches and readers, card reader input, and PostScript laser printers. The stations are configured around TI 990/101M microcomputers. They communicate at speeds ranging from 4800 to 56,000 bits per second (bps) and connect to the central computing complex host computers through IBM 3705 and 3745 communication controllers.

Other Binary Synchronous Support--Binary synchronous dial-up lines are avallable at speeds that range from $2 \mathrm{kbps}$ to $56 \mathrm{kbps}$ for both onsite and offsite stations. Dedicated binary synchronous lines are available at speeds up to $56,000 \mathrm{bps}$. These lines provide services for equipment which uses the HASP Workstation, 3780, 2780, and NJE protocols. These lines are connected to ports on the IBM 3705 and 3745 communication controllers which are connected to the central computing complex host computers.

VAX DECnet Network--The Laboratory's Divisional Digital Equipment Corporation (DEC) VAX and PDP-11 computers are connected in a single Laboratory-wide homogeneous DECnet computer network via the PBX I.ANmark Ethernet capability. DECnet is a networking protocol developed by the Digital Equipment Corporation. These computers use the VMS, RSX, and RT operating systems and interchange files and mail in an efficient manner. Terminal passthrough exists between systems. The VAX gateway computer in Bullding 221 is part of the network allowing the VAX DECnet nodes access to MFEnet. The divisional local area DECnets are all interconnected via the Laboratory-wide Ethernet. The VAX-11/75() at ANL-W is connected via a 9.6 kilobaud asynchronous connection through existing multiplexed hardware. 
All of the VAX computers are licensed to run DECnet, which is the protocol for use on the network. The full-function DECnet nodes handle all the message routing for their attached nodes, which are unaware of the network's topology. Nodes participating in the Laboratory-wide DECnet have to conform to node name conventions adopted by the Laboratory.

The Laboratory has purchased a site-wide Multinet license to run the TCP/IP protocol on VAX VMS computers. Many of the Laboratory's VAX systems are now running Multinet.

Several divisions at the Laboratory use DECnet to join their VAX, PDP-11, and LSI computers together in one network (see Exhibit 1.3). The High Energy Physics Division (HEP) connects their VAX computers together with a national DECnet network of computers (HEPnet) for High Energy Physics research purposes. The Physics Division gains access to HEPnet through HEP via the ANL PBX LANmark ethernet. The HEPnet network provides interactive, real-time access to the major high energy facilities located at HEP accelerator laboratories and collaborating universities throughout the USA for experiment monitoring and data analysis. Biological Environmental and Medical Research Division/Center For Environmental Research (BEM) connects their VAX to several computers, terminal servers, and a print server.

The Chemistry Division (CHM) has a VAX cluster consisting of seven MicroVAX computers. One MicroVAX computer serves as a front-end processor for 16 LSI 11/23s, and the other is a front-end processor for elght LSI 11/23s. The Chemical Technology Division (CMT) has a VAX which connects to two PDP $11 / 44$ computers, which function as front-end processors for an array of other DEC processors. We have integrated Ethernet into the VAX DECnet networks in the Advanced Photon Source Division (APS), the Chemical Technology Division, the Chemistry Division, the Intense Pulsed Neutron Source Program (IPNS), and the Physics Division. Ethernet is a local area network transmission medium developed by Xerox, Intel, and Digital Equipment Corporation that implements local area communications at data rates to $10 \mathrm{M}$ bits per second. 
ANL Site Response for the DOE FY1994 Information Resources Management Long Range Plan A. Telecommunications

Exhibit 1.3: ANL DECnet Network

\section{Argonne National Laboratory DECnet}

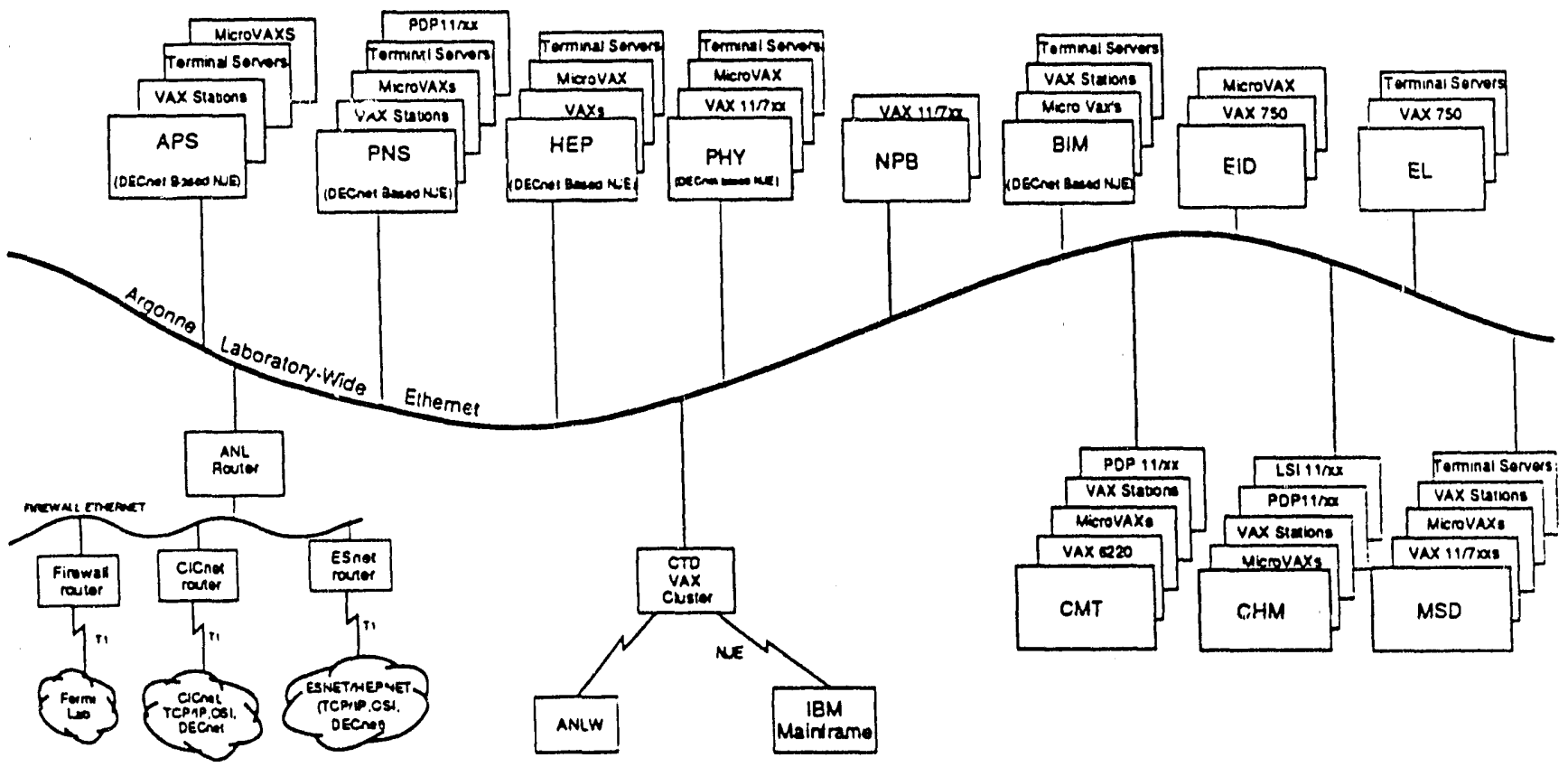


ANL Site Response for the DOE FY1994 Information Resources Management Long Range Plan March 25, 1992

A. Telecommunications

TCP/IP Networks--Argonne has a large and growing Laboratory-wide TCP/IP network (see Exhibit 1.4 ). Argonne has a registered domain, ANL.GOV, and runs primary and secondary name servers. The central IBM computers and VAX cluster computers all support TCP/IP access. Many divisions have scientific workstations connected to the network. The Mathematics and Computer Science Division's Advanced Computing Research Facility (ACRF), which contains a large parallel computer complex, is connected to the network. The network also supports IBM and Macintosh personal computers using the NCSA software.

The ANL TCP/IP network is connected to several external TCP/IP networks: ESnet (see above), and CICnet/NSFnet. CICnet is a regional network. A T1 link connects ANL to FNAL and ANL to UIC. ANL and FNAL are thus interconnected to CICnet through UIC. CICnet has two connections to the National Science Foundation Network, NSFnet; one at the University of Illinois-Urbana-Champaign (UIUC), and one at Michigan.

PC Local Area Networks--Personal Computers are an important tool of the scientist, engineer, and administrator at the Laboratory. IBM and Apple Maciniosh represent the major models. IBM PCs use TCP/IP (See TCP/IP Networks above) or DECnet (see above) to communicate with larger computers and local area networks to share disks, printers, and mail among themselves.

Apple Macintoshes are connected throughout the Laboratory either directly through an external connection or through a local talk to Ethernet gateways. Like IBM PCs, these machines use TCP/IP and I.AN protocols. Additionally, they use the Appletalk Protocol to share disks, printers and mail.

Other data comımunications systems and services are listed below.

Facsimile Service--Over three hundred facsimile terminals expedite the dissemination of information and programmatic coordination between the ANL main site and ANL-Idaho, other ANL offices, DOE, and contractors. All terminals utilize dial network services. Facsimile terminals are strategically located throughout the main site to provide convenient access for users.

Database and Literature Search--The Technical Library, the Environmental Assessment and Information Sciences Division, and the Office of International Energy Programs use Database and Literature Search, with access via the FTS 2000 and commercial switched networks (TELNET). The ANL technical libraries have twelve printer terminals dedicated to database and literature search. Regular FTS and commercial telephone billing includes the communication costs.

Wire Services--The Laboratory uses wire services such as TELEX and TWX. The onsite DOE-CH communications center operates the TELEX and TWX terminals. Costs shown in Schedule 4-1B include charges from DOE-CH for DOE-CH comcenter operations.

Site Alarm and Monitoring Systems--Site alarm and monitoring systems use the sitewide and cable plant for communications. These include the fire alarm system, the criticality alarm system, security systems, and plant monitor/ control systems. 
ANL Site Response for the DOE FY 1994 Information Resources Management Long Range Plan A. Telecommunications

Exhibit 1.4: ANL TCP/IP Network

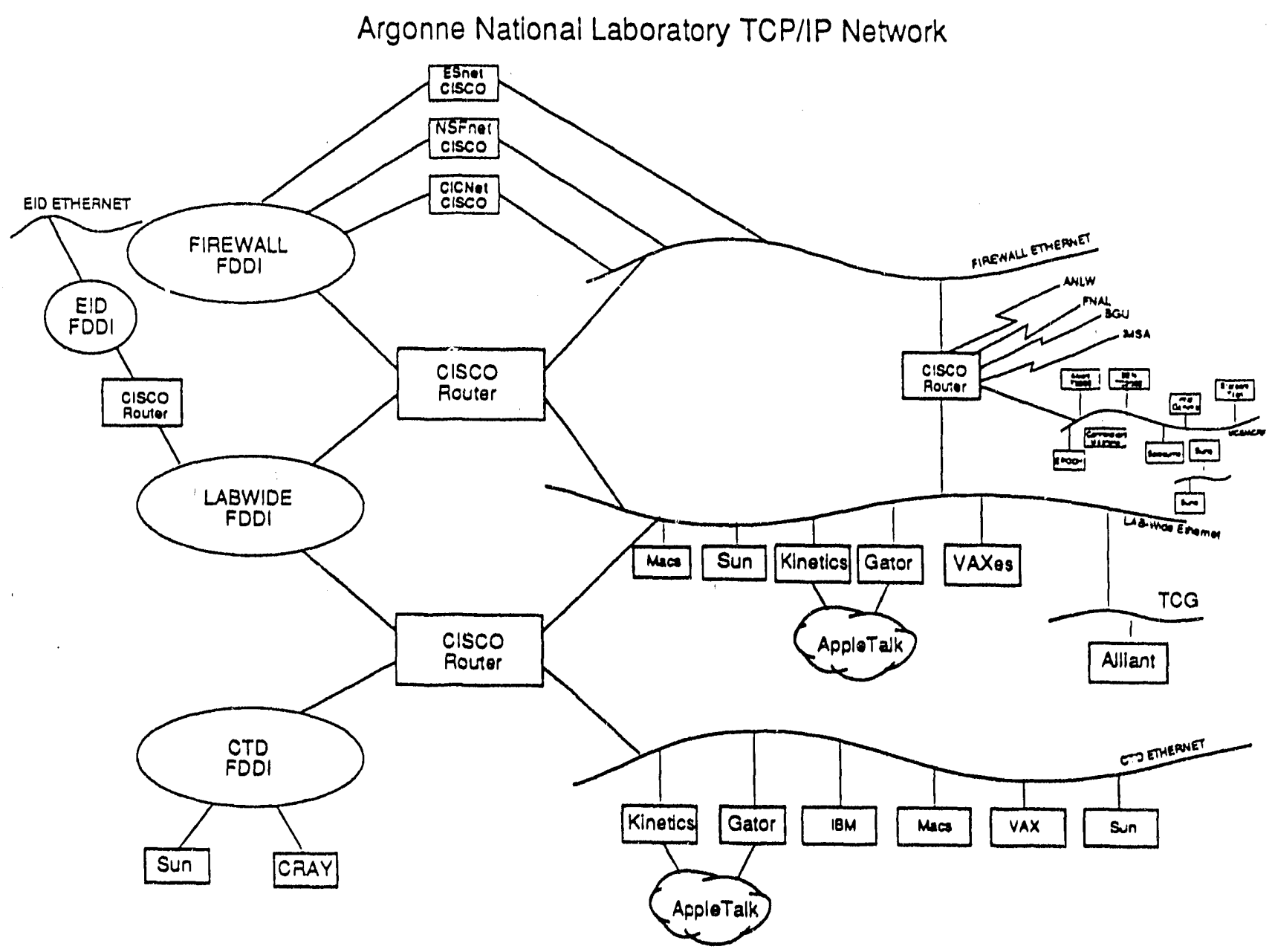


ANL Site Response for the DOE FY1994 Information Resources Management Long Range Plan March 25, 1992

A. Telecommunications

\section{Planned Minor Initiatives/New Systems or Services}

The trend is toward more scientific workstations on the worker's desk, higher speed parallel processors, and visualization tools (hardware and software), all of which require more interchange of information over networks at higher speeds. Thus the emphasis will be on higher speed connectivity, on local area networks, Laboratory-wide networks, and wide-area networks. In addition, emphasis will be placed on a transition to networks that conform to the Government Open Systems Interconnection Profile (GOSIP) standard.

Local Area and Laboratory-wide Networks--There will be a continued growth in Digital Equipment Corporation computers, Unix-based computers, workstations, parallel processors, and Macintosh and IBM personal computers. This will necessitate a growth in the number and size of local area networks as well as a need to interconnect these networks. In addition, a number of new technologies and standards are emerging. These technologies will be tracked and implemented as they become available. Argonne anticipates the following activities:

- Installấdion of additional IP routers.

- Administration of Laboratory-wide personal computer name space and installation of XNS routers.

- Replacing one of two ANL EastWest $14.2 \mathrm{kbps}$ data links with a 56kbps fractional T1 link.

- Migration to the new DECnet/OSI software.

- Migration to the new Open System Interconnection (OSI) protocols which are being developed and in particular to the GOSIP standards. ANL is participating on the DOE GOSIP Migration Working Group and is developing a GOSIP transition strategy. The migration to DECnet/OSI will be a part of that strategy.

- Migration from the Laboratory-wide Ethernet (1M bits per second speeds) to the emerging Fiber Distributed Data Interface (FDDI) technologies (100M bits per second). A FDDI network was installed in FY1990. FY1992 GPP funds are being requested to extend the ring to other ANL buildings.

- Installation and testing of 1 gigabit per second fiber optic local area networks for applications such as visualization (graphics) that require very high speed data transfer.

External Networks--As existing national network communication backbones are upgraded and new ones are added, Argonne will upgrade and add new gateways between these external networks and the ANL Laboratory-wide networks as appropriate. Argonne anticipates the following activities:

- Argonne is a major hub for CICNet. T1 links to the University of Wisconsin, Northwestern University, Michigan State University, University of Illinois at Chicago, and Notre Dame have been installed. 
ANL Site Response for the DOE FY1994 Information Resources Management Long Range Plan

- Connection will take place to BLANCA, a national gigabit testbed that is being used to support very high speed (622 Mbps) networking.

- Argonne will be testing OSI products by participating in IETF, CICnet, ESnet and EDWG working groups.

Other Data Communications--We anticipate gradual increases in facsimile services during the plan years. We expect modest expansion in the use of Database and Literature Search services. We anticipate only minor increases in Teletype services during the plan years.

Planning for expansion of the PBX for a new experimental complex is continuing. The Adyanced Photon Source (APS) will require installation of a PBX switching node to serve 800 stations. Buildings will be completed in phases from 1992 through 1995. Other buildings to be served in 1992 are the Transportation Facility and the Child Care Facility.

\section{E. Planned Major Initiatives}

None 
ANL Site Response for the DOE FY 1994 Information Resources Management Long Range Plan March 25, 1992

A. Telecommunications

\title{
F. Schedule 4-1A, Telecommunications Resource Estimates
}

\author{
DRPARINENT OP DNERG! \\ TELECOMTCKICATIONS RESOURCES ESTIMATE
}

Schedule $1-\mathrm{L}$

Pari 1

SItE: ARGONNE MATIONAL LABORATORY (ANL)

Punctional Area: relecoununications

REPORTIIG CATECORY

1. CAPITAL INVESTNETTS

A. Purchase of lardware

B. Purchase of softuare

C. site Preparation

SUBTOTAL CATECORY I

2. TELECOWOHICATIONS

OPERATIHG COSTS

A. Government Horkyears

B. Inhouse Personnel costs

1. Systen operacions

2. Syster Halatenance

3. Analysis/Design/engineering

1. Systen studies and other

c. Other Inhouse operating costs

1. Bardware/Softuare Purchases

2. Lease of Bardware

3. Lease of Software

4. Space

5. Supplies and other

SUBTOTAL CATEGORY 2

3. CONIIRRCIAL SERVICES

A. Laased Voice Comunications

B. Lased Data Comunications

C. Operations/Haintenance

D. Systeas Analysis, Programing

Design, and Bngineering

R. Studies and otber

SOBTOTAL CATECORY 3

4. HOHCOMERCIAL SERVICRS

A. Paprents

1. Other DOR sites

2. Other Executive Branch Agencies

3. Otber Monconercial Serrice

B. Offsetting collections (-)

SUBTORAL CATECORY 1

SUBTOTAL POR CONBLNED CATEGORIRS $2+3+4$

GRAND TOHAL

MORR: GOVERHNEMT rORKYRARS (section 2A) are not included in subtotal for Category 2 or Grand Total.
Resource Rstiuates in Thousands

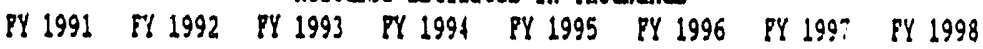

\begin{tabular}{|c|c|c|c|c|c|c|c|}
\hline 158 & 230 & 390 & 240 & $8 \times 8 \times 8 \times 8 \times$ & $x \times X 8 X 8 X X$ & XXYYYXYY & $8 X 8 X 8 X 8 X$ \\
\hline 0 & 0 & 50 & 0 & $x \times x \times x \times x$ & $\triangle X \times X X \times \triangle X$ & XXYXXXYY & $X X X X X$ \\
\hline 86 & 212 & 150 & 150 & $X X X X X X X X$ & $X X X X X X X X$ & XXYYYYXY & $x x x y x y$ \\
\hline $2+t$ & $\$ 72$ & 590 & 390 & 410 & 130 & 152 & \\
\hline
\end{tabular}

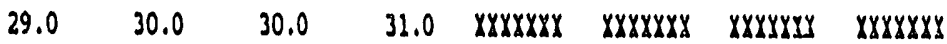

\begin{tabular}{|c|c|c|c|c|c|c|}
\hline 551 & 559 & 407 & 605 & $x \times x \times x \times x$ & X8X8X8XX & XXXXYXYY \\
\hline 461 & 480 & 500 & 527 & $x \times 8 \times 8 \times 18 x$ & $88 x \times 8 \times 8 \times$ & XXXYYYYY \\
\hline 431 & 453 & 173 & 198 & $X X X X X X X X$ & $X X X X X X X X$ & $X X X X X Y X Y$ \\
\hline 190 & 198 & 16 & 218 & $X X X X Y X X Y Y$ & $x \times x \times 8 \times 8 x$ & XXYXYYX \\
\hline
\end{tabular}

\begin{tabular}{|c|c|c|c|c|c|c|c|}
\hline 11 & 20 & 20 & 70 & 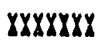 & $X \times 8 X X X X X$ & XXXXXXYI & XXXXXXYX \\
\hline 2,199 & 1,707 & 1,707 & 1,707 & $X X X X X X \times X$ & XXXXXXXX & XXYXYYYY & $X X X X X X X X$ \\
\hline 0 & 0 & 0 & 0 & $X X X X X X X X$ & $X X X X X X X X$ & XXXXYXIX & XXI \\
\hline 255 & 344 & 345 & 357 & $X X X X X X X Y$ & $x \times x X X X X X$ & XXXXXYXX & \\
\hline 26 & 273 & 310 & 297 & $X X X X X X X X$ & $x \times X X X X X X$ & XXYXXYXX & \\
\hline 36 & $t, 03 t$ & 3,808 & 4,279 & $x \times X X \times X X 8$ & $X X X X X X$ & & \\
\hline
\end{tabular}

\begin{tabular}{|c|c|c|c|c|c|c|c|}
\hline 1,125 & 1,190 & 1,250 & 1,312 & XXXXXXXX & $X X X X X X X X$ & XYXXXXX] & $X X X X X X Y$ \\
\hline 24 & 25 & 26 & 28 & $X X X X X X X X$ & $X X X X X X X X$ & $\triangle X X Y X Y Y Y$ & $X X X X X X X X$ \\
\hline 408 & 497 & 542 & 578 & XXXXXXXX & $X X X X X X X X$ & XXYYIXI & $X X X X X X Y X$ \\
\hline 0 & 0 & 0 & 0 & $X X X X X X X X$ & $X X X X X$ & $X X X X X$ & $x x x x y$ \\
\hline 0 & 0 & 0 & 0 & $x 8 \times 18 \times 8 X$ & XXXXXXXX & XXYXXYYY & $X X X X X X X X$ \\
\hline., 557 & 1,712 & 1,818 & 1,918 & $X X X X X X X$ & XXXXXXXX & XXYXYYYY & \\
\hline
\end{tabular}

\begin{tabular}{|c|c|c|c|c|c|c|c|}
\hline 117 & 93 & 93 & 93 & $X X X X X X X X$ & XXXXXXXX & XXXXXXY & $X X X X X X X Y$ \\
\hline 34 & 0 & 0 & 0 & $X X X X X X X X$ & $X X Y X X X X X$ & XXXXXYXY & $X X X X X X X$ \\
\hline 0 & 0 & 0 & 0 & XXXXXXXX & $X X X X X X X X$ & XXXXXXXX & $X X X X X$ \\
\hline-11 & 0 & 0 & 0 & XXXXXXXX & $X X X X X X X Y$ & $X Y X X X X X]$ & XXXYYY \\
\hline 140 & 93 & 93 & 93 & XXXXXXXX & $X X X X X X Y X$ & YYYXYYIY & $X X X X$ \\
\hline 6,062 & 5,839 & 5,719 & 6,290 & 6,602 & 6,932 & 7,279 & \\
\hline 6,306 & 6,311 & 6,309 & 6,680 & 7,012 & 7,362 & 7,731 & 8,1 \\
\hline
\end{tabular}




\section{DEPLRTYEIT OF EYIRCY \\ TELECOWNONICATLOHS RESCCRCES ESTIMATE \\ Resource Estiuates in rhousands}

Schedule +-11

Part 2

Site: ARCONA NATYONAL LABORITORY (ANL)

Punctlonal Irea: Telocoununications

PROGRAVATIC DISTRIBUTION OP CATPCOR! 1 - CAPITAL INVESTMENTS

\begin{tabular}{|c|c|c|c|c|c|c|c|c|}
\hline BSRC CODE & FY 1991 & FY 1992 & PY 1993 & PY 1994 & FY 1995 & FY 1996 & FY $199 \%$ & FI 1998 \\
\hline & - cuman- & nan & . & 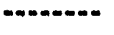 & navaman- & - & 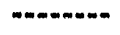 & 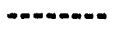 \\
\hline 10 & 12 & 81 & 102 & 67 & 71 & 74 & 78 & 82 \\
\hline$M$ & 3 & 7 & 8 & 6 & 6 & 6 & 6 & 7 \\
\hline$d F$ & 60 & 117 & 116 & $9 \vec{i}$ & 101 & 106 & 112 & 117 \\
\hline$d T$ & 2 & $t$ & 6 & $t$ & 1 & 4 & $t$ & 5 \\
\hline$K d$ & 5 & 9 & 11 & 7 & 8 & 8 & 8 & 9 \\
\hline$K B$ & 8 & 15 & 13 & 12 & 13 & 13 & 14 & 15 \\
\hline KC & 108 & 209 & 262 & 173 & 182 & 191 & 200 & 210 \\
\hline$R P$ & 6 & 12 & 16 & 10 & 11 & 11 & 12 & 12 \\
\hline NOL & 6 & 12 & 15 & 10 & 11 & 11 & 12 & 12 \\
\hline \multirow[t]{2}{*}{ N109 } & 3 & 5 & 6 & $t$ & 1 & 5 & 5 & 5 \\
\hline & 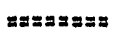 & 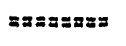 & มะมะมะมะ & $y=\operatorname{cyz} z=2$ & 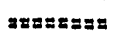 & มะมะมะxa & $x=28 z=2 x$ & $z z=z=2 z=$ \\
\hline OTdLS: & $2+3$ & 171 & 590 & 390 & 111 & 129 & 451 & 174 \\
\hline
\end{tabular}

Onwatched SUBTOTALS for CATECORY 1 - CAPITLL INTESTMENTS

$\begin{array}{lllll}244 & \$ 72 & 110 & 130 & 452\end{array}$

PROCRANALTIC DISTRIBUTION OP CATEGORIES 2+3+1 - OPERATING EXPENSES

\begin{tabular}{|c|c|c|c|c|c|c|c|c|}
\hline B\&RC CODE & FY 1991 & PV 1992 & PY 1993 & PI 1991 & PV 1995 & PY 1996 & PY 1997 & PY 1998 \\
\hline 10 & 1044 & 1005 & 985 & 1083 & 1137 & 1194 & 1253 & 1316 \\
\hline$d$ & 86 & 83 & $\partial 1$ & $3 ?$ & 94 & 98 & 103 & 108 \\
\hline$\Delta P$ & 1500 & $14+5$ & $1+15$ & $155^{\circ}$ & 1634 & 1715 & 1801 & 1891 \\
\hline$\Delta I$ & 58 & 55 & 54 & 50 & 63 & 60 & 69 & 73 \\
\hline$R d$ & 114 & 110 & 108 & 118 & 121 & 130 & 137 & Lit \\
\hline$R B$ & 189 & 182 & 178 & 135 & 206 & 216 & 227 & 238 \\
\hline$R C$ & 2688 & 2589 & 2536 & 2789 & 2928 & 3074 & 3228 & 3390 \\
\hline$R P$ & 159 & $15 t$ & 150 & 155 & 174 & 182 & 191 & 201 \\
\hline 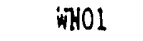 & 158 & 152 & $1+9$ & $16 t$ & 172 & 181 & 190 & 199 \\
\hline \multirow[t]{2}{*}{ WNOS } & 65 & 63 & 61 & 60 & 71 & 74 & 78 & 82 \\
\hline & $=\because z=z=\pi$ & $==x x=2$ & $z=2=x=2$ & $s=z=x=z$ & =:s=z:zz & :x=2zaz & $=2= \pm= \pm$ & $z=2 x=8 x$ \\
\hline OTALS: & 6061 & 5838 & 5717 & 6288 & 6603 & 6930 & 7277 & 7612 \\
\hline
\end{tabular}

Onaatched SOBTOTALS for CCYBINED CATEGORIES $2+3+4$ - OPRRATIHG EXPENSES

$\begin{array}{llllllll}6062 & 5339 & 5719 & 6290 & 6602 & 6932 & 7279 & 7643\end{array}$ 
ANL Site Response for the DOE FY1994 Information Resources Management Long Range Plar March 25, 1992

A. Telecommunications

\section{G. Schedisie 4-2, Major Telecommunications Initiatives}

None 
ANL Site Response for the DOE FY 1994 Information Resources Management Long Range Plan

\section{H. Schedule 4-5, Computer Networking Resources}

COMPCTER NETHORKING RESOURCES

SCECDOLE $4-5$

ARGONNE NATIONAL LABORATORY (ANI)

ror S1te-Managad Notworka, complat.e all 1tams. For External Networka, complete only 1tama 1 through 9.

1. Netrork Name: $\quad x, 400-x, 25$ Prototype

2. Netrork Acronym: $\times 400 / 25$ Proto

3. Currently Used Network _ Planned Network/Syutem"

* Implementation Planned for FY 1992

*ype of Inttlative: Major $x_{-}$Minor

4. X_ S1t Managed Network Externa: Network**

*Natwork Owner:

*\#oat Computing Syatara:

*\#ost Looution:

5. Netrork Management Organization: Computing and Telecommunicationa Diviaton Point of Contact:

Tolaphone No.:

R.J. MaYabon

strent Addrens:

$708-252-7270$

9700 S. Cass Avenue

Azgonne, TL 60439-4844

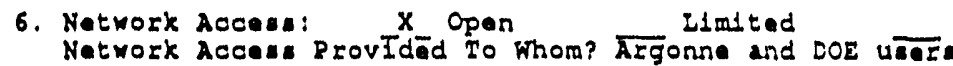

7. 8rotocol: Supported:

$x .400$ matl over $x .25$

8. Gateway Access Used:

None

9. Comminty of servica:

Argonse and DOE mall usera

10. Netrork Oparation Organization: Roint of Contact:

Teleplone No.:

stront Addres: :

Computing and Telecommunicationa Diviaton

J. Love

$708-252-5421$

9700 5. Cass Avenue

Argonne, II 60439-4844

11. Technical point of Contact: L. Whakler

Telopbone No.:

$708-252-7236$

9700 S. Cass avenuse

Argonne, IE 60439-4844

12. Adminlatertive Point of Contact: R.J. MeMabon

Teleptone No.: 708-252-7270

stroet Address: $\quad 9700 \mathrm{~S}, \mathrm{Cass}$ Avenue

Argonne, IE 60439-4844

13. Network Topology: Packat Swilsted

Primary Noden (Number/Location): Bulding 22:

14. Transmiston Technology Used:

ITS2000 Packe: Switched Network

15. Bardware Used:

C1.co rolte:, Drop/1nsert T1 multiplexer

16. Operating syatom Oant:

17. Applicatione supported:

$\times .400$

18. Security Rantraint. Employed:

19. CosIp Standarda/Compliance:

Network is a GoSIP teatbed 
ANL Site Response for the DOE FY 1994 Information Resources Management Long Range Plan March 25, 1992

A. Telecommunications

COMPOTER NETHOTUKING RESOURCES

SCHEDULE 4-5

ARGONNE NATIONAL LABORATORY (ANI)

ror S1te-Managed Natworks, conplate all 1toms. For External Notworks, complete only 1 tams 1 through 9.

1. Network Nama: Argonne SNA Network

2. Natwork Acronym: SNA

3. X_ Currently Oaed Network Planned Network/Syatem*

* Implementation Planned for FY

type of Initiativa: $\operatorname{Majox}$ Minor

4. X_ Site Managed Network External Network**

**Network Omer: * Bost Computing system: * Bost Location:

5. Natrork Managomant Organiza:1on: Computing and Telecomunications Division Point of Contact: Telepbone No.: Street Addrese: R.J. Makibon $708-252-7270$

9700 S. Cass Avenue

Azgonne, IL 60439-4844

6. Network Access: $x$ Open Iimited Network Access Providēd To whom? $\overline{A F g}$ nne and DOE IBM Users

7. Protocol. Supported: SNA

8. Gateray Accens Osed:

None

9. Community of Servica:

Argonne and DOE IBM Uuers

10. Network Operation Organization: Polnt of Contact:

Telephone Ho.:

Computing and Telecommintcations Division J. Love

708-252-5421

$9700 \mathrm{~S}$. Cass Avenue

Argorne, II 60439-4844

11. Tachnical Point of Contact:

R. Carluon

$708-252-7289$

9700 S. Cass Avantse

Tolephone No.:

AIgonne, IL 60439-4844

12. Adminietrative Point of Contaot: R.J. MaMabon

Telephone No.: $\quad 708-252-7270$

Street Addresa: $\quad 9700 \mathrm{~s}$. Cass Avenue

A=gonne, II 60439-4844

13. Natwork ropology: Polnt - Point

Primary Nodes (Number/Location): Building 221

14. Tranemtation Technology Used:

Copper

15. Hardware Oeed:

Point - Point modems

16. Operating Syetam Used:

VM/CWS and MVS

17. Applioations supported:

Full screen lnteractive terminals, remote printing

18. Security Reatrainta Employed:

Primary Nodes in secure area

19. GOSIP standarda/Compliance:

Existing ystem - no plans to upgzade 
ANL Site Response for the DOE FY 1994 Information Resources Management Long Range Plan A. Telecommunications

Tor site-Managed Networkn, complete all dtews. Tor external Networks, complete only 1 teme 1 througb 9.

1. Notwork Nam: National solence roundation Natwork

2. Natwork Acronym: NSFNET

3. $x_{\text {_ Currantly Osad Natwozk }}$ _ Planned Network/Syetem*

- Iaplementation Plannad for PY

Type of Indtiative: Major Mnor

4. s1te Managed Notwork - Extarmal Network*

"Natwork ownar: * Hoat Couputing Syatam: NST

*\#But Location:

5. Network Kanagemant Organdzation: NSTNET Polnt of Contact: Telophone No.: El1se Gerleb $800-666-3748$

1075 Basl Avente

Ann Arbor, MII 18109

6. Network Accens: Opan wom? Ist approvad users Restricted Network Ascese Provided to Whom

7. Protocola supported: TCP / IP

8. Gatoway Acoess Oued: LGR

9. Community of Sazvice: Interactive acoese, e-matl, flle tranalez

10. Network Operation Organdzation: point of Contact:

Telephone No.:

streot Addreas:

11. Tuobnical Point of Contact:

Telophone No.:

strant Addrana:

12. Adminiutrative polnt of Contact: Telepbone No.:

strent Address:

13. Natwork Topology:

Primary Nodes (Number/Location):

14. T=ansmiseson Technology Used:

15. Bardware Osed:

16. Operat1ing syatem Oaed:

17. Applicatione supported:

18, Security Rautraint: Employed:

19. CosIR standarda/Compliance: 
ANL Site Response for the DOE FY1994 Information Resources Management Long Range Plan March 25, 1992

A. Telecommunications

COMPUTER NETWORKING RESOURCES

SCHEDU: $24-5$

ARGONNE NATIONAL LABORATORY (ANL)

For s1to-Managad Natworka, oomplete all 1toms. For External Natworke, complate oniy 1 tams 1 through 9.

1. Network Name: Argionne Laboratory-Wide Etbernet - IANmark (RBX)

2. Network Aaronym: Lahtuark

3. X_Cuzzently Oaed Natwork

* Implementation II Iarred for FY

Planned Network/Syatem*

4. X_ S1te Managed Network

type of Indtiative: Major Minor External Network**

* Natwork Owrez:

* Hoat Computing Syatem:

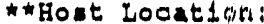

5. Notwork Managument organdzation: Point of Concact:

Telepbone Nu: :

R.J. Mcyibon

$708-252-7270$

$9700 \mathrm{~S}$. Case Ave

Argonne, IL 60439-4844

6. Natwork Accens: $x$ Open Networt hecass Provided To whom? Ind ted Restricted

7. Protocolis Supported:

TCP/IP, DECnet, Apple Talk, XNS, OSI

8. Gatemay Access Osed:

CIsco routers to external natworks

9. Community of Survice:

Argonne computez users

10. Network Operation Organization: Point of Contact

Telepbone No.:

Streat Addreas:

Computing and Telecomrinnioations Division

J. Love

$708-252-5421$

9700 S. Cass Ave

Argonna, IL 60439-4844

11. Teabnical Roint of Contaot:

Talepbone No.:

T.C. Xubfuas

$708-252-4360$

9700 S. Cams Ave

Afgonne, IL 60439-4844

12. Adminiatrative Point of Contact: R.J. MeMabon

Telephonio No.:

Streat Addrees:

$708-252-7270$

9700 S. Casa Ave

Argonse, IL 60439-4844

13. Network Topology:

Etbornet Emiato: - LANmark

Prlmary Nodes (Numbe=/Locat1on): Building*221,200,308

14. Transmiston Technology Usad:

Carzler sanse miltiple access/coll1sion detecsion

15. Bardware Used:

Etbernet / InceCom S/80 PBX

16. Operating Syotem Doed:

Rroprietary

17. Applicationa supported:

T11. tzanafer, zemote login, visualization, central 11le molnting, LaN interoonnection

18. Security Reotralnte Enployed:

suitcb, primary malnerames, routera in wecure azea

19. GosIP standarda/Compliance:

OSI gataway undez developmant 
ANL Site Response for the DOE FY 1994 Information Resources Management Long Range Plan A. Telecommunications

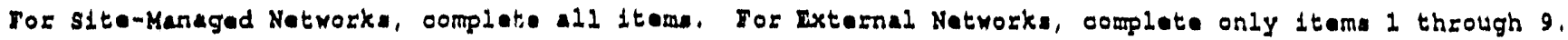

1. Network Name: Argonne ESnat/EDP Video Confureneing

2. Network Aoronym: HePvideo

3. Currently Joed Network

* Implemantation Planned for FY 1992 R lanned Natwoyk/Syatem

1. Site Kanaged Network _. External. Natwork**

Type of Inttiazive: Major $-x$ Minor "*Network Owner: **Boat Computing syatam: DOE Energy Renearab \#*Hout Location:

5. Natwork Management Organdzation: NDRSC at LWNT Point of Contact: Telephone No.: stzeot Addroos:

S. Inelgaton $510-422-4025$

Lawrence Ilvermore National Laboratory Livermore, CA 94551

6. Network Accens: $x$ IImited Ratileted Wetwork Accous Provided To Woom? DOE Energy acientist:

7. Protocola supported: Video relecom proprietary

8. Gatoway Aocasa Uaod:

9. Comminity of Service: DOE Energy setentiate

10. Network Oparation Organization: Roint of Contact: Talepbone No.: stroat Addreas:

11. Teabnioal polnt of Contaot: Telophone No.: strout Addren:

12. Adminlatrative point of Contace: Telapbone No.: straet Addrane:

13. Network Topology:

Rrimary Nodes (Number/Location):

14. Tranemasion Technology Used:

15. Bardware Deed:

16. Oparating Syutom Used:

17. Appliaution supportad:

18. Securtty Rentraint. Employed:

19. Cosip standarda/Compliano: 
ANL Site Response for the DOE FY 1994 Information Resources Management Long Range Plan March 25, 1992

A. Telecommunications

COMPOTER NETWORKING RESOUNCES

Sciesu:e 4-5

ARGONNE NATIONAL LABORATORY (ANL)

Tor Site-Managud Networks, complate all 1tam. Foz External Natworks, oomplete only 1 tams 1 tarough 9.

1. Natwark Nam: Energy Solence Network

2. Network Acronym: Esnet

3. _ _ Currantiy Vaed Natwork

- Implementation Planned for FY RLanned Natwork/Syztem*

- Site Managed Network _X_ External Network**

\#ype of Initiativa: Major _ Minoz

* Natwork Ownar:

* Hout Computing Syotem:

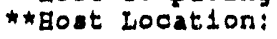

DOI Inergy Reweazch

Untx based systems and VAX VMS syatems

NERSC at LiND

5. Network Management Organlzation: NERSC at LINL

Point of Contact:

Telephone No.:

J. Leighton

$510-422-4025$

Stroet Address:

Lawrence Livermose National Laboratory

Livermore, CA 94551

6. Natwork Accesa:

Network Accesa:
Network Access Provided To fhom? DOE Energy sctentist:

$x$ inited

7. Protocol supported:

TCP/IP, DECnet, NSP/IP, OSI

8. Gateway Access Used:

CIsco multiprotocol router

9. Comminity of Service:

DOE Energy sotersiats

10. Network Operation Organization: Point of Contact:

Telaphone No.:

street Addreas:

11. Technical polnt of Contact:

Telophone No.:

street Address:

12. Adminiatzative Point of Consact:

Telepbone No.:

streat Addres:

13. Network Topology:

Primary Nodes (Number/Location):

14. Tranamialon Technology Used:

15. Bardware Used:

16. Operating Syatem Osed:

17. Application Suppozted:

18. Security Restralnts Employed:

19. Gosip standarda/Compliance:

ANL-4.1.24 
ror S1to-kanaged Notworks, complote all 1tems. Tor Ixtermal Networke, complete only 1 tems 1 through 9.

1. Network Name: CIONET Ragional Network

2. Hetwork Acronym: CICNET

3. X_ Currently Uand Network

- Implamantation Planned fo= $F Y$

4. Stte Maraged Network

* Hetwork Omer: - Most Computing syatem: -"Most Location: Rlanned Natwork/Syotem*

. Natwork Managomant Organdza:Lon: CICWrT Point of Contect: Telopbone No.: Executive Dizector stroet iddras:

313-998-6106

2901 Bubbard st. Pod $G$

Ans Arbos, MII 48205

6. Netrork Access: Network Access Rroviced Io irbom?

X_ Limitad Rostricted

7. Protocole supported:

TCP/IR, DECnet

8. Gateway Access Dead:

2G?

9. Comanity of Service:

Interactive access, e-ma1l, E12e transfer

10. Network Oparation Organization: Point of Contact:

Telephone No.:

Street Addreas:

11. Technical polnt of Contact:

Telephone No.:

Straet iddrase:

12. Adminiatrative Point of Consact: Telapbone No.:

stzent Addrese:

13. Notwork Topology:

Pelmary Nodes (Number/Location):

14. Tranemeston Tachnology Osed:

15. Bardware Osod:

16. Operating Syatem Used:

17. Application supportad:

18. Security Restratnts Eoployed:

19. COSIP Standarda/Compliance: 
ANL Site Response for the DOE FY 1994 Information Resources Management Long Range Plan March 25, 1992

A. Telecommunications

COMPOTER NETHORRING RESOURCES

SCHEDULE $4-5$

ARGONNE NATIONAI LABORATORY (ANL)

For Site-Managed Networke, complete all itewn. For External Networks, complete oniy itams 1 through 9.

1. Wetwork Name: O.S. (and wozld wide) Oniversity Network

2. Network Acronym: BIInet

3. X_ Currently Jaed Network

* Impiementation Planned $50=F Y$ Planned Natwork/Syotem

†rye of Initlative: __ Major _ Minor

4. S1te Managed Network

*Netrork Orner:

** Bost Computing System:

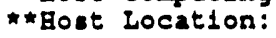

5. Network Management Organization: BImIC Point of Contact:

Telepbone No.:

Street Addreas:

INTOCBIMNIC

$202-872-4200$

1112 16tb St. NW, sutte 600

Wasbington, DC 20036

6. Network Accens: $x$ Open Network Access Providéd To whom? Iintead Restricted

7. Protocols supported:

IBM, NJE, RSCS

8. Gateray Access Used:

None

9. Comulity of Service:

International I3M user:

10. Netrork Oparation Organization: Point of Contact:

Telepbone No.:

street Addrese:

11. Technlcal point of contact:

Telepbone No.:

street Address:

12. Administrative Point of Consact:

Telephone No.:

Street Address:

13. Network Topology:

Primary Nodes (Number/LOcation):

14. Transmiseion Technology Used:

15. Bardware Used:

16. Operating Syetem Used:

17. Applicatione Supported:

18. Security Rastralnts Employed:

19. GoSIP standards/Compliance: 
ANL Site Response for the DOE FY 1994 Information Resources Management Long Range Plan A. Telecommunications

ror slte-Managed Networka, complete all 1tame. Tor Extamal Natworks, complate only 1tems 1 through 9.

1. Natrork Name: Argonne riber Distributed Data Natwork

2. Network Acronym: Argonne Lab Wide FDDI

3. X_ Currently Uoed Network Planned Network/Systern*

- Implementation Planned for EY 1992

trype of Iattiative: _ Majoz Minor

4. X_ Site Managed Network External Network**

* Netrork Orner:

* \#ost Computing syatem:

* Bost Location:

5. Natwork Managament Organization: Computing and Telocomunication: Divialon Rolnt of Contact: Telephone No.: Streat Addrane: R.J. Makahon 708-252-7270 9700 S. Cass Ave Asgonne, II 60439-4844

6. Network Access: Open $X$ Iladted Restricted Network Accese Provided to whom? Irḡonne computez Tsers requiring lazge bandwidth

7. Protocols Supported: TC2/IP, DECnet, Apple Talk, OSI (Euzuze)

8. Gateway hocese Jsed: C1sco routers to external networks

9. Cominity of Service: Argonne complez users

10. Network Operation Organization: Point of Contact: Telephone No.: street Addres:

Computing and Telecommanicatione DLvilion J. Love $708-252-5421$

9700 S. Case Ave

Argonne, IL 60439-4844

11. Tacbnical Polnt of Contact: Telephone No.:

T. Xuhtus: streot Addrans:

$708-252-4360$

9700 S. CasB Ave

Argonne, II 60439-4844

12. Administrative Point of Contact: R.J. MaMabon Telepbone No.: $\quad 708-252-7270$ Street Addreas:

9700 S. Case Ave Argonne, II 60439-4844

13. Network Topology: Token pasaing zing Primary Nodes (Number/Location): Building: 221,308,362,900

14. Transmiseion Technology Used:

Fiber optic

15. Bardware Osed:

FDDI route:s

16. Operating Syotem Doed:

Proprietary

17. Applicationa Supported:

Fast flle $x$ Eez, remote visualizat on, LAN only connection, Necrork File Sya window based apps

18. Security Reatrainta Employed: All equipment is locked areas

19. Gosir standards/Compliance:

Equipment $w 111$ =oute OSI protocols 
ANL Site Response for the DOE FY1994 Information Resources Management Long Range Plan March 25, 1992

A. Telecommunications

COMPUTRR NETHORKING RESOURCES

SCHEDULE $4-5$

ARGONNE NATIONAI LABORATORY (ANL)

For S1te-Managed Networks, complete all 1tems. For External Networks, complete only 1 tems 1 through 9.

1. Netrork Name: Argonne East-West Data Communicationa

2. Network Acronym: ANLE-W

3. X_ Currently Joed Network Planned Network/System

- Inplamentation Planned for FY 1992 \#YYpe of InItlative: _ Majoz _ Minor

1. _. Site Managad Network External Network*

\#*Network Owner: \#\#ost Comput1ng System:

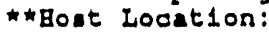

5. Network Managornant Organization: Computing and Telecommunications Division Point of Contact: Telephone No.: Street Addrese: R.J. Makahon $708-252-7270$

9700 S. Cass Avenue Argonne, IL 60439-4844

6. Netrork Access: Network Acceas Provided To whom?

X_ Limited Rextricted

7. Protocol: Supportad:

TCP/IR, DECnet, Asyne

8. Gateray Access Osed:

None

9. Comunity of Service:

Argonne East/Weat compluter users

10. Natwork Oparation Organization: point of Contact: Telephone No.:

Computing and Telecommancations Division J. Love

708-252-5421

9700 S. Cass Avenue

street Addrens:

Argonne, IL 60439-4844

11. Technical Point of Contact: Telephone No.:

Strent Addres:

L. Winkler

$708-252-7236$

9700 S. Cass dvenue

$A=g \circ n n e$, IL $60439-4844$

12. Administrative Point of Contact: R.J. Mayabon

Telephone No.: $\quad 708-252-7270$ Strent Addreas:

9700 S. Cass Avanue

Argonne, IL 60439-4844

13. Natwork Topology:

Point - Point, Etbernet

Prlmary Nodes (Number/Location): ANL East - Building 221, Argonne West

14. Transertasion Tuchnology Used:

Copper, 1zactional T1, carrier sense mult access

15. Bardware Uaad:

Etbernet, Intecom s/80 $\mathrm{PBX}$, Copper cable

16. Operating Systam Osed:

VMS, IBM, UVS, VM, OnIX

17. Applicatione Supported:

Central systems, LAN Interconnections

18. Security Reatraints Eroployed:

pBX, primary mainframe, routerg in secure area

19. GOSIP Standarda/Compliance:

existing netwo=k - minor upgrade 
ANL Site Response for the DOE FY1994 Information Resources Management Long Range Plan A. Telecommunications

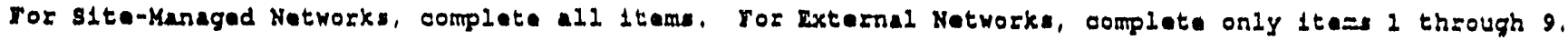

1. Notwork Nama: Argonna/Navy San Diego Data Commialiona

2. Natwork Aaronym: AsL-Wavy

3. X_ Cuzzently Jaed Network

* Implementation Plansed for $F Y$

\section{_ Rlanned Natrork/Syutam*}

trype of Indtiative: _ Majo: Minor

4. X_ s1te Maragad Natwo=k External Natwork*

* Natrork Orner:

- Hoot Computing sys=ar:

* Bont Location?

5. Notwork Management Ozganlzation: Computing and Felecommancationa Division Point of Contact:

Telophone No,:

R.J. MaYabon

$708-252-7270$

9700 s. Casa Avenue

Argonne, II 60439-4844

6. Notwork Accens: Open To Whom? - - - Limited Reatrieted Network decen: Rrovidad To whom?

7. Protocoln supportad:

SNA, NJE, RSCS

8. Gateway Accens Jued:

9. Comminity of Servion:

Navy users of Argonse central eyetome

10. Natwork Oparation Orgenization: Point of Contact:

Talopbone No.:

Computing and Tolecomminicationa Divinion J. Love

$708-252-5422$

stroat Addrea:

$9700 \mathrm{~S}$. Case Avenue

Argonse, IL 60439-4844

11. Tecbrical point of Costact:

Telephone No.:

R. Carlaon

$708-252-7289$

9700 S. CaAn Avanue

Argonne, IL 60439-1844

12. Adminiatrative Roint of Contact: R.J. MaMahon

Telepbone No.:

stroet Addrean:

$708-252-7270$

9700 S. Cass Avenue

Axgonne, II 60439-4844

13. Network Topology:

Point - Point

Primary Nodas (Number/Location): Building 222

14. Tranamiaton Tachnology Used:

Fractional TI

15. Bardwaza Oned:

CSU/DSO

16. Oparating Syatam Used:

MVS at vis

17. Applicationa supported:

Navy personnel database

18. Security Rantralnte Eloyed:

Primary node in secure room

19. CosIs standarda/Compliance:

Exieting ayutem - minor upgrade 
ANL Site Response for the DOE FY 1994 Information Resources Management Long Range Plan March 25, 1992

A. Telecommunications

COMPUTER NETWORKING RESOURCES

SCHEDOLE 4-5

ARGONNE NATIONAL LABORATORY (ANL)

Tor S1te-Managed Networks, complete all 1toms. Tor External Notworks, complete oniy 1tams 1 through 9.

1. Network Name: Argonne NJe Network

2. Network Acronym:

3. X-Clrrently Oeed Network

- Implementation Planned foz TY

Planned Network/Syatem*

-X_ Site Managed Network _Extermal Notwork*

* Network owner:

**Bost Computing System:

**Host Location?

5. Network Management Organization: Computing and Ielecommuniations Division Point of Contact:

Telepbone No.:

street Addreas:

R.J. Meyabon

$708-252-7270$

9700 S. Case Avenue

Argonse, II 60439-4844

6. Network Acceas: $x$ Opan

Indited

Network Accean Providēd To Whom? Arģonne DEC \& IBM tumera

7. Proto001: Supported: IBM NJE

8. Gataway Acoess Doed:

9. Community of service:

Argonne DEC \& IBK Users

10. Network Operation Organdzation: Point of Contact:

Talepbona No.:

*ype of Indtiative: Majo: Minor street Addres:

Compting and Inlecommnleations Diviaion

Barm Tinkel

$708-252-7277$

9700 S. Cass Ave

Argonse, IL 60439-4844

11. Tocbnical Point of Contact:

Telepbone No.:

street Address:

Rich Rafienat:

$708-252-7236$

9700 S. Case ave

Argonne, IL 60439-4844

12. Administrat1ve Point of Contact: R.J. MaMabon

Telephone No.:

strent Addrese:

$708-252-7270$

9700 S. Case Ave

Argonna, IL 60439-4844

13. Natwork Topology:

Yoint-Point, ztbernet

Primary Nodes (Number/Location): Building 221

14. Tranandasion Tachnology Used:

Copper

15. Bardware Used:

'Poist-Point modems, Etharnat

16. Operating Syutem Ozed:

VMS

17. Applications Supportad:

T11. tranefer, remote printing

18. Security Restratnts Enployed:

Switab a primary Nodes in necure area

19. Gosip standarda/Complianca:

zxisting aystem - no plana to upgrade 
ANL Site Response for the DOE FY1994 Information Resources Management Long Range Plan A. Telecommunications

\section{Schedule 4-6, Long Distance Transport Cost Estimates}

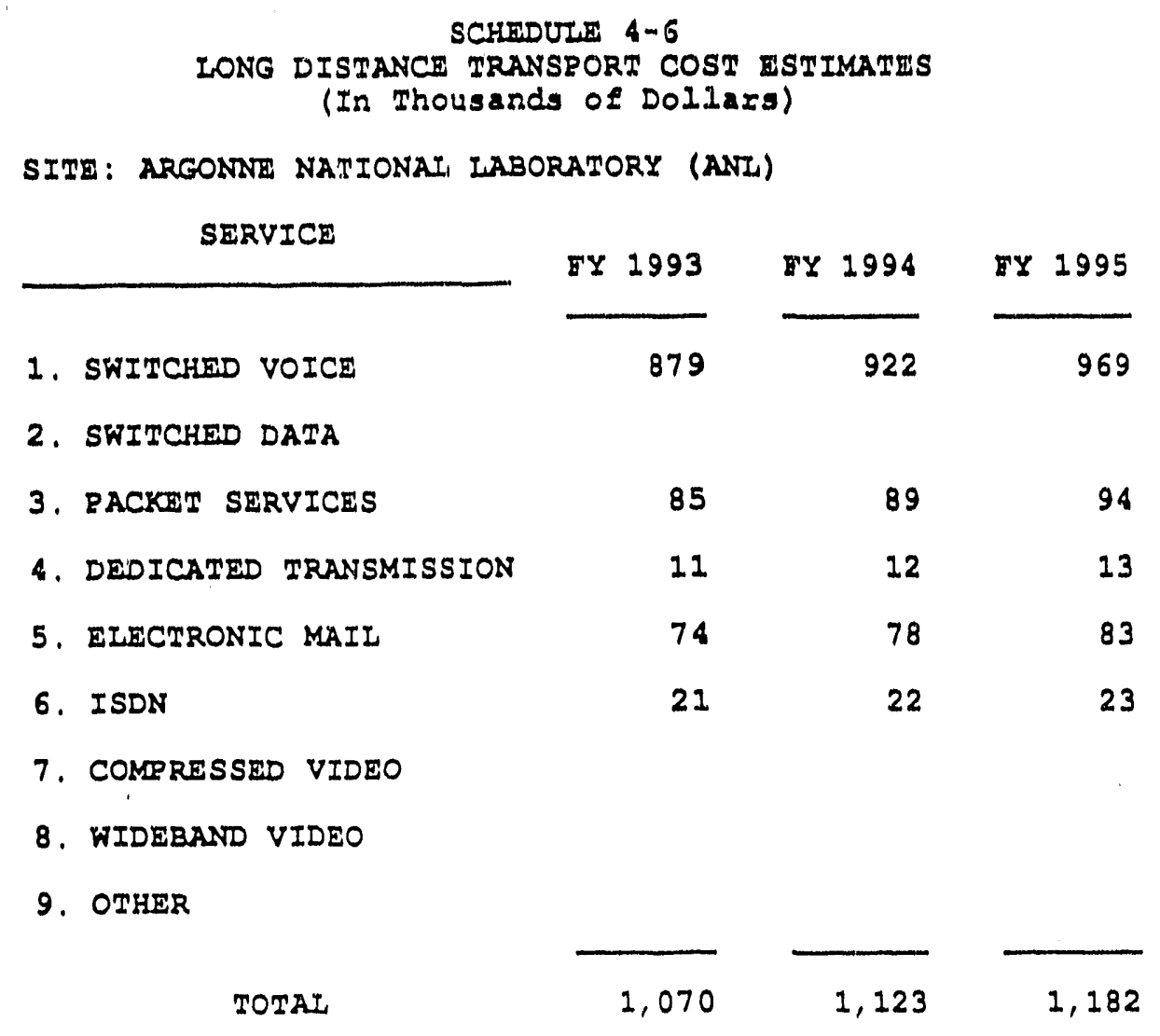


ANL Site Response for the DOE FY1994 Information Resources Management Long Range Plan March 25, 1992

A. Telecommunications

J. Schedule 4-7, SACNET Resource Estimates

None 
ANL Slte Response for the DOE FY 1994 Information Resources Management Long Range Plan

\section{Section B}

\section{Frequency Spectrum-Dependent Communications}

\section{A. Strategy and Major Accomplishments}

\section{Strategy}

The Laboratory plans to continue support of operations and programs through existing systems with minor enhancements and replacement of old equipment. CTD has reviewed the site radio coverage and has determined that relocation of a repeater and the installation of passive repeaters with radiating coaxial cable are needed to improve site radio communication. CTD has issued a service request to the site engineering for the installation of a new antenna tower and relocation of two base stations to the new tower. A second revlew of site coverage will be conducted after the relocation. Determination will be made as to where passive repeaters and radiating coaxial cables are required for service floor coverage.

The Laboratory is planning its changes keeping in mind the possible effect of the Emerging Telecommunication Technologies Act, which proposes that the Federal Government relinquish 2(K) $\mathrm{MHz}$ of the spectrum. Argonne will be reviewing its frequency allocations and defining where the Laboratory can utilize its frequencies more effectively. The Laboratory will be looking at trunked radio systems as a way of reducing the number of required radio frequencies.

\section{Major Accomplishment}

None

\section{B. Reconciliation to FY1993 Plan}

None.

\section{Currently Utilized Services/Planned Minor Enhancements}

Administrative Radio System-- Argonne owns and operates a radio paging system which generally covers the site and the southwestern Chicago metropolitan area. The primary transmitter and encoder accommodate both voice and digital pagers. The backup transmitter has only volce paging capability and will be upgraded in FY 1992. Approximately 750 pagers are currently in use at the laboratory.

Wide Area Radio Paging-uThe Laboratory has contracted for the use of a vendor wide area paging service to provide contact with key personnel for emergency operations.

Security Department Network--The Argonne Security Department has several portable/mobile radios which share the frequency of the DOE-CH subcontractor, AM-PRO, for coordinating security activities. 
ANL Site Response for the DOE FY 1994 Information Resources Management Long Range Plan March 25, 1992

B. Frequency Spectrum-Dependent Communications

Fire Department Network-. The primary responsibility of the Fire Department is the protection of Laboratory personnel, buildings, and equipment onsite. The Fire Department operates two ambulances in close cooperation with the Health Department. The ambulances are staffed with quallfied paramedic personnel.

The radio communications equipment of the Fire Department consists of ten mobllo radios, 30 portable radios, and one base station. The mobiles and portables are all four-frequency radios; the base station is single frequency. The Fire Department has one command vehicle which is equipped with a 15-charnel mobile radio, transportable cellular and a mobile cellular telephone.

The Fire Department radio equipment is part of the Emergency Radio Network and is avallable for all site emergencles. Through a mutual-ald agreement with local fire departments, the department responds to local of fsite emergencies when requested. Radio communication with outside local fire departments is through three mobile radios and two portables under the mutual-ald agreement. The ambulances carry mobile radios, transportable cellular telephones with telemetry equipment for communication with local hospltals during emergency transportation of the injured. Argonne has been invited to participate in these community networks.

Emergency Radio Network-. The Emergency Radio Network provides communications among the various emergency response groups and personnel throughout the silte. The network consists of two repeater base stations, one backup base station, and most of the multifrequency mobile and portable radios used by emergency response personnel.

Environment, Safety and Health Network-m The general responsibility of the Environmental, Safety and Health Divisions (ESH) is to provide technical service, information, and guidance to promote the health and safety aspects of all Laboratory operations. The primary function is to detect, evaluate, and recommend controls for all types of environmental hazards. ESH collects air particles, gas samples, and water samples onsite and at varlous locations surrounding the site on a routine basis.

ESH communications consist of three base stations, 24 portables, and four mobiles. ESH operates two twenty-three-foot vans. One van is assigned to the Radiological Assistance Program (RAP). Radio communications for the RAP van consist of a base station, two single-frequency mobile radios, ten four-frequency portable radios, and cellular telephones. The second van is assigned to the Manhattan Engineering District/Atomic Energy Commission site resurvey team (MED/AEC). Radio communications for the MED/AEC van consists of four four-frequency portables. The radio equipped vehicles and vans are avallable for site emergencies and local community or national radiation incidents.

Argonne-Fermilab Microwave Link--A one-hop microwave link between Argonne and Fermilab provides both data and volce communications. These communications and costs are included in Section A.

Monitor \& Control Telemetry--A radio telemetry system controls and monitors an offisite canal water pumping station. The system is part of the Energy Monitoring and Control System (EMCS). It is a full duplex, digital radio communications link used to control six operating functions and monitor 16 status points.

Industrial, Scientific, and Medical (ISM) Communications

None

ANI $-4,2.2$ 
ANL SIte Response for the DOF FY 1994 Intormatton Resources Management Long Range Plan B. Frequency Spectrum-Dependent Communlcations

\section{Planned Minor Initlatlves/New Systems or Services}

Argonne has issued a service request to site engineering for the Installation of a new antenna tower and relocation of two base stations to the new tower. Plans are being made for a back-up digital base station and a new antenna tower for the paging system.

\section{E. Planned Major Initlatives}

None 
ANL Site Response for the DOE FY1994 Information Resources Management Long Range Plan March 25, 1992

B. Frequency Spectrum-Dependent Communications

\title{
F. Schedule 4-1B, Telecommunications Resource Estimates
}

\author{
DEP.APTHENT OP ENRROY \\ TRLCONWHICATYOHS RESOURCES ESTHATE
}

Schedule $+-1 B$

Part 1

SITEI ARGONAE HATIONAL LABORITORY (ANL)

Functlonal drea: Frequenc'y spectrun-Dependent Coununications

REPORTIHO CATECORY

1. CAPITAL INVESTMENTS

$\lambda$. Purchase of Bardware

B. Purchase of Softivare

C. Slte Proparation

SUBTORAL CATEGORY 1

2. TELECOHANICATIOHS

OPERATING COSTS

A. Goverment Workjears

B. Inhouse Personnel costs

1. Systen operations

2. Syster Haintenance

3. Analysis/Design/engloeering

1. Systan studies and other

c. Other Inhouse operating costs

1. Bardware/Softwara Purcbases

2. Lease of Bardware

3. Laase of Soltware

4. Space

5. supplies and other

SOBTOTAL CITECORY 2

3. COWHERCIAL SERVICES

A. Leased Volce Comuntcat!ons

B. Leased Datd Conaunlcatlons

C. Operatlons/Halntenance

D. systens dnalysis, Programing

Des!gn, and Englneering

R. Studles and other

SUBTOTAL CATECORY 3

4. HOHCOMMERCIAL SERUICES

A. Payrents

1. Other DOR sites

2. Other Executlye Branch Igencles

3. Other Honcounerclal Ser/lce

B. Offsetting Collectlons (-)

SUBTOTAL CATEGORY +

SUBTOTAL POR COHBINED CITEGORIES $2+3+4$

GRAND TOTAL
Resource Rstluates In Tholisands

\begin{tabular}{|c|c|c|c|c|c|c|c|}
\hline PY 1991 & PY 1992 & PY 1993 & FY 1994 & PY 1995 & Fy 1996 & PY 19997 & FY 1998 \\
\hline 76 & 82 & 65 & 75 & $8 x x x x x>x$ & XXXYXXXXX & XXYYYYYXX & $X X X X X X X X X$ \\
\hline 0 & 0 & 0 & 0 & XXXXXYXXX & XXXXXXXXX & XYYYYYYY & $X X X X X X X X$ \\
\hline 25 & 0 & 0 & 0 & XXXXXXYY & $88938 \times 8.88$ & 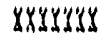 & צXXXXXXXX \\
\hline 101 & 82 & 65 & 75 & 155 & 190 & $1+5$ & 110 \\
\hline
\end{tabular}

\begin{tabular}{|c|c|c|c|c|c|c|c|}
\hline 0.0 & 0.0 & 0,0 & 0.0 & $X X X X X X Y X$ & XYXYYYXXY & ХХХYYYYХ & XXXXXXXXX \\
\hline 139 & 113 & 147 & $1+7$ & ХХХХХХХХ & XXXXXXXX & ХУУУУЗЗУ & $X X Y X X X X$ \\
\hline 93 & 96 & 96 & 99 & $X X X X X X X X$ & $X X X X X X X X$ & XYYISYYY & XYYXYXXXY \\
\hline 17 & 17 & 18 & 18 & $X X X X X X X X$ & $X X X X X X X$ & УУYYYYYYY & $X X X X X X X Y$ \\
\hline 1 & 11 & 12 & 13 & XXXXXYXY & $x y \times x y \times x y$ & 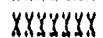 & $X_{X Y Y Y Y X X Y}$ \\
\hline
\end{tabular}

\begin{tabular}{|c|c|c|c|c|c|c|c|}
\hline 0 & 0 & 0 & 0 & XXYXYXXX & $88 \times 8 X 8 X 8$ & ХХХYYХYXX & X8XXXXX8 \\
\hline 0 & 0 & 0 & 0 & ХXXYXXXXX & XXXXXXXX8 & XXYYYYYX & $X X X X X X X X$ \\
\hline 0 & 0 & 0 & 0 & $X X X X X X X X$ & $8 X X X X X X 8$ & ХXYYYYYY & XXXYXXXXX \\
\hline 0 & 0 & 0 & 0 & $X X X X X X X X$ & XXXXXXXX & XXYYYYSX & XXXXXXXX \\
\hline 6 & 6 & 5 & 6 & XXXXXXXY & $X X X X X X X X$ & $X X Y Y Y X X X$ & $X Y Y Y$ \\
\hline 65 & 273 & 278 & 283 & XXXXXXXX & $X X X X X X X$ & ХХХУУУХХ & \\
\hline
\end{tabular}

\begin{tabular}{|c|c|c|c|c|c|c|c|}
\hline 5 & 5 & 6 & 6 & ХYXXXXXYY & YYYXXYYYX & XXXYYSSY & $8 \times 383888$ \\
\hline ?. & 2 & 3 & 3 & ХXYXXXXXX & ХצXXXXXX & XYXYYYY & XYXXYXXXXX \\
\hline 0 & 0 & 0 & 0 & УXXXXXXX & \XXXXXXX & YYXXXYYY & 8XXYצXYYX \\
\hline 0 & 0 & 0 & 0 & XXXXXXXX & צXXXXXXX & ХХУУУУУУ & XYXYYXY \\
\hline 0 & 0 & 0 & 0 & ХXXXXXXYZ & XXXXXXXY & XXYYXIYY & CXXXXYXX \\
\hline & 7 & 9 & 9 & ХXXYYXXY & XXXXYYXXX & ХХХХYЧऽУ & XXXXXXXX \\
\hline
\end{tabular}

NOIE: GOVERHKENT WORKYEARS (Section 21) are not Included in subtotal for Category 2 or Grand yotal. 


\section{DEPLRTYENT OP EYIROY TELECOHAWICATIONS RESTRECS ESTLHTE Resource Eatiates is thousands}

Schedule 4-1B

Part 2

SI toI ARGONAE ILTIOHAL LABORATORY (ANL)

Functional Area: Rrequenoy Spectrun-Dependent Counusications

PROORAHALTIC DISTRIBTTICH OF CATECOR:! 1 - CAPTTAL INVESTMENTS

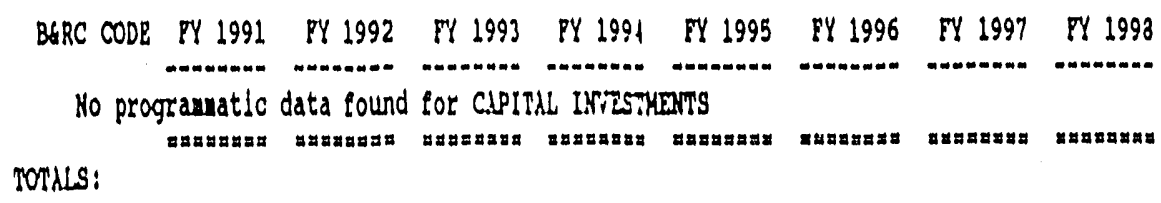


ANL Site Response for the DOE FY1994 Information Resources Management Long Range Plan Murch 25, 1992

B. Frequency Spectrum-Dependent Communteations

\section{G. Schedule 4-2, Major Telecommunications Initiatives}

None 
ANL Site Response for the DOE FY1994 Information Resources Management Long Range Plan C. Other Teleservices Activities and Programs

\section{Section C}

\section{Other Teleservices Activities and Programs}

\section{A. Teleconferencing Activities}

\section{Strategies and Major Accomplishments}

The Laboratory expects to use teleconferencing to improve productivity, expand educational and training opportunities, and further reduce travel costs. The Laboratory is planning to expand the site fiber optic network needed for telephone operations and data communication. The fiber optic network will include fibers for onsite video conferencing.

The Laboratory will provide communications from ESnet to the DOE-CH New Production Reactor program's video teleconferencing facility beginning in 1992. Program direction and equipment funding is by DOE Headquarteis. The Laboratory's High Energy Physics Division is to be on the Superconducting Super Collider (SSC) video conferencing network over existing ESnet communication facilities beginning in 1992.

The Laboratory already utilizes satellite downlink for educational programs. The Laboratory has investigated the installation of a satellite up/down link and has determined that it is not yet cost effective at this time. The Laboratory will lease satellite service when there is a need. This service will be distributed throughout the site on a fiber optic network.

New DOE requirements for Emergency Operations Center compatibility requires VSAT communications. No Laboratory funds will be used.

\section{Reconciliation to FY1993 Plan}

The FY1993 Plan include significant increases in video teleconferencing activities. The satellite up/down link portion of the plan has been deleted.

\section{Currently Utilized SeryicesiPlanned Minor Enhancements}

Voice Teleconferencing--Speakerphones and the PBX conferencing feature are commonly used for teleconferencing. Common carrier conferencing service is used for larger groups.

Portable Conference Telephones--Eight ANL-owned portable conferencing telephones are used for small telephone conference meetings.

Conference Room Audio Teleconferencing--The Laboratory has one conference room permanently equipped to provide teleconferencing service for the Office of the Director.

Auditorium Audio Teleconferencing--The Laboratory has one auditorium permanently equipped to provide audio teleconferencing service with any location on the telephone network. The teleconferencing equipment is electrically connected with the auditorium sound system. 
ANL Site Response for the DOE FY 1994 Information Resources Management Long Range Plan March 25, 1992

C. Other Teleservices Activities and Programs

Video Teleconferencing--The Laboratory uses satellite downlink and voice telephone service to participate in education and training programs.

\section{Planned Minor Initiatives/New Systems or Services}

The Laboratory's High Energy Physics Division is to be added to the existing Superconducting Super Collider video teleconferencing network via an existing microwave link to Fermilab using ESnet. Video teleconferencing equipment and network interface equipment are on order.

5. Planned Major Initiatives

None 
ANL Site Response for the DOE FY 1994 Information Resources Management Long Range Plan C. Other Teleservices Activities and Programs

March 25, 1992

\title{
6. Schedule 4-1C1, Telecommunications Resource Estimates
}

\author{
DEPARTKEAT: OP DUERO! \\ TRLECONTNICATIONS RESOURCES ESTIMATE
}

Schedule $4-1 C 1$

Part: 1

Site: ARGONE MATHONAL LABOR!TOR! (ANL)

Functional Area: Teleconfarencing Actirities

REPORIING CAIECORY

1. CAPITAL IWVESTYENTS

A. Purchase of Bardware

B. Purchase of Sof tiare

C. Site Preparation

SUBTOTAL CATECOR! 1

\begin{tabular}{|c|c|c|c|c|c|c|c|}
\hline \multicolumn{8}{|c|}{ Resource istiaates in Thousands } \\
\hline FY 1991 & FY 1992 & PX 1993 & NI 1994 & ก! 1995 & FY $19: 5$ & FI 1999 & If 1998 \\
\hline 95 & 325 & 115 & 115 & XXYYYYYX & XXXYYYXY & XYXYXXYXX & 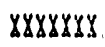 \\
\hline 0 & 1 & 6 & 6 & XYXXYXXY & XXXXXXYY & XYXXYXXXX & $X X X X X X X 3$ \\
\hline 26 & 25 & 60 & 65 & YYYYYYYY & XXYXXYYY & YXXXXXYY & XYXXYXXYY \\
\hline 121 & 354 & 181 & 186 & 191 & 196 & 201 & $20:$ \\
\hline
\end{tabular}

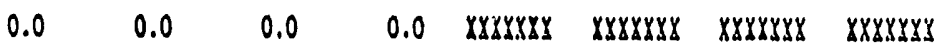

OPERATING COSTS

A. Government iorkjears

B. Inbouse Personnel costs

1. Systea Operations

2. Systes Maintenance

3. Analysis/Design/Dogineering

4. Systen studies and other

C. Other Inhouse operating costs

1. Bardware/Softrare Purcbases

2. Lease of Baruivare

3. Lease of Software

1. Space

5. Supplies and other

SUBTOTAL CATECORY 2

3. COMUERCIAL SERTICES

$\lambda$. Leased Voice Comunications

B. Leased Data Counuications

C. Operations/Maintenance

D. Systeus analysis, Progranaing

Design, and engineering

R. Studies and other

SUBTOTAL CATRGORY 3

4. MOHCOHMERCIAL SERIICES

d. Paynents

1. Other DOE Sites

2. Other Execuitive Brancb dgencies

3. Other Honcomercial Serifice

B. Offsetting Collections $(-)$

SUBTOTAL CATECORY \&

SOBTORAL FOR CONBINED CATEGORIES $2 \div 3-4$

GRAND TOTAL

MOTE: GOVRRMENT inRRIELRS (Section 2i) are not included in subtotal for category 2 or Grand total.
XXXYYXYY XYYYYYYY XXY XXYYYYY

XXXXXYXX $X X X Y Y X X X \quad X X X X Y X X$

XYXYXXYY XXXYYYXX XXXXXXYYY

XXXXXXXX $X X Y Y Y X X X \quad X X X X X Y X$

\begin{tabular}{|c|c|c|c|c|c|c|c|}
\hline 2 & 5 & 10 & 10 & XXXXXXXY & XXXXXXXY & $X X X X X Y X X$ & $x y X X X Y Y Y$ \\
\hline 1 & 0 & 0 & 0 & XXXXXYYY & XXXXXXXX & XXXXXYXX & XXXXXXXX \\
\hline 0 & 0 & 0 & 0 & $X X X X X X X X$ & XXXXXXYY & XXYYYYXX & XXXXXXXX \\
\hline 30 & 50 & 55 & 60 & XXYYYYYXX & $X X X X X X X X$ & XXXXXYXXX & $x X X X X X X Y Y$ \\
\hline 2 & 6 & 12 & 13 & XXXXXYXX & XXYXXXXX & XXXYYXXY & XXXXYYYY \\
\hline 85 & 176 & 192 & 226 & XXYYYYXXX & ХXYYXXXX & XXYYYXXY & $X X X X X X X$ \\
\hline
\end{tabular}

\begin{tabular}{|c|c|c|c|c|c|c|c|}
\hline 0 & 0 & 0 & 0 & XXYYYYXX & УXXXXXXX & ХYYYXYY & XXXXYYYY \\
\hline 0 & 17 & 133 & 158 & XXXXXXXX & $X X X X Y X Y X$ & XXYYYXXY & $X X X X X X Y Y$ \\
\hline & 0 & 0 & 0 & XXXYYXXY & XXXXXXXY & ХXXYYYYY & $X X X X Y Y X$ \\
\hline & 0 & 0 & 0 & YYXXXXYX & $X X X X X X X X$ & ХXYYYYXY & XXXXXXY \\
\hline 0 & 0 & 0 & 0 & $\triangle X X Y X X Y Y$ & XXXXYYYY & ХXXYYYYY & XXXXXXY \\
\hline & 17 & 133 & 158 & XYXYXYYY & XXXXXYYY & ХХХYYYY & $X X X X X Y X$ \\
\hline
\end{tabular}

\begin{tabular}{|c|c|c|c|c|c|c|c|}
\hline 0 & 0 & 0 & 0 & $X X X X X X X Y$ & XXXXXXXX & XYYYXYX & XXXXXXY \\
\hline 0 & 0 & 0 & 0 & $X X Y Y X X X Y$ & $X X X X X X Y Y$ & XXXXYYXY & $X X X X X Y Y Y$ \\
\hline 0 & 80 & 80 & 80 & XXYXXYYX & XXXXXXXX & XXXYXXXY & $X X Y Y Y Y Y Y$ \\
\hline 0 & 0 & 0 & 0 & $\triangle X X X X X Y$ & $X X X X X X X X$ & XXXYYYYY & XXXXXYXY \\
\hline 0 & 80 & 80 & 80 & XXXXXXXX & XXXXXXYY & Х\УYYYY\} $&{X X X X X Y Y} \\
{\hline 85} &{273} &{405} &{164} &{507} &{560} &{500} &{500} \\
{\hline 206} &{627} &{586} &{650} &{698} &{756} &{761} &{761} \\
$\hline
\end{tabular}


ANL Site Response for the DOE FY 1994 Information Resources Management Long Range Plan March 25, 1992

C. Other Teleservices Activities and Programs

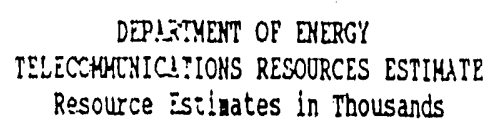

Schedule $+-: C !$

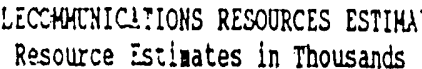

Part 2

Site: ARGONNE NITIONAL LLBCRITORI (INL)

Punctional Area: Teleconierencing dcti;i::

PRCGRAMMITIC DISTRIBTICS Ji CATEGORY 1 - CIPITIL INVESTMEITS

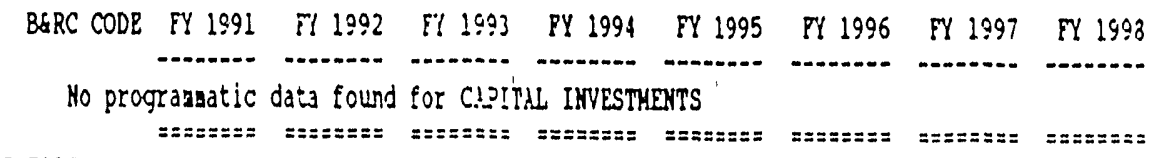
TOT!LS:

Onuatched SCBTOMLLS for CITECORII 1 - CIOITAL INVESTMENTS

$\begin{array}{llllllll}121 & 354 & 131 & 186 & 191 & 196 & 201 & 201\end{array}$

PROGRAHLITIC DISTRIBCTICA C? CITECORIES $2+3+4$ - OPRRATING EXPEHSES
B\&RC CODE PY 199! FY 1992 TI 19993 PY 1994 PY 1995 FY 1996 FY 1997 FY 19?3
No progranatic data found for CFPIIING EXPENSES

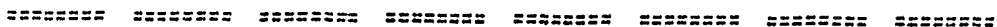
TOTALS:

Onwatched SOBTOTILS for CCFBLYED CATEGARIRS $2+3+4$ - OPERATING EXPEYSES

$\begin{array}{llllllll}85 & 273 & 4,5 & 464 & 507 & 560 & 560 & 560\end{array}$ 
ANL Site Response for the DOE FY 1994 Information Resources Management Long Range Plan C. Other Teleservices Activities and Programs

\section{Schedule 4-2, Major Telecommunications Initiatives \\ None}

\section{B. Communications Security (COMSEC) Programs}

1. Communications Security (COMSEC)

\section{a. Strategies and Major Accomplishments}

Four STU-III telephones are currently in use for Security and Engineering Research. The STU-III telephones are used for voice communications. There are no plans for data communications.

\section{b. Reconciliation to FY1992 Plan}

The STU-III ordered by ANL was cancelled.

c. Currently Utilized Services

Four STU-III telephones are in operation that use Commercial Telephone Service.

\section{d. Planned Minor Initiatives}

DOE's Emergency Operation Center (EOC) compatibility requirements may determine that COMSEC equipment be installed in a joint Argonne/DOE-CH EOC. Argonne has no independent plans.

e. Planned Major Initiatives

None 


\section{f. Schedule 4-1C2.1, Telecommunications Resource Estimates}

DEPIRTYEYI OP ENERG!

TELECCHINACATIONS RESOURCES ESTIKATE
Schedule $4-162.1$ Part 1

SIte: ARGOMIE NATIONAL LIBORATORY (ANL)

Punctional Area: CCHSEC

REPORTIHG CATECORY

1. CAPITAL INVESTMEMTS

A. Purchase of Bardvare

B. Purchase of Softuare

C. Site Preparation

SUBTOTAL CATEGORY I

2. TELECOHONICATYONS

OPERATING COSTS

A. Covernment Workyears

B. Inhouse Personnel costs

1. Systel Operations

2. Syste Maintenance

3. Analysis/Design/Engineering

4. Syster studies and other

C. Other Inbouse Operating costs

1. Bardware/Software Purchases

2. Lease of Barduare

3. Lease of softrare

4. Space

5. Supplies and other

SOBTOTAL CATEGORY 2

3. COMERCINL SERTICES

A. Leased Voice Comunications

B. Leased Data Comminications

C. Operations/Maintenance

D. Systers Analysis, Prograaning

Design, and Engineering

E. Studies and otber

SUBTOTAL CATECORY 3

1. NONCOMUERCIAL SERVICES

A. Paysents

1. Other DOR Sites

2. Other Bxecurive Branch Agencies

3. Other Noncomercial Serrice

B. Offsetting collections $(-)$ SUBTOTAL CATEGORY +

SCBTOTAL FOR COKBINED CATEGORIES $2 \div 3+4$

GRAND TOTAL
Resource Estiuates in Thousands

FI 1991 FI 1992 FY 1993 FI 1994 FY 199: FY 1996

FI' 1997 F'" 1998

\begin{tabular}{|c|c|c|c|c|c|c|c|}
\hline 15 & 13 & 13 & 16 & 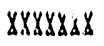 & $X X X X X X X X$ & YYYXXXXXX & ХХYYXXXX \\
\hline 1 & 0 & 1 & 0 & $X X X X X X X X$ & $X X X X X X X X$ & XYXXXXXXX & XYYYYYYXX \\
\hline 0 & 0 & 0 & 0 & $\triangle 8 X X X X X X$ & $x x \times x \times x \times x$ & YY\XXXXX & ХXXYYYY \\
\hline 16 & 13 & If & 16 & 17 & 17 & 17 & 17 \\
\hline
\end{tabular}

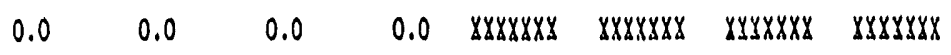

\begin{tabular}{|c|c|c|c|c|c|c|c|}
\hline 33 & 37 & 38 & 40 & XXXXXXXX & XXXXXXXX & $X Y Y X X X X X$ & XYXXYYYYY \\
\hline 29 & 30 & 30 & 33 & $8 \times x \times x \times x \times$ & $X X X X X X X X$ & XYYXXXXX & XXXXXXXY \\
\hline 1 & 1 & 1 & 1 & XXXXXXXY & $\triangle X X X 8 X 8 x \times$ & XYYYXXXX & $X X Y X X Y Y$ \\
\hline 2 & 2 & 2 & 2 & $x 8 \times x \times x \times x$ & XXXXXXXX & XXXXXXXX & XXXXXXXX \\
\hline
\end{tabular}

\begin{tabular}{|c|c|c|c|c|c|c|c|}
\hline 0 & 0 & 0 & 0 & XXXXXXX & $8 \times X \times 8 \times 8 \times$ & YYYXXXXX & XXXYYYY \\
\hline 0 & 0 & 0 & 0 & $\triangle X X X X X X X Y$ & $X X X X X X X X$ & XXXYXXXX & XXXXYXXXX \\
\hline 0 & 0 & 0 & 0 & $X X X X X X X X$ & XXXXXXXXX & YXYYXXXX & XYXXYXYXX \\
\hline 0 & 0 & 0 & 0 & $X X X X X X X X$ & XXXXXXXX & $X X X X X X X X X$ & YXYXXYYY \\
\hline 1 & 3 & $t$ & 3 & XXXXXXYX & X8XXXXXX & XYXXXXXX & XXXXXYYYY \\
\hline 69 & 73 & 75 & 79 & $X X X X X X X$ & $X X X X X X X$ & XYYYXXXX & XYYXXYY \\
\hline
\end{tabular}

\begin{tabular}{|c|c|c|c|c|c|c|c|}
\hline 2 & 2 & 2 & 2 & $8 X 8 Y X 8 X 8$ & XXXXYYXY & YXYYXXXXX & XYXXYYYYY \\
\hline 9 & 9 & 9 & 9 & XXXX88X8' & XXXXXXXX & УYYYYYXXX & XXXXYYSX \\
\hline 0 & 0 & 0 & 0 & $\triangle X X 8 X X 8 X$ & $X X X X X X X X$ & YYXXXXXX & XXXXXYYY \\
\hline 2 & 2 & 2 & 2 & $\triangle X X X X X X X$ & $X X X X X X X X$ & YY\ХXXXX & YYXYYYY \\
\hline 2 & 2 & 2 & 2 & $x .8 \times 88 \times 8 x$ & XXXXXXXX & YYYXYXXX & XXXXXYXYY \\
\hline & 15 & 15 & 15 & XXYXXXXXX & ХХХXXXXX & XXYYXYXX & ХУYYYУYY \\
\hline
\end{tabular}

\begin{tabular}{|c|c|c|c|c|c|c|c|}
\hline 0 & 0 & 0 & 0 & $X X X X X X X X$ & XXXXXYXXX & УYYYYXXX & \ХХХXYYY \\
\hline 0 & 0 & 0 & 0 & XXXXXXXX & $X X X X X X X X$ & YIIXYYXX & ХХXXXXXX \\
\hline 0 & 0 & 0 & 0 & XXXXXXXX & XXXXXXXX & ХYХYYXXX & $X X X X X Y X X$ \\
\hline 0 & 0 & 0 & 0 & $X X X X X X X X$ & $X X X X X X X Y$ & YXXXXXXX & ХХХХХYY \\
\hline 0 & 0 & 0 & 0 & $\triangle \triangle X X X X Y Y$ & XXXXYXXY & ХYYXXXXX & ХYYYYYYY \\
\hline 84 & 88 & 90 & 94 & 96 & 100 & 102 & 106 \\
\hline 100 & 101 & 104 & 110 & 113 & 117 & 119 & 123 \\
\hline
\end{tabular}

HOMR: GOVRRMKENT WORRYERS (Section 21) are not included in subtotal for Category 2 or Grand Total. 
ANL Site Response for the DOE FY1994 Information Resources Management Long Range Plan

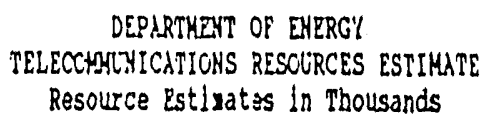

Schedule $\$-1 C 2.1$

Part 2

Site: ARCONNE NAPIONAL WHBORATORY (ISL)

Punctional Area: COHSEC

PROCRAMATIC DISTRIBTTIOH OP CATEGORY 1 - CAPITAL INVESTHENTS

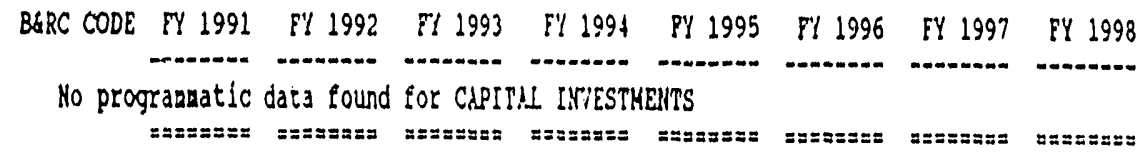
TOTALS:

Onuatched SCBTOTALS fOr CATECORY 1 - CAPITML INTESTMEMTS

$\begin{array}{lllllllll}16 & 13 & 14 & 16 & 17 & 17 & 17 & 17\end{array}$

PROCRAMUATIC DISTRIBOTICH OP CITEGCRIES $2+3+4$ - OPERATIHC EXPEISES

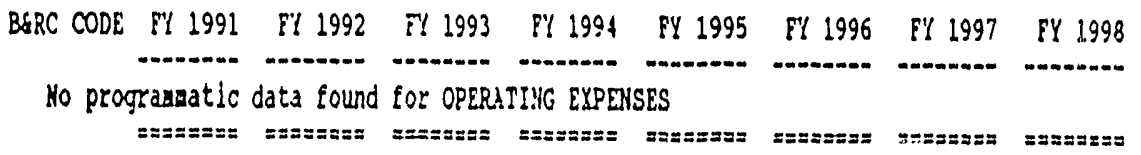

TOTALS:

Onatched SCBTOTALS for COYBIMED CAIECORIES $2+3+4$ - OPERATIMG EXPPYSES

$\begin{array}{llllllll}81 & 88 & 90 & 94 & 96 & 100 & 102 & 106\end{array}$


ANL Site Response for the DOE FY1994 Information Resources Management Long Range Plan March 25, 1992

C. Other Teleservices Activities and Programs

\section{g. Schedule 4-2, Major Teiecommunications Acquisitions}

None

\section{Emission Security (TEMPEST) Testing Program}

At the present time the Laboratory has no programs which meet the TEMPEST Testing program criteria as described in the call for FY1994 Information Technology Resources LongRange Plans.

\section{Protected Disiribution System (PDS) Program}

At the present time the Laboratory has no programs which meet the Protected Distribution System (PDS) program criteria as described in the call for FY1994 Information Technology Resources Long-Range Plans.

\section{National Security Emergency Preparedness Program (NSEP)}

At the present time the Laboratory has no programs which meet the NSEP program criteria as described in the call for FY1994 Information Technology Resources Long-Range Plans. 
ANL Site Response for the DOE FY 1994 Information Resources Management Long Range Plan

D. DOE Teleprocessing Services Program (TSP)

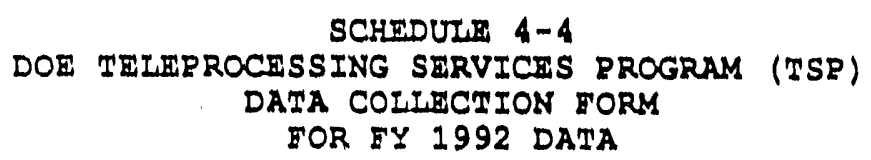

Rlease Print or Type

SITE CODE: ANL GORM NO.:

(Assignad by $A D-252$ )

1. SITE NAME: ARGONNE NATIONAI IABORATORY

2. TECFNICAI CONMACT NANIE: Shannon D. Savage

TITIE: IPD/TIS Director

TELEPHONE NUMBER: 708-252-4221

ADDRsSS: TIS, Bldg 203 - D140, 9700 S, Cass Avenue

Argonne, IL $60439-4843$

3. VENDOR NAME: STN - Int'1, 0/0 Chemical Abotracts Service

ADDRESS: R.O. BOX 2228, 2540 Olertangy Rlver Rd.

Columbus, OH 43202

4. TYPE OF SERVICE: 03 - Bibliographic Retrieval

5. DATA BASE OR. SOETWARE USED: STN

6. TOTAL EY 1991 EXPENDITURES: $\$ 17,164$

7. TYRE OE CONTRACT: PO

8. CONTRACT END DATE: 09/92

9. DISCOUNT NEGOTIATED?: ___ YaS _ _ NO

IE YES, TYPE OF DISCOUNT:

10. PIANNED EXPENDITURES:

$\begin{array}{rrr}\text { FY } 1992 & \text { ZY } 1993 & \text { FY } 1994 \\ 25,000 & \$ 27,000 & \$ 30,000\end{array}$


ANL. Site Response for the DOE FY 1994 Information Resources Management Long Range Plan Murch 25, 1992

C. Other Tuleservices Activites and Programs

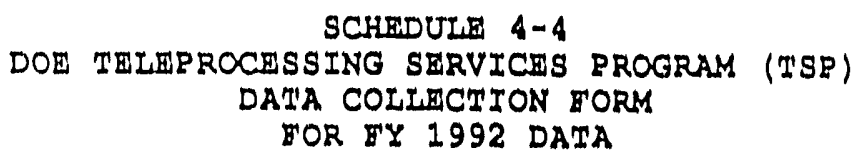

Please Print or Type

SITE CODE: ANI EORN NO.:

(Asslgned by $A D-252$ )

1. SITE NAME: ARGONNE NATIONAI LABORATORY

2. TECHNICAI CONTACT NAME: Shannon D. Savage

TITLE: IPD/TIS Diractor

TELERHONE NUMBER: $708-252-4221$

ADDRESS: TIS, Bldg 203 - D140, 9700 S. Cass Avenue

Argonne, II $60439-4843$

3. VENDOR NAME: Regearch Libraries Group, Inc.

ADDRESS : 1200 V 111 a street

Mountain V1ew, CA 94041-1100

4. TYPE OF SERVICE: 03 - Blbliographlo Retrleval

5. DATA BASE OR SOFTHARE USED: RIIN

6. TOTAL EY 1991 EXPENDITURES: $\$ 377$

7. TYRE OF CONTRACT: 20

8. CONTRACT END DATE: $12 / 92$

9. DISCOUNT NEGOTIATED? : YES $-X$ NO IE YES, TYRE OH DISCOUNT:

10. PLIANNED EXPENDITURES:

$$
\begin{array}{r}
\text { EY } 1992 \\
\$ \quad 1,000
\end{array}
$$


ANL Slte Response for the DOE FY 1994 Informatton Resources Management Long Range Plan C. Othor Teleservices Activitles and Programs

\section{SCHADETI $4-4$ \\ DOH TELMROCHSSING SWRVICHS PROCRAM (TSR) \\ DATA COLIJCWION TORM \\ HOR TY 1992 DATA}

Rlasse Relnt or Type

SITE CODE: ANI

EORM Nu:

(Ass dgnad by $A D-252$ )

1. SITE NAME: ARGONND NATIONAI LABORATORY

2. TECHNICAT CONTACI NAMA: Shannon D. Saraga

TIIIT: IED/TIS DIractor

TELIPHONE NUMBER: 708-252-4221

ADDRBSs: TIS, Bldg 203 - D140, 9700 s, Cass Avanua

Argonna, II $60439 m 4843$

3. VIANDOR NAMOH: Orbit Saarch Sarvioe

ADDRESS: 8000 Weatpark DrLue

Mo Lean, VA 22102

4. TYRE OF SERVICE: 03 - Blbllographla Ratrleval

5. DATA BASE OR SOETWARE USED: ORBIT

6. TOTAL FY 1991 EXPINDITURES: \$

7. TYRE OI CONTRACT: PO

8. CONTRACT RND DATH: $09 / 92$

9. DISCOUNT NEGOMIATED?: YRS $\quad x$ NO

II YIS, TYRE OF DISCOUNT:

10. PIANNWD EXPENDITURES:

$\begin{array}{lrl}E Y 1992 & E Y 1993 & \text { EY } 1994 \\ 2,040 & \$ 2,040 & \$ 2,040\end{array}$


ANL Stle Response for the DOE FY 1994 Informatlon Resources Management Long Range Plan Murch 25, 1992

C. Other Teleservices Actlvittes and Progranis

\section{SCHBDUTH $4-4$ \\ DOE TILEEROCESSING SERVICES RROGRAM (TSP) \\ DATA COLLICTION E'ORM \\ BOR BY 1992 DATA}

Plase Print or Type

SIII CODH: ANL FORM NO : :

(Assigned by $A D-252$ )

1. SITE NAMP: ARGONNE NATIONAI IABORATORY

2. TECHNICAI CONTACT NAME: Shannon D. Savaga

TITIH: IRD/TIS Director

TILIIPHONE NUMBER: $708-252-4221$

ADDRESS: TIS, Bldg 203 - D140, 9700 s. Cass Avenue

Argonne, IL 60439-4843

3. VINDOR NANA: NASA Sclentifio Technical Information gaotitty

ADDRESS: P. O. BOX 8757

BatILmore/Wash Intnl Alrport, MD 21240

4. TYPE OF SERVICE: 03 - Blbllographio Retrieval

5. DATA BASE OR SOETWARE USAD: NASA/RECON

6. TOTAL FY 1991 EXPENDITURES: $\$ 67$

7. TYPE OF CONTRACT: PO

8. CONTRACT END DATE: $12 / 92$

9. DISCOUNT NEGOTIATED?: __ YES _X_ NO IF YES, TYPE OF DISCOUNT:

10. PLANNED EXPENDITURES:

$$
\$ \begin{array}{r}
1992 \\
300
\end{array}
$$$$
\$ \begin{array}{r}
1993 \\
300
\end{array}
$$$$
\text { FY } 1994
$$

$\$ 300$ 
ANL Slte Response for the DOE FY1994 Information Resources Munagement Long Range Plan C. Other Teleservices Actuvitles and Programs

\section{SCHFDUTE 4-4 \\ DOE TELERROCESSING SERVICAS RROGRAM (TSP) \\ DATA COLIRCTION FORM \\ FOR TIY 1992 DATA}

Rlease Print or Type

SITE CODE: ANL BORM NO.:

(Assigned by $A D-252$ )

1. SITE NAME: ARGONNE NATIONAL IABORATORY

2. TECHNICAL CONTACT NAME: ShannON D. Savage

TITIE: IRD/TIS DIrector

TEIEPHONE NUMBER: 708-252-4221

ADDRESS: TIS, BLdg 203 - D140, 9700 S. Cass Avenue

Argonne, II $60439-4843$

3. VIRDOR NAME: IIlinet/OCLC Services

ADDRESS: Illinols state Ilb., 288 Centennial Bldg.

Springfield, II 62756

4. TYPE OF SERVICE: 03 - Blbliographic Retrieval

5. DATA BASE OR SOETWARE USED: OCLC

6. TOTAL EY 1991 EXPENDITURES: $\$ 16,786$

7. TYRE OT CONMRACT: PO

8. CONTRACT END DATE: $08 / 92$

9. DISCOUNT NEGOTIATED?: _ YES

IE YES, TYPE OF DISCOUNT:

10. PIANNTD EXPENDITURES:

$\begin{array}{rrr}\text { TY } 1992 & \text { TY } 1993 & \text { FY } 1994 \\ \$ 18,500 & \$ 20,000 & \$ 20,000\end{array}$


ANL Site Response for the DOE FY 1994 Information Resources Management Long Range Plan March 25, 1992

\section{SCHEDUTE $4-4$
DOE TELERROCMSSING SERVICES RROGRAM (TSR) \\ DATA COLIECTION EORY \\ IOR EY 1992 DATA}

Please Print or Type

SITE CODE: ANI BORY NO.:

(Ass Igned by $A D-252$ )

1. SITE NAME: ARGONNE NATIONAI IABORATORY

2. TECHNICAI CONTACT NAME: ShannOR D. Savage

TITIE: IRD/TIS DIrector

TEIEPHONE NUMEER: $708-252-4221$

ADDRESS: TIS, BIdg 203 - D140, 9700 S. Cass Avenue

Argonne, II 60439-4843

3. VINDOR NAME: DOE Offlce of Sclentific a Technical Information

ADDRESS: 2.0. BOX 62

Oak RIdge, IN 37831

4. TYRE OF SERVICE: 03 - BLblographic Retrleval

5. DATA BASE OR SOETHARE USED: ITIS \& SIS

6. TOTAI TY 1991 EXPENDITURES: $\$ 3,590$

7. TYPE OF CONTRACT: Deposit account

8. CONTRACT END DATE: 09/92

9. DISCOUNT NEGOTIATED?: __ YaS _

IF YES, TYRE OT DISCOUNT:

10. PIANNED EXPENDITURES:

$\begin{array}{lll}\text { EY } 1992 & \text { TY } 1993 & \text { FY } 1994 \\ 4,000 & \$ 5,000 & \$ 5,000\end{array}$


ANL Site Response for the DOE FY 1994 Information Resources Management Long Range Plan

C. Other Teleservices Activities and Programs

March 25, 1992

\section{SCHEDUTE 4-4 \\ DOE TEIEPROCESSING SERVICES PROGRAM (TSP) \\ DATA COLIECTION FORM \\ FOR EY 1992 DATA}

Please Print or Type

SITE CODE: ANI

FORM NO.:

(Assigned by $A D-252$ )

1. SITE NAME: ARGONNE NATIONAL IABORATORY

2. TEChNICAI CONTACT NAME: Shannon D. Savage

TITLE: IPD/TIS Dizector

TELEPHONE NUMBER: 708-252-4221

ADDRESS: TIS, BIdg 203 - D140, 9700 S. Cass Avenue

Argonne, II 60439-4843

3. VENDOR NAME: Dialog Information Services

ADDRESS: 3460 Hillview Avenue

Palo Alto, CA 94304

4. TYPE OF SERVICE: 03 - Bibliographic Retrieval

5. DATA BASE OR SOETWARE USED: DIALOG

6. TOTAL FY 1991 EXPENDITURES: $\$ 48,811$

7. TYPE OF CONTRACT: PO

8. CONTRACT END DATE: 09/92

9. DISCOUNT NEGOTIATED?: _ Y YES _X_NO

IF YES, TYPE OF DISCOUNT:

10. PLANINED EXPENDITURES:

$\begin{array}{rrr}\Sigma Y 1992 & F Y 1993 & F Y 1994 \\ \$ 65,000 & \$ 65,000 & \$ 65,000\end{array}$


ANL Site Response for the DOE FY1994 Information Resources Management Long Range Plan March 25, 1992

C. Other Teleservices Activities and Programs

\section{SCHEDUTE 4-4 \\ DOE TEIEPROCISSING SERVICES PROGRAM (TSP) \\ DATA COLLECTION FORM \\ TOR FY 1992 DATA}

Please Print or Type

SITE CODE: ANI FORM NO.:

(Assigned by $A D-252$ )

1. SITE NAME: ARGONNE NATIONAI IABORATORY

2. TEChNICAI CONTACT NAME: Shannon D. Savage

TITIE: IPD/TIS Director

I'ELEPHONE NUMBER: 708-252-4221

ADDRESS: TIS, Bldg 203 - D140, 9700 S. Cass Avenue

Argonne, II 60439-4843

3. VENDOR NAME: Defense Techrical Information Center

ADDRESS: Cameron Station

Alexandria, VA 22304-6145

4. TYPE OF SERVICE: 03 - Bibliographic Retrieval

5. DATA BASE OR SOFTWARE USED: DROLS

6. TOTAI FY 1991 EXPENDITURES: $\$ 219$

7. TYPE OF CONTRACT: Deposit accourt

8. CONTRACT END DATE: 09/92

9. DISCOUNT NEGOTIATED?: YES _X_ No

IF YES, TYPE OF DISCOUNT:

10. PLANNED EXPENDITURES:

$$
\text { FY } 1992
$$

$\$ 300$

$\$ \begin{array}{r}1993 \\ 400\end{array}$

FY 1994

$\$ 400$ 
ANL Site Response for the DOE FY 1994 Information Resources Management Long Range Plan

\section{SCHEDUTE 4-4 \\ DOE TELERROCESSING SERVICES RROGRAM (TSP) \\ DATA COIIECTION FORM \\ EOR EY 1992 DATA}

Rlease Print or Type

SITE CODE: ANI FORM NO.:

(Assigned by $A D-252$ )

1. SITE NAME: ARGONNE NATIONAI LABORATORY

2. TECHNICAI CONTACT NAME: ShannOR D. Savage

TITIE: IPD/TIS Director

TEIEPHONE NUMBER: 708-252-4221

ADDRESS: TIS, Bldg 203 - D140, 9700 S. Cass Avenue

Argonne, IL $60439-4843$

3. VENDOR NANE: BRS Information Technologies

ADDRESS: 8000 Westpark Drive

Mc Lean, VA 22102

4. TYRE OF SERVICE: 03 - Bibliographic Retrieval

5. DATA BASE OR SOETWARE USED: BRS

6. TOTAL EY 1991 EXPENDITURES: $\$ 5,851$

7. TYRE OF CONTRACT: 20

8. CONTRACT END DATE: $09 / 92$

9. DISCOUNT NEGOTIATED?: __ YES _ $X$ NO

IF YES, TYPE OF DISCOUNT:

10. RLANNED EXPENDITURES:

$\begin{array}{lrr}\text { FY } 1992 & \text { FY } 1993 & \text { FY } 1994 \\ \$ 15,100 & \$ 16,000 & \$ 18,000\end{array}$


ANL Site Response for the DOE FY 1994 Information Resources Management Long Range Plan Part 5:

\section{Part 5}

\section{Printing and Publishing Plan}

ANL-5.0.1 
ANL Site Response for the DOE FY1994 Information Resources Management Long Range Plan

A. Three-Year Printing and Publishing Activities Plan

\section{Section A}

Three-Year Printing and Publishing Activities Plan 
ANL Site Response for the DOE FY 1994 Information Resources Management Long Range Plan March 25, 1992

A. Three-Year Printing and Publishing Activities Plan

\section{A. Printing and Publishing Activity}

The Information and Publishing Division (IPD) of Argonne National Laboratory was established in August 1991. Its mission is to provide services that enhance the quality, timeliness, and costeffectiveness of communication in two contexts:

- Exchange of scientific and technical information between Argonne and its research and development $(\mathrm{R} \& \mathrm{D})$ sponsors and between Argonne and the R\&D community at large.

- Exchange of administrative and operating information within Argonne and between Argonne and the Depart.nent of Energy.

The Division fulfills its mission as follows:

- Acquiring, managing, and disseminating information:

IPD operates specialized libraries; manages and provides access to electronic information systems; purchases publications for libraries and R\&D staff; and disseminates Argonne publications through Department of Energy channels.

- Preparing information products:

IPD provides a full range of services to support preparation of publications and presentation materials, including design and production planning, writing, editing, computer-based text and graphics processing, photographic and digital imaging, and printing.

- $\quad$ Representing Argonne's information and publishing interests:

IPD serves as the Laboratory's point of contact with the Department of Energy for planning and policy development regarding scientific and technical information, printing, and publishing.

The Division is committed to pursuing continuous improvement within its operations and to providing broad leadership within Argonne in achieving excellence in information management and communication. In all activities, IPD places the highest priority on employee safety and environmental protection. 
ANL, Site Response for the DOE FY 1994 Information Resources Management. Long Range Plan

A. Three-Year Printing and Publishing Activities Plan

March 25, 1992

Schedule 1.1: Schedule 5-1, Equipment Acquired During Fiscal Year 1991

None

ANL-5.1.3 
ANL Site Response for the DOE FY1994 Information Resources Management Long Range Plan March 25, 1992

A. Three-Year Printing and Publishing Activities Plan

Schedule 1.2: Schedule 5-2, Narrative Report - JCP Approved Equipment only

None 
ANL Site Response for the DOE FY 1994 Information Resources Management Long Range Plan

PRIATINO AKO PUBLISHINO ACTIVITY BLOOEY PROJECTIONS (Dollers in thousands)

FACILITY NAME: Argome Natlonal Laboratory: East

ADDRESS:

9700 s. Cass, Bldg, 222, Med Argonne, IL $60439 \cdot 4828$

In-House Printing (Schedule 5-9)

(JCP form No, 1)

In-House Dupl leating (Scliedule 5-12)

(Duplicating Facillty Report)

Private sector Printing:

QPO/RPPO Activities (Schedule 5-13)

INICOR Activities (Schadule 5.14)

Direct Commerclal Procurement (Schedule 5.10)

(Report full FY date from JCP form 2's)

Composition:

In-House

OPO/RPPO

Copying Activily (schedule 5-15)

(Conventence Cuplers Only)

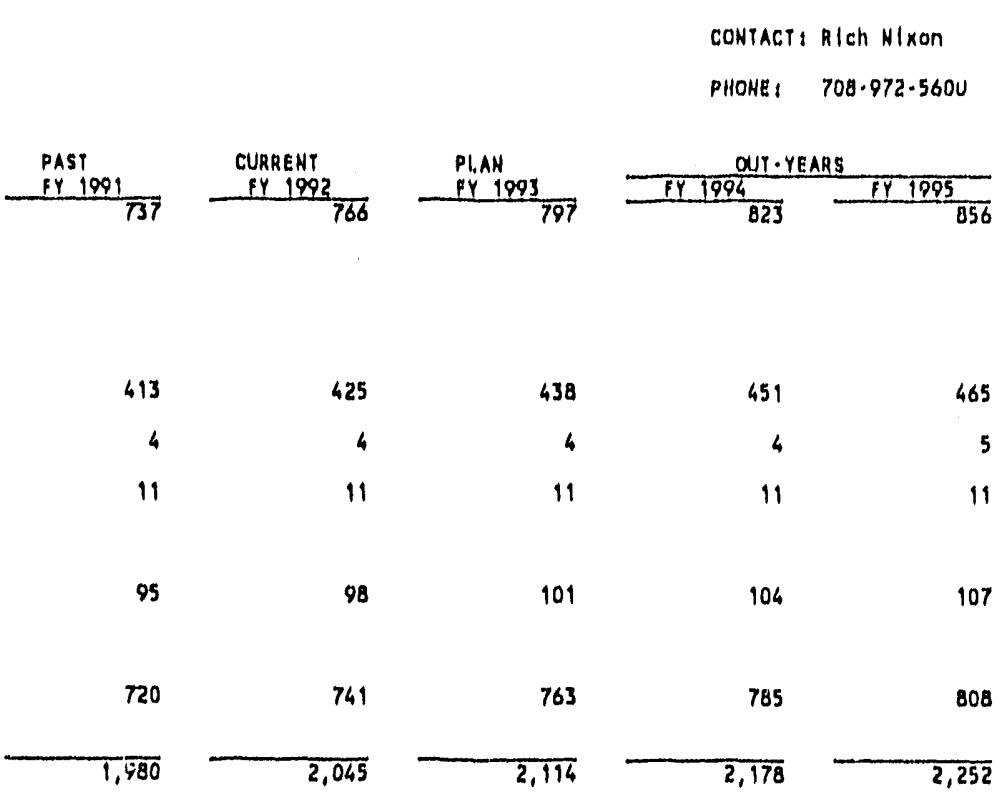


ANL Site Response for the DOE FY 1994 Information Resources Management Long Range Plan March 25, 1992

A. Three-Year Printing and Publishing Activities Plan

PRINTINO AHD PUULISHIHQ ACTIVITY PRCOUCTION PROJECTIOHS

PAClLIYY HAME: Argorme Hatlonal Laboratoryt Eawt

ADDRESS1 9700 s. CayH, gldo, 222, hod Argonne, IL $60439 \cdot 4820$

Acrivity

In-Houso Printing (schedule 5.9)

(JCP Porm Ho, 1)

Product Ion Units/100018

Aotual Jobs

In Houne Dupl loating (Schedule 5.12)

(Oupl laating Facllity Report)

Production Units/1000's

Private sector Printing

OPO/RPPO Activitles (Sohedulo 5.13) Actual Jobs

UNICOR Activitien (schedule 5.14) Actual Jobs

Dlrece commerolal prosurement (schedule 5-10)

(Roport full er data from JCP form 2's) Actual Jobs

Compositions

In. House

GPO/RPPO

Acrual Jobs

Pages

Actual Jobs

Pages

Copylng Aotivity (Schedula 5.15)

(Conventance Coplers only)

Coples/10001.

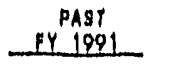

$\begin{array}{r}\text { CURRENT } \\ \text { YY } 1092 \\ \hline\end{array}$

23,725

7,724

$$
24,196
$$

PLAH

EY 1993

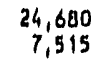

24,600
7,515

25,174
7,665

Soliedule $5 \cdot 4$

$11 / 91$

COHTACr, Rlahard O. Wixon

PIIONA I $700 \cdot 972 \cdot 9600$

FY OUY - YHARS

452

466

480

494

1

3

3

19

15

15

16

16

451
5,007

1,051

1,072

6,226

1,003

6,351

1,115

30,186

31,400

32,342

33,312

34,311 
PACILITY NAHE! Argome Hatlonal Laboratorys East

ADDRESS1 9700 S, CaAs, OLdo, 222, Mad

Argarme, IL $60439 \cdot 4020$

Equipment Description

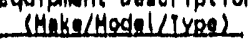

DALH SOO R/H YOLO Alyellation

Paper roldur - progray commitments a supports alh PROORAHS

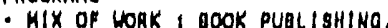
PAMPHLEYS, MYYBAS, AHD AHHOUNCEMENTS - WORK FLON I MAINTAIH PRESENT WORK LOAD OF 345546 SHEETS POLOEO - respohrstole ohganizarlon i aroonhe ORAPHIC ARTS DEPARTMEHT
Annual Cose 4 beaseleurghaus $\$ 20,000$ purchase
Jiest ll lacatlon Unelucle erologlod Gost avoldences)

\begin{tabular}{|c|c|}
\hline Turnaraunel llnwes 3 day & clasulfladi ix \\
\hline Profectc I cost Avoldanous & 82,083 \\
\hline $\begin{array}{l}\text { CURAENT } \\
545,546 \\
\$ 5,015\end{array}$ & $\begin{array}{r}\text { PROPOSED } \\
545,564 \\
52,932\end{array}$ \\
\hline $\begin{array}{l}\text { EOUIPMEH DISPOSED OP OR } \\
\text { Make/Model/PYpe } \\
17,5 \mathrm{KZ2.5}\end{array}$ & $\begin{array}{l}\text { IRAOED. IH } \\
\text { Serf 1.1 Number } \\
5591.54\end{array}$ \\
\hline
\end{tabular}

PRESENT EOUIPMEHT IS 24 YEARS OLD, USED WELL BEYOND ITS EXPECTEO LIFG. IT IS

ONLY CAPABLE OP DOINO THO FOLDS,THE PROPOSED EOUIPHEHT WILL DO FIVE POLDS, AVOIDINO IIIE EXTAA COST OF HAHD FOLDIHO. 
ANL Site Response for the DOE FY 1994 Information Resources Management Long Range Plan March 25, 1992

A. Three-Year Printing and Publishing Activities Plan

PRINTINO AHO PUDLISBHINO ACTIVIIY

HEW EQUIPHENT JUSTIFICATION

Schodule 5.5

flacal Year 1993

PACILITY NAMEI ARgOMme Hatlonal Laboratorys East

AOORESSi 970 s, Cass, aldg, 22z, Mad

Argorne, IL $60439 \cdot 4828$

Equipment Deycription

SHake/Hodel/Iype)

SULBY 1250 BINDEA Appl Lcation

Book Blnder

- PROORAH COMHITHENTS I SUPPORTS ALL PROQRAHS

- MIX OF NORK I GOOK PUULISSHIHO

PAMPIILETS, FORHAL AHD IHFORHAL REPORTS

- IMPROVEMENTS + ReDUCE PRESENT TWO MaH

OPERATION TO ONE HAH OPERATION

Armual Cost a Leasg/Purchava

849,000

Purchave 9 Slnclude prolegifleation

Turnaround times 3 days classifled $1 x$

Prolected Cost Avoldances se, siro

Horkload CURRENT PROPOSEO

$30,000 \quad 30,000$

EQUIPMENT DISPOSED OF OR TRADED.IH

Hake/Model/TYPo Sorlal Number SULOY MINABINDER 7033

NEEDED YO REPLACE EOUIPMENT PURCHASED IH 1962, PRESEHYLY COSTIHO $\$ 2150,00$

IH ANHUAL REPAIRS TO KEEP IN OPERATION 
ANL SIte Response for the DOE FY 1994 Information Resources Management Long Range Plan A. Three-Year Printing and Publishing Activittes Plan

FACILITY NAME, Argonse Hatlonal Laboratory! Eayt

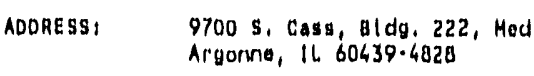

ADDRESS:

9700 s, Cass, Bldg, 222, Hed

Argonne, Ih 60439.4828

Equlpment Description (Make/Modol/TYPa)

MULTIORAPIIICS 1650

Two color printing
Appl loatlon

- prodRam COMMITMEnTS I supports all

PROQRAHS

- HIX of WORK I GOOK PUIglishilha

PAHPHLETS, FLYERS, ANNOUNCEMENTS

- WORK FLOW I MAIHTAIN PRESENT WOAK LOAO

OF $3,040,609$ UHITS

- Responsigle organization I argonhe

ORAPHIC ARTS DEPARMENT
Ainual Cost \& Lease/Purchase

$\$ 26,000$

Purctiase

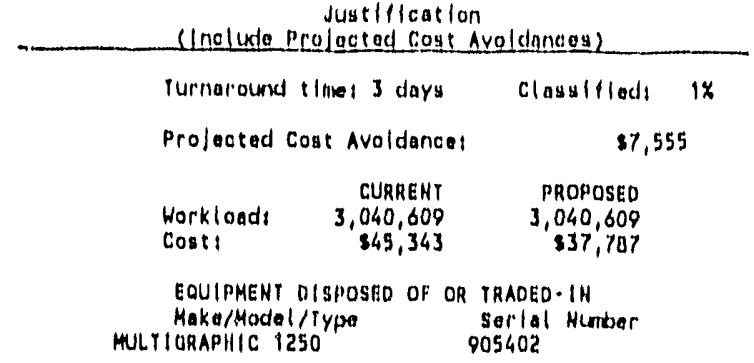

IHIS EOUIPMENT WOULD REPLACE EOUIPMENT PURCHASED IN 1960, UY PURCHASIHO A TWO COLOR PRESS WE CAH REDUCE THE COST OF LABOR $\$ 10900.00$

ANL -5.1 .9$ 
ANL Site Response for the DOE FY 1994 Information Resources Management Long Range Plan March 25, 1992

A. Three-Year Printing and Publishing Actlvittes Plan

PRINTIHO AND PU⿴囗ISHIHO ACYIVIPY NEW YECIINOLOOY APPLICAYIOH

sohedul $5 \cdot 6$ Hool Yaar 1903

PACILITY NAKE, Argome Natlonal Laboratoryt Ease

AODREss, 9700 8, Cass, Bldy, 2z2, Mod

Argorna, It $60439 \cdot 4020$

Agelleacton

Desorlation of Hey Iesting losy

Xorox 9790

Thlo uppl lostion of electronic, on dentuand prlitiling

technology wlll Interface wlth the laboratory's

slewide ethernat, permleting direct transmlssion

of dociments from the author. location, to the

printing devloe.

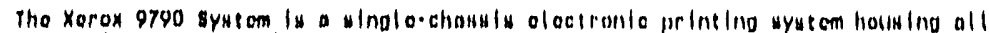

production functiony in one device. The operatlon of theso funotions is

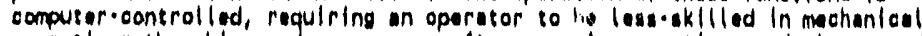

operastions than his preducessors, oraftemen mak ing negativas and plates and running

presses. This toohnology la expocted to save abstantial dollars ehrough el imination

of expens lve prepress operations and makeready costs. As consequence of thlo

- llmiration, shors production runs, producing only, lie mount of books currently

requlred, become practloal, wubstont lally reduolng malling and akorago costs as wall, 
ANL Site Response for the DOE FY 1994 Information Resources Management Long Range Plan A. Three-Year Printing and Publishing Activities Plan

March 25, 1992

PRINIING AND PUBLISHING ACIIVITY
PROJECTED PUBLISHING ACTIVITIES

PROJECTED PUBLISHING ACTIVITIES
(AClual Number of Publications)

PACllitr MAME: Argonne National Laboratory: East

NDORESS: $\quad 0700$ S. Cass, 81dg. 222, Med 9700 s. Cass, 81 dg. 222,
Argonne, IL $60439 \cdot 4828$

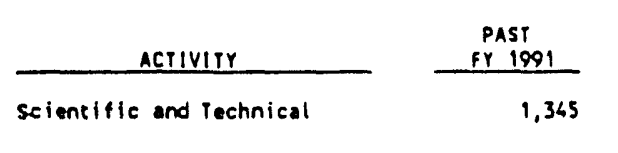

Public Comminications

20

Adniniseretive

16

statistical

\begin{tabular}{|c|c|}
\hline $\begin{array}{l}\text { CURRENT } \\
\text { FY } 1992 \\
\end{array}$ & $\begin{array}{l}\text { PLAN } \\
\text { FY } 1093\end{array}$ \\
\hline 1,412 & 1,482 \\
\hline 20 & 20 \\
\hline
\end{tabular}

2
Schedule $5 \cdot 7$

11191

CONIACT: David R. Hamrin

PHONE: $708 \cdot 252 \cdot 5611$

$\frac{\text { QUT-YEARS }}{\text { FY 1994 }} \frac{\text { FY } 1995}{1,557}$

20

20

19

20

2 
ANL Site Response for the DOE FY 1994 Information Resources Management Long Range Plan March 25, 1992

A. Three-Year Printing and Publishing Activities Plan

PRINTING ANO PUBLISHING ACTIVITY JOURHAL PUBLLISHING ACTIVITIES

(Dollars In Thousands)

FACILIIY HAME: Aigorne National Laboratory: East

ADORESS:

9700 S. Cass, Bldg. 222, Hed

Argonne, IL $60439 \cdot 4828$
Quantity

Current Year

\begin{tabular}{c} 
Past Year \\
FY 1991 \\
\hline
\end{tabular}

480

175

Cost (in thousends)
184
Schedule 5.8

$11 / 91$

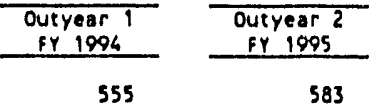

203

213 
ANL Site Response for the DOE FY 1994 Information Resources Management Long Range Plan B. Printing Activities Report

\section{Section B}

\section{Printing Activities Report}


ANL Site Response for the DOE FY1994 Information Resources Management Long Range Plan March 25, 1992

B. Printing Activitjes Report

\section{A. Printing Plant Report}

PRIHTING PLAKT REPORT

JCP FORM HO. 1 (REV. 3.71)

DOE (REY. 7.86)

Reglan: 05

Deoartment heados

schedule 5.9

Depariment or Agency

DEPARTMENT OF ENERCY

Name and Location of Plant

Argonme National Laboratory: East

9700 s. Cass, Bldg. 222, Med

Argonne, $16 \quad 60439 \cdot 6828$

Part 1. - Cost information (for fiscal Year

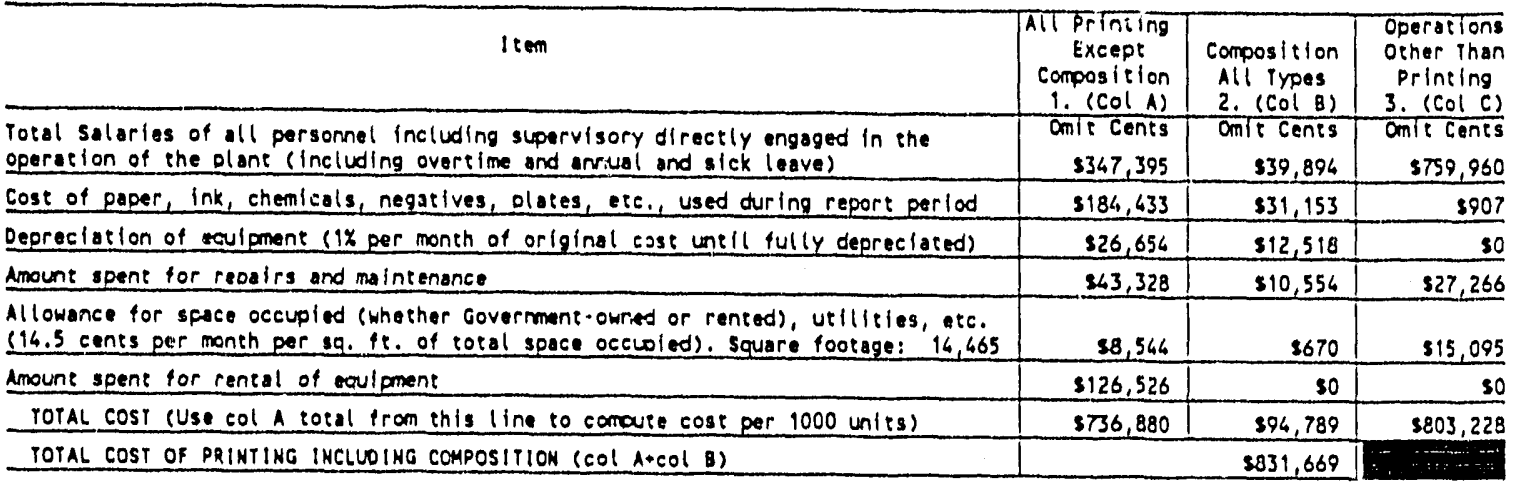

- Inelude in col a cost of all of fset camera work, negativa work, imposition, platemaking, duplicating, presswork, scoring, pertorating, numbering, folding, collating, gathering, drilling, punching, stitching, sewing, inserting,

tipping, padding, triming, tying, wrapping, and all other operations needed to complete printing or binding product.

2. Include in Col B cost of all composition proctued by plant.

3. Include in Col C cost of all operation not involving printing (Col A) and compos/etion (Col B). Costs to be included in Col C will Include addressing, distribution, camers work (other than (lithographic), photostating, ozalid, B/W, e:c.

\begin{tabular}{|c|c|c|c|c|c|}
\hline & Presswork & $\begin{array}{c}\text { Units Per } \\
\text { Press } \\
\text { Impression } \\
\text { (Col D) }\end{array}$ & $\begin{array}{c}\text { Number of Presses } \\
\text { In Each Category } \\
\text { Reported } \\
\text { (Col E) }\end{array}$ & $\begin{array}{l}\text { Number } \\
\text { of Masters } \\
\text { and Plates } \\
\text { (Col F) }\end{array}$ & $\begin{array}{c}\text { Total Units } \\
\text { Produced, } \\
\text { Excluding Overruns } \\
\text { (Col G) }\end{array}$ \\
\hline \multirow{7}{*}{$\begin{array}{l}0 \\
F\end{array}$} & $11 \times 17$ (1mage $<=103 / 4 \times 141 / 4$ ) & 1 & 2 & 3,046 & $1,759,107$ \\
\hline & $11 \times 17$ Tandem (Image $<103 / 4 \times 161 / 4$ ) & 2 & 1 & 14,929 & $3,501,990$ \\
\hline & $11 \times 17$ (1mage) $103 / 4 \times 161 / 6)$ & $\underline{2}$ & & & \\
\hline & $14 \times 20$ and $15 \times 18$ & 2 & 2 & 1,152 & $1,969,212$ \\
\hline & $11 \times 17$ Tandem (1mage) $103 / 4 \times 141 / 4$ ) & 4 & 1 & 5,360 & $4,502,688$ \\
\hline & $17 \times 22$ and $19 \times 25$ & 4 & & & \\
\hline & $22 \times 29$ & 6 & & & \\
\hline \multirow{8}{*}{$\begin{array}{l}\text { F } \\
\text { S } \\
E \\
T\end{array}$} & $22 \times 34$ & 8 & & & \\
\hline & $23 \times 36$ & 8 & & & \\
\hline & $23 \times 36$ Perfecting & 16 & & & \\
\hline & $34 \times 44$ & 16 & & & \\
\hline & Other (specify) & & & & \\
\hline & & & & & \\
\hline & & & & & \\
\hline & TOTAL UNITS PROOUCED BY OFFSET & & & & $11,732,997$ \\
\hline \multirow{7}{*}{$\begin{array}{ll} & D \\
L & U \\
\text { E } & P \\
C & L \\
T & 1 \\
R & C \\
0 & A \\
S & 1 \\
1 & 0 \\
A & R \\
\end{array}$} & XEROX MOOEL 9900 & 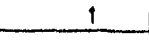 & 2 & 642,210 & $11,726,507$ \\
\hline & XONICA 7090 & 1 & 1 & 63,352 & 267,557 \\
\hline & & & & & \\
\hline & & & & & \\
\hline & & & & & \\
\hline & TOTAL UNITS PRCOUCED BY ELECTROSTATIC DUPLICA ORS & & $=-n$ & i. & $11,992,064$ \\
\hline & TOTAL UNITS PROOUCED IN PLAKT THIS FISCAL YEIR & & & & $23,725,061$ \\
\hline \multicolumn{6}{|c|}{$\begin{array}{l}\text { COST PER } 1000 \text { UHITS (total cost of printing, excluding composition, part } 1 \text {, col } A \text {, divided by total } \\
\text { production units oroduced in the olant. Dron last } 3 \text { digits of col G then conouting cost per } 1000 \text { units). } \\
\text { Prepared by (Person in charge of plant) }\end{array}$} \\
\hline Prepar & ed by (Person in charge of plant) & & & Date & $\begin{array}{l}\text { Submitted: } \\
11 / 01 / 91 \\
\end{array}$ \\
\hline
\end{tabular}

- Electrostatic delicaters include, but are not limited to, Xerox 1000 and 9000 series; Xodak 100 and 200 series; and I8M copier IIl's mere stafted. 
PRINIIHO PLANY REPORI

JCP FORM NO. 1 (REY, 3.71)

DOE (ReV. 7.86 )

Region: 05 Degartment headeuarters shall submlt 2 cooles of this resort to the JCP wlehin 60 days after the close of the fiscal year.

Schedule 5.9

\begin{tabular}{|c|c|c|c|}
\hline $\begin{array}{l}\text { Departiment of Agency } \\
\text { DEPARTMENT OF ENERGY }\end{array}$ & $\begin{array}{l}\text { Hame and Loeaston of Plane } \\
\text { Argonne Hational Laboratoryt East } \\
9700 \mathrm{~s} \text {. Cass, } 8 \text { (dg, } 222 \text {, Hed } \\
\text { Argonne, IL } 60439.4828\end{array}$ & $\begin{array}{l}\text { JCP Authorizatlon } \\
\text { Number } 08538\end{array}$ & $\begin{array}{l}\text { For Perlad } \\
\text { Ended } 9 / 30 / 91\end{array}$ \\
\hline
\end{tabular}

Part 111 . - Llst of Reportable Jobs Run During the Perlod (for flscal Year)

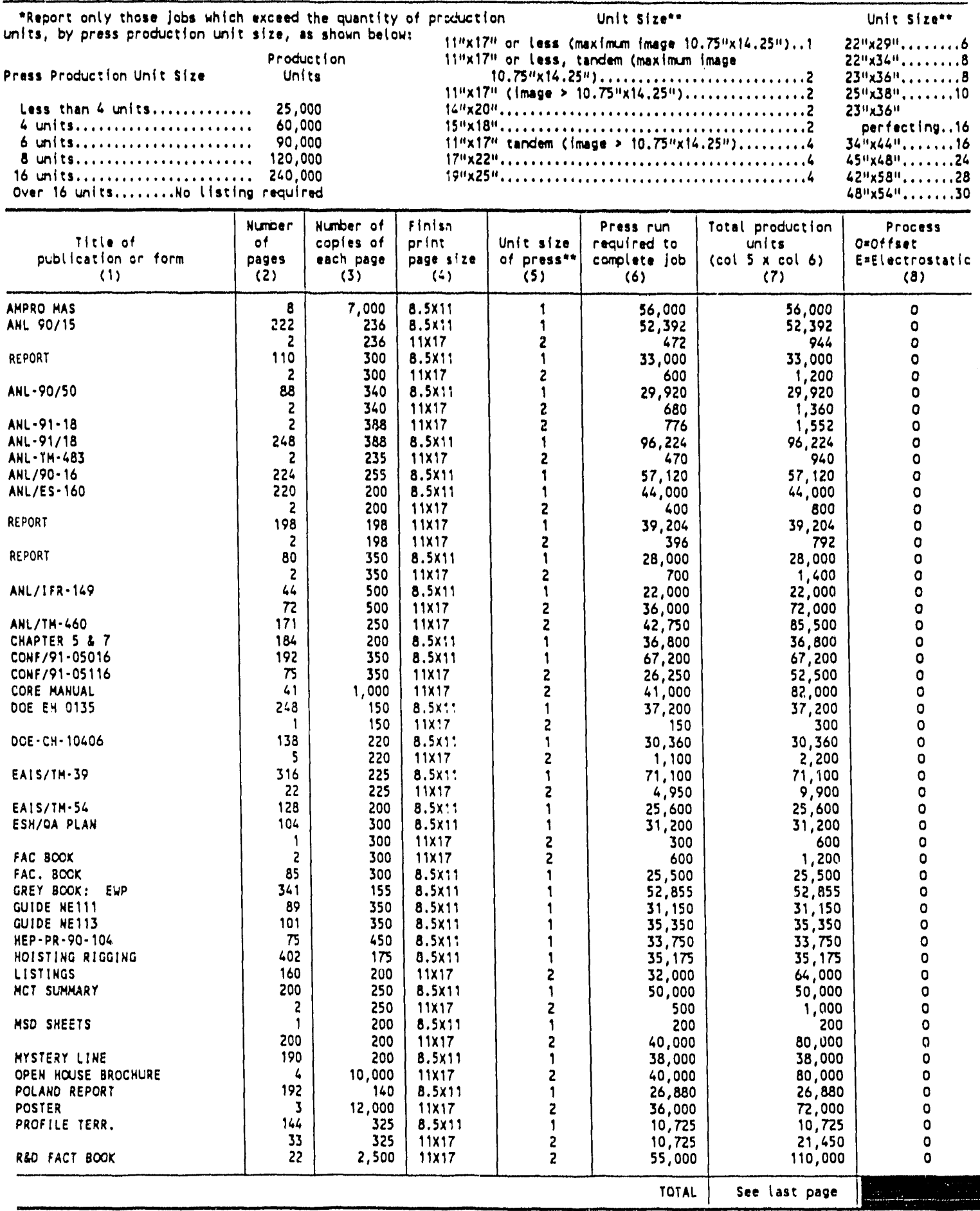


ANL Site Response for the DOE FY 1994 Information Resources Management Long Range Plan March 25, 1992

PRINTING PLANT REPCRT

JCP FORM NO. 1 (REV. 3-71)

Regloni 05

DOE (ReV. $7-86$ )

Decartment heodouarters shall submit 2 ceoles of this report to the JCP within 60 days after the close of the fiscal year.

Department or Agenc DEPARTMENT OF ENERGY

\section{Name and locotion of $P$ lant}

JCP Authorlicilon

for perlod

9700 s. Cass, Bldg. 222, Med

Number 08538

Ended $9 / 30 / 91$

Argonne, 1160639.4823

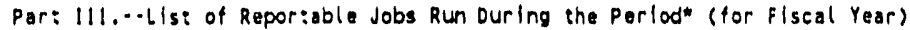

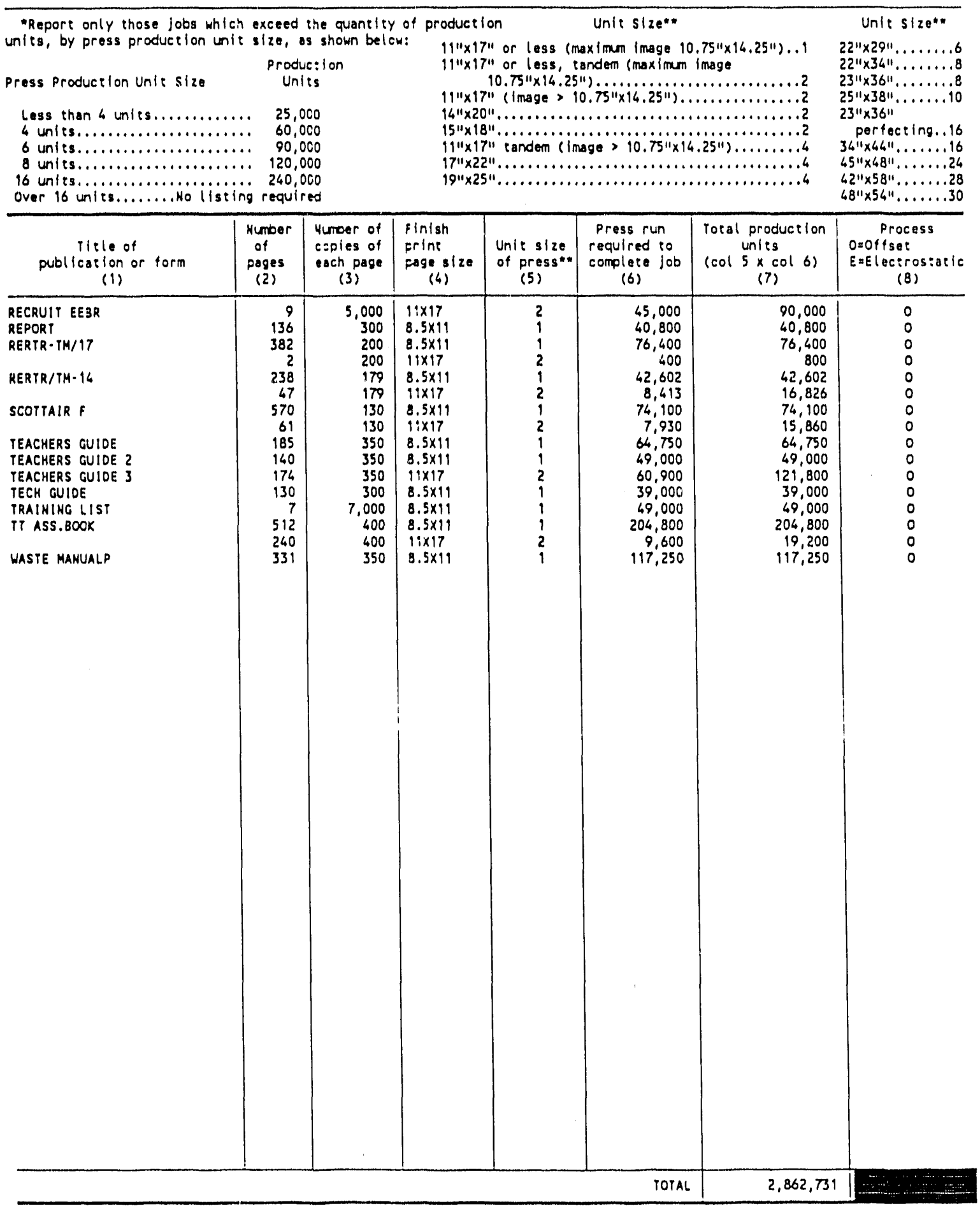


ANL Site Response for the DOE FY 1994 Information Resources Management Long Range Plan B. Printing Activities Report

March 25, 1992

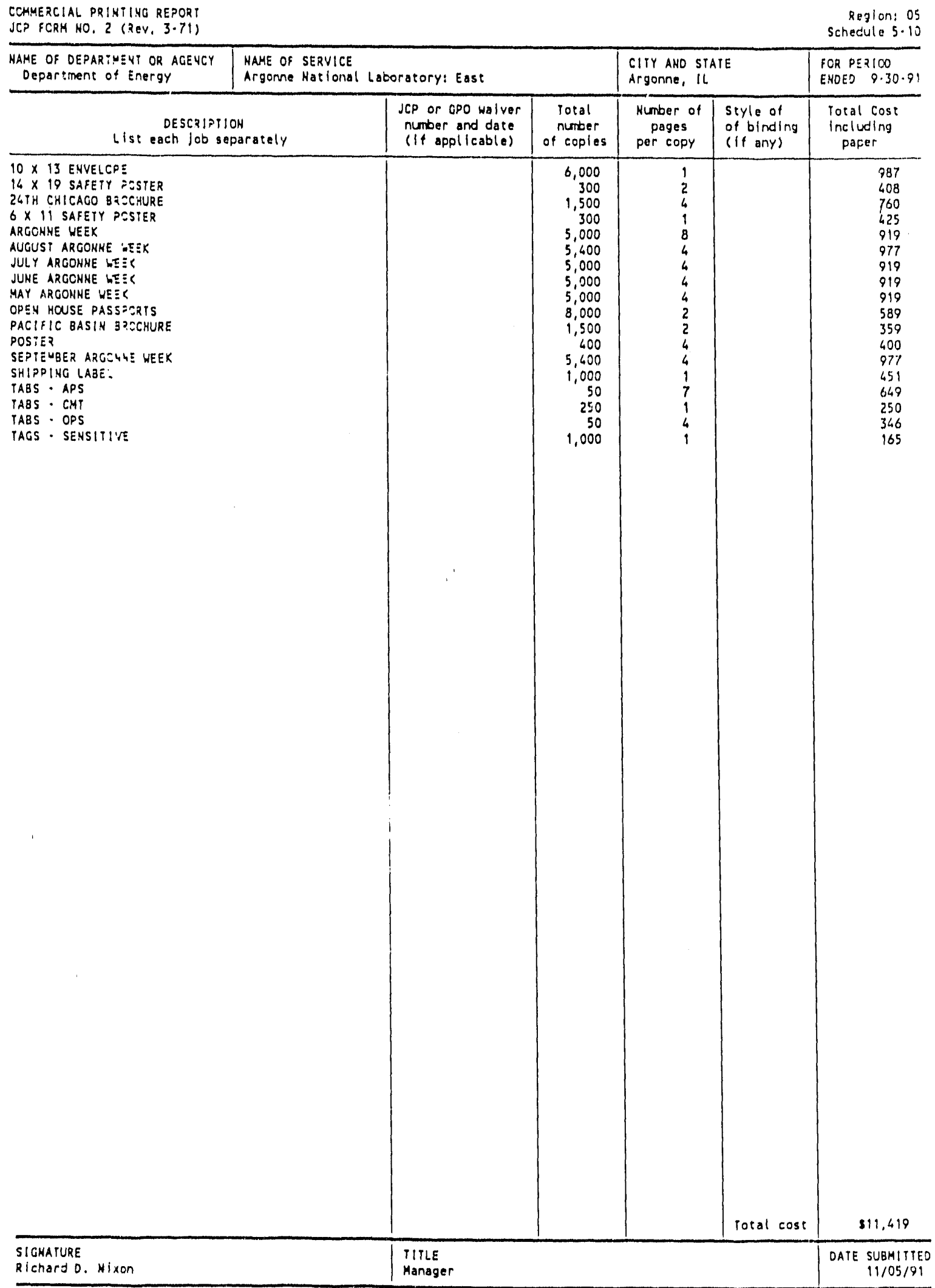

ANL-5.2.5 
ANL Site Response for the DOE FY1994 Information Resources Management Long Range Plan March 25, 1992

B. Printing Activitles Report

AHHUAL PLANT INVENTORY

JCP YORK NO. 5 (REV. 3.65 )

Angloni 05

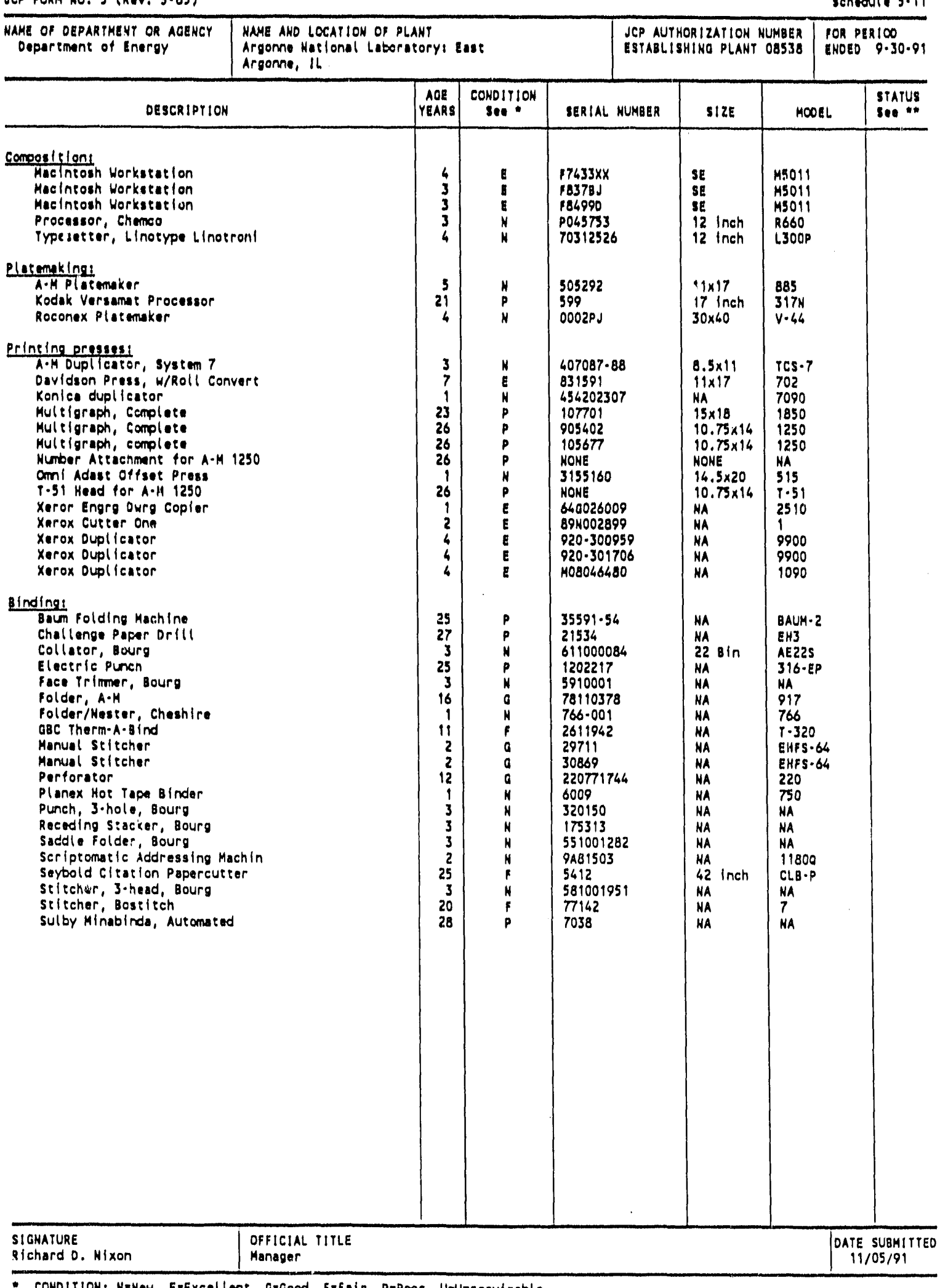

- CONDITION: NaNew, EnExcell lent, GuGood, Fafair, Pxpoor, UaUnaervicable

" STATUS: "ADDEO" Or "OELLETED" when applicable. 
ANL Site Response for the DOE FY'1994 Information Resources Management Long Range Plan B. Printing Activitles Report

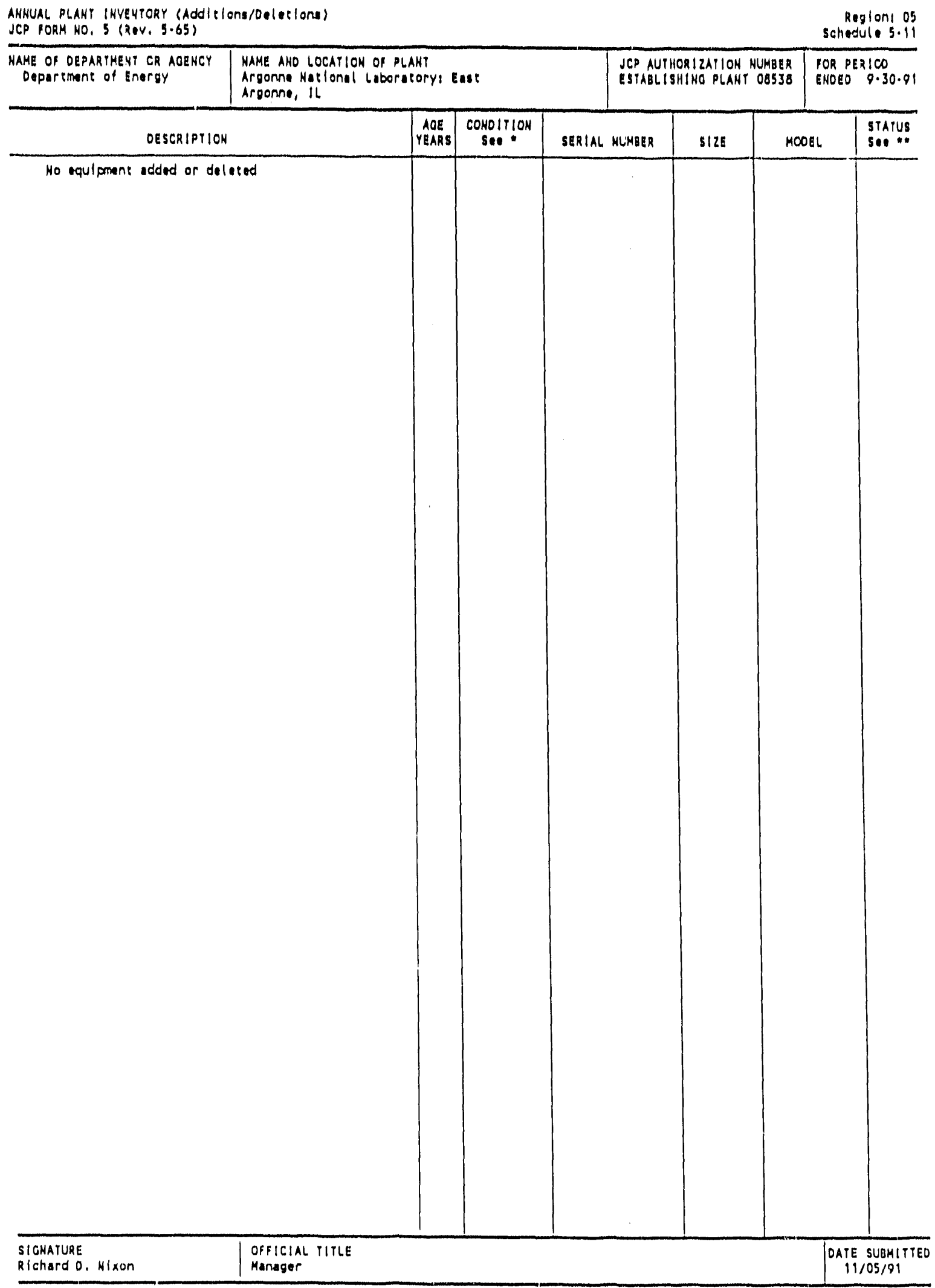

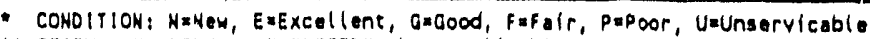

"M STAYUS: "ADDED" Or "DELETED" when applicable. 
ANI. Site Response for the DOE FY 1994 Information Resources Management Long Range Plan March 25, 1992

B. Printing Activitles Report

Schedule 2.4: Schedule 5-12, Duplicating Facility Report

None

ANL-5.2.8 


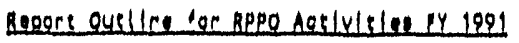

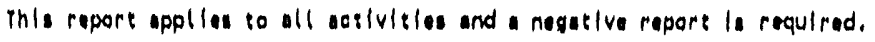

PAGILITY HAMEI Argonne Haclonal Luboratorys tas:

AOOREss: $9700 \mathrm{~s}$, coss, $810 \mathrm{dg}, 222$, Hed

CONIACS HAMEI RIOC NIXON

TELAPHONE NUMBERI $708 \cdot 972 \cdot 5600$

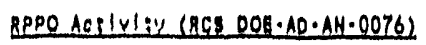

1. Puslleationa

1. Yumber of orders

b. Humber of production unlis

$\frac{67}{11,496,015}$

c. Number of original pages (mastors)

33,480

d. rocal dollar aoslylisy

8247630

-. cost per 1,000 production unles (d. divides by b. times 1,000)

321,21

2. Porms

1. Cut sheots and snopouts

(1) Number of orders

(2) Total dollar activley

2.64

b. Computer forms (marginally punctiod continuous formas)

(i) Number of orders

(2) rotal dollar activity

c, iotals (sum of 2,a, (2) and 2,b.(2))

$\$ 103,756$

3. Spoclalty Items (tags, labels, and all ltems not inclucied above)

a. Number of orders

b. Tocal dollar activliy

4. ro:als (sum of 1, 2, and 3 above)

a. Orders (sum of 1.a., 2.a.(1), 2.b.(1), and 3.a.)

b. Total dollar activity (sum of 1.d., 2.c., and 3.b.) 
ANL Site Response for the DOE FY 1994 Information Resources Management Long Range Plan

CHS Acproval Humber $1910 \cdot 1300$

Schadul $9 \cdot 14$

\section{e for puderal pelson

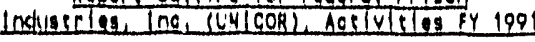 \\ This report appllas to all aosfuleles and a negaslve roport is requlred.}

PaCllitiy HaMe, Argonria Hatlonal Laboratory! Eas:

ADORESSI $9700 \mathrm{~s}, \mathrm{Cas}, \mathrm{Bldg}, 222, \mathrm{Had}$

Argonne, 1L $60439 \cdot 4820$

COHTACT HAMEI

TELEPHOHE NUMBERI 708.972.5600

QHICOR ACEIVI:Y (BCS OOE:AD-AH.0076)

1. Publloastons

n. Number of orders

b. Yumber of production unles

c. Number of orlglnal pages (mastars)

d. lotal dollar aceluley

1. Cost per 1,000 production units (d. divided by b, times 1,000)

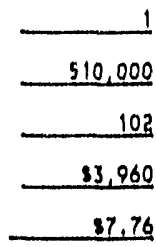

2. Forms

A. Cut sheots and snapouts

(1) Number of orders

(2) Total dollar activlty

b. Computer forms (marginally punched continuaus formas)

(1) Number of orders

(2) Total dollar acelvity

c. Potals (sum of 2,a, (2) and 2,b, (2))

3. Speslalty Items (tags, labels, and all ltems not Included abova)

1. Number of orders

b. Total dollar activity

4. Toials (sum of 1,2 , and 3 above)

a, urders (stm of 1.a., 2.a.(1), 2.b.(1), and 3.a.)

b. rotal dollar actlulty (sum of l.d., 2.c., and 3.b.) 
ANL Slte Response for the DOE FY1994 Information Resources Management Long Range Plan B. Printing Activities Report

March 25, 1992

CHE Approval Humber $1910 \cdot 1300$

gohodute 8.15

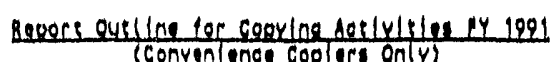

sconyenlence Geeters onlyi

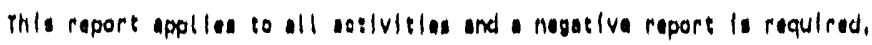

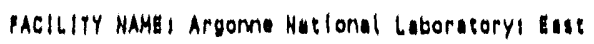

AOOREss! 0700 \&. Cass, Bldo, 222, Had

Argonne, 1660439.4828

CONTACY HAMEI RlOCh HIXON

THLEPHOHE HUMOER: 708.972.9600

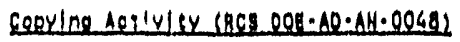

1. Hurber of Coplers:

Begin RY 199: Ind IY 1991

a. Lensed

b. Owned

a. cost-per-copy oontruce

d. Total

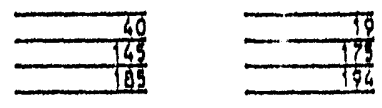

2. Cooles Reproduceds

1. Leased

b. Owned

o. Cost.per-oopy coneract

d. Total

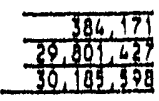

3. cost of suppltes (1,e., paper, ropier, dovelsper, etc.)

Cost per 1000

1. Lensed

b. Owned

a. Costeper-oopy contraot

d. Total

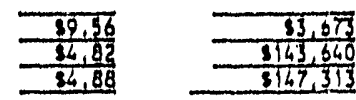

4. Cost of Equipments

Cost per 1000

1. Leased

b. Owned (cost of mintenanae)

c. cost-per-copy contract

d. Total
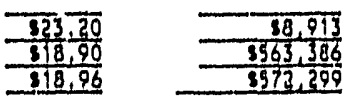

5. Yo:al supply and t tulpment coses $(3, d,+4,5,8)$

$3719,3: 2$

6. cosi-per-copy:

a. Leased $(3,0,+4, a, 12,0$,

b. Owned $\left(3, b_{1}+4, b_{1} / 2, b_{1}\right)$

c. Cost-per-copy contract $(3, c,+4,0, / 2.2$.

d. Total $(5, / 2, d$,

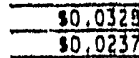

7. Huncer of Coplors Purchased During Fy 1991 :

8. Cost of Coplors purchased During $\$ 41991 \%$

9. Plamed Action to Reduce Copying Cast Durlmy Next FY:

CONTIHUE TO REPLACE OWHE COPIERS WITH COST PER COPY EOUIPMENT. ALSO, PERIODICALLY BID COST PER COPY CONTRACT TO INSURE GEST PRICE AHD SERVICE FOR THE LAB. 
ANI. Slte Response for the DOE FY 1994 Information Resources Munngement Long Range Plan March 25, 1992

B. Printling Activilies Report

PRIHIINO AND PUILISIIIHO ACTIVIIY SURYEY OF UPO PERFORHANCE FOR FISCAL YEAR FY 1991

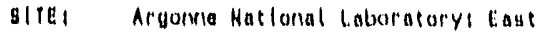

LOCAIIONI Arourme, IL

aro iorm

Contract

Hindiar

$1517 \cdot 8$

SELF COVEA HOOK

MUST AI DESTIHATION

3919.5 SEPAKATH COVER GOOK HUST AT DESTIHATIOH

$3522 \cdot 5$

HCH POHMS

MUST AT OESTIHATIOH

3537.5 SELF COVEH BOOK MUST AI UESTIHATIOH

$5514 \cdot 9$

HEWSLETTER

HUST AT OESTIHATIOH

$5514 \cdot 9$

MUST AT OESYINATIOH

5527.S EHVELOPE PRINTINO

HUST AT OESTINATION

$5527 . \mathrm{S}$ ENVELOPE PRIHITHO MUST AT DESIIHATION

5527.S EHVELOPE PRINTINO

HUST AI DESTIHATIOH

5527.9 EHVELOPE PRIHTINO HUST AI DESTIHATIOH

\$527.5 ENVELOPE PRIHIINO MUST AT OESIIHATIOH

SF.1 HISCELLAHEOUS

TOTALS

\section{Home and locallon of contraclor}

QEOROE PRIHTIHO

AURORA, IL.

ERIC HUOO PRIHTIHO

SCHEHECTAOY, NY

OEM UUSIKESS PORHS

CHICAOO, IL

KELLER QRAPHICS

ARL I HOYOH HPS., IL

BURCZYK PRIHTERS

CALUMET CIIY, IL

TAKMS LITHO

CEOARSQURO, HI

EHVELOPF PACTOHY

HEW HAYISH, GT

ILLINOIS ENVELOPE KALAHA2OO, HI

INTERMOUHTAIH ENVELOPE

SAL.T LAKE CITY, UT

MCQUIRK EHVELOPE

CHICAOO, IL

OUILOOK ENVELOPE

HUHTLEY, IL schadula $5 \cdot 16$

$11 / 91$

comracte Hichard 0 , HIxon

PHIHE: 7011.972.5600

\begin{tabular}{|c|c|c|}
\hline $\begin{array}{l}\text { Prlat } \\
\text { ortlors } \\
\text { alacoul }\end{array}$ & $\begin{array}{c}\text { Roportod } \\
\text { Lata } \\
\text { Lel Ivarley }\end{array}$ & $\begin{array}{l}\text { Hoportad } \\
\text { Guallty } \\
\text { Defacty }\end{array}$ \\
\hline 7 & 0 & 0 \\
\hline 2 & 0 & 0 \\
\hline 100 & 0 & 0 \\
\hline 1 & 1 & 1 \\
\hline 6 & 0 & 0 \\
\hline 6 & 2 & 0 \\
\hline 39 & 0 & 0 \\
\hline 4 & 0 & 0 \\
\hline 35 & 0 & 1 \\
\hline 1 & 1 & 0 \\
\hline 5 & 0 & 0 \\
\hline 207 & 0 & 0 \\
\hline 421 & 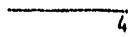 & $\bar{z}$ \\
\hline
\end{tabular}




\section{Appendix A \\ Computer Protection Policy}

\section{PURPOSE}

This policy exists to provide guidance for the protection of Laboratory unclassified computer systems and computerized information.

\section{SCOPE}

This policy covers all unclassified computer systems, including (1) personal computers and word processing systems, (2) computer systems used for scientific and engineering computations, information processing, and experimental control, (3) new, experimental computing systems, and (4) the central computing systems operated by the Computing and Telecommunications Division.

\section{POLICY}

It is Laboratory policy to protect its computers, the information stored in them, and the sensitive applications running on them. They are to be protected, as far as is reasonably possible, from unauthorized access to applications and computing resources, and unauthorized (or accidental) modification (or destruction) of information. Adequate protection wiil be based on an evaluation of risks, a cost/benefit analysis of protection measures, and the sensitivity and value of the assets to be protected.

It is Laboratory policy that the primary responsibility for protection of Laboratory computers, programs, and data lie directly with the users, operators, and managers of those Laboratory assets.

It is Laboratory policy that all users, operators, and managers of computing resources be trained in their computer protection responsibilities.

It is Laboratory policy that Laboratory-owned computers be used only for Laboratory-approved work.

4. GOALS

- To protect sensitive computer applications (e.g., accounts payable, personnel, and sensitive DOE energy programs) from unauthorized alteration or disclosure.

- To protect computer systems from deliberate or accidental physical damage.

- To protect computer data and applications from deliberate or accidental modification or destruction.

- To provide adequate and realistic backup procedures and contingency plans that will protect the Laboratory from the consequences of any serious computer failures, and to provide for coñtiniuity of opcrations for computer applications supponting DOF mission-essential functions. 
ANL Site Response for the DOE FY 1994 Information Resources Management Long Range Plan March 25, 1992

Appendix A: Computer Protection Policy

- To prevent the use of Laboratory computers for unauthorized purposes.

- To follow DOE requirements for reporting computer security incidetits.

5. RESPONSIBILITIES

Laboratory Director:

- Appoints the members of the Computing Policy Committee.

Chief Operations Officer:

- Approves Compurer Protection Policies.

Computing Policy Committee:

- Advises the Laboratory Chief Operations Officer on the suitability of proposed Computer Protection Policies.

- Approves plans for implementing proposed policies.

Director of Computing and Telecommunications:

- Appoints the ANL Computer Protection Program Manager.

Deputy for ANL-West to the Associate Laboratory Director for Engineering Research:

- Appoints the Associate Computer Protection Program Manager for Argonne West.

ANL Division Directors, Program Managers, and Department Heads:

- Appoint a Divisional, Program, or Departmental Computer Protection Progsam Representative for their organization.

- Appoint an Assistant Computer Protection Program Manager for each sensitive computer in their organization (one person may be responsible for more than one system). This person is usually (but need not be) the system manager for the computer.

- Ensure that computer security awareness and education training is provided for their organizations.

\section{Computer Protection Program Manager:}

- Formulates ANL computer protection policies.

- Prepares the Laboratory's Computer Protection Plan.

- Manages a program to identify sensitive computer applications. 
ANL Site Response for the DOE FY 1994 Information Resources Management Long Range Plan Appendix A: Computer Protection Policy

- Manages a program to ieview, test, and approve protection plans for sensitive applications and computer systems.

- Reviews and approves the computer protection aspects of audit inspections.

- Conducts appraisals of adherence to the Laboratory's Computer Protection Plan.

- Manages a computer security education and awareness program.

- Manages a program to train divisional Computer Protection Program Representatives and Assistant Computer Protection Program Managers.

- Manages the Laboratory's computer-incident reporting system.

- Maintains the Laboratory's computer protection files.

- Coordinates requirements for the unclassified computer protection program with Laboratory personnel having responsibilities for telecommunications security and classified computer security.

- Serves as a Laboratory focal point to coordinate with DOE on matters involving unciassified computer security.

\section{Associale Computer Protection Program Manager for Argonne West:}

- Coordinates computer protection activities at Argonne West to comply with the ANL Computer Protection Program.

- Formulates computer protection policies for Argonne West (in cooperation with the Computer Protection Program Manager).

- Reviews and approves the computer protection aspects of audit inspections at Argonne West.

- Reviews protection plans and conducts appraisals of adherence to the Laboratory's Comruter Protection Plan at Argonne West.

- Coordinates the computer security education and awareness training at Argonne West.

- Coordinates Argonne West's computer-incident reporting and subsequent investigations for incidents at Argonne West.

\section{Computer Protection Program Representatives:}

- Charge the manager of each new or significantly changed application to determine the sensitivity of the application and forward that information to the Computer Protection Program Manager.

- Review, approve, and have available spon request risk assessments and protection plans for sensitive applications and computer systems in their organizations. 
ANL Site Response for the DOE FY 1994 Information Resources Management Long Range Plan March 25, 1992

Appendix A: Computer Protection Policy

- Ensure compliance with generic Laboratory risk assessments and protection plans (or write an individual risk assessment and protection plan) for non-sensitive computer applications and systems in their organizations.

- Conduct security-design reviews and tests, and certify and re-certify protection measures for sensitive computers and applications in their organizations.

- Ensure that personnel in their organizations receive computer security education and awareness training.

- Report and document computer security incidents in their organizations in compliance with the ANL Computer Incident Reporting Procedures.

- Review the contents of unclassified divisional computer systems at unannounced intervals with the knowledge and cooperation of division management by random sampling. Document the results, and forward any findings to the Computer Protection Program Manager.

This review must occur at least annually, but may not cover every computer. The resources used should be commensurate with the loss expectancy.

Director of Management Information Systems:

- Appoints a Computer Protection Program Representative for systems maintained hy Management Information Systems.

- Reviews risk assessments and protection plans for all Laboratory-wide sensitive informationsystem applications.

\section{Computer Protection Program Representative for Management Information Systems:}

- Charges the manager of each new or significantly changed application managed by Management Information Systems to determine the sensitivity of the application and forwards that information to the Computer Protection Program Manager.

- Reviews, approves, and has available upon request risk assessments and protection plans for sensitive applications maintained by Management Information Systems.

- $\quad$ Ensures compliance with generic Laboratory risk assessments and protection plans, (or writes individual risk assessments and protection plans) for non-sensitive computer applications and systems maintained by Management Information Systems.

- Conducts security-design reviews and tests, certifies, and re- certifies security specifications for sensitive applications .

- Ensures that personnel in Management Information Systems receive computer security and awareness training commensurate with their responsibilities.

- Manages the documentation and reporting of computer security incidents involving applications maintained by Management Information Systems. 
ANL Site Response for the DOE FY 1994 Information Resources Management Long Range Plan Appendix A: Computer Protection Policy

- Reviews and approves the computer protection aspects of audit inspections made on systems maintained by Management Information Systems.

\section{Assistant Computer Protection Program Managers:}

- Prepare and have available on request risk assessments and Computer Protection Plans for each of the sensitive computers for which they are responsible.

This task can be delegated to the system manager for the computer system and then approved by the assistant, where the two are not the same person.

- Submit the protection checklist for their computer(s) to the Computer Protection Program Manager.

\section{Managers of Computer Applications:}

- Complete a Computer Application Sensitivity Questionnaire for each new or significantly changed application and verify the information as requested by the Computer Protection Program Manager.

- Ensure that adequate back-up protection exists for the application data.

- Comply with protection measures documented in the protection plan.

Managers of Sensitive Computer Applications:

- Prepare risk assessments and protection plans (and, where appropriate, contingency plans) for each sensitive computer application.

- Ensure that the protection of any computer system on which the application runs is adequate for the protection needs of the application.

System managers of Non-sensitive Computer Systems:

- Ensure that the computer system complies with Laboratory policy and procedures for the protection of computing resources.

Requisitioners of Sensitive Computer Applications or Significant Computer Systems:

- Include appropriate protection requirements in the Procurement specifications.

- Provide completed sensitive computer system or application check lists.

Procurement Department:

- Ensures that procurement requests for sensitive computer systems and computer applications are in compliance with ANL procurement procedures.

\section{Human Resources Department:}

- Performs normal pre-employment screening checks on prospective employees. 
ANL Site Response for the DOE FY 1994 Information Resources Management Long Range Plan March 25, 1992

\section{Internal Audit Department:}

- Reviews the contents of the ANL mainframe computer systems at unannounced intervals by random sampling at the request of the Computer Protection Program Manager (subject to effort constraints).

\section{Computer Users:}

- Provide adequate protection, including proper password selection and protection and data backup, for the applications, data, and computers they use.

- Report computer-security incidents and other suspicious happenings or atuvities to the proper authority.

- Understand and comply with the ANL Computer Protection Policy and computer protection pians for the applications and computer systems they use.

\section{DEFINITIONS:}

a. An application is a set of all computer programs and related data used in an activity or project or closely related set of activities or projects. Examples of individual applications are the Laboratory's Integrated Financial System, the codes used to calculate the energetics and dynamics of molecular systems, and the codes used to determine core neutronics.

b. A sensitive computer application is an application that requires protection because it contains data that must legally be protected (e.g., Privacy Act Information, Unclassified, Controlled Nuclear Information, Official Use Only Information) or because of the risk and magnitude of loss or harm that could result from improper operation or deliberate manipulation of the application (e.g., payroll, personnel, proprietary code, DOE energy code, reactor control code, substantial financial loss).

c. A sensitive computer system is a computer system that processes sensitive applications or one that qualifies as sensitive because it is significant (see below).

d. A significant computer system is a computer system that consists of a stand-alone computer with peripheral equipment or a network of computer systems. The capacity of the system or network is such that its computing capacity currently requires it to be reported in the annual DOE Information Technology Resources long range planning process.

e. A protection checklist is either of two specific forms. The "Sensitive Application Check List" describes the information needed to complete a protection plan for a sensitive application. The "Sensitive Computer System Check List" describes the information nieeded to complete a protection plan for a sensitive computer system. 

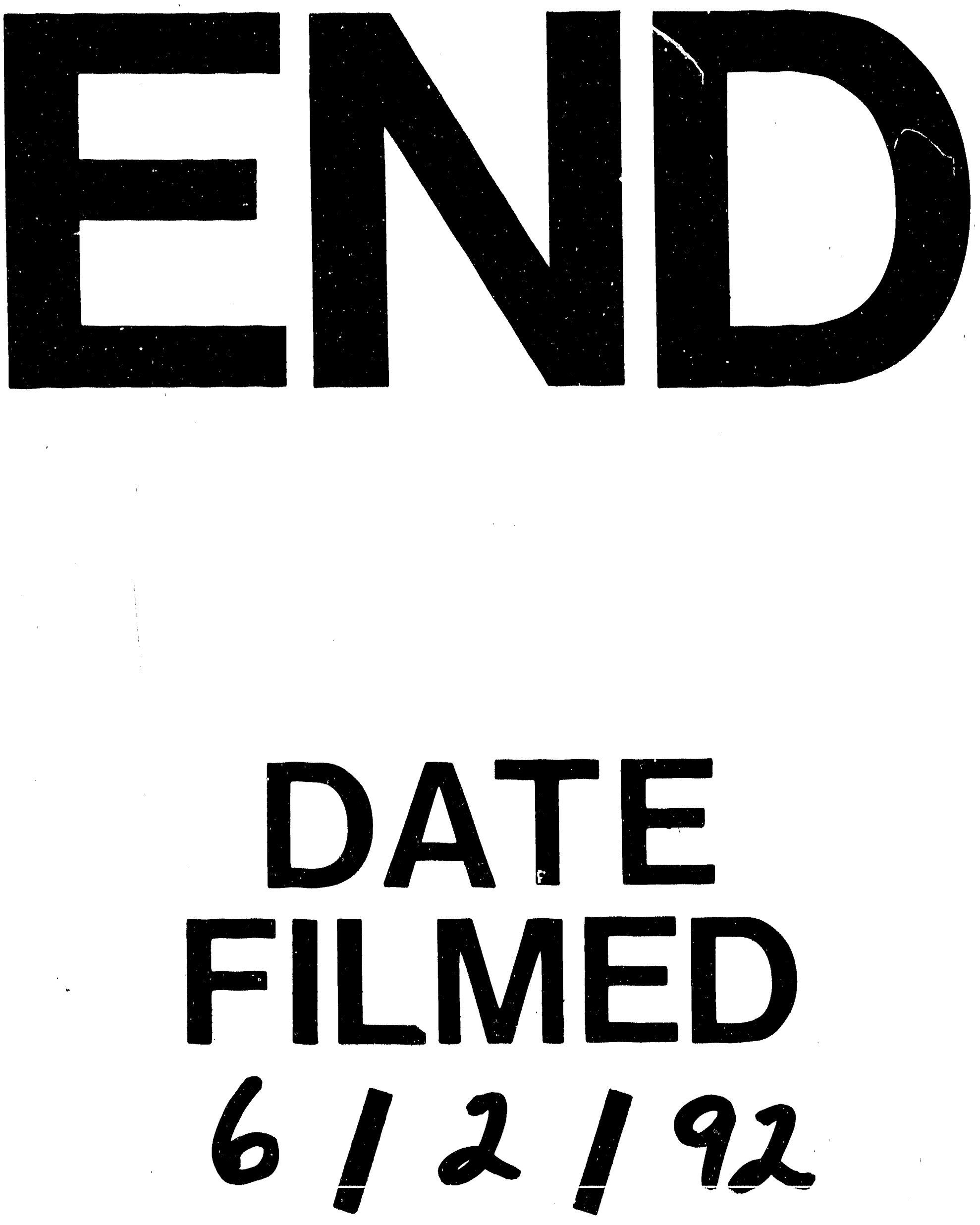

1 
